Um modelo de hipertexto para apoio ao ensino mediado pela Web 


\title{
Um modelo de hipertexto para apoio ao ensino mediado pela Web
}

\author{
Willie Dresler Leiva
}

Orientador: Prof. Dr. Paulo Cesar Masiero

Co-Orientadora: Prof ${ }^{a}$. Dr ${ }^{a}$. Maria Cristina Ferreira de Oliveira

Tese apresentada ao Instituto de Ciências Matemáticas e de Computação - ICMC-USP, como parte dos requisitos para obtenção do título de Doutor em Ciências - Ciências de Computação e Matemática Computacional.

\section{"VERSÃO REVISADA APÓS A DEFESA"}

Data da Defesa:

$12 / 09 / 2003$

Visto do Orientador: 
À jovem Camile Ernandorena dos Santos, amada por mim há muitas vidas. 


\section{Agradecimentos}

Aos meus pais, Antonio e Érica, que me garantiram a educação escolar necessária para a elaboração desta tese.

Aos professores que orientaram esta tese, Paulo Cesar Masiero e Maria Cristina Ferreira de Oliveira.

Aos professores doutores Ivan Luiz Marques Ricarte, Renata Pontin de Mattos Fortes e Maria da Graça Campos Pimentel, que participaram da banca do meu Exame de Qualificação e colaboraram para o aperfeiçoamento desta tese.

Aos colegas, anteriores e atuais, do LABES (Laboratório de Engenharia de Software), principalmente ao Adenilso, André e Marco Aurélio pelo apoio no uso do $\mathrm{LT}_{\mathrm{E}} \mathrm{X}$, PHP, MySQL e Linux.

A todos os professores e funcionários do ICMC.

A dois professores do Instituto de Física de São Carlos da USP, Marcos Lúcio de Sousa Góis e Águida Celina de Méo Barreiro, com os quais aprendi técnicas de comunicação escrita e obtive conhecimentos pedagógicos durante a disciplina SFI-5835 - Práticas Pedagógicas e Comunicação-Expressão.

Aos professores e funcionários do Departamento de Computação da UFSCar que me propiciaram os conhecimentos suficientes em Informática para a concretização desta tese.

A todos os pesquisadores voluntários da ciência denominada Conscienciologia, pela amizade e apoio mútuo indispensáveis à execução de uma programação existencial grupal, em especial ao Prof. Dr. Waldo Vieira — fundador da Conscienciologia.

À FAPESP, pelo apoio financeiro.

E a todos que, direta ou indiretamente, prestaram sua colaboração. 


\section{Resumo}

\section{UM MODELO DE HIPERTEXTO PARA APOIO AO ENSINO MEDIADO PELA WEB}

Atualmente há uma demanda crescente por aplicações hipermídia baseadas na WWW (World Wide Web), conhecidas como WIS (Web Information Systems). Esse novo tipo de aplicação apresenta requisitos adicionais aos sistemas de software clássicos, o que resulta na necessidade de investigar modelos mais adequados para apoiar o seu desenvolvimento. Em especial, os sistemas para apoio ao EaD (Ensino a Distância) baseados na Web apresentam características e requisitos ainda mais específicos. Os modelos atuais para modelagem e especificação de hiperdocumentos não são completamente adequados para representar características deste domínio, como a necessidade de acompanhamento dos aprendizes e a realização de avaliações diagnósticas e formativas. Isso motivou a proposta de um modelo para apoiar WISs voltados especificamente para $\mathrm{EaD}$, denominado MDE (Modelo para Documentos Educacionais), que estende o modelo HMBS (Hyperdocument Model Based on Statecharts) para a descrição de conteúdo nesse domínio. O MDE adota como modelo formal subjacente uma variante da técnica Statecharts, cuja estrutura e semântica operacional possibilitam especificar a estrutura organizacional e a semântica navegacional de hiperdocumentos complexos. Adicionalmente, foi integrada ao MDE a técnica de mapeamento conceitual, que acrescenta um significado educacional aos grafos hierárquicos. Dessa forma, o modelo apresenta como pontos fortes a possibilidade de captar várias informações relevantes do comportamento do usuário no estudo do material disponível on-line e a disponibilização desses dados ao instrutor, como importante apoio à avaliação formativa. Como prova de conceito, foi desenvolvido o protótipo de um ambiente para autoria e oferecimento de cursos denominado ATEnA (Ambiente para Treinamento, Ensino e Aprendizagem). Esta tese apresenta também avaliações conceituais e práticas do modelo e do protótipo desenvolvidos. 


\section{Abstract}

\section{A HYPERTEXT MODEL TO SUPPORT WEB-MEDIATED TEACHING}

There is an increasing demand for hypermedia applications based on the WWW (World Wide Web), known as Web Information Systems (WIS). These applications present specific requirements in addition to those of traditional software systems, thus fostering the need for investigating suitable models to support their development. In particular, systems for Distance Education based on the Web present very specific characteristics and requirements. Current models for hyperdocument modeling and specification are not completely suitable for representing domain specific characteristics such as the need of tracking student progress and evaluating their learning process through diagnostic and formative assessments. This scenario motivated the proposal of a model to support WISs targeted at distance education, called MDE (Model for Distance Education). MDE extends the HMBS (Hyperdocument Model Based on Statecharts) hyperdocument model to describe hypertext content in the educational domain. It adopts as its underlying model a variant of the Statecharts formal specification technique, whose organizational structure and operational semantics allows defining the organizational structure and navigational semantics of complex hyperdocuments. MDE also incorporates the technique of conceptual mapping, that adds educational meaning to hierarchical graphs. MDE's major strengths are thus the ability to capture relevant information about user behavior when studying on-line educational material and make such information available to the teacher / instructor in order to support formative assessment of students. As a proof of concept, the prototype of an environment for authoring and offering distance courses based on MDE has been developed, called ATEnA (Adaptive Training Environment with Support for Assessment). The results of practical and conceptual evaluations of the model and system developed are also presented in this thesis. 


\section{Sumário}

Sumário vii

Lista de Figuras $\quad$ xi

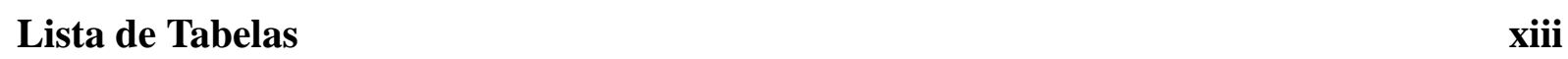

Lista de Abreviaturas $\quad$ xiv

\begin{tabular}{|lll}
1 & Introdução & 1
\end{tabular}

1.1 Considerações Iniciais $\ldots \ldots \ldots \ldots$. . . . . . . . . . . . . 1

1.2 Contexto . . . . . . . . . . . . . . . . . . . . . 2

1.3 Motivação . . . . . . . . . . . . . . . . . . . . . 3

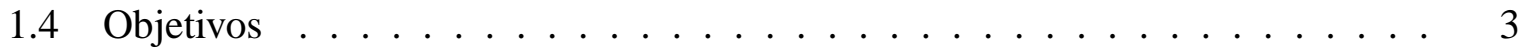

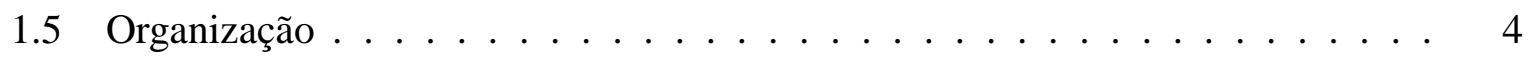

2 Sistemas de Informação na Web para Ensino a Distância 5

2.1 Considerações Iniciais $\ldots \ldots \ldots \ldots$

2.2 Modelagem Estrutural de Sistemas Hipermídia $\ldots \ldots \ldots$

2.3 WWW: Hipermídia em Rede . . . . . . . . . . . . . . . . . . 7

2.3 .1 Sistemas de Informação na WWW . . . . . . . . . . . . . . . . 7

2.4 Recursos Hipermídia . . . . . . . . . . . . . . . . . . . . 8

2.4 .1 Características Avançadas de Ligações . . . . . . . . . . . . . . . 8

2.4 .2 Nós Computados . . . . . . . . . . . . . . . . . . . . . 8

2.4 .3 Trilhas e Roteiros Guiados . . . . . . . . . . . . . . . . . . . . 9 9

2.4 .4 Listas de História . . . . . . . . . . . . . . . . . . . . . . . . . 9

$2.4 .5 \quad \operatorname{Marcos} \ldots \ldots \ldots \ldots \ldots \ldots$

2.4 .6 Adaptatividade . . . . . . . . . . . . . . . . . . . 10

2.5 Pontos Fortes e Fracos de Hipertexto $\ldots \ldots \ldots$. . . . . . . . . . . . 11

2.6 Ensino a Distância . . . . . . . . . . . . . . . . . . . . . . 11

$2.6 .1 \quad$ Sistemas para Ensino a Distância _ . . . . . . . . . . . . . . 12 
2.6.1.1 Classificação . . . . . . . . . . . . . . . 12

2.6 .1 .2 AulaNet . . . . . . . . . . . . . . . . . 13

2.6 .1 .3 TelEduc . . . . . . . . . . . . . . . . . 15

2.6 .1 .4 CALM . . . . . . . . . . . . . . 16

2.6 .1 .5 CyberQ $\ldots \ldots \ldots \ldots \ldots \ldots$

2.6 .1 .6 Eureka . . . . . . . . . . . . . . . . 18

2.6.1.7 Hyperlearning Meter . . . . . . . . . . . . . . 18

2.6 .1 .8 WebCT . . . . . . . . . . . . . . . . 20

2.6 .1 .9 Outros Sistemas Educacionais na WWW . . . . . . . . . 21

2.6.1.10 Características de Alguns Ambientes Educacionais. . . . . . 22

2.7 Considerações Finais $\ldots \ldots \ldots \ldots$

3 Modelagem de Hiperdocumentos 2

3.1 Considerações Iniciais $\ldots \ldots \ldots$. . . . . . . . . . . . . . . 26

3.2 Grafos e Dígrafos . . . . . . . . . . . . . . . . . . 27

3.2 .1 Definições . . . . . . . . . . . . . . . 27

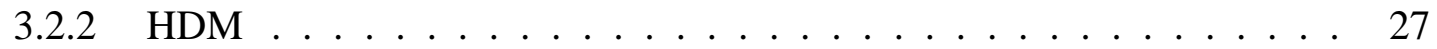

3.2.3 Modelo Simples de Hiperdocumentos . . . . . . . . . . . . . . . . . . 29

3.2 .4 Modelo de Contextos Aninhados . . . . . . . . . . . . . . . . 30

3.2 .5 Modelo de Tompa . . . . . . . . . . . . . . . . . 31

3.2 .6 RMDM . . . . . . . . . . . . . . . . . . . 32

3.3 Hígrafos e Statecharts $\ldots \ldots \ldots$. . . . . . . . . . . . . . 33

3.3 .1 Definição . . . . . . . . . . . . . . . 33

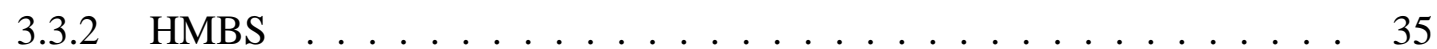

3.4 Modelo Baseado em Redes de Petri ． . . . . . . . . . . . . . . . . . . . . 37

3.5 Considerações Finais $\ldots \ldots \ldots$. . . . . . . . . . . . . . . . . 37

4 Um Modelo para Hiperdocumentos Educacionais Baseado no HMBS 38

4.1 Introdução . . . . . . . . . . . . . . . . . . . . . . . 38

4.2 Descrição do MDE $\ldots \ldots \ldots \ldots$. . . . . . . . . . . . . . . . . . . . . . 38

4.2 .1 Conceitos . . . . . . . . . . . . . . . . . . . . 39

4.2 .2 Mapa Conceitual . . . . . . . . . . . . . . . . . . . . 39

$4.2 .3 \quad$ Curso . . . . . . . . . . . . . . . . . . . . . . . 40

4.2 .4 Unidade de Estudo (UE) . . . . . . . . . . . . . . . . . . . . . . 41

4.2 .5 Tópico . . . . . . . . . . . . . . . . . . . . . . . . . . . . 41

4.2 .6 Avaliação . . . . . . . . . . . . . . . . . . . . . . 42

$4.2 .6 .1 \quad$ Avaliação Diagnóstica (AD) . . . . . . . . . . . . . . . 43 
4.2.6.2 Avaliação Formativa (AF) . . . . . . . . . . . . . . . 43

$4.2 .6 .3 \quad$ Avaliação Somativa (AS) . . . . . . . . . . . . . 43

4.2 .7 Questão . . . . . . . . . . . . . . . . . . . . 4 44

4.3 Extensões ao HMBS $\ldots \ldots \ldots \ldots \ldots$

4.3 .1 Estados Parametrizados e Estrutura Padronizada . . . . . . . . . . . . 45

4.3 .2 Condição Avaliada por Expressão Lógica . . . . . . . . . . . . . . . . 46

4.3 .3 Comportamento Adaptável ao Tipo de Página . . . . . . . . . . . . . . 47

4.3 .4 Atributos Estruturados . . . . . . . . . . . . . . . . . . . 47

4.3 .5 Mapa Conceitual Associado às Páginas de Conteúdo . . . . . . . . . . 48

4.3 .6 Associação de Mais de uma Página por Estado . . . . . . . . . . . . . 48

$4.4 \quad \mathrm{O}$ modelo MDE $\ldots \ldots \ldots \ldots$

4.4 .1 Estrutura do conteúdo . . . . . . . . . . . . . . . . . . . . 49

4.4 .2 Páginas . . . . . . . . . . . . . . . . . . . 52

4.4 .3 Avaliações $\ldots \ldots \ldots \ldots$. . . . . . . . . . . . . . . . . 54

4.4.3.1 Avaliação Diagnóstica . . . . . . . . . . . . . . 55

4.4 .3 .2 Avaliação Somativa . . . . . . . . . . . . . . 55

4.4 .3 .3 Avaliação Formativa . . . . . . . . . . . . . . . . . 55

4.5 Semântica Navegacional $\ldots \ldots \ldots \ldots$. . . . . . . . . . . . . 56

4.5 .1 Nível de Visibilidade . . . . . . . . . . . . . . . . . . 56

4.5 .2 Apresentação do Conteúdo . . . . . . . . . . . . . . . . 56

4.6 Exemplo: Curso Básico sobre HTML ～. . . . . . . . . . . . . . . . . . 57

4.7 Considerações Finais $\ldots \ldots \ldots \ldots$. . . . . . . . . . . . . . . . 62

5 ATEnA: um WIS para apoio ao EaD 63

5.1 Considerações Iniciais $\ldots \ldots \ldots$. . . . . . . . . . . . . . . 63

5.2 Projeto da Arquitetura $\ldots \ldots \ldots \ldots$. . . . . . . . . . . 63

5.2 .1 Administração . . . . . . . . . . . . . . . . 65

5.2 .2 Autoria . . . . . . . . . . . . . . . . 67

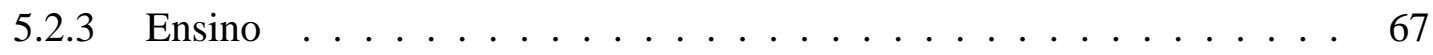

5.3 Modelos de Classes . . . . . . . . . . . . . . . . . . . . . . 68

5.4 Implementação . . . . . . . . . . . . . . . . . . . 71

5.4 .1 Restrições . . . . . . . . . . . . . . . . . . . . . 71

5.5 Interface com o Usuário . . . . . . . . . . . . . . . . . 72

5.5 .1 Acesso ao Sistema . . . . . . . . . . . . . . . 72

5.5 .2 Administração . . . . . . . . . . . . . . . . . . 74

5.5 .3 Autoria . . . . . . . . . . . . . . . . . . . . . 74

$5.5 .4 \quad$ Ensino $\ldots \ldots \ldots \ldots \ldots \ldots$ 
5.6 Considerações Finais $\ldots \ldots \ldots \ldots$. . . . . . . . . . . . . . 86

\begin{tabular}{lll}
\hline & Avaliação da Proposta & 87
\end{tabular}

6.1 Considerações Iniciais $\ldots \ldots \ldots$. . . . . . . . . . . . . . . . 87

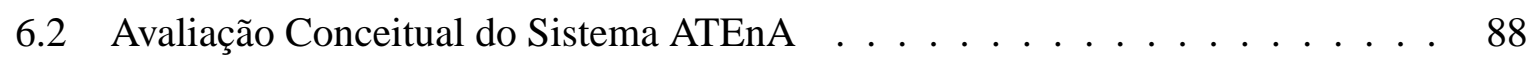

6.2 .1 Requisitos Gerais para Sistemas de Autoria Hipermídia. . . . . . . . . 90

6.2.1.1 Recursos de Apoio à Geração de Material . . . . . . . . . . 90

6.2 .1 .2 Recursos de Edição e Alteração da Aplicação . . . . . . . . 92

6.2.1.3 Recursos que Facilitam a Evolução da Aplicação. . . . . . . . . . . . . . . . . . . . 93

6.2 .1 .4 Amenidade de Uso . . . . . . . . . . . . . . . . . . 93

$6.2 .1 .5 \quad$ Recursos de Auxílio (Help) Oferecidos ao Autor . . . . . . . 94

6.2 .1 .6 Recursos de Documentação . . . . . . . . . . . . . . 94

6.2 .2 Requisitos para Sistemas Autoria Hipermídia Educacional . . . . . . . 95

6.2.2.1 Recursos Disponíveis ao Projeto de Hiperdocumentos para

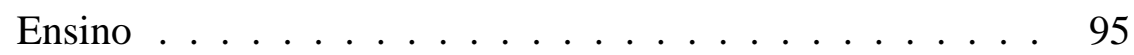

6.2 .2 .2 Recursos de Distinção de Material … . . . . . . . . . 95

6.2.2.3 Recursos de Apoio à Construção de Aplicações para Ensino. 96

6.3 Comparação do MDE com Outros Modelos … . . . . . . . . . . . . . . 96

6.4 Avaliação de Uso do Sistema ATEnA $\ldots . \ldots \ldots$. . . . . . . . . . . . 97

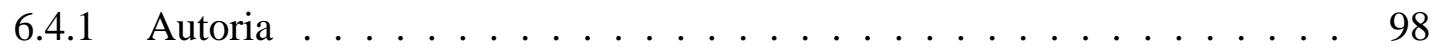

6.4 .2 Oferecimento . . . . . . . . . . . . . . . . . . . . . . . 99

6.5 Utilização de Recursos Hipermídia . . . . . . . . . . . . . . . . . . . . . . 104

6.5 .1 Adaptatividade . . . . . . . . . . . . . . . . . . . . 106

6.5.1.1 Apresentação e Conteúdo Adaptativos . . . . . . . . . . 106

6.5.1.2 Navegação Adaptativa . . . . . . . . . . . . . . . . . . 107

6.6 Comparação do ATEnA com Ambientes de EAD … . . . . . . . . . 107

6.7 Considerações Finais . . . . . . . . . . . . . . . . . . . . . . . . . 108

$\begin{array}{llr}7 \text { Conclusões } & 109\end{array}$

7.1 Considerações Gerais . . . . . . . . . . . . . . . . . . . . . . . . . . . . 109

7.2 Contribuições . . . . . . . . . . . . . . . . . . . . . . . . . . . . . . . 109

7.3 Trabalhos Futuros $\ldots \ldots \ldots \ldots \ldots$

\begin{tabular}{ll}
\hline Referências Bibliográficas & 112
\end{tabular} 


\section{Lista de Figuras}

2.1 Modelo de apoio à avaliação informal no AulaNet (Menezes et al [1 1998) . . . . 14

$\begin{array}{llll}2.2 & \text { Exemplo de mapa conceitual (Hyperlearning Center[, 1998) } & \ldots\end{array} \ldots$. . . . . . . 19

3.1 Exemplo de grafo . . . . . . . . . . . . . . . . . . . 27

3.2 Exemplo de dígrafo $\ldots \ldots \ldots \ldots$

\begin{tabular}{|ll|r|r|}
\hline 3.3 & Esquema HDM de uma aplicação sobre tutoriais (Bochicchio \& Paolini., 1998) 28 \\
\hline
\end{tabular}

\begin{tabular}{|lll|ll|}
\hline 3.4 & Representação de um hiperdocumento como dígrafo (Tompa [1989) & . . . . . . . & 29 \\
\hline
\end{tabular}

\begin{tabular}{|lll|ll|}
\hline 3.5 & Hierarquia parcial de classes do MCA (Soares \& Souza, 1997) & . . . . . . . . 30 \\
\hline
\end{tabular}

\begin{tabular}{lll|ll|}
\hline 3.6 & Representação de um hiperdocumento como hipergrafo (Tompa 1989) . . . . 31 \\
\hline
\end{tabular}

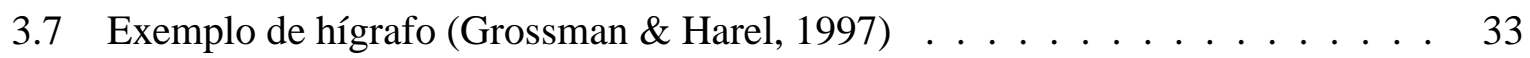

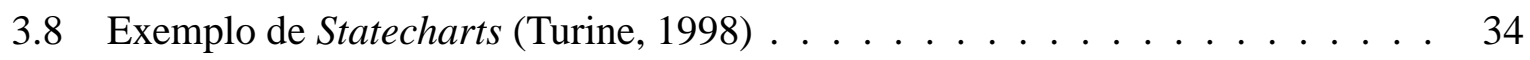

\begin{tabular}{|lll|ll|}
\hline 3.9 & Relacionamento entre objetos do HMBS (Oliveira et al [2001) & $\ldots$ & $\ldots$
\end{tabular} . . . . 36 .

4.1 Exemplo de Mapa Conceitual (Konrath $[2000)$. . . . . . . . . . . . . . . 40

\begin{tabular}{|lll|ll|}
4.2 & Parametrização simples do tipo OR (Paulo et al|[1999) & $\ldots$ & $\ldots$
\end{tabular} . . . . . . . . 45

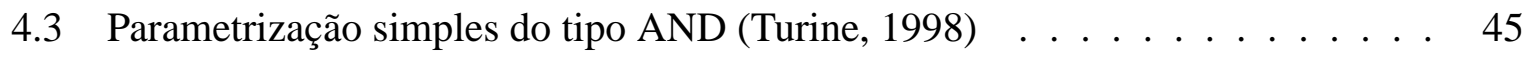

4.4 Representação gráfica da estrutura de um Curso . . . . . . . . . . . . . . . . 50

4.5 Statechart parametrizado de uma Unidade de Estudo . . . . . . . . . . . . . . 50

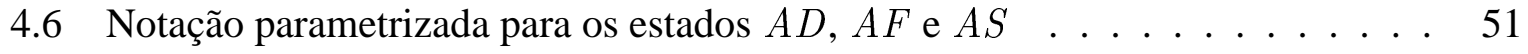

4.7 Organização das referências, por meio de um statechart parametrizado . . . . . 51

$4.8 \quad M C_{H T M L}-$ Mapa Conceitual de um Curso básico sobre HTML . . . . . . . . 57

4.9 Representação gráfica, mais abstrata, de Conteúdo ${ }_{H T M L} \ldots \ldots \ldots$. . . . . . 58

4.10 Possível estado associado à AD do Curso básico sobre HTML . . . . . . . . . 59

4.11 Estado associado à $U E_{\text {Ligações }}$ do Curso básico sobre HTML . . . . . . . . . . . 59

4.12 Possíveis subestados da AF relacionada ao Tópico sobre pontos de chegada . . 60

4.13 Statechart parametrizado da AS sobre HTML . . . . . . . . . . . . . . 60

4.14 Possíveis subestados associados à AS do Curso sobre HTML . . . . . . . . . . 60

4.15 Statechart das referências do Curso de HTML . . . . . . . . . . . . . . . . . 61 
5.1 Arquitetura física do ATEnA $\ldots \ldots \ldots \ldots \ldots \ldots$

5.2 Arquitetura funcional do ATEnA $\ldots \ldots \ldots \ldots \ldots \ldots$

5.3 Classes dos Módulos Autoria e Ensino . . . . . . . . . . . . . . . . . . . . . . 69

5.4 Classes do Módulo Administrativo, adaptadas de (Casagrande[. 2001)] . . . . . 70

5.5 Tela principal do sistema ATEnA $\ldots \ldots \ldots \ldots \ldots \ldots \ldots \ldots \ldots . \ldots \ldots 72$

5.6 Lista de cursos encerrados . . . . . . . . . . . . . . . . . . . . 73

5.7 Exemplo de uma página com informações sobre curso . . . . . . . . . . . . 73

5.8 Ambiente do assistente acadêmico . . . . . . . . . . . . . . . . . . . 74

$5.9 \quad$ Formulário para proposta de novo curso $\ldots \ldots \ldots \ldots \ldots \ldots \ldots$

5.10 Visualização gráfica do Mapa Conceitual gerado automaticamente . . . . . . . 75

5.11 Inclusão dos principais dados do Curso . . . . . . . . . . . . . . . . 76

5.12 Entrada dos principais dados de uma questão $\ldots \ldots \ldots \ldots \ldots$

5.13 Condição para aprovação na AD $\ldots \ldots \ldots \ldots \ldots \ldots . \ldots \ldots 77$

5.14 Questões sobre pontos de chegada ． . . . . . . . . . . . . . . . . . 77

5.15 Elaboração automática da AS sobre HTML $\ldots \ldots \ldots \ldots \ldots . \ldots 78$

5.16 Interface inicial da AD sobre HTML $\ldots \ldots \ldots \ldots \ldots \ldots \ldots$

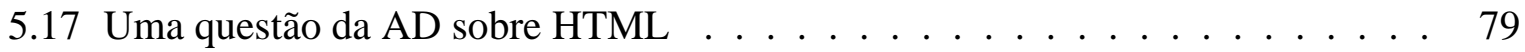

5.18 Desempenho de um aprendiz na AD sobre HTML $\ldots \ldots \ldots \ldots$

5.19 Início de um Tópico sobre HTML $\ldots \ldots \ldots \ldots \ldots \ldots \ldots$

5.20 Exibição de uma AF ao aprendiz $\ldots \ldots \ldots \ldots \ldots \ldots$

5.21 Tópico com ligação embutida para outro Tópico . . . . . . . . . . . . . . 81

5.22 Conteúdo visualizado como referência webliográfica $\ldots \ldots \ldots \ldots$. . . . 82

5.23 Conteúdo visualizado como Tópico $\ldots \ldots \ldots \ldots \ldots \ldots \ldots \ldots$

5.24 Relatório parcial de um curso . . . . . . . . . . . . . . . . . . 83

5.25 Relatório parcial por aprendiz . . . . . . . . . . . . . . . . . 84

5.26 Estatísticas parciais de um curso $\ldots \ldots \ldots \ldots \ldots \ldots$. . . . . . . 85

6.1 Estatísticas de um oferecimento (primeira parte) $\ldots \ldots \ldots \ldots$. . . . . 100

6.2 Estatísticas de um oferecimento (segunda parte) . . . . . . . . . . . . . . 101

6.3 Estatísticas de um oferecimento (terceira parte) $\ldots \ldots \ldots \ldots$

6.4 Atividades de um aprendiz durante um curso . . . . . . . . . . . . . . . . . 103 


\section{Lista de Tabelas}

2.1 Características de ambientes educacionais . . . . . . . . . . . . . . 22

3.1 Primitivas do RMDM (Isakowitz et al|[1995) $\ldots \ldots \ldots \ldots \ldots \ldots$

$4.1 \quad$ Função $V C_{H T M L}$ de $M C_{H T M L} \ldots \ldots \ldots \ldots \ldots \ldots \ldots$

5.1 Ações do autor e do instrutor $\ldots \ldots \ldots$. . . . . . . . . . . . . . . 65

5.2 Dados quantitativos dos programas PHP $\ldots \ldots \ldots \ldots \ldots$

$6.1 \quad$ Requisitos Gerais para Sistemas de Autoria Hipermídia . . . . . . . . . . . . . 89

6.2 Requisitos para Sistemas de Autoria Hipermídia Educacional . . . . . . . . . . 90

6.3 ATEnA e outros ambientes de EaD . . . . . . . . . . . . . . . . . . . . . 108 


\title{
Lista de Abreviaturas
}

\author{
AD Avaliação Diagnóstica \\ AF Avaliação Formativa \\ AS Avaliação Somativa \\ ATEnA Ambiente para Treinamento, Ensino e Aprendizagem ou \\ Adaptive Training Environment with Support for Assessment \\ CALM Computer-Aided Learning Material \\ EaD Ensino a Distância \\ EHDM Educational Hyperdocuments Design Method \\ GIF Graphics Interchange Format \\ HDM Hypertext Design Model \\ HMBS Hyperdocument Model Based on Statecharts \\ HTML Hypertext Markup Language \\ JPEG Joint Photographic Experts Group \\ MC Mapa Conceitual \\ MCA Modelo de Contextos Aninhados \\ MDE Modelo para Documentos Educacionais ou \\ Model for Distance Education \\ PHP PHP: Hypertext Preprocessor \\ RMDM Relationship Management Data Model \\ RMM Relationship Management Methodology \\ UE Unidade de Estudo \\ URL Uniform Resource Locator \\ WebCT World Wide Web Course Tools \\ WIS Web Information System \\ WWW World Wide Web
}




\section{Introdução}

\subsection{Considerações Iniciais}

Um fato que favoreceu o desenvolvimento da computação em geral, na década de 60, foi a corrida espacial. O governo estadunidense investiu bilhões de dólares em pesquisas, para que os norte-americanos fossem os primeiros a chegar ao espaço. A criação de um pólo de pesquisas avançadas, a ARPA (Advanced Research Projects Agency), fez com que surgissem vários conceitos que refletem direta e indiretamente o mundo da informática hoje; dentre eles, as redes descentralizadas de computadores que possibilitaram a criação de redes globais de computadores como a Internet (Torres, 1996).

Até o início da década de 90, a Internet era utilizada essencialmente por pesquisadores industriais, governamentais e acadêmicos. Uma nova aplicação, a WWW (World Wide Web), trouxe milhões de novos usuários, não-acadêmicos, para a Internet. Esta aplicação não modificou quaisquer recursos básicos, mas sim facilitou seu uso. Associada ao visualizador Mosaic, a WWW possibilitou a criação e a disponibilização de documentos eletrônicos com informações multimídia (texto, imagens, som e vídeo) e ligações embutidas para outros documentos (Tanenbaum, 1996). Este conjunto de documentos interligados que incluem várias mídias é designado como aplicação hipermídia ou hiperdocumento.

Com o desenvolvimento da WWW, as fronteiras para o Ensino a Distância (EaD) se expandiram. É possível reunir em um só meio de comunicação as vantagens dos diferentes modos de comunicar informações e idéias, de forma cada vez mais interativa.

No próprio ensino convencional, que segue os padrões pedagógicos tradicionais, a Internet oferece um gigantesco acervo de conhecimento que enriquece o ambiente de aprendizado. Entretanto, muitos cursos disponíveis atualmente na Internet não exploram todas as possibilidades de comunicação e de interação existentes na $W e b$, visto que a maioria deles reproduz a estrutura e o projeto gráfico de textos impressos (Alves \& Santos, 2001). 


\subsection{Contexto}

Para desenvolver um curso na WWW, sem simplesmente imitar um livro, são necessários modelos de especificação e métodos que sistematizem o seu processo de desenvolvimento. Métodos e técnicas tradicionais da Engenharia de Software não são adequados para o projeto de aplicações hipermídia, as quais apresentam requisitos próprios, tais como (Garzotto et al., 1994; Hardman et al., 1993a, Nanard \& Nanard, 1995):

- gerenciar um grande volume de informações;

- combinar a navegação controlada pelo usuário com a própria natureza das informações multimídia;

- capturar e organizar a estrutura do domínio de informação, para torná-la clara e acessível aos usuários;

- criar diferentes versões a partir de uma única especificação ou projeto; e

- estabelecer abordagens sistemáticas para que sejam definidas a estrutura organizacional e a semântica de navegação de hiperdocumentos.

A necessidade de satisfazer os requisitos listados acima impulsionou a pesquisa por modelos e métodos que forneçam diretrizes para gerenciar o projeto de hiperdocumentos estruturados, auxiliando a disciplinar a atividade de autoria. O uso de modelos não apenas melhora o processo de projeto e desenvolvimento de hiperdocumentos (Cavallaro et al., 1993; Schwabe \& Rossi, 2003), como também facilita sua análise e avaliação (Garzotto et al., 1995).

Pesquisadores do Grupo de Engenharia de Software do ICMC já vêm atuando na investigação de técnicas para a especificação de aplicações hipertexto e hipermídia (Turine, 1998). Como resultado dessa pesquisa, foram propostos dois modelos de especificação denominados HMBS (Hyperdocument Model Based on Statecharts) e XHMBS (eXtended Hyperdocument Model Based on Statecharts), os quais têm sido divulgados nas principais conferências da área (Paulo et al., 1998; Turine et al., 1997). Também foi desenvolvido, com base no modelo HMBS, o protótipo de um ambiente de autoria e navegação de hiperdocumentos denominado HySCharts (Turine et al., 1999) e um método - HMBS/M — orientado a objetos para o projeto de aplicações hipermídia (Carvalho, 1998; Carvalho et al., 1999). Quando a aplicação hipermídia consiste em conteúdo educacional para ensino a distância, além dos requisitos acima existem outros próprios desse domínio em particular. Nesta tese, foi verificada a viabilidade de estender o HMBS para a modelagem do domínio específico de Ensino a Distância, com ênfase na avaliação contínua e no acompanhamento do progresso do aprendiz pelo instrutor. 


\subsection{Motivação}

Sistemas para Ensino a Distância $(\mathrm{EaD})$, bem como sistemas on-line para apoio a cursos presenciais, vêm-se tornando cada vez mais presentes. Seu uso tende a se difundir ainda mais por uma série de razões, dentre as quais o baixo custo e a facilidade de acesso por um amplo número de pessoas. Apesar da evolução tecnológica abrir uma infinidade de possibilidades potencialmente positivas, educadores preocupam-se com vários problemas fundamentais associados à utilização de tais sistemas, particularmente no contexto de EaD. Um deles é a dificuldade do instrutor acompanhar a evolução dos aprendizes durante o curso. Outro é a dificuldade de realizar avaliações precisas capazes de medir as diferentes dimensões do processo de aprendizado.

Um modelo formal de hiperdocumentos educacionais contribui para a especificação mais precisa e rigorosa da semântica navegacional e das avaliações. Essa especificação formal pode ainda ser utilizada para coletar e processar os dados do curso - incluindo a dedução ou derivação de novas informações - , bem como para gerar um protótipo de implementação executável. Além disso, a formalização facilita a compreensão do modelo, visto que ele é definido matematicamente e sem ambigüidades (Alencar, 1999).

\subsection{Objetivos}

O objetivo principal desta tese é propor um modelo computacional para apoiar o Ensino a Distância, considerando que o aprendiz estudará on-line e que vários aspectos da sua interação com o material didático podem ser capturados para auxiliar o instrutor a avaliar o desempenho dos aprendizes. Do ponto de vista pedagógico, vários conceitos e técnicas propostas na literatura são integradas ao modelo, tais como:

- diferentes tipos de avaliação (e.g., diagnóstica, formativa e somativa);

- definição de mapas conceituais (Novak, 2000), que possibilitam relacionar o conteúdo e as avaliações aos conceitos apresentados no curso; e

- total flexibilidade para o autor do curso determinar tanto os critérios de avaliação quanto o fluxo de estudo do material.

Adicionalmente, e de forma complementar ao anterior, outro objetivo deste trabalho é propor extensões e adaptações ao modelo HMBS (Hyperdocument Model Based on Statecharts) (Oliveira et al., 2001; Turine et al., 1997), para permitir a formalização de modelos computacionais para a modelagem de aplicações de EaD. Usando o HMBS, pretende-se tornar possível definir aspectos estáticos (atributos das páginas de conteúdo, estrutura, elementos repetitivos etc.) e dinâmicos (controle de acesso às páginas, i.e., semântica navegacional) dos cursos. 
Finalmente, para validar o modelo, pretende-se desenvolver como prova de conceito um sistema de oferecimento de cursos a distância que implemente os aspectos principais do modelo proposto, bem como avaliá-lo e compará-lo com outros sistemas semelhantes, relativamente aos aspectos que integram os objetivos propostos.

\subsection{Organização}

Esta tese está organizada em sete capítulos. No próximo Capítulo, são abordados aspectos relacionados a sistemas hiperdocumento e ao Ensino a Distância via WWW. Ao comparar sistemas hipermídia educacionais, são enfatizadas a avaliação dos aprendizes e a modelagem do conteúdo didático.

No Capítulo 3 são descritos alguns modelos hipermídia baseados em grafos ou em suas extensões, destacando-se o HMBS.

No Capítulo 4 é proposto um modelo para a elaboração de hiperdocumentos educacionais.

No Capítulo 5 é descrito o sistema implementado com base neste modelo.

No Capítulo 6 este sistema é avaliado em relação aos sistemas hipermídia educacionais estudados e às características hipermídia descritas no Capítulo 3.

Por fim, no Capítulo 7 apresentam-se os resultados obtidos, as limitações do modelo e do sistema, algumas sugestões de trabalhos futuros, e as conclusões desta tese. 


\section{Sistemas de Informação na Web para Ensino a Distância}

\subsection{Considerações Iniciais}

Recursos hipertexto têm sido bastante explorados na estruturação de conteúdo educacional, principalmente após a popularização da WWW. Surgiram vários ambientes computacionais e cursos baseados na Web; e, segundo Chaves (2003), eles se tornam mais eficazes se o material didático incluir recursos como anotações, comentários, glossários, mapas navegacionais e referências (links) para textos complementares ao conteúdo básico.

Segundo Nielsen (1995), mesmo que a maioria dos hiperdocumentos não faça parte de algum curso oferecido a distância, eles tipicamente têm uma intenção educacional. Exemplos típicos são os manuais que ensinam como consertar objetos, bem como as versões hipertexto de jornais, dicionários e revistas. Além disso, observa-se que muitos sistemas hipertexto foram e são produzidos especificamente para uso educacional. Hipertexto é particularmente adequado para aplicações de livre aprendizagem nas quais o aprendiz é encorajado a assumir iniciativas. Em uma aplicação, ele pode navegar por diversas informações e examinar aquelas que mais lhe interessam ou fazem sentido no contexto da tarefa que precisa executar.

Neste capítulo são abordados aspectos relacionados a sistemas hiperdocumento, enquanto no Capítulo 3 são destacados modelos para a especificação e o projeto de hiperdocumentos. Na próxima Seção, são descritos dois modelos de sistemas hiperdocumento. Na Seção 2.3 são apresentadas algumas características da Web e a definição de um WIS (Web-based Information System), visto que nesta tese foi implementado um WIS para ensino. Alguns recursos hipermídia, tema da Seção 2.4, foram estudados e incluídos neste WIS. Na Seção 2.5 são sintetizados os pontos fortes e fracos de ambientes hipertexto. Pelo fato do sistema implementado modelar conceitos educacionais, a Seção 2.6 é dedicada ao Ensino a Distância (EaD). São classificados os diferentes softwares para EaD; posteriormente, alguns sistemas hipertexto educacionais são apresentados e contrastados. As considerações finais sobre hiperdocumentos e EaD são incluídas na Seção 2.7. 


\subsection{Modelagem Estrutural de Sistemas Hipermídia}

No contexto da Engenharia de Software, um modelo é uma representação abstrata dos elementos envolvidos na construção de um sistema. Esse modelo fornece uma infra-estrutura por intermédio da qual elementos e seus relacionamentos podem ser representados, definidos e analisados. Diferentes modelos de sistemas hipertexto foram criados para representar arquiteturas genéricas que pudessem ser utilizadas em diferentes implementações. Os dois principais modelos de referência são HAM (Hypertext Abstract Machine) e Dexter.

O modelo HAM, baseado na separação entre front-end (interação) e back-end (armazenamento), distingue três camadas de um sistema hipertexto: banco de dados, HAM ou máquina abstrata de hipertexto, e apresentação. Na camada do banco de dados está um servidor que armazena e compartilha as informações. A camada da máquina abstrata contém a estrutura organizacional do hiperdocumento, usando cinco componentes organizados hierarquicamente: grafo, contexto, nó, ligação e atributo. A camada de apresentação especifica como as informações são exibidas, sem detalhar a interação com o usuário (Campbell \& Goodman, 1988). Embora ligações sejam armazenadas no nível HAM, a posição de uma âncora em um nó depende da estrutura de armazenamento do nó; portanto, a ancoragem da ligação não pode ser tratada nesse nível. Isso motivou o desenvolvimento do modelo Dexter.

O modelo Dexter define uma interface explícita entre a camada HAM ("camada de armazenamento" no Dexter) e a camada do banco de dados ("camada de componentes" no Dexter). $\mathrm{O}$ mecanismo de ancoragem traduz entre identificadores de âncora na HAM e os reais valores das âncoras no conteúdo do nó (Halasz \& Schwartz, 1994). A especificação formal do Dexter deixa em aberto algumas decisões de projeto; entre elas, o apoio a compartilhamento de hipertextos e de componentes entre diferentes usuários, além do relacionamento entre as camadas do modelo com uma arquitetura distribuída multi-usuário (Grønbæk et al., 1993). Apesar disso, o modelo Dexter oferece uma base rigorosa para descrever e comparar as arquiteturas de várias implementações de sistemas hipermídia, bem como para o desenvolvimento de padrões para intercâmbio de informação hipermídia.

HAM e Dexter são modelos arquiteturais para sistemas hipermídia. Eles detalham a arquitetura do sistema, que é uma máquina hipertexto genérica, mas não são adequados para modelar aplicações. Seu escopo era limitado aos sistemas hipertexto existentes quando foram definidos; por isso, não atendem a alguns requisitos de sistemas hipermídia atuais, como o estabelecimento de sequiência temporal entre componentes. Além disso, não possibilitam ligações entre hipertextos e não distinguem entre conteúdos administrados pelo sistema e aqueles gerenciados por outras aplicações. Objetos compostos são limitados quanto à composição, que é por cópia e não por referência, impedindo o reuso de objetos de conteúdo. Para superar tais restrições, outros modelos foram elaborados como, por exemplo, Amsterdam Hypermedia Model AHM (Hardman et al., 1993b) e DeVise Hypermedia DHM (Grønbæk \& Trigg, 1994). 


\subsection{WWW: Hipermídia em Rede}

O sistema mais usado para acesso a documentos na Internet é a World Wide Web (WWW ou W3) (Berners-Lee, 2002), baseada em uma arquitetura cliente-servidor para hipertexto distribuído. Essa arquitetura é dividida em três níveis, conforme o modelo HAM. A camada do banco de dados consiste na Internet e em todos os computadores espalhados pelo mundo todo que fornecem materiais para outros computadores na WWW. A máquina abstrata de hipertexto combina HTML (Hypertext Markup Language) e HTTP (Hypertext Transfer Protocol). A camada de apresentação é gerenciada por navegadores (browsers) como Mozilla, Netscape Navigator ou Microsoft Internet Explorer (Nielsen, 1995).

HTML concentra-se na representação da aparência do texto, desconsiderando o que a informação representa ou como ela está estruturada ${ }^{1}$. Por sua vez, XML (eXtended Markup Language) - uma meta-linguagem elaborada para facilitar a especificação de hiperdocumentos em diversos domínios - possibilita a separação entre estrutura, apresentação e conteúdo. Entretanto, nem todos os navegadores disponíveis atualmente interpretam hiperdocumentos descritos no formato XML (Bray et al., 2000; Johnson, 1999).

\subsubsection{Sistemas de Informação na WWW}

A WWW, usada originalmente apenas para estabelecer uma presença on-line, passou a ser uma plataforma que apóia todos os aspectos do trabalho organizacional. Esforços importantes dos profissionais de sistemas de informação estão voltados para o desenvolvimento de sistemas de informação baseados na WWW, abreviados como WISs (Web-based Information Systems). Eles combinam navegação em um espaço de informações heterogêneas com operações que consultam ou afetam aquelas informações. Há quatro categorias de WISs: sistemas para intranets, que processam informações internas às redes locais; sítios (sites) WWW, que funcionam como uma estratégia de marketing, levando informações e serviços ao público externo; sistemas de comércio eletrônico, que apóiam interações com o consumidor, como shopping on-line; e sistemas para extranets, um conjunto de sistemas internos e externos que se comunicam para apoiar negócios das organizações (Isakowitz \& Bieber, 1998; Isakowitz et al., 1998; Schwabe \& Rossi, 1998).

Como qualquer sistema de informação, WISs gerenciam informações por meio de operações de registro, recuperação e controle de dados, visando à otimização desse processo. Contudo, WISs requerem novas abordagens de projeto e de desenvolvimento e é necessário atualizar regularmente o conteúdo e as ligações. Com planejamento e projeto adequados, é possível evitar dificuldades na manutenção de documentos gerados por um WIS (Balasubramanian \& Bashian, 1998; Isakowitz et al., 1998).

\footnotetext{
${ }^{1}$ Arquivos no formato HTML são, tipicamente, designados como páginas.
} 
Um sítio WWW é utilizado para disseminar informação a usuários anônimos, enquanto um WIS é projetado para executar tarefas específicas de negócios, tais como aquisição de bens, recrutamento e gerenciamento do fluxo de trabalho (workflow) organizacional. Os sítios fornecem normalmente uma única visão aos usuários; ao contrário, usuários de WISs têm tarefas específicas a realizar e freqüentemente necessitam de visões específicas para realizar seu trabalho. WISs possuem os seguintes requisitos: estrutura navegacional projetada para apoiar fluxos de trabalho específicos, modelo estruturado de dados representando relacionamentos entre partes da informação, características que possibilitam aos usuários o processamento interativo de dados de negócios, apoio ao estilo distribuído de trabalho colaborativo e integridade referencial rígida de ligações para tarefas indispensáveis (Dennis, 1998; Takahashi, 1998). Duas importantes áreas de aplicação dos WISs são o comércio eletrônico e o Ensino a Distância (EaD), área na qual esta tese está inserida.

\subsection{Recursos Hipermídia}

Alguns pesquisadores em hipermídia são favoráveis à incorporação, nos protocolos padrão da WWW, de funcionalidades de alto nível disponíveis em alguns sistemas hipertexto, o que possibilitaria o desenvolvimento de aplicativos para a WWW que integrariam funcionalidades típicas de hipermídia às demais funcionalidades específicas da aplicação, para benefício de autores e leitores de aplicações WWW em diversas áreas.

\subsubsection{Características Avançadas de Ligações}

É importante que um sistema permita aos usuários personalizar os dados e a sua forma de exibição, bem como restringir o acesso a certas ligações. A criação de visões e a permissão de acesso por certos leitores a informações específicas requer personalização baseada tanto no papel do usuário quanto nas permissões de acesso. Muitas organizações exigem tal segurança. Além das permissões de acesso sobre documentos, pode ser necessário registrar permissões de leitura e escrita sobre ligações e anotações. Para certos documentos, alguém poderia ter autorização sobre autoria e atualização de ligações, sem poder alterar seu conteúdo. Pode-se também restringir o acesso de autoria a certos tipos de nós e de ligações (Bieber et al., 1997).

\subsubsection{Nós Computados}

A maioria dos sistemas hipertexto fornece informação fixa nos nós, conforme estabelecida pelo autor original. Em alguns sistemas hipertexto é possível existir nós computados, gerados para o leitor pelo sistema. Determinar o conteúdo de um nó dinamicamente pode levar à infecção por vírus ou a outros problemas. O problema é minimizado quando o programa é executado em um servidor remoto que se limita a transmitir os dados resultantes para o computador do usuário. Se 
o código precisar ser executado no computador do usuário, precauções devem ser adotadas na forma de programas anti-vírus (Nielsen, 1995). Na WWW não há atualmente um mecanismo que possibilite computação em nós da rede. A computação na rede hipermídia estaria mais próxima da idéia de um agente que realiza processamentos em nós remotos da WWW, podendo ou não retornar ao seu nó de origem (Vasconcelos et al., 1998).

\subsubsection{Trilhas e Roteiros Guiados}

Trilhas conectam uma cadeia de ligações por meio de espaços de informação, podendo gravar um caminho de informação que o leitor deseja lembrar e compartilhar com outros. A trilha deve ser claramente marcada para que os usuários saibam quais ligações os conservam na trilha e quais os desviam da trilha. Um roteiro guiado restringe os usuários à trilha, proibindo desvios. Ele conecta uma sequiência de nós, ao invés de apenas dois nós. Enquanto os usuários permanecem no roteiro, eles podem simplesmente ativar um comando "próximo nó" para ver mais informação relevante.

Trilhas podem ser usadas para apresentar aos novos leitores os conceitos gerais sobre hipertexto. É possível também fornecer diversos roteiros guiados diferentes para diferentes leitores com interesses especiais. O leitor do hipertexto pode sair do roteiro guiado em qualquer ponto e continuar seguindo quaisquer outras ligações que pareçam interessantes. Quando o leitor quiser voltar ao roteiro, basta emitir um único comando para ser levado de volta ao ponto onde o roteiro foi suspendido.

Em aplicações educacionais, trilhas e roteiros guiados podem autorizar o aprendiz a navegar por partes selecionadas do material do curso voltadas para principiantes ou especialistas, permitindo diferentes tipos de estratificação do material a ser apresentado. Este recurso deve estar disponível tanto para os autores definirem caminhos alternativos pelo material, como para os aprendizes definirem seus próprios "caminhos de navegação", dentro das restrições impostas pelos instrutores.

\subsubsection{Listas de História}

Embora retroceder um nó por vez traga eventualmente o leitor de volta a um nó anterior específico, leitores freqüentemente desejam saltar diretamente para um ponto específico; nesses casos, o sistema deve exibir claramente uma lista de história, a fim de que o leitor possa escolher para qual nó deseja voltar.

\subsubsection{Marcos}

Marco (landmark) é um ponto de referência como, por exemplo, uma página principal (home page) de um sítio WWW ou um nó especialmente saliente. Quase todos os sistemas hipertexto definem um nó específico em um documento como o nó introdutório e permitem acesso rápido a 
ele, mas é possível também definir marcos locais adicionais para regiões especiais no espaço de informação e enfatizá-los visualmente nos diagramas de visão geral. Marcos são, geralmente, definidos pelo autor de um hipertexto com o objetivo de fornecer uma estrutura útil para os leitores (Nielsen, 1995).

\subsubsection{Adaptatividade}

A Hipermídia Adaptativa trata do estudo e desenvolvimento de sistemas, arquiteturas, métodos e técnicas capazes de adaptar hiperdocumentos às expectativas, necessidades, preferências, conhecimento prévio, estilos de interação e características cognitivas de seus usuários (Höök et al., 1996). Um sistema hipermídia adaptativo identifica e reflete algumas características de seus diferentes usuários em modelos e aplica tais modelos para adaptar diversos aspectos visíveis do sistema a cada usuário.

Vários sistemas com essas características são descritos na literatura. Por exemplo, o sistema HYPERFLEX fornece ao usuário orientações global e local, listando os nós relacionados ao nó atual em ordem decrescente de relevância para os objetivos do usuário; além disso, o usuário pode organizar essa lista, mudando a ordem dos nós conforme sua preferência. Já o sistema Adaptive HyperMan utiliza feedback dos usuários para aprender gradualmente sobre suas preferências, enquanto no Hypadapter a relevância de uma ligação é definida por meio de um conjunto de regras. Ao utilizar o Hynecosum, o usuário informa qual tarefa está atualmente executando a partir de uma hierarquia pessoal e, com base nesta informação, o sistema pode esconder os nós irrelevantes para a tarefa. Por fim, HYPERCASE adapta a forma dos mapas local e global para o objetivo didático ou de informação do usuário (Brusilovsky, 1996b).

A adaptatividade é particularmente importante em aplicações educacionais, porque a maioria delas é utilizada por diversos tipos de usuários. Uma aplicação projetada para uma categoria específica de usuários pode não ser adequada aos demais. Além disso, em muitos casos, o aprendiz está estudando "sozinho" (possivelmente em casa) e não dispõe do auxílio que um colega ou instrutor tipicamente fornece, de forma adaptativa, em uma sala de aula (Brusilovsky et al., 1997).

AvalWeb é um exemplo de sistema hipermídia, no domínio do Ensino a Distância, que possui algumas características adaptativas. Suas avaliações possuem nível de dificuldade progressivamente maior ou menor. Se o autor do conteúdo didático preferir avaliações adaptativas, ao contrário do padrão normal, será apresentada ao aprendiz somente uma questão por vez, pois a próxima questão dependerá da resposta do aprendiz à questão anterior. No caso de avaliações com nível de dificuldade progressivamente maior, o sistema busca descobrir os pontos fracos do aprendiz, alternando entre tópicos e níveis de dificuldade adequados à situação. No nível de dificuldade progressivamente menor, ocorre o contrário (Cardoso \& Lima, 2001; Zambrini \& Lima, 2001). 


\subsection{Pontos Fortes e Fracos de Hipertexto}

Um dos pontos fortes do hipertexto é o fato de integrar três distintas tecnologias e indústrias: publicação, computação e radiodifusão na forma de televisão e filme. Hipertexto oferece a oportunidade de publicar estruturas de informação para o público em geral, da mesma forma que livros ou jornais. Essas estruturas de informação estão baseadas principalmente em imagens móveis, conforme a tradição da indústria cinematográfica, e são controladas pelo computador, a fim de possibilitar a interação com o usuário. Um sistema hipertexto trabalha em colaboração com o usuário, o qual pode compreender o conteúdo semântico dos vários nós e determinar qual das suas ligações seguirá. Um hipertexto está sob controle do usuário, que pode personalizá-lo ao acrescentar ligações e anotações, enquanto a maioria dos outros sistemas computacionais é monolítica e pode ser modificada apenas por especialistas. Hipertexto tem potencial para reduzir o custo de certas aplicações, devido principalmente ao menor espaço de armazenamento e ao baixo custo para atualizar a informação (Nielsen, 1995).

Muitos estudos foram realizados para tratar dois pontos fracos típicos de hipertextos (Conklin, 1987): desorientação do usuário e sobrecarga cognitiva. O primeiro refere-se à tendência do usuário perder o sentido de localização e direção em documentos que não são lineares, enquanto o segundo consiste em uma sobrecarga na concentração e esforço exigidos do leitor porque ele pode percorrer diversas trilhas ao mesmo tempo. Nielsen cita três abordagens para reduzir a sobrecarga de informação. A primeira (e freqüentemente a mais bem-sucedida) é um bom projeto da interface com o usuário e uma boa preparação editorial dos dados, garantindo agilidade para o usuário examinar rapidamente a informação e escolher os itens que lhe interessam. As duas outras soluções envolvem a inclusão de recursos para recuperação e filtragem da informação. A recuperação normalmente é ativada diretamente pelo usuário em casos específicos em que ele está procurando uma determinada informação, enquanto a filtragem ocorre continuamente quando o usuário deseja manter-se informado sobre certos eventos.

Os recursos hipermídia analisados neste Capítulo conseguem diminuir ambos os problemas típicos de hipertextos.

\subsection{Ensino a Distância}

Os termos "educação a distância (EaD)", "ensino a distância" e "aprendizagem a distância" são tratados como sinônimos neste documento, embora alguns autores façam distinção entre eles. Algumas definições de EaD destacam a distância geográfica entre instrutor e aprendizes, enquanto outras enfatizam a adoção de tecnologias de comunicação. A definição mais abrangente inclui todas as formas de ensino-aprendizagem nas quais aprendizes e/ou instrutores se comunicam de algum modo, além de reuniões presenciais em sala de aula. O produto desejado de EaD é a aprendizagem a distância, a qual também é definida como o processo de aprendizagem 
sem contato pessoal regular com um instrutor ou com outros colegas em sala de aula presencial, enquanto ensino a distância significa o processo de ensino sem contato pessoal regular em regime presencial (Kaplan-Leiserson, 2002; Romiszowski et al., 1997; Sherry, 1996).

Segundo Chaves (2003), as expressões "Educação a Distância" e "Aprendizagem a Distância" são inadequadas, pois educação e aprendizagem são processos que ocorrem dentro da pessoa, sem possibilidade de serem realizados a distância. Ensinar a distância, porém, é possível e ocorre o tempo todo. A expressão "ensino a distância" faz sentido aqui porque quem ensina está "espacialmente distante" (e talvez distante no tempo) de quem aprende. O termo "distância" foi originalmente usado para se referir ao espaço, mas pode também se referir ao tempo.

\subsubsection{Sistemas para Ensino a Distância}

É possível classificar os sistemas para $\mathrm{EaD}$ conforme os seguintes tipos: notas didáticas, sistema tutor inteligente, interface adaptativa, ambiente para aprendizagem cooperativa, sala de aula virtual, sistema de apoio à autoria e ambiente de aprendizado por simulação. Nas próximas subseções define-se e exemplifica-se estes tipos. Vários sistemas de EaD são discutidos. Para concluir, apresenta-se uma comparação, considerando características relevantes para este trabalho, entre alguns sistemas educacionais descritos.

\subsubsection{Classificação}

A interação existente em notas didáticas limita-se à ativação de ligações, sendo possível enviar mensagens eletrônicas ao autor das notas, o qual não necessariamente é um instrutor. A maioria informa pouco sobre como navegar pelo material; trata-se de um reservatório de informação, sem estrutura didaticamente ordenada e compreensível para os leitores, e que apenas recomenda textos ou inclui ligações para arquivos (Romanato et al., 1996). Um exemplo é um tutorial sobre PHP e MySQL com três lições principais subdivididas em algumas páginas (Merrall, 1999).

Um sistema tutor inteligente (STI) adapta dinamicamente o conteúdo às preferências e objetivos específicos de um aprendiz (IEEE, 2000). Alguns STIs são listados em (American Association for Artificial Intelligence, 2003).

Uma interface adaptativa molda-se às habilidades do usuário; para isso, o sistema arquiva as preferências do aprendiz e/ou o que ele sabe. Ela possibilita mudar a apresentação em vários níveis, como nas estratégias de ensino (incluindo mais exercícios ou teoria), ou na interface do sistema (Preto \& Gabriel, 2000). Existe um protótipo de interface adaptativa, denominado Athena, que pode ser anexado a diferentes sistemas (Siebra \& Ramalho, 1999).

Um ambiente para aprendizagem cooperativa possibilita a comunicação e cooperação de duas ou mais pessoas que podem trocar e compartilhar informações, de forma simultânea ou não. Ele organiza e facilita a comunicação entre seus participantes (Castro, 1997; Preto \& Gabriel, 2000). A Biblioteca Kidlink, por exemplo, oferece espaços de troca de informações 
e cooperação, espaços virtuais de auto-expressão textual ou não textual, espaços virtuais de expressão compartilhada, cursos on-line e seminários virtuais (Santos \& Ferreira, 1998).

Uma sala de aula virtual apóia o instrutor na criação, manutenção e aplicação de cursos, incluindo ferramentas que possibilitam incorporar outros softwares e vários tipos de mídia. Há, geralmente, ferramentas que apóiam a elaboração e a correção de avaliações, além de outras que fornecem informações sobre o progresso dos aprendizes. Algumas salas de aula virtuais, como WebCT e AulaNet, contêm ferramentas síncronas de comunicação. Assim como uma sala de aula virtual, um sistema de apoio à autoria apóia o instrutor na elaboração de cursos, não destaca o trabalho cooperativo mas, geralmente, fornece ferramentas para comunicação.

Um ambiente de aprendizado por simulação agrupa ferramentas gráficas para simular certas situações em diversos assuntos. Em um ambiente menos interativo, o aprendiz somente especifica alguns valores, seleciona opções e assiste à simulação; em um ambiente mais interativo, ele cria suas próprias simulações que, geralmente, correspondem à solução de problemas propostos a partir de ferramentas disponíveis (Preto, 2000). Os sistemas Enxuto e Jonas, por exemplo, integram um ambiente computacional para modelagem e simulação em um contexto de treinamento em manufatura (Borges \& Baranauskas, 1998).

\subsubsection{AulaNet}

AulaNet é um ambiente para a criação e administração de cursos baseados na WWW, com um alto nível potencial de interatividade, sem que o autor precise ser especialista em programação na WWW. Seus objetivos são: adotar a WWW como ambiente educacional, estimular uma transição viável da sala de aula convencional para a sala de aula "virtual" apoiando o reuso de materiais didáticos já existentes e promover a criação de comunidades de conhecimento (Fuks, 2000; Lucena et al., 2000b, 1999a b).

O AulaNet apóia avaliações formais ou explícitas e informais ou baseadas em dados qualitativos. A avaliação formal ocorre por meio de provas, testes e listas de exercícios, enquanto a informal baseia-se na interação dos aprendizes com o ambiente, entre si e com o instrutor. A avaliação informal do aprendiz inclui, por exemplo: caminhos percorridos no material didático, referências consultadas e freqüência da consulta, utilização de referências suplementares fornecidas pelo instrutor, iniciativa em pesquisar outras referências, contribuição em atividades conjuntas, contato com o instrutor (regular ou em datas próximas a entrega de trabalhos), assiduidade em tarefas em grupo e aproveitamento dos recursos do ambiente em trabalhos ou provas (Menezes et al., 1998).

Como apoio à avaliação formal, é utilizada uma ferramenta gráfica para gerar e avaliar testes de preenchimento de lacunas, múltipla escolha e verdadeiro ou falso. Ao editar uma questão, o instrutor pode atribuir, dentre outras, as seguintes propriedades: tópico correspondente no material de estudo, peso e nível do domínio cognitivo (Bloom et al. 1971). O teste pode 
ser corrigido automaticamente se o instrutor especificar as respostas corretas; após a correção, várias estatísticas ficam disponíveis ao instrutor, tais como: lista de notas, com opção de revisar as respostas fornecidas pelos aprendizes; estatísticas baseadas em tópicos do conteúdo, classificadas por domínios cognitivos e por questão; e a média do grupo (Choren et al., 1998).

Para coletar dados necessários à avaliação informal, o instrutor pode visualizar dados sobre o uso, no total e na média, dos materiais e das ferramentas de comunicação disponíveis no curso. Estes dados possibilitam saber como as tarefas do curso estão sendo realizadas pelos aprendizes e medir o grau de envolvimento dos aprendizes. Por exemplo, se a lista de discussão foi muito usada, o instrutor pode supor que os aprendizes demonstraram grande interesse em cooperar para aprender, a não ser que a lista tenha sido utilizada para assuntos alheios ao curso; por outro lado, se um material foi pouco usado, o instrutor pode inferir que o material não desperta o interesse dos aprendizes ou que não está adequado. Os dados da interação dos aprendizes com materiais e com os demais participantes do grupo são coletados por um componente de software no computador-cliente que alimenta um banco de dados com os eventos ocorridos nas interações dos aprendizes (Lucena et al., 1999c). O modelo subjacente à avaliação informal é baseado em agentes (Figura 2.1).

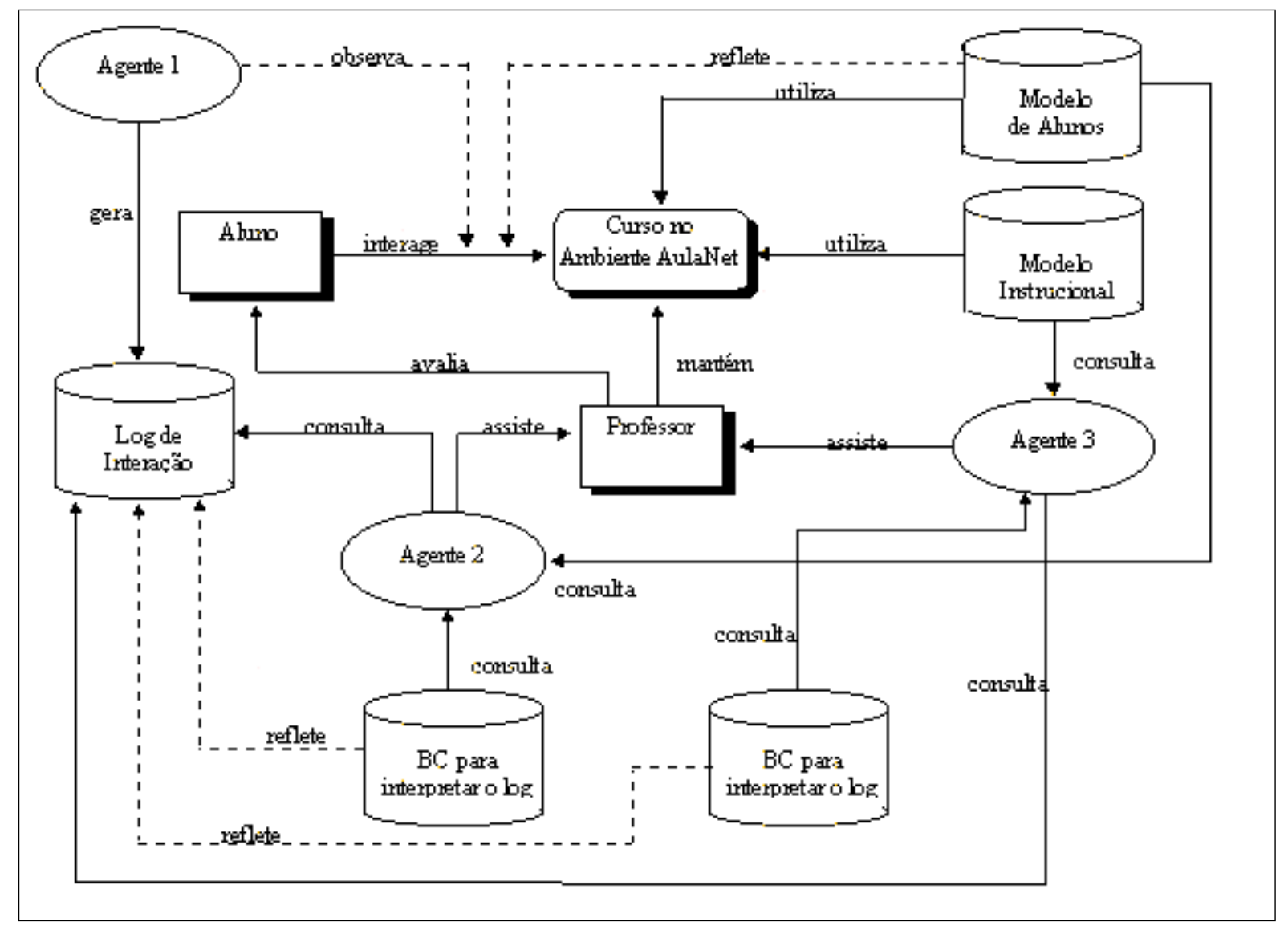

Figura 2.1: Modelo de apoio à avaliação informal no AulaNet (Menezes et al., 1998) 
Nesse modelo, há três agentes assistentes de tarefa. O processo de interação dos aprendizes com o AulaNet é monitorado por um Agente Assistente de Tarefa de Monitoração (Agente 1), o qual cria um arquivo que armazena a interação desses aprendizes com o ambiente. Esse agente possui componentes no cliente, produzindo um histórico de navegação dos aprendizes, e no servidor, para percorrer as listas de discussão, a fim de verificar a participação de aprendizes em atividades conjuntas. O instrutor é assistido por um Agente Assistente de Tarefa de Avaliação de Aprendizes (Agente 2), que consulta o arquivo gerenciado pelo Agente 1, o Modelo de Alunos e uma base de conhecimentos responsável pela interpretação desse arquivo que registrou a interação. Esse agente confronta informações decorrentes da avaliação informal com informações resultantes da avaliação formal, auxiliando o instrutor. O instrutor também é assistido por um Agente Assistente de Tarefa de Avaliação de Projeto (Agente 3), que consulta o arquivo da interação, o modelo educacional do AulaNet e uma base de conhecimentos responsável pela interpretação do arquivo de interação. Esse agente indica possíveis distorções no projeto educacional, refletidas em decorrência do comportamento verificado dos aprendizes e conseqüentemente proporcionando mecanismos que realizam as correções verificadas. Os agentes assistentes de avaliação atuam como consultores. Qualquer decisão cabe ao instrutor.

\subsubsection{TelEduc}

TelEduc é um ambiente para a criação e administração de cursos na Web que possibilita a comunicação entre os participantes, facilita a consulta às informações geradas em um curso e apóia a execução de atividades práticas orientadas pelos instrutores. Suas funcionalidades são agrupadas em três categorias: coordenação, comunicação e administração (Otsuka, 2002, Otsuka et al., 2002b; Rocha, 2002).

$\mathrm{Na}$ primeira categoria, constam os seguintes serviços: Agenda, que contém dicas ou sugestões dos instrutores para os aprendizes; Atividades, que organiza e disponibiliza atividades do curso; Dinâmica, na qual o instrutor expõe o andamento do curso, duração, objetivos, etc.; Grupos, que possibilita organizar os aprendizes em subgrupos de trabalho; Histórico, que armazena seqüencialmente todas as agendas de um curso; Leituras, usada para incluir textos e material bibliográfico geral; Material de Apoio, vinculado a uma atividade específica; Parada Obrigatória, uma atividade especial que explora o conteúdo já estudado até um determinado momento; e Perguntas Freqüentes, com dúvidas que aparecem durante um curso.

Os recursos de comunicação englobam: Bate-Papo, cujas sessões são registradas; Correio Eletrônico, interno ao ambiente; Diário de Bordo, um diário pessoal no qual o aprendiz registra seu percurso ao longo do curso, refletindo sobre seu processo de aprendizagem; Fórum de Discussões sobre temas específicos do curso; Mural de recados gerais, como avisos de eventos; Perfil, para o aprendiz incluir informações sobre si próprio; e Portfolio, um espaço onde o aprendiz pode disponibilizar, por exemplo, respostas de atividades. 
O componente de administração possibilita o gerenciamento do curso e oferece ao instrutor as seguintes funcionalidades: editar o material didático, distribuído pelos vários serviços de coordenação, atualizar a Agenda e a Dinâmica, escolher os recursos que utilizará no curso e, finalmente, verificar os acessos diários dos aprendizes ao ambiente em cada componente. Esta verificação é realizada pelo componente Acessos e pelo aplicativo Interaction Map (InterMap).

Relatórios gerados pelo componente Acessos contêm o número de acessos e a data e hora do último acesso de cada participante ao curso, a freqüência dos acessos de cada um durante determinado período do curso, e os acessos dos aprendizes a cada componente do TelEduc. Este componente possibilita a diferenciação entre o "aprendiz calado", mas presente, e o "aprendiz ausente" (Otsuka et al., 2002a; Otsuka \& Rocha, 2002).

InterMap analisa quantitativamente os dados de participação dos aprendizes (comentários, respostas, conversa no bate-papo etc.). Para fazer essa análise, são utilizadas técnicas de visualização de informação que representam graficamente os dados registrados nos componentes de comunicação. Algumas formas de representação gráfica usadas são: grafo, gráficos de barra e código de cores (Romani \& Rocha, 2000).

No TelEduc, o processo de avaliação contínua é composto por três módulos: acompanhamento, auxílio à análise de aproveitamento, e validação. O primeiro módulo oferece quatro funcionalidades: rastreamento das interações dos aprendizes e do andamento das tarefas; seleção e apresentação das informações de acompanhamento relevantes ao instrutor; detecção de possíveis problemas (como ausência de acesso ao curso, falta de interação, atraso na execução de tarefas, e falta de participação em atividades em grupo) e tomada de decisão (alerta ao instrutor, envio de mensagem aos aprendizes); e geração, no componente Acessos e no InterMap, de relatórios de acompanhamento da participação dos aprendizes. O segundo módulo consiste em: seleção e exibição das informações relevantes ao instrutor para a análise final do aproveitamento do aprendiz em uma atividade; e auxílio na atribuição do conceito final, através da observação dos critérios usados pelo instrutor na análise das informações exibidas. O último módulo constrói dinamicamente o perfil do aprendiz, refletindo seu nível de conhecimento em tópicos do curso, e valida resultados de avaliações incentivando a colaboração entre aprendizes (por exemplo, solicitando que respondam a dúvidas em um fórum ou comentem suas atividades). Observa-se que no TelEduc não há a aplicação de provas, como forma de avaliação. Essa avaliação ocorre durante o curso, baseada no uso dos componentes pelos aprendizes.

\subsubsection{CALM}

CALM (Computer-Aided Learning Material) é um ambiente de EaD que recomenda lições conforme o perfil e o objetivo de aprendizagem do usuário, apoiando interações entre os participantes e o material de estudo (Delgado et al. 1998). É favorecido o estudo individualizado, no qual cada um estabelece seu próprio objetivo de aprendizagem. É possível a auto-avaliação, 
sem que o resultado faça parte das notas oficiais do curso. Contudo, o CALM não monitora o desempenho do aprendiz, não oferece aos instrutores uma proposta de estruturação dos cursos e não permite a avaliação adaptativa conforme o perfil do aprendiz.

Os objetivos do CALM são: possibilitar o teste de novos conceitos, idéias e tecnologias, com liberdade de criticar e alterar a implementação conforme a necessidade (Magalhães, 1999, pág. 109); procurar estabelecer as características essenciais necessárias ao desenvolvimento de um ambiente computacional de apoio a atividades educacionais (Magalhães, 2001, pág. 14-15); e apoiar o aprendizado, extra-curso, do ensino teórico e de laboratório computacional oferecido nas Faculdades (Adriano et al., 1999; Basso Júnior, 1999).

A primeira interação de um aprendiz com o CALM visa estabelecer um objetivo de aprendizagem, determinado a partir de uma lista de tópicos oferecidos para a seleção. Esses tópicos são estruturados em grafos dirigidos, nos quais um arco do nó A para o nó B indica que o conteúdo de $\mathrm{B}$ requer conhecimento do conteúdo apresentado em $\mathrm{A}$. A partir da definição do objetivo de aprendizagem, da estrutura do grafo de tópicos ao qual o objetivo pertence e do registro de tópicos já visitados, o sistema determina um roteiro recomendado de unidades de estudo para atingir esse objetivo (Adriano et al., 1999; Magalhães, 2001).

\subsubsection{CyberQ}

CyberQ é um sistema de avaliação automatizado que inclui vários módulos, tais como um software de monitoração de transações e um software de avaliação adaptável.

O software de monitoração de transações controla o movimento das informações, registrando a proporção da entrada e saída de bytes do instrutor ao aprendiz, do aprendiz ao instrutor e do aprendiz ao grupo de trabalho. Ele apresenta a quantidade de informações trocadas e, a partir de tais dados, são inferidas algumas informações, tais como: se o instrutor responde ou não à dúvida de um aprendiz e, caso tenha respondido, quanto tempo transcorreu entre a colocação da dúvida e a resposta do instrutor.

O software de avaliação adaptável obtém medidas fazendo perguntas específicas aos participantes durante o acesso ao sistema ou quando um determinado tópico é atingido. Em muitos casos, o aprendiz pode "passar" a questão; entretanto, algumas questões devem ser respondidas na hora e sem consulta, enquanto em outras é permitido consultar o material. As principais características da avaliação adaptável são o ajuste das questões de forma a refletir respostas a questões anteriores, e a avaliação pelos instrutores quanto ao texto, currículo, preparação geral dos aprendizes e serviços de apoio acadêmico (Tarouco, 1999; Tucker, 1995). 


\subsubsection{Eureka}

Eureka é um WIS adaptado para atividades de aprendizagem cooperativa. Ele integra diversas funções como: fórum de discussão; cronograma de curso; comunicação, simultânea ou não, entre os participantes; conteúdo do curso definido por arquivos em qualquer formato; correio eletrônico; avisos importantes; ligações para textos relevantes, que podem ser incluídas por qualquer participante; dados cadastrais dos participantes; e estatísticas dos aprendizes.

O módulo de estatísticas transmite informações de acompanhamento dos participantes e dos módulos quanto à quantidade e à qualidade na utilização do Eureka. A informação de acompanhamento é agrupada em quatro partes: gerais, por usuário, por módulo e por período. As estatísticas gerais ilustram a participação dos usuários em relação aos demais, em termos de acessos individuais a cada módulo. As estatísticas por usuário mostram quanto cada aprendiz participou em cada módulo. As estatísticas por módulo categorizam essa participação por módulo, sem identificar os usuários. As estatísticas por período demonstram, em períodos de duas horas, a quantidade de acessos ao curso (Eberspächer et al., 1999, PUC-PR, 2002).

\subsubsection{Hyperlearning Meter}

O termo hyperlearning significa um modelo de aprendizado não-linear que abrange novas práticas de ensino e aprendizagem facilitadas pela WWW, mais adequadas para quem pretende desenvolver e certificar sua competência em um domínio. Enquanto o modelo tradicional de sala de aula apresenta uma trajetória pré-determinada, tempo fixo e resultado variável representado pela nota atribuída ao aprendiz, hyperlearning exibe trajetória e tempo variáveis, além de um resultado fixo na forma de um certificado (Denning et al., 1997).

O Hyperlearning Meter implementa o modelo descrito e destina-se àqueles que querem desenvolver e certificar sua competência em um assunto específico. Ele apresenta testes personalizados para cada aprendiz, nunca repetindo a mesma questão, porque as questões são geradas dinamicamente a partir de gabaritos preparados por instrutores. Os gabaritos podem ser incluídos em testes de auto-avaliação ou em certificações. Após cada teste, são apresentados ao aprendiz os seus pontos fracos, indicando módulos que podem auxiliá-lo (Center for the New Engineer, 1998). O ambiente obtém amostras e medidas estatísticas do progresso do aprendiz, contrastando-o com um mapa conceitual do domínio - um grafo dirigido e acíclico, no qual todos os termos ou rótulos são conceitos inter-relacionados cujas ligações contêm pesos que representam a importância dos subconceitos em relação aos conceitos-pai (Laboratório de Teleducação, 1997; Lanzing, 1997). Na Figura 2.2, é apresentado um mapa de um curso hipotético de matemática, denominado MiniMath, que aborda três conceitos principais: números binários, equações e geometria. O conceito sobre equações abrange equações lineares e quadráticas. Os pesos das ligações, exibidos como números, indicam a importância relativa de conceitos semelhantes. No mapa do MiniMath, os conceitos semelhantes são igualmente importantes. 


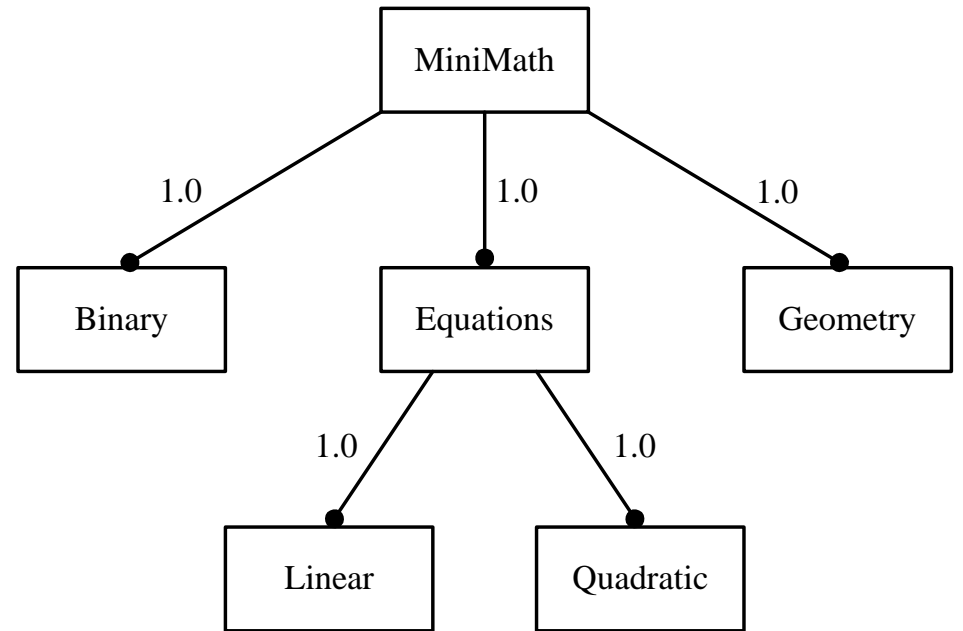

Figura 2.2: Exemplo de mapa conceitual (Hyperlearning Center, 1998)

O ambiente HLM oferece as seguintes ferramentas para os instrutores: gerenciador de curso, editor de mapas conceituais, autoria de gabaritos de avaliação paramétrica, construtor de testes, monitor de desempenho e mensageiro.

O editor de mapas conceituais é utilizado para construir um mapa conceitual da disciplina. Em seguida, o instrutor pode criar gabaritos de questões, os quais podem conter vários tipos de objetos (texto, imagens, clips de vídeo, som, grafos, tabelas, equações, URLs e parâmetros). Os valores dos parâmetros são gerados aleatoriamente, dentro de uma faixa especificada pelo instrutor, quando o gabarito se transforma em uma questão apresentada para um aprendiz. Cada gabarito pode incluir uma lista de URLs, indicando documentos na WWW que explicam mais detalhadamente a questão. Os tipos de questões possíveis são: múltipla escolha, verdadeiro ou falso, texto curto, seqüência de respostas, resposta dissertativa ou relacionamento entre duas colunas. Quando apresentadas em um teste, todas as questões (exceto as dissertativas) são avaliadas imediatamente pelo HLM e o resultado é apresentado ao aprendiz. O sistema entrega as questões dissertativas ao instrutor, para que ele as avalie e comunique as notas aos aprendizes.

O instrutor pode consultar gabaritos locais ou remotos; após recuperá-los, eles podem ser visualizados e acrescentados ao teste. Pode, também, definir quantas questões serão exibidas ao aprendiz, bem como especificar quais gabaritos devem aparecer sempre que o teste for gerado.

A monitoração do progresso de um aprendiz, ou de um grupo de aprendizes, ocorre por meio de um mapa conceitual codificado por cores para revelar quais conceitos os aprendizes dominam. Também é possível visualizar o desempenho dos aprendizes por meio de categorias de desempenho codificadas por cores; a cor verde significa que o aprendiz assimilou os conceitos subjacentes aos testes, vermelho é o caso contrário, enquanto amarelo representa um valor intermediário. Os limites entre estas categorias podem ser definidos pelo instrutor. Cada aprendiz pode ver sua própria cor, mas não pode identificar os demais. 
O instrutor pode agendar mensagens para serem enviadas automaticamente para si mesmo e/ou para os aprendizes quando ocorrerem alguns eventos, tais como: "o aprendiz não fez um teste específico" e "nota em determinado teste foi inferior ao limite estabelecido".

Para os aprendizes, estão disponíveis ferramentas para resolução de testes, certificação e visualização dos resultados dos testes. Testes de auto-avaliação podem ser resolvidos várias vezes, mas gabaritos de questões já respondidas corretamente pelo aprendiz tendem a aparecer menos freqüentemente do que aqueles nos quais o aprendiz enfrentou dificuldades. Quando o aprendiz conclui um curso, é-lhe entregue um certificado. O relatório de resultados do teste mostra os resultados do teste atual, ligações para materiais de apoio, histórico de resultados de tentativas anteriores e resultados gerais da classe.

\subsubsection{WebCT}

WebCT é um ambiente educacional que permite a criação de cursos completos. Sua meta é fornecer um conjunto de ferramentas úteis para muitos métodos de ensino e facilitar a experimentação de novas técnicas (Goldberg \& Salari, 1997).

Algumas ferramentas disponíveis ao instrutor na versão 3.6 Standard Edition são: verificação do progresso do aprendiz, com base em informações detalhadas sobre os acessos efetuados por cada aprendiz a um curso; elaboração de testes; gerenciamento de aprendizes (incluindo cálculo automático de notas, conforme fórmula cadastrada pelo instrutor); geração de leiaute de apresentação das páginas do curso; sistema de agendamento de reuniões; correio eletrônico; calendário compartilhado entre instrutor e aprendizes; apoio à construção de um banco de imagens, com mecanismo de busca; organização do conteúdo baseada em um índice analítico; e geração automática de índice, referências bibliográficas e glossário (WebCT.com, 2002).

O desempenho dos aprendizes pode ser acompanhado por meio das informações obtidas em diversas páginas (Tarouco, 1999):

Página resumo: apresenta os aprendizes (nome completo e identificador de login), e informações sobre a data do primeiro acesso, o último acesso e o número total de acessos;

Perfil do aprendiz: além das informações da página de resumo e do título da última página visitada, inclui informações mais detalhadas sobre sua navegação, tais como:

Distribuição do acesso: exibe o percentual do tempo gasto pelo aprendiz com acesso a conteúdo, glossário, objetivos da aprendizagem, referências externas, anotações, questões, listas de discussão, mensagens e respostas enviadas;

Número de páginas acessadas: inclui o número de páginas que o aprendiz acessou em relação ao número total de páginas;

Histórico das páginas visitadas: apresenta as páginas que foram acessadas e o tempo gasto por acesso. Assim, é possível perceber em quais páginas o aprendiz gastou mais tempo; 
Página de uso: relaciona o uso de cada componente do curso, apresentando o número de acessos, tempo total e médio destes acessos, bem como mensagens enviadas.

Os seguintes recursos estão disponíveis para a avaliação do aprendiz (Goldberg \& Salari), 1997; WebCT.com, 2001):

Auto-avaliação: questões para auto-avaliação (self test) estão no formato de múltipla escolha, podendo complementar qualquer documento didático do curso. As respostas fornecidas são corrigidas automaticamente, e o WebCT pode indicar porque a resposta escolhida estava correta ou incorreta e fornecer informações adicionais. O resultado da correção não é registrado. A auto-avaliação permite que o aprendiz estime (gauge) seu progresso antes de responder a um teste (quiz) ou submeta uma tarefa (assignment);

Teste: possibilita ao instrutor criar e administrar testes on-line corrigíveis automaticamente;

Enquete (survey): esta ferramenta é semelhante à anterior - excluindo a duração, o número de tentativas e a configuração dos resultados - e é útil para administrar avaliações do próprio curso, pois não são incluídos os nomes de quem respondeu a enquete;

Tarefa: permite ao instrutor distribuir e receber eletronicamente as tarefas do curso;

Apresentação de aprendizes: possibilita a criação de grupos de aprendizes e atribuir-lhes um projeto, que pode ser posteriormente avaliado por outro grupo.

\subsubsection{Outros Sistemas Educacionais na WWW}

Outros sistemas para EaD na WWW são LiveBOOKs, Lotus LearningSpace 4.0, o sistema da Universidade de Carnegie Mellon e Virtual-U.

LiveBOOKs foi desenvolvido pela Universidade de Waterloo para facilitar a criação e a manutenção de cursos, com apoio à auto-avaliação (Crespo et al., 1998). Foram especificados o projeto e a arquitetura do ambiente OwlNet que integra o AulaNet e o LiveBOOKs (Alencar et al., 1998).

Lotus LearningSpace 5.01 é um sistema aberto, flexível e escalável (IBM, 2003). Ele oferece serviços para: auto-avaliação, estruturação dos cursos e monitoração do progresso dos aprendizes. Contudo, não possibilita a avaliação personalizada.

O sistema da Universidade de Carnegie Mellon gera conteúdo personalizado (por exemplo, avaliações e feedback) para cada aprendiz, a partir de vários critérios e parâmetros, incluindo os trabalhos já realizados pelo aprendiz. A correção pode ser automática ou manual, e o seu resultado (detalhado e personalizado) é enviado ao aprendiz. É registrado todo o caminho que o aprendiz faz durante o curso, mas ele é obrigado a cumprir as diretrizes específicas do curso, tais como: restrições de limite de tempo e momento para exames. O instrutor define pré-requisitos para controlar o progresso do aprendiz no material, possibilitando uma progressão adaptada ao seu ritmo e estilo de aprendizagem (Mellon, 2000; Tarouco, 1999). 
Virtual-U é um ambiente desenvolvido pela Universidade Simon Fraser que possibilita a integração de ferramentas e gabaritos para cursos on-line (Harasim, 1999), com apoio à auto-avaliação. O material didático é criado em HTML. Há uma ferramenta para estruturação dos cursos, incluindo gerenciamento da manutenção e da evolução dos mesmos. É possível consultar estatísticas relativas ao fórum, mostrando o número de mensagens escritas, lidas e ainda não lidas por cada participante (Crespo et al., 1998; VLEI, 2000).

\subsubsection{Características de Alguns Ambientes Educacionais}

$\mathrm{Na}$ Tabela 2.1, são sintetizadas as seguintes características de alguns ambientes educacionais estudados: monitoração do desempenho, auto-avaliação, formato proprietário, estruturação dos cursos, e avaliação personalizada.

\begin{tabular}{|c|c|c|c|c|c|}
\hline & $\begin{array}{c}\text { Monitoração } \\
\text { do desempenho }\end{array}$ & $\begin{array}{c}\text { Auto- } \\
\text {-avaliação }\end{array}$ & $\begin{array}{c}\text { Formato } \\
\text { proprietário }\end{array}$ & $\begin{array}{c}\text { Estruturação } \\
\text { dos cursos }\end{array}$ & $\begin{array}{c}\text { Avaliação } \\
\text { personalizada }\end{array}$ \\
\hline AulaNet & $\operatorname{sim}$ & $\operatorname{sim}$ & $\operatorname{sim}$ & $\operatorname{sim}$ & não \\
\hline CALM & $n \tilde{a} o$ & sim & sim & não & não \\
\hline Carnegie Mellon & $\operatorname{sim}$ & $\operatorname{sim}$ & não & $\operatorname{sim}$ & $\operatorname{sim}$ \\
\hline CyberQ & $\operatorname{sim}$ & não & sim & $\operatorname{sim}$ & $\operatorname{sim}$ \\
\hline Eureka & $\operatorname{sim}$ & não & $\operatorname{sim}$ & não & não \\
\hline HLM & $\operatorname{sim}$ & $\operatorname{sim}$ & $\operatorname{sim}$ & não & $\operatorname{sim}$ \\
\hline LearningSpace & $\operatorname{sim}$ & $\operatorname{sim}$ & sim & sim & não \\
\hline TelEduc & $\operatorname{sim}$ & não & sim & sim & $\operatorname{sim}$ \\
\hline Virtual-U & sim & sim & não & sim & não \\
\hline WebCT & $\operatorname{sim}$ & $\operatorname{sim}$ & $\operatorname{sim}$ & $\operatorname{sim}$ & não \\
\hline
\end{tabular}

Tabela 2.1: Características de ambientes educacionais

A coluna "Monitoração do desempenho" refere-se à possibilidade do instrutor acompanhar o progresso do aprendiz; por exemplo, visualizando as páginas percorridas pelos aprendizes ou verificando quantas vezes eles participaram dos debates. Dentre os ambientes analisados, alguns se destacam neste aspecto. No HLM, o instrutor consegue monitorar o progresso de um aprendiz ou de um grupo de aprendizes, por meio de um mapa conceitual ou de categorias de desempenho. No AulaNet, é possível visualizar a quantidade de contribuições dos aprendizes para cada funcionalidade oferecida pelo curso, tais como: grupo de discussão, seminários apresentados e contribuições nos seminários dos colegas. Existe este tipo de visualização no Eureka, que também mostra outras estatísticas relacionadas à participação dos aprendizes. Já o sistema da Universidade de Carnegie Melon registra todo o caminho percorrido pelo aprendiz durante o curso, enquanto o CyberQ apresenta apenas a quantidade de informações trocadas entre o instrutor e cada aprendiz, bem como entre cada aprendiz e seu grupo de trabalho. $\mathrm{O}$ WebCT combina características do AulaNet e de Carnegie Melon, além de registrar a data dos acessos (inicial e mais recente) ao curso e possibilitar consultas complexas sobre o progresso dos aprendizes. No TelEduc há um módulo de acompanhamento, já descrito neste capítulo. 
Na coluna "Auto-avaliação", é indicado se o aprendiz pode realizar testes auto-corrigíveis como treinamento, sem que a nota seja considerada pelo instrutor como uma avaliação oficial. Neste aspecto, destacam-se os sistemas AulaNet, HLM e WebCT. AulaNet guarda várias informações sobre os testes deste tipo, as quais podem ser exibidas a qualquer momento para os aprendizes: nota, nota máxima possível, número total de questões, número de questões respondidas correta e incorretamente, duração da resolução do teste, tópicos cobertos pelo teste e tópicos das questões respondidas incorretamente. Eles podem revisar o teste, comparando as respostas certas com as que forneceram (Choren et al., 1998). No HLM é possível apresentar várias vezes os testes de auto-avaliação, e os gabaritos de questões já respondidas corretamente tendem a aparecer menos freqüentemente do que aqueles nos quais o aprendiz enfrentou dificuldades; além disso, todas as questões de um teste (exceto as dissertativas) são avaliadas imediatamente e o resultado é apresentado ao aprendiz. O sistema entrega as questões dissertativas ao instrutor, para que ele as avalie manualmente e depois comunique as notas. No WebCT, não há gabaritos e o único tipo de teste disponível para auto-avaliação é o de múltipla escolha, mas uma explicação pode acompanhar cada resposta, indicando porque a resposta escolhida estava correta ou incorreta e fornecendo eventualmente dicas ou informações adicionais.

Na coluna "Formato proprietário", é informado se os hiperdocumentos do curso adotam um padrão aberto (como HTML ou XML) ou proprietário, como o formato do Microsoft Word; além disso, mesmo que o formato dos documentos seja aberto, a estrutura e o relacionamento entre eles podem ser fechados. Um exemplo deste último caso é a WWW que, embora seja aberta em termos dos protocolos utilizados, pode ser classificada como um sistema hipermídia fechado porque o conjunto possível de formatos de documentos é limitado e não possibilita visões personalizadas (Goose et al., 2000). A maioria dos ambientes adota um formato proprietário para os cursos, o que dificulta o intercâmbio de informações com outras aplicações.

Na coluna "Estruturação dos cursos", é informado se os cursos criados pelo sistema adotam algum modelo organizacional, como uma hierarquia conceitual ou um grafo. O ideal é que a estrutura inclua o material essencial ou relevante, sem dispensar o secundário ou complementar, desde que este não entre em conflito com o anterior e que possa contribuir para os objetivos do aprendiz; além disso, ela também deveria incluir informações que representem as estratégias pedagógicas adotadas pela aplicação. Neste critério, pode ou não existir uma ferramenta no sistema para que o instrutor depreenda com clareza a estrutura do curso que pretende criar. No AulaNet, o instrutor utiliza uma ferramenta básica de fluxo do curso (chamada de Plano de Aulas) para criar a estrutura inicial das aulas, organizando o conteúdo didático já existente. As aulas indicam os assuntos principais do curso, discutidos semanalmente, mas o fluxo sugerido pelo instrutor não precisa ser seguido pelos aprendizes. Se o instrutor quiser evitar este desvio, ele pode liberar conteúdos a cada aula (Fuks, 2000; Lucena et al., 2000a). No sistema da Carnegie Mellon, o conteúdo do curso é representado por um modelo formal que reúne, em 
vários níveis, tipos diferentes de elementos do curso, tais como: módulos didáticos, exames, tutoriais e tarefas. O modelo do conteúdo é expandido com informações sobre a forma de apresentação, suas regras operacionais e políticas, como pré-requisitos e critérios para atribuição de notas. Todos os cursos criados no sistema adotam automaticamente esse modelo, que abrange os seguintes níveis: curso, componente, subcomponente, módulo, dispositivo, parte e questão (Rehak, 1999). CyberQ, por sua vez, adota um modelo conceitual de cursos que pode ser incorporado em qualquer sistema semelhante. No LearningSpace também é possível criar cursos estruturados; mas, por ser um sistema proprietário, não foram encontrados mais detalhes. $\mathrm{O}$ Virtual-U contém uma ferramenta para estruturação de cursos, incluindo o gerenciamento da evolução dos mesmos. Ao contrário dos demais sistemas, a estrutura dos cursos oferecidos no TelEduc é baseada em atividades, que incluem leituras e material de apoio.

Na coluna "Avaliação personalizada", é informado se o sistema oferece testes e/ou questionários diferentes para cada aprendiz, conforme seu desempenho. HLM, por exemplo, gera questões a partir de gabaritos fornecidos pelos instrutores, destacando-se dos demais sistemas pelo fato de evitar repetir questões já respondidas corretamente pelo aprendiz. CyberQ, por sua vez, possibilita ao aprendiz deixar de responder uma questão, embora certas questões devam ser respondidas na hora; em outras, é possível consultar o material didático. No TelEduc, a avaliação pode ser personalizada se o instrutor escolher projetos diferentes para os aprendizes; além disso, o TelEduc possibilita uma avaliação contínua por meio da análise de vários critérios, tais como: progresso do aprendiz no desenvolvimento das atividades, revisões e comentários realizados, participações do aluno em fóruns e bate-papos relacionados ao projeto, bem como as anotações do diário do aprendiz (Otsuka, 2002).

Dentre os sistemas analisados, o AulaNet atinge um dos objetivos desta tese: elaborar um sistema educacional com apoio à avaliação baseada em dados qualitativos. No entanto, ele não apresenta um modelo de hiperdocumentos educacionais que apóie o processo de autoria. Por outro lado, o Hyperlearning Meter adota mapas conceituais como modelo de autoria do conteúdo e possibilita a auto-avaliação, mas não há interação entre aprendizes e instrutor como no AulaNet e no WebCT. Essa interação proporcionaria mais fontes de dados qualitativos para a avaliação do aprendiz.

\subsection{Considerações Finais}

$\mathrm{O}$ apoio ao ensino por meio de ambientes computacionais apresenta diversos aspectos positivos, tais como: o aprendiz pode estudar onde e quando quiser; redução de custos, pois não é necessário o deslocamento de pessoal e material; desenvolvimento de programas com facilidade crescente de utilização e aprendizagem; e aplicação de diversos conceitos de hipermídia, inteligência artificial e pedagogia, por exemplo (Preto \& Gabriel, 2000). 
Várias inovações tecnológicas estão sendo incluídas no processo educacional, e especificamente no processo de avaliação: dos testes de múltipla escolha (de uma única resposta correta) para as questões abertas, dos trabalhos individuais para os projetos cooperativos. Hoje, quando se pensa em avaliação no domínio de EaD percebe-se claramente que um longo caminho ainda deve ser construído, pois outras perspectivas (como a auto-avaliação) se tornam mais efetivas na formação de aprendizes mais críticos, criativos e com maior autonomia. Muitas vezes não se sabe bem como medir os resultados, porque existem apenas evidências de que houve progresso, e não provas incontestáveis. A implementação de salas de diálogo interativo, listas de discussão e correio eletrônico pode auxiliar o processo de avaliação pela WWW, cujos objetivos devem ser: identificar os pontos fortes e fracos, ajudar o aprendiz a aprender, e assisti-lo nos estilos de aprendizagem e preferências (Tarouco, 1999).

Neste capítulo foram abordadas características relativas a hiperdocumentos incluindo a descrição de alguns modelos, a definição de WIS (sistema de informação baseado na Web), e a enumeração de certos recursos hipermídia. Também foram comparados vários sistemas hipermídia para apoio ao Ensino a Distância, enfatizando aspectos como a modelagem do conteúdo didático e o processo de avaliação dos aprendizes.

No próximo capítulo são apresentados alguns modelos, baseados em grafos ou em suas extensões, para a especificação de hiperdocumentos. 


\section{Modelagem de Hiperdocumentos}

\subsection{Considerações Iniciais}

Projetos desenvolvidos durante as décadas de 1970 e 1980 comprovaram o potencial da hipermídia para organizar e recuperar informações em vários domínios de aplicação. Entretanto, surgem muitas dificuldades no projeto de hiperdocumentos, tais como capturar e organizar a estrutura do domínio de informação, geralmente complexa, de forma a torná-la clara e acessível aos leitores; adotar abordagens sistemáticas para definir a estrutura organizacional e a semântica de navegação, bem como para modelar o conteúdo e a interface; estabelecer formas apropriadas para organizar e recuperar as informações em sistemas hiperdocumento; construir mecanismos eficientes para navegar em hiperdocumentos; obter modelos do domínio subjacente que possam ser mapeados de modo simples e direto para um modelo de projeto; especificar os requisitos de informações multimídia; e criar hiperdocumentos que possam ser implementados em plataformas diferentes. Por isso, paralelamente ao rápido progresso tecnológico em hipermídia, surgiram modelos que fornecem mecanismos de organização para apoiar a especificação de hiperdocumentos e dos sistemas que os gerenciam. Hiperdocumentos são produtos de software que podem se beneficiar de modelos de especificação e métodos que apresentam vários pontos fortes, tais como: gerenciamento sistemático do projeto, disciplina da atividade de autoria e estímulo ao desenvolvimento de hiperdocumentos estruturados (Turine, 1998).

Neste Capítulo são apresentados alguns modelos apropriados à representação de hiperdocumentos, limitando-se àqueles que são baseados em grafos. Na Seção 3.2 são definidos grafos e dígrafos, e apresentados alguns modelos baseados em dígrafos; na Seção 3.3 são apresentadas as definições de hígrafo e Statecharts, e um modelo baseado em Statecharts; na Seção 3.4 define-se o formalismo Redes de Petri e apresenta-se um modelo baseado neste formalismo; as conclusões são apresentadas na Seção 3.5. 


\subsection{Grafos e Dígrafos}

\subsubsection{Definições}

Um grafo é uma estrutura $G=(V, A)$, em que $V$ é um conjunto discreto, finito e não vazio e $A$ é um conjunto não vazio cujos elementos $a$ são definidos em função dos elementos $v$ de $V$. $\mathrm{Na}$ Figura 3.1. $V=\{1,2,3,4,5\}$ e $A=\{(1,2),(1,4),(2,3),(2,5),(4,3),(5,1)\}$.

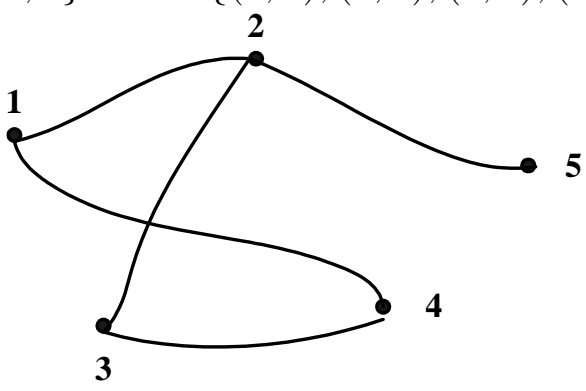

Figura 3.1: Exemplo de grafo

Elementos de $V$ são denominados vértices, nós ou pontos. Elementos de $A$ são designados, em geral, como ligações. Em particular, nos grafos orientados (ou dirigidos, ou direcionados), os elementos de $A$ são conhecidos como arcos e, nos grafos não dirigidos, como arestas. Os vértices que delimitam uma ligação definem suas extremidades; nos grafos dirigidos há uma extremidade inicial e outra final ou terminal. É possível atribuir nomes ou rótulos aos vértices e/ou às linhas, bem como valores ou pesos. No primeiro caso, o grafo é denominado rotulado em vértices e/ou em arestas.

Um grafo orientado ou direcionado $D(V, A)$, também designado como dígrafo, é composto por um conjunto finito não vazio $V$ (os vértices) e por um conjunto $A$ (os arcos) de pares ordenados de vértices distintos; portanto, em um dígrafo, cada aresta $\langle v, w\rangle$ apresenta uma única direção, de $v$ para $w$, conforme ilustrado na Figura 3.2.

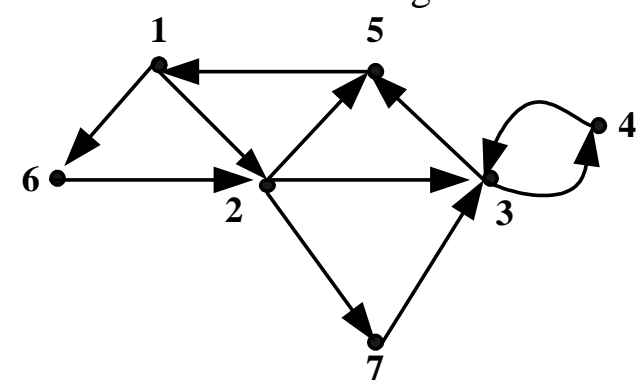

Figura 3.2: Exemplo de dígrafo

\subsubsection{HDM}

HDM (Hypertext Design Model) foi o primeiro modelo de hipermídia para a autoria global, referente à especificação e ao projeto de aspectos estruturais de hiperdocumentos, e para a definição de classes gerais de informações. No HDM, o projeto engloba três fases: especificação de um esquema da aplicação (Figura 3.3), formado por um conjunto de tipos de entidades e de ligações; instanciação do esquema; e definição da semântica navegacional. 


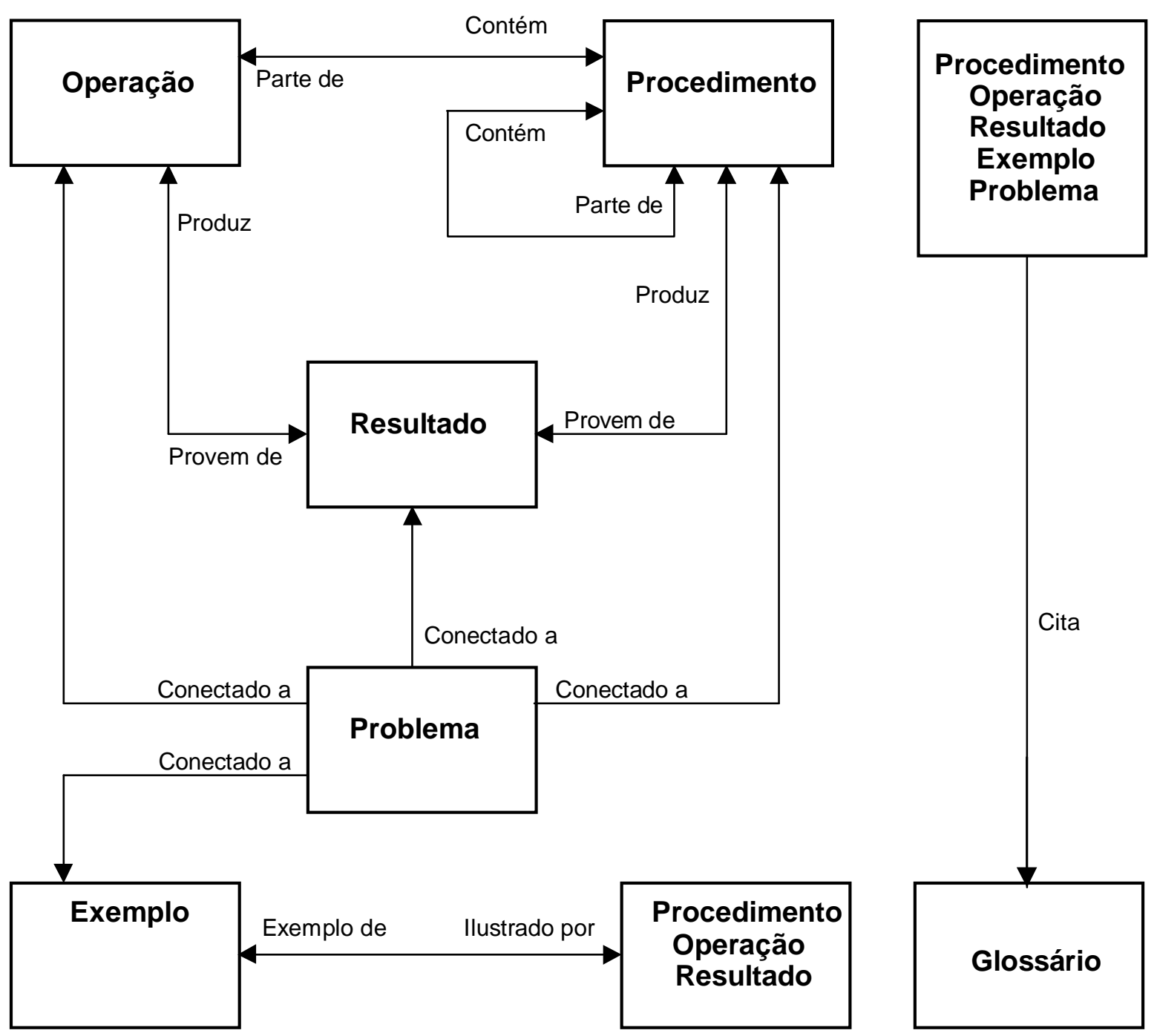

Figura 3.3: Esquema HDM de uma aplicação sobre tutoriais (Bochicchio \& Paolini, 1998)

Entidades são estruturas de informação (relativamente grandes), que representam algum objeto do domínio; por sua vez, as entidades são tipadas; por exemplo, um motor elétrico pode ser uma entidade do tipo de equipamento. Uma entidade é definida por uma hierarquia de componentes que, por sua vez, é um conjunto de unidades, as quais são semelhantes aos nós hipertexto.

Componentes e entidades podem ser associados por meio de três tipos de ligações: estruturais, de perspectiva e de aplicação. As ligações estruturais relacionam os componentes de uma mesma entidade; as ligações de perspectiva conectam as unidades de um mesmo componente; e as ligações de aplicação representam os relacionamentos dependentes do domínio, podendo conectar componentes e entidades do mesmo tipo ou de tipos diferentes.

Modelando em HDM, é possível organizar informações em formas de exibição alternativas (por exemplo, em línguas ou mídias diferentes), bem como representar relações $n$-árias no domínio e duas estruturas de acesso: outlines, semelhantes a índices, e roteiros guiados. 
Um dos aspectos positivos deste modelo é a derivação automática da definição de uma grande quantidade de ligações a partir de uma descrição conceitual (Garzotto et al., 1993). Entretanto, há pouco apoio à elaboração de visões do usuário e nenhum apoio à autoria e apresentação dos nós. Apesar de possibilitar a descrição do domínio de uma aplicação, o projeto e o desenvolvimento de aplicações não são facilitados (Isakowitz et al., 1998).

\subsubsection{Modelo Simples de Hiperdocumentos}

Um modelo simples baseia-se em dígrafos rotulados (Tompa, 1989), em que um hiperdocumento $H$ é definido como uma tripla $H=\langle N, L, E\rangle$. $N$ é um conjunto finito de nós, no qual cada elemento está associado a uma informação específica. $L$ é um conjunto de rótulos que correspondem às âncoras. $E:(N \times L) \mapsto N$ é um conjunto de arcos rotulados que especificam ligações entre nós. Além dos objetos estáticos, também foram modelados os conceitos de edição e navegação. A edição corresponde à alteração do grafo. A navegação requer uma noção da posição atual, ou estado do usuário, e um conjunto de destinos possíveis. O estado do usuário durante a navegação é definido formalmente como uma associação da tripla $H=\langle N, L, E\rangle$ à posição $M \in N$, que marca um nó atual. A Figura 3.4 exemplifica este modelo, no qual elementos de $N$ são desenhados como círculos, elementos de $E$ são indicados por setas e elementos de $L$ são seqüências de caracteres. O símbolo $\otimes$ representa graficamente o valor do marcador $M$.

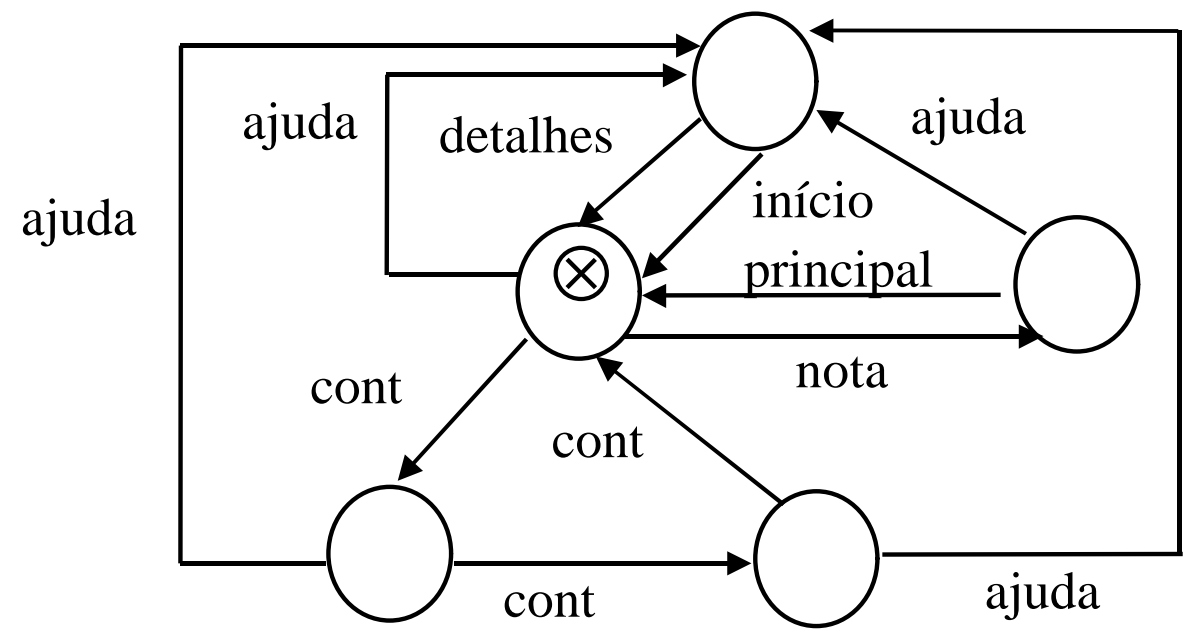

Figura 3.4: Representação de um hiperdocumento como dígrafo (Tompa, 1989)

Quando um marcador está em um nó, é exibido o conteúdo daquele nó e podem ser exibidos, provavelmente como um menu, os rótulos relacionados aos arcos com origem no nó marcado. Quando um rótulo for escolhido pelo usuário, o marcador é movido para o nó-destino. 


\subsubsection{Modelo de Contextos Aninhados}

MCA (Modelo de Contextos Aninhados) é um modelo baseado em dígrafos acíclicos para definição, exibição e navegação de hiperdocumentos (Casanova et al., 1991; Santos et al., 1998; Soares \& Casanova, 1993; Soares et al., 1995). Os nós são classificados basicamente em nós terminais (ou de conteúdo) e nós de composição, sendo estes últimos a característica principal do modelo. Deste modo, MCA possibilita a especificação de nós aninhados, formando uma hierarquia de nós (Figura 3.5).

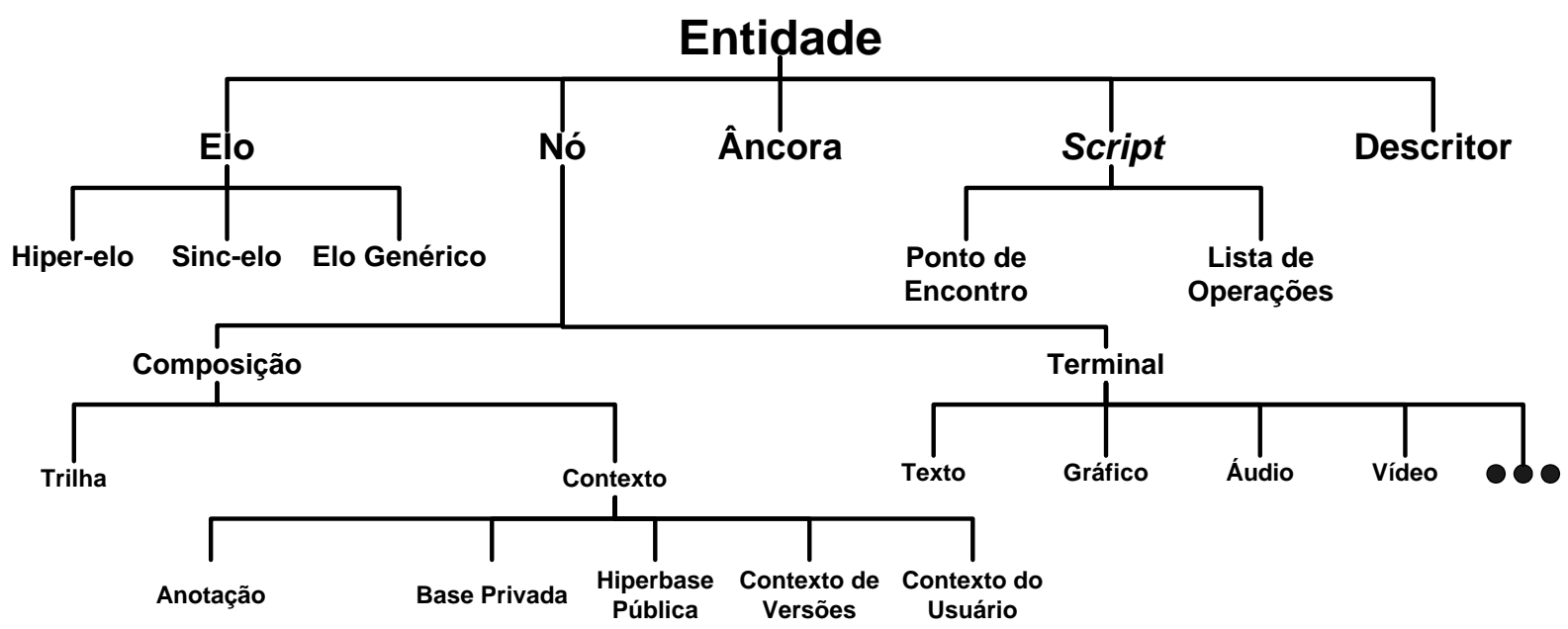

Figura 3.5: Hierarquia parcial de classes do MCA (Soares \& Souza, 1997)

No MCA, ligações são conhecidas como elos. Um elo é sempre direcional, mas pode ser percorrido em qualquer direção. Existem três tipos de elo: hiper-elo, sinc-elo e elo genérico. Um hiper-elo associa pelo menos um evento de seleção a um dos seus pontos terminais de origem. Em um sinc-elo, os pontos terminais de origem não estão associados a eventos de seleção. Um elo genérico não se aplica a um único documento e pode ser usado por uma classe de documentos; por exemplo, é possível definir um elo que possua como extremidade de destino um nó de vídeo cujo conteúdo seja uma visão aérea da região do $\mathrm{ABC}$ paulista e, como extremidade de origem, a expressão ${ }^{\star} \mathrm{ABC}{ }^{\star}$; deste modo, qualquer nó de texto com uma âncora cuja região contenha a sentença $A B C$ possuirá um elo automático com este nó de vídeo.

O MCA representa vários recursos de hipermídia, tais como: trilha, navegação por consulta a propriedades de nós, lista de história, ligações um-para-muitos, ligações implícitas (também conhecidas como globais no sistema WebVise (Grønbæk et al., 1999), ou genéricas no sistema Microcosm (Grønbæk \& Trigg, 1996)) e diagramas de visão geral ou local. Permite também especificar um hiperdocumento em níveis diferentes de abstração, criar três tipos de estruturas (linear, rede e hierárquica) para organizar os hiperdocumentos e definir formalmente as propriedades dinâmicas e de visualização do hiperdocumento durante a navegação. Além disso, ele separa estrutura, conteúdo e apresentação; desta forma, uma alteração no conteúdo não provo- 
cará mudanças na estrutura. Existe um submodelo que acrescenta às entidades as informações necessárias para a sua apresentação.

\subsubsection{Modelo de Tompa}

Como exemplo de modelo para hiperdocumentos baseado em hipergrafo rotulado e dirigido, existe um modelo que corrige algumas deficiências do modelo baseado em dígrafos, tais como separação inadequada entre nó e página, ausência da modelagem explícita de componentes (nós, ligações e rótulos) repetitivos, e não agrupamento de páginas inter-relacionadas (Tompa, 1989).

Neste modelo, os componentes repetitivos podem ser especificados formalmente. É possível fazer referências diretas a "grupos de nós" (hipernós) por meio de ligações semânticas comuns (hiperarcos). Um hiperdocumento $H$ é definido formalmente por uma sêxtupla $H=\langle N, P, R, V, L, E\rangle$, na qual: $N$ é um conjunto finito de nós; $P$ é um conjunto de páginas que armazenam o conteúdo associado aos nós; $R$ é um conjunto de programas que interpretam as páginas; $V: N \mapsto P$ é uma função que mapeia cada nó em uma página; $L$ é um conjunto de rótulos; e $E:\left(2^{N} \times 2^{L}\right) \mapsto 2^{N}$ é um conjunto de hiperarcos rotulados e dirigidos.

Conforme este modelo, os usuários podem navegar ao mesmo tempo por diversas páginas, que estão associadas aos nós marcados pelo símbolo $\otimes$. O estado de um usuário inclui todo o hiperdocumento e um conjunto $M \in N$ dos nós marcados. Na Figura 3.6 é ilustrado o estado de um usuário, em termos deste modelo, com relação ao hiperdocumento da Figura 3.4.

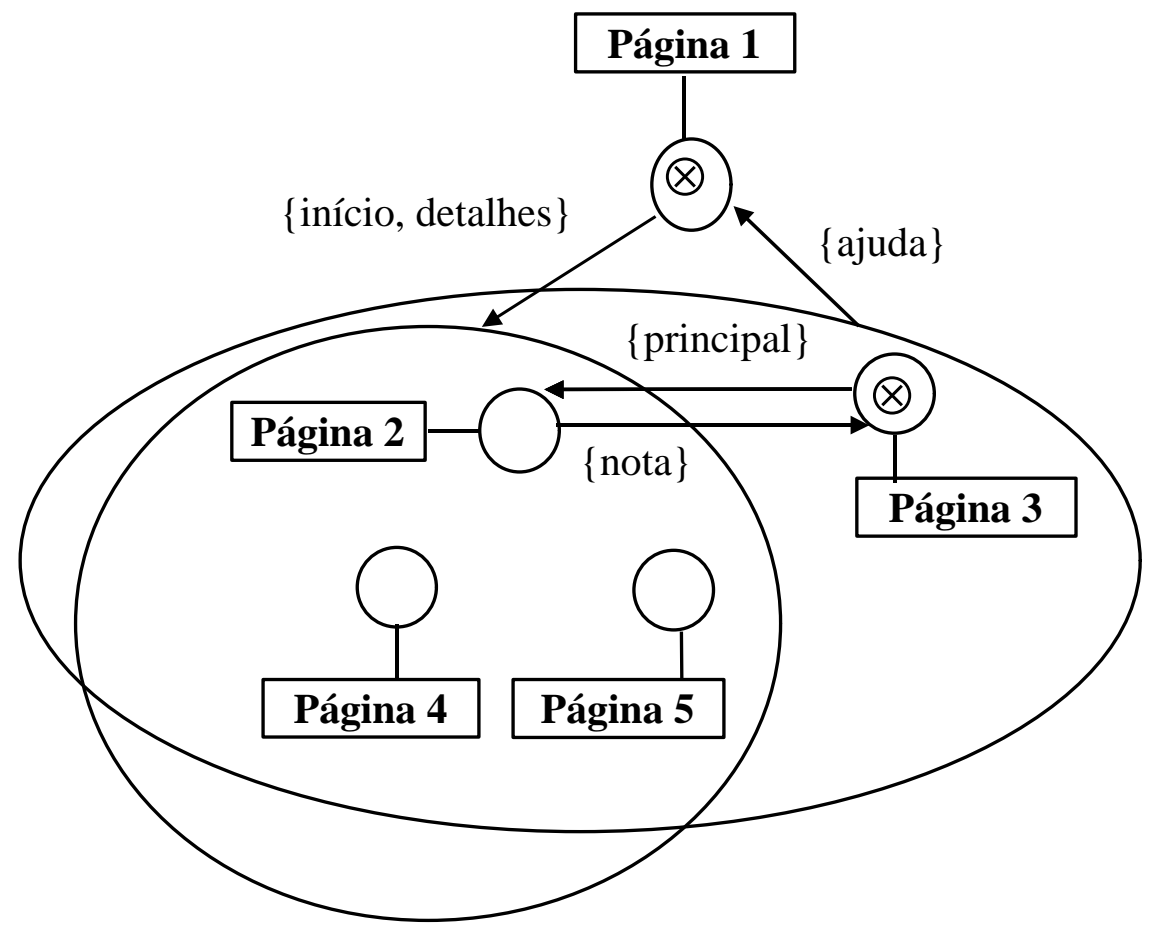

Figura 3.6: Representação de um hiperdocumento como hipergrafo (Tompa, 1989) 
As elipses representam conjuntos de nós que fazem parte de um único hiperarco. As páginas 1 e 3 poderiam ser exibidas simultaneamente. Neste mesmo estado, selecionar o rótulo detal hes marcará os nós associados às páginas 2, 4 e 5. Depois, o conteúdo destas páginas é apresentado de forma concorrente.

Embora o modelo represente naturalmente a estrutura geral de um documento, a utilização de marcação por tokens não é satisfatória. Esta abordagem é muito geral, porque não impõe restrições ao processo de marcação e os hipergrafos funcionam como máquinas de estado finito gerais; além disso, a representação gráfica associada a hipergrafos não torna claro o seu comportamento dinâmico (Oliveira et al., 2001).

\subsubsection{RMDM}

RMDM (Relationship Management Data Model) é um modelo utilizado no contexto do método RMM. Ele consiste essencialmente em um diagrama entidade-relacionamento estendido com uma notação gráfica (Tabela 3.1).

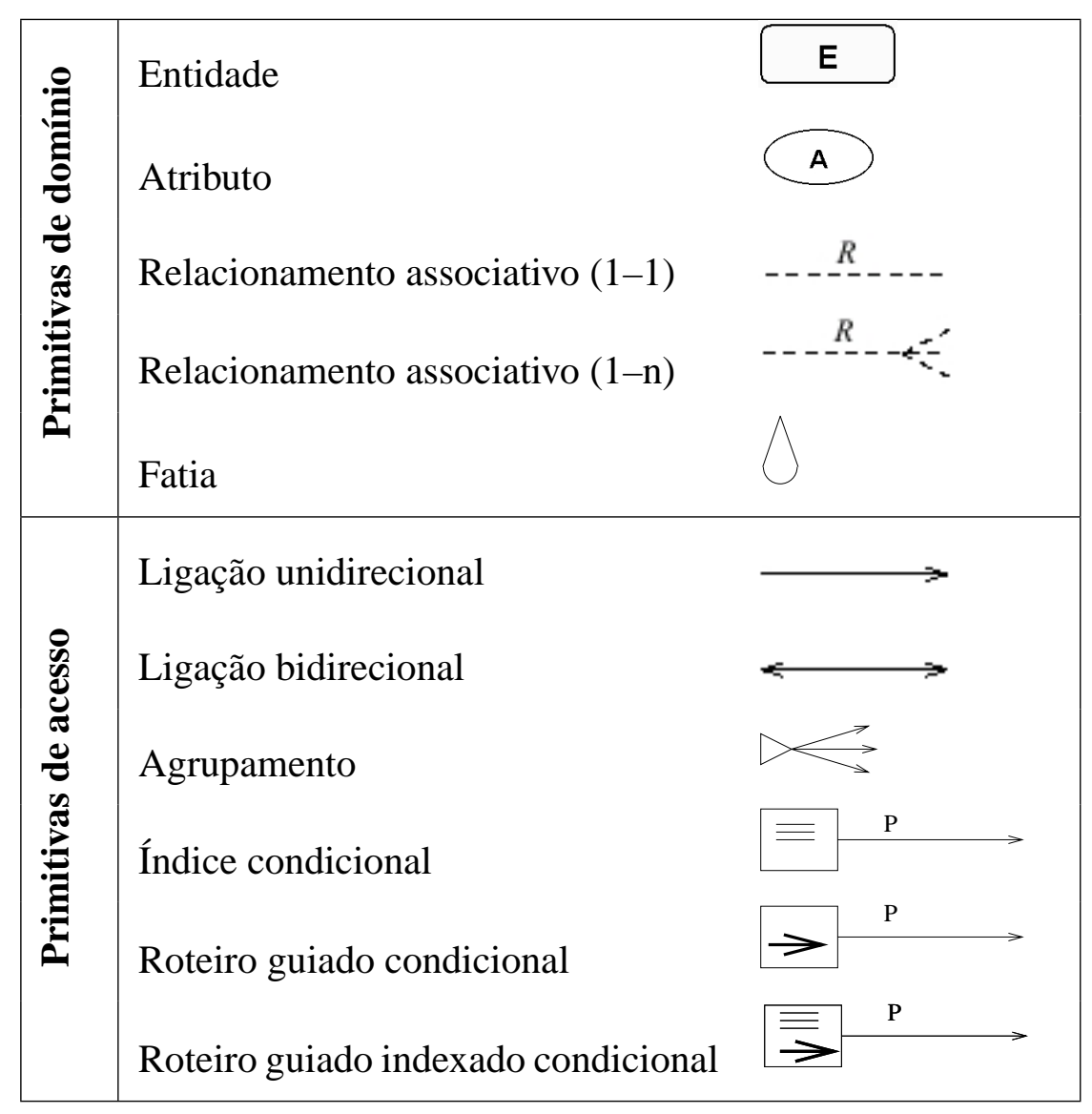

Tabela 3.1: Primitivas do RMDM (Isakowitz et al., 1995)

Na parte superior da Tabela 3.1 aparecem as primitivas de domínio, que modelam as informações e a semântica referentes ao domínio do hiperdocumento. Os tipos de entidade e seus 
atributos representam objetos abstratos ou físicos, tais como avaliação ou instrutor. Relacionamentos associativos, que podem ser um-para-um ou um-para-muitos, descrevem associações entre tipos diferentes de entidades. Os atributos de uma entidade podem ser agrupados em fatias, porque às vezes pode ser inviável ou indesejável mostrar simultaneamente todos os atributos de uma instância desta entidade.

Na parte inferior da Tabela 3.1 constam as seis primitivas de acesso, que apóiam a navegação no RMDM. As ligações uni- e bi-direcionais especificam acessos entre fatias de uma entidade, enquanto as demais primitivas de acesso são utilizadas para navegação entre entidades diferentes: um agrupamento funciona como um menu que proporciona acesso a outras partes de um hiperdocumento; um índice fornece acesso direto a cada item de uma lista de instâncias de uma entidade; um roteiro guiado define um caminho linear por uma coleção de itens, possibilitando que o usuário se desloque para frente ou para trás neste caminho (Isakowitz et al., 1995).

\subsection{Hígrafos e Statecharts}

\subsubsection{Definição}

Hígrafos combinam diagramas de Venn e hipergrafos, rotulando explicitamente as áreas e os produtos cartesianos. Os nós de um hígrafo são denominados bolhas, que são desenhadas como retângulos com cantos arredondados. As bolhas podem estar conectadas por hiperarcos, como na Figura 3.7 (Harel, 1988; Wieringa, 1998).

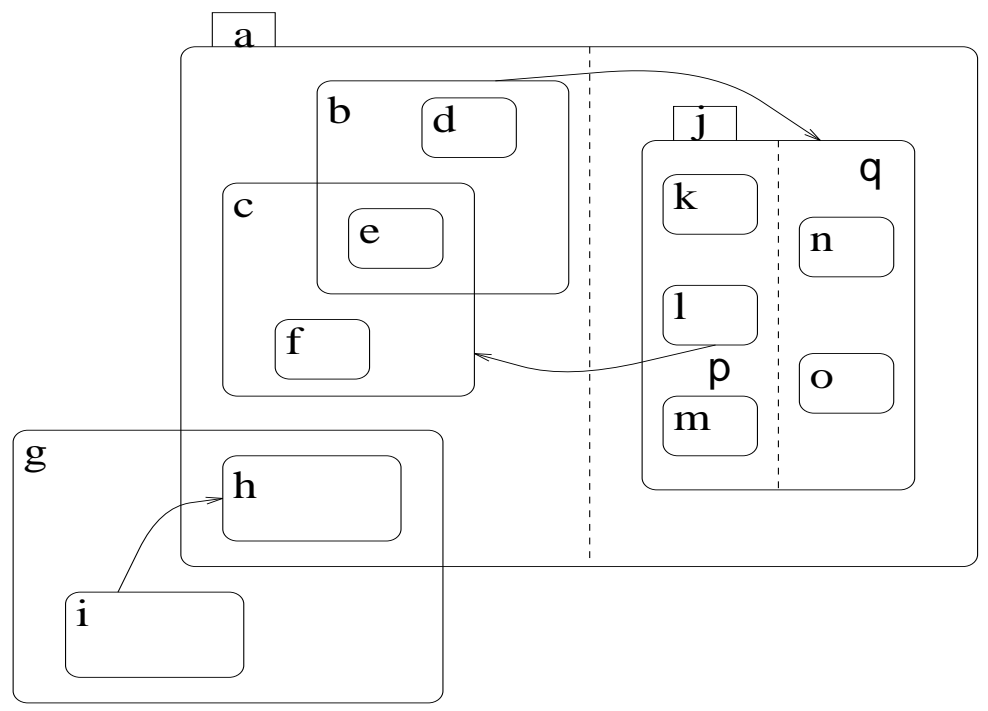

Figura 3.7: Exemplo de hígrafo (Grossman \& Harel, 1997)

Formalmente um hígrafo $H$ é uma quádrupla $\langle B, E, \sigma, \pi\rangle$, na qual $B$ é um conjunto finito de elementos denominados bolhas; $E$, o conjunto de arcos, é um subconjunto de $B \times B ; \sigma: B \mapsto$ $2^{B}$ é a função de hierarquia, que define os descendentes diretos de uma bolha; e $\pi: 2^{B \times B}$ é a função de particionamento que associa cada bolha $b \in B$ a uma relação de equivalência $\pi(b)$ sobre o conjunto $\sigma(b)$ dos descendentes de $b$. 
Statecharts são uma extensão, baseada em hígrafos, dos diagramas de transição de estado. Bolhas e setas representam, respectivamente, estados e transições (Figura 3.8). As principais características deste formalismo - hierarquia (decomposição), concorrência (ortogonalidade) e comunicação (broadcasting) — são essenciais para a especificação e projeto de sistemas complexos (Harel, 1987, 1988).

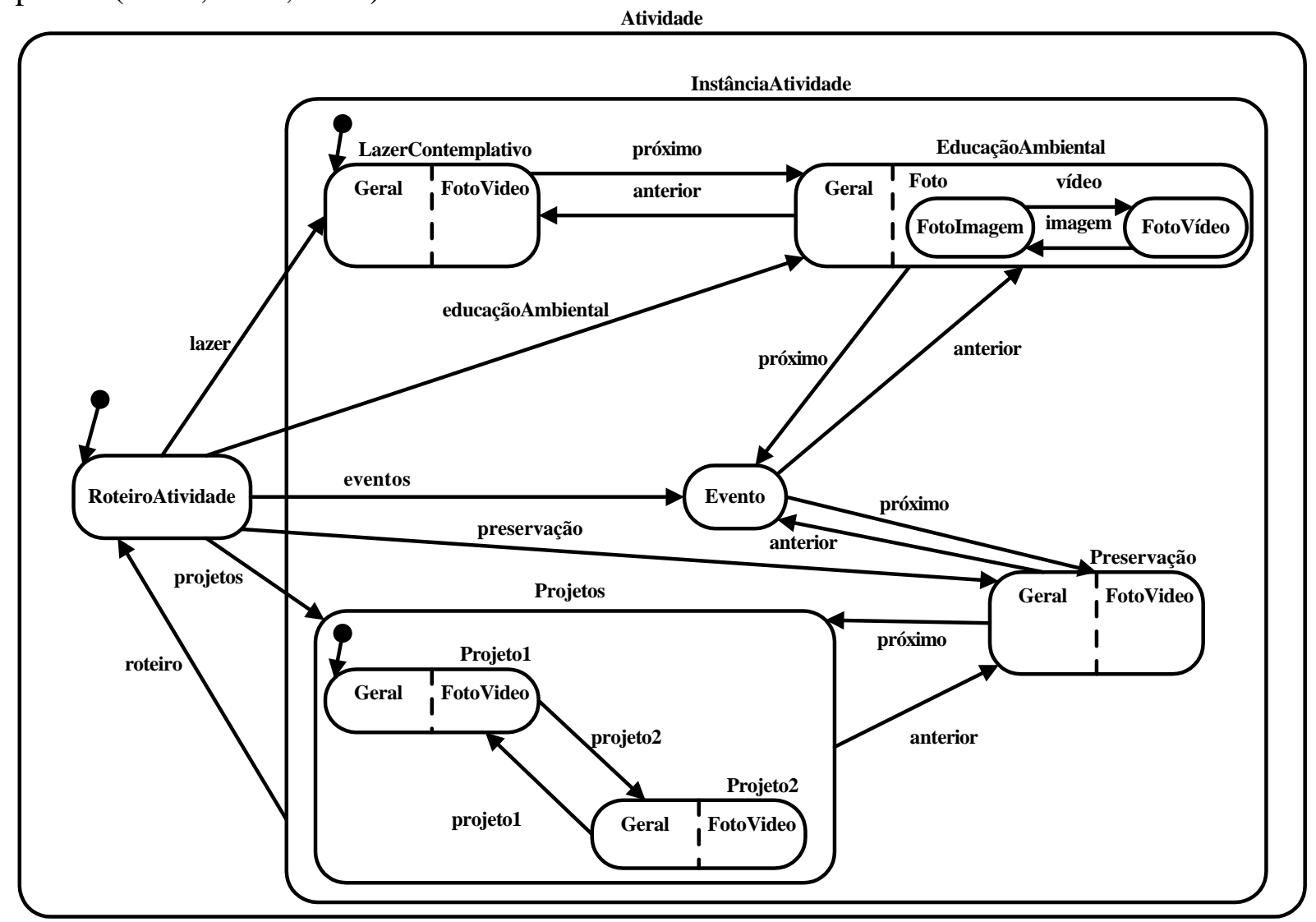

Figura 3.8: Exemplo de Statecharts (Turine, 1998)

Formalmente um statechart $S T$ é uma 11-tupla $S T=\langle S, \rho, \psi, \gamma, \delta, V, C, E, A, R, T\rangle$, na qual:

- $S=\left\{s_{1}, s_{2}, \ldots, s_{n}\right\}$ é o conjunto de estados, $n>0$;

- $\rho: S \mapsto 2^{S}$ é uma função de hierarquia que define os subestados de cada estado. Se $\rho(x)=$ $\rho(y)$, então $x=y$. Existe um único estado $r \in S$, conhecido como a raiz do statechart, tal que $\forall s \in S, r \notin \rho(s)$. Um estado $s$ é básico se $\rho(s)=\varnothing$;

- $\psi: S \mapsto\{A N D, O R\}$ é uma função que define o tipo de decomposição hierárquica para os estados não básicos;

- $\gamma: H \mapsto S$ é a função história, que define os símbolos de história associados aos estados OR;

- $\delta: S \mapsto 2^{S}$ é a função default que define um conjunto de estados iniciais para um estado não básico $s \in S$, exceto quando algum símbolo de história estiver associado a $s$;

- $V$ é o conjunto de expressões que contém números e identificadores. Os identificadores são variáveis lógicas, com valores iniciais conhecidos, pertencentes ao conjunto $V_{P}$ de variáveis primitivas do statechart; 
- $C_{P}$ é o conjunto de condições primitivas, enquanto $C$ é o conjunto de condições que incluem $T$ (true), $F$ (false), as condições primitivas e as seguintes expressões lógicas: se $c_{1} \in C_{P}$, $c_{2} \in C_{P}$ e op $\in\{=,>,<, \neq, \leq, \geq\}$, então $c_{1}$ op $c_{2} \in C$; se $c_{1} \in C$ e $c_{2} \in C$, então $u \vee v$, $u \wedge v \mathrm{e} \sim u \in C$

- $E_{P}$ é o conjunto de eventos primitivos, os quais são eventos que acontecem no ambiente do sistema especificado, enquanto $E$ é o conjunto de expressões de evento que contém $E_{P}$ e combinações de eventos primitivos (elementos do conjunto $E_{P}$ ) e condições (elementos do conjunto $C$ );

- $A$ é o conjunto de ações, que são utilizadas no statechart basicamente para expressar saída de eventos ao ambiente externo, possibilitando influenciar componentes ortogonais. Formalmente, este conjunto é definido pelas seguintes expressões lógicas: se $c \in C_{P}, d \in C$, então $c:=d \in A$; se $e \in E_{P}$, então $e \in A$; se $v_{1} \in V_{P}, v_{2} \in V_{P}$, então $v_{1}:=v_{2} \in A$;

- $R \subset E \times A$ é o conjunto de rótulos formado pelo conjunto de pares ordenados $(e, a) \mid e \in E$ e $a \in A$. Informalmente, se $e[c] / a a$ for um rótulo de uma transição $t$, então $t$ é disparado se o evento $e \in E$ for ativado com a condição $c \in C$ verdadeira; conseqüentemente, a ação $a \in A$ é executada quando $t$ ocorrer; e

- $T \subset 2^{S} \times R \times 2^{S \cup H}$ é o conjunto de transições. Uma transição $t=(X, r, Y)$ é formada por um conjunto de estados origem $X$, um rótulo $r \in R$ e um conjunto de estados destino $Y$.

\subsubsection{HMBS}

O modelo HMBS (Hyperdocument Model Based on Statecharts) adota a estrutura e a semântica operacional de Statecharts para especificar a estrutura organizacional e a semântica navegacional de hiperdocumentos, separando informações referentes à estrutura das representações físicas destes documentos (Turine, 1998). No HMBS, um hiperdocumento contém objetos estruturais (estados, transições e eventos) e navegacionais (páginas, ligações e âncoras). Os estados do statechart são associados às páginas. Os eventos contidos nos rótulos das transições representam as âncoras que disparam as possíveis ligações entre as páginas, definindo desta forma os caminhos de navegação disponíveis ao leitor. Na Figura 3.9 é ilustrado como os elementos estruturais (estados e transições) de Statecharts são associados aos objetos navegacionais (páginas e âncoras) por meio dos mapeamentos definidos no HMBS.

Formalmente, um hiperdocumento $H$ é uma 5-tupla $H=\langle S T, P, m$, ae, $N\rangle$ (Oliveira et al. 2001), na qual:

- $S T=\langle S, \rho, \psi, \gamma, \delta, V, C, E, A, R, T\rangle$ é um statechart;

- $P$ é o conjunto finito de páginas, as quais são itens atômicos de informação que serão exibidos como um todo. Cada página $p \in P$ é definida conceitualmente pela tripla $\left\langle c, t, A n c_{P}\right\rangle$, tal que: $c$ representa o conteúdo da informação, que pode ser formada por texto, gráficos, tabelas, código executável, vídeo, áudio ou quaisquer outros objetos de dados estáticos ou dinâmicos 


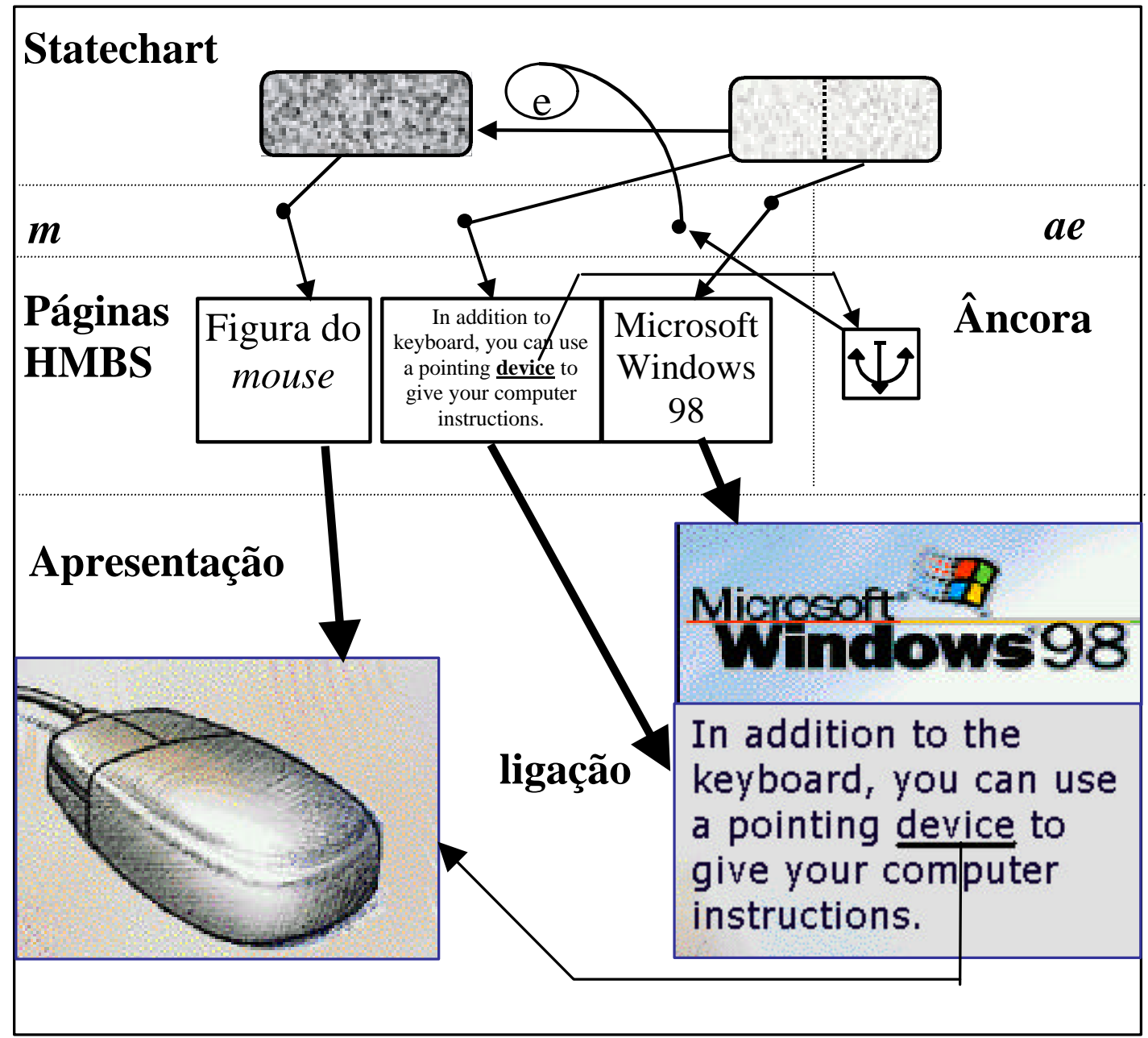

Figura 3.9: Relacionamento entre objetos do HMBS (Oliveira et al., 2001)

suportados pelo sistema hipermídia; $t$ é o título que identifica unicamente a página; e $A n c_{P}$ define uma coleção finita de âncoras associadas à página. $P$ também pode incluir uma página nula especial $(P \lambda)$, sem conteúdo, título e âncora. $P \lambda$ é, geralmente, associada a estados que não modelam apresentação de informações;

- $m: S_{s} \mapsto P$ é uma função que mapeia estados OR e estados atômicos a páginas;

- $a e: A n c_{P} \mapsto E$ é a função que associa âncoras de uma página a eventos do statechart; e

- $N$ é um número natural que determina o nível navegacional, ou de visibilidade, do hiperdocumento; por exemplo, se $N=0$, são exibidas todas as páginas associadas aos estados atômicos ativos durante a navegação; com $N=1$, as páginas apresentadas são aquelas definidas por $N=0$ mais as associadas aos estados OR ancestrais imediatos da configuração atual; e assim por diante.

Para testar e validar a aplicação do HMBS, foi desenvolvido o ambiente HySCharts (Hyperdocument System based on Statecharts), que possui recursos para autoria e simulação interativa de hiperdocumentos (Turine, 1998). 


\subsection{Modelo Baseado em Redes de Petri}

Rede de Petri é uma técnica formal para modelar o comportamento de sistemas em que componentes concorrentes interagem. Um modelo para hiperdocumentos definido formalmente por redes de Petri foi elaborado por membros do projeto Trellis, que investiga a estrutura e a semântica da interação usuário-computador no contexto de sistemas hipermídia, navegadores, notações visuais de programação e modelos de processo (Furuta, 1999). Esse modelo resolve vários problemas inerentes aos hipertextos, tais como: análise da complexidade da apresentação, alcançabilidade de um nó, caminhos concorrentes de navegação, sincronização, controle de acesso a certas informações e versões personalizadas de hiperdocumentos. Entretanto, faltam recursos satisfatórios para estruturação hierárquica, dificultando a tarefa de especificar controle de sincronização entre níveis diferentes das estruturas hierárquicas. Decomposição sucessiva de estados não é realizada facilmente, porque um estado decomposto não é uma rede de Petri, mas sim um conjunto de vários subestados. Além disso, não existem mecanismos para especificação de sincronização entre estados decompostos. Statecharts, por outro lado, favorecem qualquer nível de decomposição estrutural, porque estados decompostos são também modelos em Statecharts com semântica (Oliveira et al., 2001).

\subsection{Considerações Finais}

Os modelos apresentados neste capítulo não tratam características específicas de $\mathrm{EaD}$, pois são genéricos e independentes do domínio. Por um lado, isto é positivo, facilitando a modelagem de diversas categorias de aplicações; por outro lado, talvez eles não satisfaçam alguns requisitos particulares de cada domínio.

Um domínio complexo, como o Ensino a Distância, justifica o desenvolvimento de modelos próprios. O HMBS não foi concebido para modelar a semântica de hiperdocumentos educacionais; entretanto, ele apresenta características interessantes para esse domínio, tais como:

- separação entre estrutura, conteúdo e apresentação, facilitando a autoria global do curso;

- condições e variáveis para posicionar adequadamente o aprendiz no início do Curso;

- restrições aos leitores do hiperdocumento durante a navegação - por meio de condições, expressões e variáveis - impedem que um aprendiz estude o último tópico do curso antes do primeiro;

- modelagem da estrutura organizacional de cada hiperdocumento em particular; e

- relação de hierarquia e sequiência entre documentos, viabilizando o relacionamento entre tópicos.

Apesar destes pontos positivos, o HMBS não satisfaz a necessidade de apoio à modelagem semântica ou lógica de aspectos educacionais, como avaliação e perfil do aprendiz. Por isso, é proposta no próximo Capítulo uma extensão capaz de representar melhor o domínio do Ensino a Distância. 


\section{Um Modelo para Hiperdocumentos Educacionais Baseado no HMBS}

\subsection{Introdução}

Neste Capítulo é apresentado um modelo para a elaboração de hiperdocumentos educacionais, denominado MDE - Modelo para Documentos Educacionais ou Model for Distance Education. O modelo é baseado no HMBS, sobre o qual foram estabelecidas algumas restrições e extensões para adaptá-lo à especificação de Cursos virtuais. O MDE é inicialmente definido em linguagem natural. Para evitar ambigüidades, ele também é apresentado formalmente.

Na próxima Seção, cada item modelado é definido informalmente. Na Seção 4.3 são descritas as extensões e restrições incluídas no HMBS. Na Seção 4.4 o modelo é especificado de modo formal, enquanto sua semântica navegacional é explicada na Seção 4.5. O modelo é exemplificado na Seção 4.6 e, na Seção 4.7, são apresentadas as considerações finais.

\subsection{Descrição do MDE}

O Modelo para Documentos Educacionais (MDE) adota parcialmente a terminologia proposta pelo Comitê sobre Tecnologia Padrão para Aprendizagem (Learning Technology Standard Committee) do IEEE (IEEE, 2000), a qual também foi utilizada no ambiente CALM (Adriano et al., 1999). Nesta terminologia, a estrutura de cursos é uma hierarquia de blocos construtores (building blocks). Os componentes atômicos são denominados unidades atribuíveis (assignable units) e agrupados em lições (lessons).

O modelo proposto para hipertextos pressupõe que o conteúdo fundamental de um Curso pode ser organizado em uma estrutura hierárquica que define um tipo de Mapa Conceitual. Os conceitos são mapeados em um conteúdo didático organizado como uma sequiência de Unidades de Estudo (UEs) que, por sua vez, são compostas por Tópicos.

A navegação pelo Curso segue a organização hierárquica do conteúdo, e é controlada pelo desempenho do aprendiz nas Avaliações. Conforme esse desempenho, o aprendiz pode, por exemplo, retornar ao Tópico anterior, estudar o próximo Tópico ou ser dispensado de estudar UE(s). Antes de começar a estudar as UEs, o aprendiz é submetido a uma Avaliação Diagnóstica, caso o instrutor a tenha incluído no Curso. Após estudar cada Tópico, seu domínio sobre 
esse Tópico pode ser aferido por meio de uma Avaliação Formativa. Ao terminar o estudo da última UE do Curso, ele responde a uma Avaliação Somativa. O modelo do Curso define Avaliações compostas por questões, mas um sistema que adota este modelo poderia também incluir Avaliações Formativas que não se baseiam exclusivamente em questões e que incluem também informações colhidas sobre o comportamento do aprendiz durante a sua navegação pelo material didático. A seguir, são definidos os termos destacados neste parágrafo e no anterior.

\subsubsection{Conceitos}

Conceitos são objetos, eventos, situações, fatos, símbolos ou propriedades que possuem princípios, atributos ou características comuns (a despeito da diversidade em outras dimensões ou atributos). Um conceito pode ser definido também como uma regularidade percebida em eventos ou em objetos, ou em registros de eventos ou de objetos (Ausubel et al., 1978; Laboratório de Teleducação, 1997; Novak, 2000; Secretaria de Educação do Distrito Federal, 1999). Todo conceito pode ser sintetizado em um rótulo. O rótulo para a maioria dos conceitos é tipicamente uma palavra com significado genérico, embora às vezes sejam utilizados signos ou símbolos como + ou $\%$.

Um conceito inclui características, propriedades, atributos, regularidades ou observações de um objeto, fenômeno ou evento relativo a um domínio de conhecimento. De forma geral, descrições, definições, princípios e procedimentos podem ser considerados como conceitos. Alguns exemplos de conceitos específicos de alguns domínios são: ponto, reta e plano, da Geometria; definições de velocidade e aceleração, da Física; leis das reações químicas, da Química; sociedade, cultura e natureza, da História (Pansanato \& Nunes, 1999a).

\subsubsection{Mapa Conceitual}

Mapas Conceituais são conhecidos como "mapas de bolhas", "mapas semânticos" e "teias". Eles são usados como uma linguagem para descrição e comunicação de conceitos. Podem ser utilizados para relacionar conhecimento prévio, antes de iniciar uma atividade de pesquisa ou de aprendizagem, bem como para descrever conceitos fundamentais associados a um conteúdo educacional e seus inter-relacionamentos. Durante décadas, Mapas Conceituais vêm sendo adotados para estabelecer associações entre a experiência passada e novas informações, entre fatos conhecidos e novos conceitos, entre partes de um conceito ou problema e seu conjunto.

Esses mapas representam uma estrutura que vai desde os conceitos mais abrangentes até os menos inclusivos. Mapas Conceituais auxiliam a ordenação e a seqüência hierarquizada de um material didático, de forma a oferecer estímulos adequados aos aprendizes. As relações entre conceitos que devem ser enfatizadas ficam explícitas aos instrutores e aprendizes (Moreinis, 1998; Novak \& Gowin, 1984). 
Um Mapa Conceitual pode ser visualmente representado por um grafo, no qual cada nó é rotulado por um conceito. Uma aresta entre dois nós, rotulada ou não por uma proposição, indica que o conceito do nó-origem é mais abrangente e inclusivo do que o conceito do nó-destino. No modelo proposto neste trabalho, não são utilizadas proposições entre conceitos porque todas as arestas denotam um relacionamento de composição entre os conceitos, como se as arestas tivessem o mesmo rótulo: "é composto de". No MDE, os conceitos abordados em um Curso são organizados em três níveis hierárquicos - Curso, Unidades de Estudo, Tópicos — e os Mapas Conceituais são estruturados como árvores de altura igual a três (Figura 4.1).

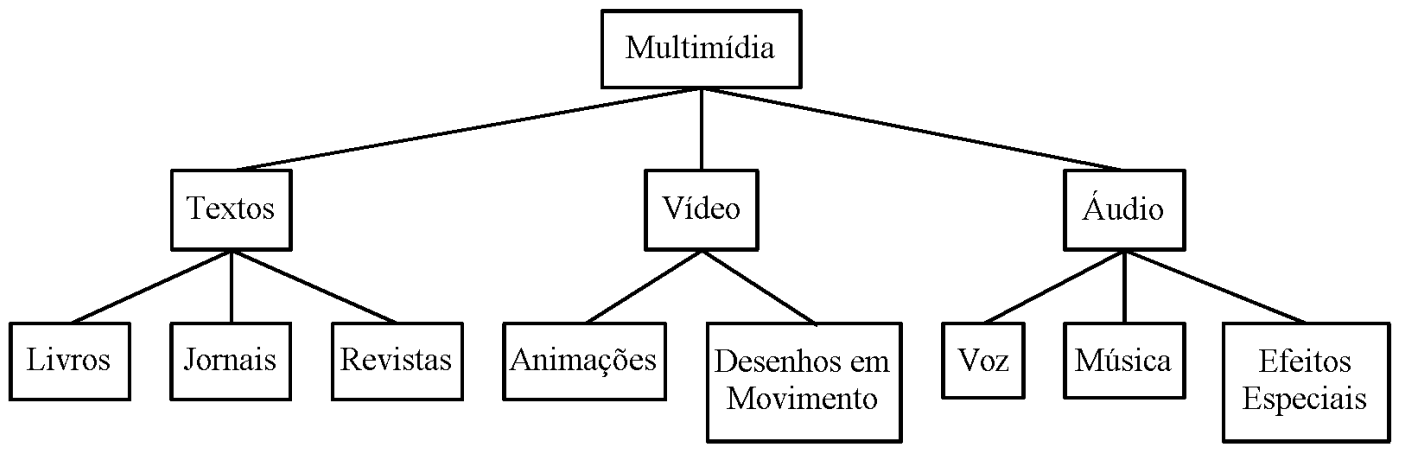

Figura 4.1: Exemplo de Mapa Conceitual (Konrath, 2000)

Essa simplificação na representação dos Mapas Conceituais é justificada pela pressuposição de que é possível organizar o conteúdo de qualquer Curso de forma que seus conceitos sejam horizontalizados conforme essa estrutura de árvore em 3 níveis, a qual combina a estrutura conceitual do conteúdo didático com a sua exibição. Entretanto, o MDE poderia ser generalizado para tratar Mapas Conceituais de Cursos descritos por árvores com mais de 3 níveis.

\subsubsection{Curso}

Um Curso é uma unidade de instrução completa que foi projetada para ser estudada por um ou mais aprendizes. Ele fornece o conhecimento ou habilidades necessárias para adquirir competência em um assunto ou para o desempenho de um grupo de tarefas relacionadas. Pode conter lições e testes, além de objetivos de aprendizagem associados, bem como integrar um currículo. Um objetivo de aprendizagem descreve uma meta de treinamento ou de aprendizagem em termos do conhecimento, habilidades ou desempenho esperado(s) de um aprendiz. Currículo é um conjunto de Cursos agrupados conforme uma ou mais especializações educacionais (IEEE, 2000) e cobrindo uma área do conhecimento. Em uma instituição de ensino, este conjunto deve ser estudado pelos aprendizes antes que um diploma (ou título acadêmico) específico seja concedido (Miller et al., 1998).

O modelo aqui proposto não contempla a representação de currículos, sendo baseado parcialmente na definição de Curso proposta pelo IEEE. No modelo, lições e testes são agrupados em uma unidade de instrução completa. Objetivos de aprendizagem não são modelados explicitamente, mas o instrutor pode utilizar as Avaliações para verificar se eles foram atingidos. 
Em consistência com a definição do IEEE, um Curso é modelado como um hiperdocumento formado por uma ou mais UEs seqüenciais que, por sua vez, são decompostas em pares seqüenciais de Tópico e Avaliação Formativa. Conceitos são associados a Cursos, UEs, Tópicos e questões. O conteúdo didático é, geralmente, o mesmo para todas as instâncias de um Curso. Essas instâncias são oferecidas aos aprendizes durante um determinado intervalo de tempo e podem ser gerenciadas por um sistema que administre aspectos não diretamente relacionados ao conteúdo didático, tais como (Casagrande, 2001): manutenção de Cursos e de seus oferecimentos; cadastramento, atualização e remoção de aprendizes e de instrutores; acompanhamento da freqüência dos aprendizes ao oferecimento dos Cursos; e verificação dos resultados das Avaliações dos aprendizes.

Embora o conteúdo não varie, ele pode ser adaptável aos perfis dos aprendizes conforme o seu desempenho nas Avaliações; por exemplo, alguém com maior dificuldade em compreender um conceito pode estudá-lo mais detalhadamente do que outro que já possui conhecimentos prévios sobre o mesmo conceito. Portanto, as Avaliações podem levar automaticamente a diferentes configurações navegacionais dos aprendizes pelo material didático de uma instância do Curso.

\subsubsection{Unidade de Estudo (UE)}

A Unidade de Estudo é o componente didático com maior nível de abstração de um Curso. Consiste em uma unidade de instrução que inclui conteúdo e objetivos de aprendizagem associados, podendo englobar parte da Avaliação do aprendiz. É projetada para ser dominada em um esforço contínuo (IEEE, 2000). Outros sinônimos de UE são: lição (IEEE, 2000), unidade de aprendizagem (Miller et al., 1998) e aula (Henze \& Nejd1, 2000).

O modelo proposto assume que o aprendiz percorre seqüencialmente as UEs, formadas por Tópicos. A seqüência dos Tópicos é determinada por sua linearização no Mapa Conceitual. Essa é uma simplificação navegacional, pois conceitualmente um sistema hipermídia deveria permitir ligações entre quaisquer documentos. Entretanto, essa estrutura de roteiro guiado pode facilitar a aprendizagem, pois diminui a sobrecarga cognitiva e garante ao instrutor que os conceitos são apresentados na seqüência apropriada. Uma Avaliação Diagnóstica pode preceder o início do Curso e permitir ao aprendiz iniciar o Curso a partir de uma UE arbitrária na seqüência, se ficar comprovado que ele já domina os conceitos associados ao conteúdo das UEs anteriores.

\subsubsection{Tópico}

É o menor elemento do material didático do Curso que pode ser atribuído a um aprendiz. Um sinônimo é "unidade designável" (assignable unit) (IEEE, 2000). A cada Tópico podem ser atribuídos uma Avaliação e um nível de dificuldade. Esse último atributo permite a inclusão de recursos de hipermídia adaptativa; por exemplo, o sistema pode apresentar Tópicos em diferentes níveis de dificuldade, conforme o desempenho do aprendiz nas Avaliações correspondentes. 


\subsubsection{Avaliação}

Compreende os diferentes tipos de elementos que podem ser utilizados para obter um indicador do conhecimento adquirido pelo aprendiz durante o Curso, bem como para avaliar a efetividade do processo de aprendizagem. Serve para verificar até que ponto os vários objetivos educacionais significativos estão, de fato, sendo alcançados (Ausubel et al., 1978).

O MDE inclui três tipos de Avaliação: Diagnóstica (AD), Formativa (AF) e Somativa (AS). A Avaliação em um Curso presencial geralmente se limita à classificação das notas dos aprendizes, proporcionada pela Avaliação Somativa. Contudo, em estudos na área de Educação, constatou-se que o instrutor precisa de outros meios para determinar o progresso do aprendiz durante o Curso (AF), bem como para averiguar conhecimentos prévios do aprendiz (AD).

No MDE a navegação do aprendiz pode ser controlada por seu desempenho nas Avaliações. O desempenho na AD, por exemplo, pode dispensar o aprendiz do estudo de uma ou mais UEs. Ao terminar de estudar um Tópico, o aprendiz efetua uma AF baseada em questões. Se ele foi bem sucedido nessa Avaliação, está autorizado a estudar o próximo Tópico; caso contrário, a critério do instrutor, o aprendiz estuda um Tópico associado ao mesmo conceito com conteúdo mais detalhado. Portanto, podem existir condições na AF para verificar se o aprendiz pode estudar o próximo conceito ou se ele precisa reestudar o conceito que ainda não dominou. Após responder satisfatoriamente à última $\mathrm{AF}$ de uma UE, o aprendiz obtém acesso à próxima UE - a não ser que aquela seja a última UE do Curso. Terminando o estudo de todas as UEs, o aprendiz está habilitado a realizar a AS. As condições para que o aprendiz seja aprovado em uma Avaliação são determinadas pelo instrutor.

Como subsídio para o instrutor, é útil que o sistema registre o número de vezes que o aprendiz fez cada Avaliação, a nota obtida em cada um desses acessos e a duração da Avaliação. O instrutor pode receber um relatório com estas e outras informações, tais como: maior e menor notas de uma turma em cada avaliação, quantidade de acessos realizados pelo aprendiz a cada página do curso (Tópico, UE, referência) e o tempo de estudo de um Tópico por cada aprendiz.

$\mathrm{A} A \mathrm{~A}$ pode ser realizada apenas uma vez pelo aprendiz, mas não há limite para o número de vezes que o aprendiz pode responder às AFs. Como os Tópicos do Curso podem ser apresentados em três níveis de detalhamento, a apresentação do Tópico pode mudar, expondo o conceito de outra forma, quando o aprendiz revê um determinado Tópico após falhar na respectiva AF. Entretanto, no MDE há apenas três variações possíveis para esse nível, independentemente do número de tentativas realizadas pelo aprendiz. É possível a existência de vários tópicos por nível; porém, após apresentar o primeiro Tópico no terceiro nível, o nível de todos os Tópicos seguintes sobre o mesmo conceito não se altera. No caso da AS, é estabelecido um limite máximo para o número de vezes que o aprendiz pode repeti-la em uma única inscrição no curso. 


\subsubsection{Avaliação Diagnóstica (AD)}

Consiste em verificar conhecimentos prévios indispensáveis para a realização de determinadas atividades de aprendizagem. Possibilita determinar o nível de conhecimento inicial dos aprendizes e, ainda, detectar as causas subjacentes às dificuldades de aprendizagem.

No modelo proposto, a Avaliação Diagnóstica ocorre antes da primeira UE do Curso e verifica, por meio de questões sobre conceitos do próprio Curso, os conceitos do Curso já dominados pelo aprendiz. Desse modo, ele pode ser dispensado de estudar UE(s) cujo conteúdo já conhece.

O modelo de dados do sistema que implementa o modelo de Curso pode prever a inclusão de conceitos relacionados a Cursos anteriores ou a pré-requisitos curriculares, a critério do instrutor. Se existirem questões sobre conceitos de Cursos anteriores, e se o desempenho do aprendiz nessas questões for considerado insatisfatório pelo instrutor, sua matrícula pode ser indeferida.

\subsubsection{Avaliação Formativa (AF)}

É uma Avaliação cuja função é retroalimentar (proporcionar feedback) aprendizes e instrutores sobre o desenvolvimento da aprendizagem durante a UE. Ela busca atender às diferenças individuais dos aprendizes, e permite identificar as falhas dos aprendizes e as deficiências na organização do ensino, de modo que técnicas corretivas possam ser introduzidas. A cada Tópico pode ser associada uma Avaliação Formativa composta por uma ou mais questões relativas ao conceito associado àquele Tópico.

Alguns ambientes computacionais para EAD adotam também AFs cuja função é retroalimentar os instrutores e que não se baseiam em questões, mas sim na análise de dados coletados automaticamente. No AulaNet (Menezes et al., 1998), por exemplo, são disponibilizados ao instrutor:

- sequiência de documentos didáticos consultados sobre o Curso,

- referências webliográficas / bibliográficas consultadas e a freqüência da consulta,

- uso de referências suplementares fornecidas pelo instrutor,

- tipo de contato com o instrutor (regular ou próximo à entrega de trabalhos, por exemplo),

- iniciativa do aprendiz em pesquisar outras referências, etc.

Informações dessa natureza baseiam-se, por exemplo, em dados obtidos durante a execução do sistema, relativos à navegação do aprendiz. A manutenção dessas informações pode estar prevista no modelo de dados do sistema.

\subsubsection{Avaliação Somativa (AS)}

É uma Avaliação cuja função é determinar os resultados obtidos no Curso e atribuir qualificações, tais como: conceitos, notas, graus e créditos. Ocorre após a última UE de um Curso, com a finalidade de verificar quais conceitos foram efetivamente assimilados pelos aprendizes. Contém questões associadas às UEs e aos Tópicos do Curso. 


\subsubsection{Questão}

É uma frase, geralmente interrogativa, que testa o conhecimento do aprendiz. Alguns possíveis tipos de questões são:

1. aberta: é respondida livremente e geralmente inicia com um verbo que esclarece o objetivo pretendido pelo instrutor, tais como: defina, relacione, compare, critique;

2. dissertativa: o instrutor apresenta um tema, que é desenvolvido pelo aprendiz;

3. curta: o aprendiz digita uma palavra ou uma frase curta, que é então comparada com as respostas aceitáveis previamente definidas pelo instrutor (WebCT, 2000);

4. preenchimento de lacuna(s): em uma frase apresentada pelo sistema, o aprendiz substitui espaços em branco por palavras ou expressões;

5. múltipla escolha: dentre um conjunto de itens, o aprendiz escolhe uma ou mais respostas corretas para a questão;

6. certo-ou-errado: o aprendiz deve decidir se a frase da questão representa uma declaração falsa ou verdadeira, podendo haver um espaço para o aprendiz justificar a escolha;

7. calculada: é uma questão matemática. O instrutor especifica a fórmula matemática, o conjunto de variáveis e uma faixa de valores para cada variável. Um conjunto de respostas é gerado para um conjunto de variáveis selecionadas aleatoriamente (WebCT, 2000);

8. associação: o aprendiz deve relacionar itens entre duas colunas; e

9. ordenação: o aprendiz ordena itens, por exemplo, em ordem cronológica ou de relevância.

Em geral, os dois primeiros tipos de questão não são avaliados automaticamente. Os demais tipos contêm uma ou mais respostas certas, incluídas pelo instrutor. A cada questão pode ser atribuído um nível de dificuldade. Uma questão pode ser associada a um ou mais conceitos.

Como as questões não estão vinculadas rigorosamente a uma Avaliação específica, é possível criar um banco de questões classificadas por conceito(s) relacionado(s), Tópicos correlatos, nível de dificuldade e tipos de questões.

\subsection{Extensões ao HMBS}

Nesta seção apresentam-se as extensões propostas ao modelo HMBS para que ele possa melhor modelar hiperdocumentos educacionais que contêm os elementos descritos na seção anterior. Além disso, essas extensões possibilitam utilizá-lo como o modelo subjacente a um sistema baseado na Web para apoio ao Ensino a Distância. Elas são apresentadas de forma simplificada, sendo exemplificadas com o próprio modelo proposto e apresentado na seção posterior. Foram incluídas as seguintes extensões no HMBS:

- a notação de estados parametrizados, reduzindo a repetição de alguns elementos do modelo;

- a condição avaliável por uma expressão matemática, determinando para qual nó posterior o usuário navegará; 
- a associação de um único tipo (UE, Tópico, Questão etc) a cada página;

- atributos estruturados nas páginas, os quais variam conforme o tipo;

- comportamento e semântica navegacional associados ao tipo da página;

- mapa conceitual associado à estrutura de cursos, possibilitando a compreensão das principais idéias abordadas em um hiperdocumento educacional específico; e

- a associação de várias páginas por estado.

Conseqüentemente, combina-se na especificação a formalização dos principais componentes do MDE com uma descrição informal de outros aspectos.

\subsubsection{Estados Parametrizados e Estrutura Padronizada}

Para reduzir a complexidade e o tamanho dos statecharts, devidos ao possível grande número de elementos, propõe-se o uso de estados parametrizados (Harel, 1987; Paulo et al., 1999, 1998). A parametrização proposta é relativa a um superestado cujos subestados são descritos pela notação parametrizada, usando os operadores lógicos OR $(\vee)$ e AND $(\wedge)$.

A declaração da forma de parametrização de um estado inclui, além do seu tipo (OR ou AND), o nome do superestado, o nome genérico dos subestados que serão parametrizados, a variável de parametrização (ou índice) e a definição do intervalo de parametrização. Na Figura 4.2 (a), é mostrado um exemplo de parametrização simples do tipo OR. O conjunto de subestados é determinado pelo índice, que varia dentro do intervalo definido. NaFigura 4.2 (b), exibe-se como seria o statechart equivalente à Figura 4.2 (a) em notação parametrizada. Uma parametrização simples do tipo AND e o statechart equivalente são apresentados na Figura 4.3 (Turine, 1998).

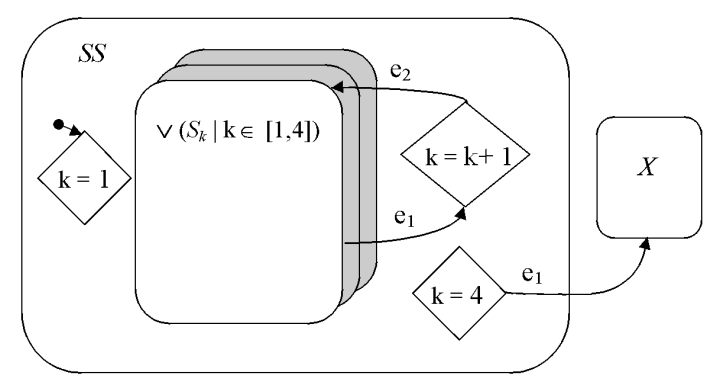

(a) Estado parametrizado

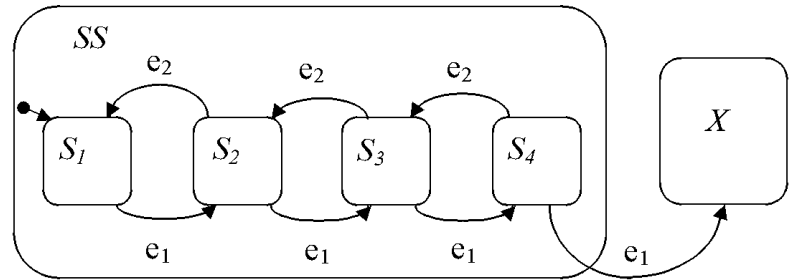

(b) Decomposição da parametrização

Figura 4.2: Parametrização simples do tipo OR (Paulo et al., 1999)

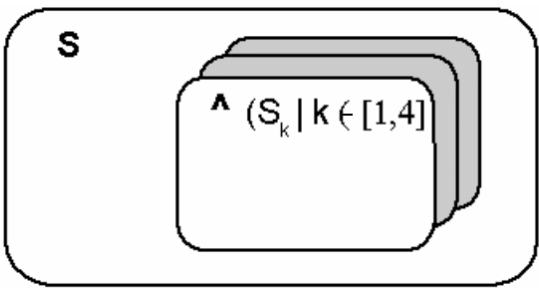

(a) Estado parametrizado

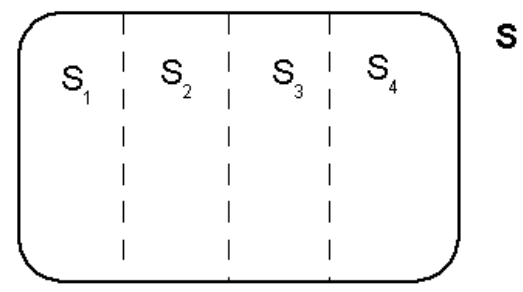

(b) Decomposição da parametrização

Figura 4.3: Parametrização simples do tipo AND (Turine, 1998) 
Além disso, os statecharts devem adotar uma estrutura-padrão fixa para todos os elementos do MDE, tais como: Cursos, UE, Tópicos, Avaliação e Questões. Essas estruturas padronizadas são apresentadas na Seção 4.4, juntamente com o modelo proposto.

\subsubsection{Condição Avaliada por Expressão Lógica}

No modelo aqui proposto, condições são associadas às Avaliações para determinar a progressão do aprendiz no Curso, com base no resultado das Avaliações. Assim como em statecharts, eventos disparam transições. No MDE, os eventos permitidos estão ilustrados nas Figuras 4.4 a 4.6. Condições podem ser utilizadas para representar diferentes classes de usuários e diferentes contextos navegacionais (Oliveira et al., 2001). As seguintes variáveis são utilizadas para especificar as extensões propostas:

a:

a quantidade total de questões respondidas corretamente em uma Avaliação, ou uma pontuação calculada com base no atributo Valor das questões respondidas corretamente;

$\mathbf{a}_{\mathbf{c}}$ :

a quantidade total de questões respondidas corretamente sobre o conceito $c$ abordado em uma UE, ou a soma dos pesos (atributo Valor) dessas questões;

$\mathbf{n}, \mathbf{n}_{\mathbf{1}}, \mathbf{n}_{\mathbf{2}}, \ldots, \mathbf{n}_{\text {numUEs }}, \mathbf{n}_{\text {numTops }}$ :

o número global de respostas corretas, ou a pontuação valorada, ou o número de respostas corretas relativas à i-ésima UE ou ao k-ésimo Tópico, exigidas pelo instrutor para possibilitar ao aprendiz o estudo da $(i+1)$-ésima UE ou do $(k+1)$-ésimo Tópico; e

op:

um dos seguintes operadores matemáticos relacionais: $>$ ou $\geqslant$.

Com exceção de $o p$, as demais variáveis representam números naturais. Enquanto os valores de $a$ e $a_{c}$ são determinados em tempo de execução pelo sistema, os valores de $n_{i}$ são estipulados pelo instrutor antes dos aprendizes iniciarem o estudo do curso.

Com base nessas variáveis, pode-se descrever condições que determinam o sucesso ou insucesso do aprendiz em cada tipo de Avaliação; por exemplo: $C_{1}=a \geqslant 5$ significa que, para ser aprovado na Avaliação associada à condição $C_{1}$, o aprendiz deve acertar pelo menos cinco questões desta Avaliação, independentemente de quais conceitos estão associados às questões. Uma condição mais complexa, $C_{2}=\left(a_{c_{1}}>3\right) \wedge\left(a_{c_{2}} \geqslant 4\right)$, exige que o aprendiz acerte mais que três questões sobre o conceito $c_{1}$ e quatro questões, no mínimo, sobre $c_{2}$. Em ambas as condições, o peso individual das questões é igual a 1.

Para especificar as regras de formação desse tipo de condição, desenvolveu-se a linguagem formal LEA (Linguagem para Especificação de Avaliações), cuja gramática GEA (Gramática para Especificação de Avaliações) foi especificada conforme a notação BNF - Backus-Naur Form (Aho et al., 1988; Backhouse, 1979). GEA é composta das seguintes regras: 


$$
\begin{aligned}
\langle\text { CondAval }\rangle & :=\langle\text { AvalGeral }\rangle \mid\langle\text { AvalPorConceitos }\rangle \\
& \mid\langle\text { AvalAlternativas }\rangle ; \text { condição geral } \\
\langle\text { AvalGeral }\rangle & :=a\langle\text { op }\rangle n ; n \in \mathbb{N} \\
& ; \text { correção sem considerar conceitos associados às questões } \\
\langle\text { AvalPorConceitos }\rangle & :=\langle\text { AvalUmConceito }\rangle\langle\text { AvalOutrosConceitos }\rangle \\
\langle\text { AvalUmConceito }\rangle & ::=a_{c}\langle\text { op }\rangle n_{c} ; \text { avaliação do conceito } c \mid a_{c}, n_{c} \in \mathbb{N} \\
\langle\text { AvalOutrosConceitos }\rangle & :=\langle\text { AvalUmConceito }\rangle\langle\text { AvalOutrosConceitos }\rangle \mid \epsilon \\
& ; \text { avalia mais de um conceito (parte } 1 \text { ) ou nenhum (parte } 2) \\
\langle\text { AvalAlternativas }\rangle & ::=\langle\text { AvalPorConceitos }\rangle\langle\text { OutrasAlternativas }\rangle \\
\langle\text { OutrasAlternativas }\rangle & ::=\epsilon \mid \vee\langle\text { AvalAlternativas }\rangle \\
\langle o p\rangle & ::=>\mid \geqslant ; \text { operador utilizado para comparação }
\end{aligned}
$$

Portanto, ao conjunto $C$ de condições (Seção 3.3), acrescentam-se todas as frases que podem ser geradas pela gramática. As fórmulas genéricas permitidas para cada tipo de avaliação proposto no modelo são apresentadas na Subseção 4.4.3, enquanto na Seção 4.4 há outros exemplos.

\subsubsection{Comportamento Adaptável ao Tipo de Página}

A cada tipo de página estão associadas funções semânticas específicas; por exemplo, ao estudar um Tópico, o aprendiz pode executar as seguintes ações: fazer uma pausa no estudo; ver o conteúdo da página associada ao Curso; visitar a página associada à Unidade de Estudo que contém o Tópico em estudo; reestudar um Tópico anterior; e responder à AF referente ao Conceito estudado no Tópico ou, no caso dele estar estudando o último Tópico do Curso, à Avaliação Somativa referente a todos os Conceitos do Curso.

A essas ações, devem corresponder rotinas semânticas; além disso, independentemente de ações do usuário, o sistema deve armazenar os momentos da abertura e da saída desse Tópico. Já para uma Questão, há apenas duas funções semânticas: escolher uma alternativa e exibir a próxima questão ou, se for a última Questão da Avaliação, finalizar a Avaliação.

\subsubsection{Atributos Estruturados}

A definição formal de uma página contém outros atributos além dos elementos $c, t$ e $A n c_{P}$

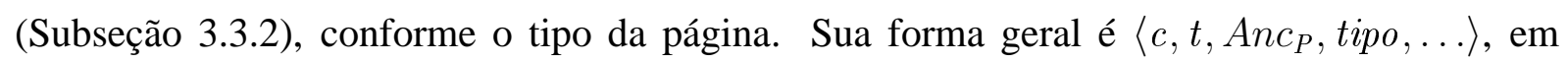
que tipo $\in\{C U R S O, U E, T O ́ P I C O, Q U E S T \tilde{A} O$, REFERÊNCIA, ...\}. Outros atributos são definidos na Seção 4.4 . 


\subsubsection{Mapa Conceitual Associado às Páginas de Conteúdo}

Conforme descrito na Subseção 4.4.2, um dos elementos da página associada a um Curso é um mapa conceitual, que pode ser formalizado pela tripla

$$
M C=\langle A r v(\text { Vert, Are), Conc, } V C\rangle \text {, na qual: }
$$

- $\operatorname{Arv}\left(\right.$ Vert, Are) é uma árvore enraizada ordenada (Szwarcfiter, 1984), com altura ${ }^{1}(A r v)=$ 3. Vert $=\left\{v_{1}, v_{2}, \ldots, v_{i}\right\}, i \geqslant 0$, é o conjunto de vértices de Arv. Are $=\left\{a_{1}, a_{2}, \ldots, a_{j}\right\}$, $j \geqslant 0$, é o conjunto de arestas de Arv;

- Conc $=\left\{c_{1}, c_{2}, \ldots, c_{k}\right\}, k \geqslant 0$, é um conjunto de conceitos. Cada conceito é representado por um identificador. O conjunto dos conceitos do sistema, denotado por CSist, consiste na união dos $Q t d$ Conc $\in \mathbb{N}$ conjuntos de conceitos abordados em todos os Cursos existentes no sistema em um determinado momento. Formalmente,

$$
\text { CSist }=\bigcup_{l=1}^{\text {QtdConc }} \text { Conc }_{l} ; \mathrm{e}
$$

- VC: Vert $\nrightarrow$ Conc é uma função sobrejetora parcial que associa vértices $v_{i} \in$ Vert a conceitos $c_{k} \in$ Conc. Assim, conceitos podem ser reutilizados, mas um vértice está associado no máximo a um conceito. Portanto, Vert e Conc apresentam cardinalidades diferentes (\#Vert $\geqslant \#$ Conc). O autor de uma instância de $M C$ é responsável pelo significado de $V C$. Segundo o modelo proposto na Seção 4.4, um dos atributos da página do curso é $M C$ e um dos atributos de qualquer página associada a uma UE ou a um Tópico é um único conceito $c \in M C$; ao contrário, questões podem abordar um conjunto finito (unitário ou não), mas não vazio, de conceitos $c_{k} \in M C, k>0$.

\subsubsection{Associação de Mais de uma Página por Estado}

A apresentação de informações conforme o perfil do usuário é interessante em sistemas hipermídia educacionais. Ela pode facilitar a aprendizagem e possibilitar a avaliação personalizada. Um método utilizado para a adaptação de conteúdo modifica as informações apresentadas sobre um conceito dependendo do nível de conhecimento do usuário para conceitos relacionados; por exemplo, no MDE o primeiro Tópico estudado pelo aprendiz em um curso pode ser determinado a partir do seu desempenho na Avaliação Diagnóstica.

Uma das técnicas de Hipermídia Adaptativa consiste em armazenar no sistema duas ou mais variações de um Tópico com diferentes apresentações do mesmo conceito, preparando cada variação para um dos possíveis perfis do usuário. Em sistemas educacionais, essa técnica pode ser implementada por meio de um atributo que estabelece o nível de dificuldade de cada questão; além disso, é possível configurar níveis de detalhamento para os Tópicos. Conseqüentemente, para o mesmo conceito e estado, podem estar associadas diferentes páginas.

\footnotetext{
${ }^{1}$ A altura de uma árvore $A r v$ é igual ao valor máximo de nível $(v), v \in V$. O nível de um vértice $v$ é o comprimento do caminho da raiz a $v$ (Szwarcfiter, 1984).
} 
Em termos formais, isso significa que a função $m: S_{s} \mapsto P$ (Subseção 3.3.2) deixa de ser uma função e passa a ser uma relação. Obviamente, quando esta característica do MDE for implementada, uma função de escolha deverá ser definida para decidir qual página será apresentada primeiramente e quais deverão ser exibidas em seguida. Um atributo associado à página é uma possível solução para esse problema.

\subsection{O modelo MDE}

Um Curso é definido pela seguinte tupla:

Curso $=\left\langle I d_{C}\right.$, Título, Dados $_{C}, M C_{C}$, Conteúdo $\left.{ }_{C}\right\rangle$, na qual:

- $I d_{C}$ é um identificador do Curso, que indica seu principal ponto de acesso. $I d_{C}$ pode ser o diretório do computador que armazena o Curso, prefixado ou não por uma URL;

- Título é o nome do curso;

- $\operatorname{Dados}_{C}$ identifica o registro que contém os seguintes dados do Curso: autor, descrição longa, ementa, pré-requisitos e objetivos;

- $M C_{C}$ é um Mapa Conceitual associado ao Curso; e

- Conteúdo ${ }_{C}$ é um modelo HMBS (Oliveira et al., 2001) do Curso, com restrições quanto à estrutura do conteúdo, às páginas associadas aos estados e às condições. Estas restrições são detalhadas nas próximas subseções.

\subsubsection{Estrutura do conteúdo}

Quanto à estrutura do conteúdo, o statechart associado ao Curso deve obedecer ao modelo genérico apresentado nas Figuras 4.4, 4.5, 4.6 e 4.7.

$\mathrm{Na}$ Figura 4.4 é representada a estrutura de um Curso no nível de abstração mais alto. O estado Trilha do Curso recebeu este nome porque se comporta como uma trilha (Bush, 1945) que conecta os principais documentos do curso.

Ao terminar a Avaliação Diagnóstica, representada pelo estado $A D$, o resultado da condição $C_{1}$ determina a UE a ser estudada pelo aprendiz. Se ele dominar conceitos de algumas UEs, então uma função baseada em $C_{1}$ retorna o índice $i, i>1$, da UE a ser inicialmente acessada; senão, o estudo é iniciado pela primeira UE.

Tendo finalizado a última UE, o aprendiz é conduzido à realização da Avaliação Somativa, simbolizada pelo estado $A S$. Terminando-a, o resultado da avaliação de $C_{2}$ estipula se o aprendiz foi aprovado ou não.

Em qualquer estado do curso, com exceção da AD e da AS, o aprendiz pode encerrar a sessão do Curso, fazendo com que o sistema ative o estado Pausa e salve o contexto (dado pela configuração atual do statechart) no perfil do aprendiz. 


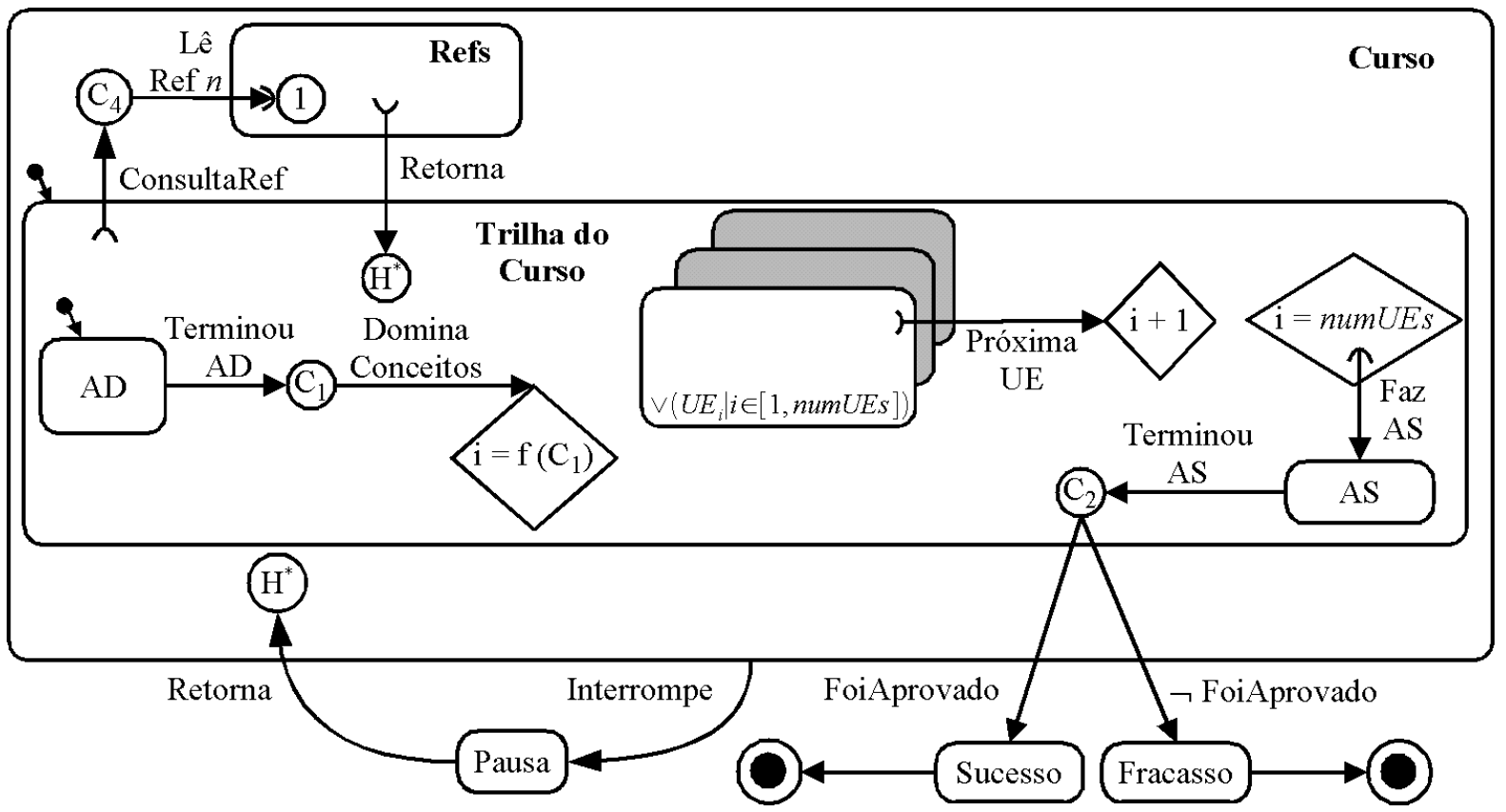

Figura 4.4: Representação gráfica da estrutura de um Curso

Conforme especificado na Figura 4.5, o estudo de uma UE começa pelo seu Tópico inicial. Após estudá-lo, o aprendiz faz a Avaliação Formativa associada ao Tópico, representada pelo estado $A F$. Terminando essa Avaliação, se o resultado for satisfatório (o que é determinado pela avaliação da condição $C_{3}$ ), o aprendiz poderá estudar o próximo Tópico; caso contrário, precisará reestudar o mesmo Tópico. Ao finalizar com sucesso a AF associada ao último Tópico dessa UE, o aprendiz pode passar para a UE seguinte $\left(U E_{i+1}\right)$.

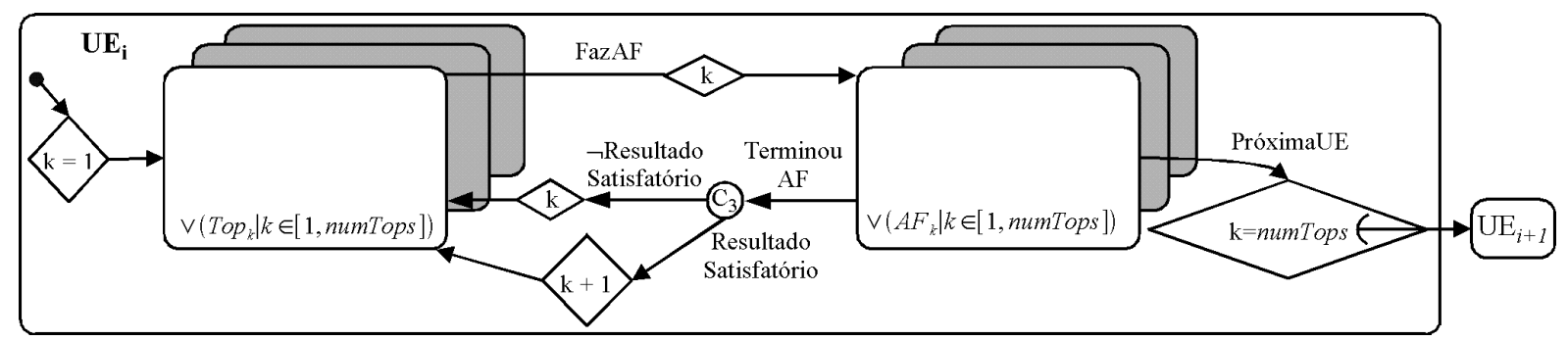

Figura 4.5: Statechart parametrizado de uma Unidade de Estudo

$\mathrm{Na}$ Figura 4.6 é ilustrada a estrutura dos três tipos de Avaliação previstos no modelo. Em qualquer tipo de Avaliação baseada em questões, o aprendiz começa pela primeira questão e, enquanto não sinalizar que terminou de responder à Avaliação, pode a qualquer momento avançar para uma próxima questão ou retornar à anterior. A sinalização do término da Avaliação segue diferentes comportamentos, de acordo com o tipo da Avaliação e com eventos especificados nos statecharts das Figuras $4.4 \mathrm{e} 4.5$. 


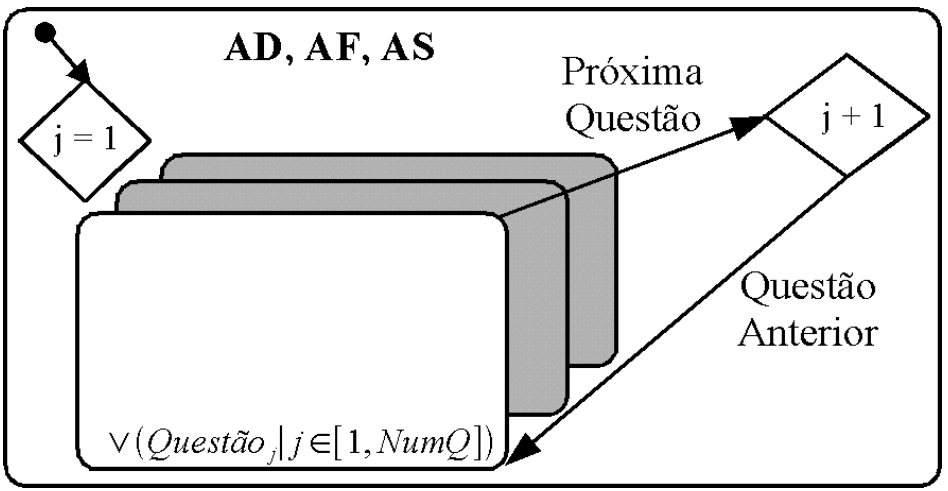

Figura 4.6: Notação parametrizada para os estados $A D, A F$ e $A S$

$\mathrm{O}$ acesso às referências citadas no conteúdo do curso é habilitado pelo evento ConsultaRef (Figura 4.4), disparado quando o usuário seleciona uma citação bibliográfica ou webliográfica incluída em alguma página do hiperdocumento do curso.

O resultado da condição $C_{4}$ (Figura 4.7) determina a referência a ser exibida. Para isso, é aplicada a função ae do HMBS que associa âncoras de uma página $p\left(a_{p} \in A n c_{p}\right)$ a eventos do statechart que controlam a ativação de transições (Oliveira et al., 2001). No MDE, esta função é utilizada para associar citações bibliográficas, marcadas como âncoras, ao evento ConsultaRef.

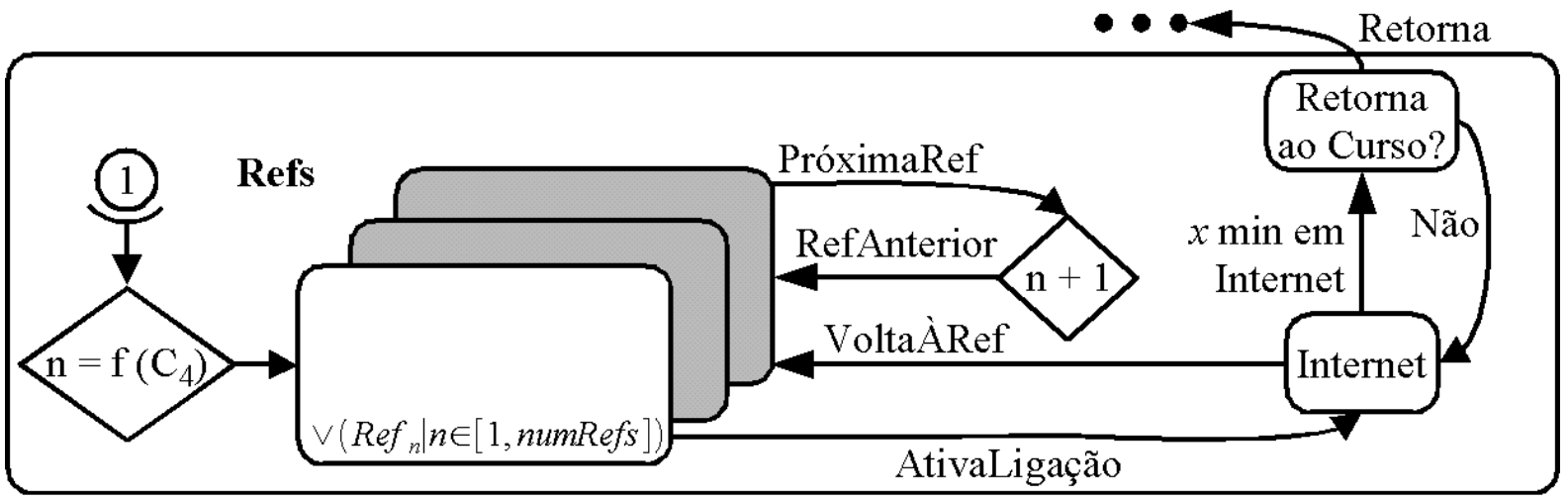

Figura 4.7: Organização das referências, por meio de um statechart parametrizado

A volta ao estado do curso mais recentemente ativo é representada pelo evento Retorna. Ao consultar uma referência webliográfica, o aprendiz pode percorrer uma ligação (simbolizada pelo evento AtivaLigação) contida na referência para um documento disponível na Internet. A qualquer momento, ele pode voltar à referência consultada, disparando o evento VoltaÀRef.

Após um tempo limite de permanência no estado Internet, é disparado o evento $x$ min em Internet. O valor de $x$ é determinado pelo instrutor, usando "minutos" como unidade. Esse evento é um tipo de restrição temporal por meio de cronômetros implícitos (Harel, 1987), representada formalmente pela expressão timeout (entered Internet, $x$ ).

Entrando no estado Retorna ao Curso?, o sistema pergunta se o aprendiz deseja retornar à mesma sessão (evento Retorna) ou se prefere continuar navegando na Internet (evento Não). 


\subsubsection{Páginas}

Uma página corresponde a um conteúdo didático associado a um conceito tratado no Curso. O MDE e o HMBS associam páginas a estados do statechart que representa a organização do conteúdo. No MDE são estabelecidas as seguintes restrições sobre as páginas associadas a estados:

1. Uma página associada ao estado tipado Curso é descrita pela tripla

$$
P_{\text {Curso }}=\langle I d P \text {, Título, Conceito } \text { Curso }\rangle \text {, na qual }
$$

- IdP é um identificador da página. IdP pode ser, por exemplo, o nome do arquivo com o conteúdo dessa página ou a URL desse arquivo;

- Título é o nome do Curso; e

- Conceito $_{\text {Curso }}=c \mid r \in \operatorname{Vert}_{M C} \wedge r=$ raiz de $M C \wedge V C(r)=c$, isto é, o principal conceito $c$ do Curso é mapeado na raiz da árvore associada ao Mapa Conceitual $M C$.

2. Uma página associada ao estado tipado $U E$ é descrita pela tripla

$P_{U E}=\left\langle I d P\right.$, Título, Conceito $\left.{ }_{U E}\right\rangle$, na qual

- IdP é um identificador da página,

- Título é o nome da UE, e

- Conceito $_{U E}=c \mid v \in \operatorname{Vert}_{M C} \wedge$ nível $(v)=2 \wedge V C(v)=c$, isto é, o conceito associado a uma UE é um conceito $c$ mapeado em um vértice $v$ de $M C$, o qual está no segundo nível da árvore relacionada a $M C$.

3. Um estado do tipo Tópico pode estar associado a mais de uma página, pois o sistema pode exibir páginas alternativas sobre o mesmo conceito de um Tópico, conforme o desempenho do aprendiz nas AFs correspondentes. Cada página relacionada a um Tópico é representada pela tupla

$$
P_{\text {Tópico }}=\left\langle I d P \text {, Título, NivDet, Conceito }{ }_{\text {Tópico, }} \text { OrdemApres }\right\rangle \text {, na qual }
$$

- IdP é um identificador da página;

- Título é o nome do Tópico;

- NivDet $=d \mid d \in\{0,1,2\}$ é o nível de detalhamento adotado na explicação de Conceito ${ }_{\text {Tópico; }}$

- Conceito $_{\text {Tópico }}=c \mid v \in \operatorname{Vert}_{M C} \wedge$ nível $(v)=3 \wedge V C(v)=c$, isto é, o conceito associado a um Tópico é um conceito $c$ mapeado em um vértice $v$ de $M C$, o qual está no terceiro nível da árvore relacionada a $M C$; e

- OrdemApres é um número natural que indica a posição desta página na apresentação do Tópico ao aprendiz, no caso do Tópico corresponder a mais de uma página.

4. A página associada ao estado tipado $A D$ é definida pela tupla

$$
\begin{aligned}
& P_{A D}=\langle I d A D, \text { Título, TextoIntro, PercentualDif } 1, \\
& \text { PercentualDif 2, PercentualDif } 3 \text {, NroQuests }\rangle \text {, na qual }
\end{aligned}
$$


- IdAD é um identificador da AD;

- Título é o nome da AD;

- TextoIntro é um texto introdutório que explica a AD;

- PercentualDif 1 é um número real referente à porcentagem, na $\mathrm{AD}$, de questões cujo nível de dificuldade $N i v D i f Q$ seja igual a 1;

- PercentualDif 2 é a porcentagem, na AD, de questões com nível 2 de dificuldade;

- PercentualDif 3 é a porcentagem, na AD, de questões com nível 3 de dificuldade; $\mathrm{e}$

- NroQuests é a quantidade de questões da AD.

5. As páginas associadas ao estado tipado $A F$ são definidas pela tupla

$$
\begin{gathered}
P_{A F}=\langle I d A F, \text { Título, TextoIntro, PercentualDif } 1, \text { PercentualDif2, } \\
\text { PercentualDif } 3, \text { NroQuests, NroTentativa }\rangle \text {, na qual }
\end{gathered}
$$

- IdAF é um identificador da AF;

- Título é o nome da AF;

- TextoIntro é um texto introdutório que explica a AF;

- PercentualDif 1 é a porcentagem, na AF, de questões com nível 1 de dificuldade;

- PercentualDif 2 é a porcentagem, na AF, de questões com nível 2 de dificuldade;

- PercentualDif 3 é a porcentagem, na AF, de questões com nível 3 de dificuldade;

- NroQuests é a quantidade de questões da AF; e

- NroTentativa é um número natural que indica quantas vezes o aprendiz vem tentando ser bem sucedido na AF, incluindo a instância atual da AF.

6. A página associada ao estado tipado $A S$ é definida pela tupla

$$
\begin{array}{r}
P_{A S}=\langle\text { IdAS, Título, TextoIntro, PercentualDif } 1, \text { PercentualDif } 2, \\
\text { PercentualDif } 3, \text { NroQuests, NroTentativa, MaxTent }\rangle \text {, na qual }
\end{array}
$$

- IdAS é um identificador da AS;

- Título é o nome da AS;

- TextoIntro é um texto introdutório que explica a AS;

- PercentualDif 1 é a porcentagem, na AS, de questões com nível 1 de dificuldade;

- PercentualDif 2 é a porcentagem, na AS, de questões com nível 2 de dificuldade;

- PercentualDif 3 é a porcentagem, na AS, de questões com nível 3 de dificuldade;

- NroQuests é a quantidade de questões da AS;

- NroTentativa é um número natural, variável entre 1 e MaxTent, que indica quantas vezes o aprendiz vem tentando ser bem sucedido na AS, incluindo sua instância atual; e

- MaxTent é o número máximo, estabelecido pelo instrutor, de tentativas permitidas.

7. Uma página associada ao estado tipado Questão apresenta a seguinte estrutura:

$$
\begin{gathered}
P_{\text {Questão }}=\langle\text { IdQ, Enunc, NivDifQ, Dica, Alternativas, } \\
\text { Soluc, TempoMax, Conceitos } \\
\text { Questão }\rangle \text {, na qual }
\end{gathered}
$$


- $I d Q$ é um código que identifica unicamente uma questão;

- Enunc é um texto que explica o problema;

- NivDifQ $=f \mid f \in\{1,2,3\}$ é o nível de dificuldade da questão;

- Dica é um texto ou URL que sugere formas para solução da questão;

- Alternativas é um conjunto finito de respostas corretas e falsas;

- Soluc $\subset$ Alternativas é um conjunto finito (unitário ou não) de respostas corretas;

- TempoMax é o tempo máximo para que o aprendiz responda a questão; caso TempoMax = $+\infty$, não há limite de tempo e

- Conceitos $_{\text {Questão }}=\left\{c_{k} \in\right.$ Conc $\mid V C\left(v_{k}\right)=c_{k} \wedge v_{k} \in$ Vert $\left._{M C_{C}}\right\}$ é um conjunto finito (unitário ou não), não vazio, de conceitos avaliados pela questão.

8. Uma página associada ao estado tipado Ref é definida pela tupla $P_{\text {Ref }}=\langle$ IdItem, Título, Autor, Data, Resumo, Tipo, Local, ISBN, Editora, Periódico, Congresso, Edição, URL, ÚltimoAcesso $\rangle$, na qual

- IdItem é um identificador do item bibliográfico ou webliográfico;

- Título é o nome do item;

- Autor é o nome do criador do item;

- Data é a data em que o item bibliográfico foi publicado ou em que o item webliográfico foi disponibilizado na Internet;

- Resumo é uma descrição do item;

- Tipo é uma classificação do item em livro, artigo ou tese de Doutorado, dentre outros tipos;

- Local é o local da publicação do item bibliográfico, não se aplicando ao item webliográfico;

- ISBN (International Standard Book Number) é um número de referência atribuído a todo item bibliográfico publicado;

- Editora é o nome da editora que publicou o item bibliográfico;

- Periódico é o nome da publicação periódica que contém o item;

- Congresso é o nome do congresso no qual o item bibliográfico foi apresentado;

- Edição é um número natural, maior que 0, que equivale à edição do item bibliográfico;

- URL (Uniform / Universal Resource Locator) define a localização do item webliográfico na Internet; e

- ÚltimoAcesso é a data em que o item webliográfico foi acessado pela última vez.

\subsubsection{Avaliações}

Para cada tipo de Avaliação, sua fórmula genérica será especificada nas próximas subseções. 


\subsubsection{Avaliação Diagnóstica}

Dado que $V C\left(U E_{1}\right)=c_{1}, V C\left(U E_{2}\right)=c_{2}, \ldots, V C\left(U E_{\text {numUEs }}\right)=c_{\text {numUEs }}$, a condição na AD que determina se o aprendiz poderá acessar a i-ésima UE ( $\left.U E_{i}\right)$ é dada por $C_{1}$ (Figura 4.4), tal que

$$
C_{1}=\left(\left(a_{c_{1}} \text { op } n_{1}\right) \wedge\left(a_{c_{2}} \text { op } n_{2}\right) \wedge \ldots \wedge\left(a_{c_{\text {num } U E s}} \text { op } n_{\text {numUEs }}\right)\right)
$$

Se $a_{c_{1}}$ op $n_{1}$ for verdadeira e numUEs $\geqslant 2$, a próxima cláusula é avaliada; senão, o aprendiz deve iniciar o estudo do Curso pela $U E_{1}$. Se ambas as subexpressões $a_{c_{1}}$ op $n_{1}$ e $a_{c_{2}} o p n_{2}$ forem verdadeiras e $n u m U E s \geqslant 3$, então a cláusula seguinte é também verificada. Se esta última falhar, o aprendiz começa o Curso pela $U E_{2}$. Genericamente, o aprendiz inicia o estudo pela $i$ -ésima UE, $i=1, \ldots$, numUEs, se todas as subexpressões $a_{c_{j}}$ op $n_{j}, j=1, \ldots, i-1$, foram avaliadas como verdadeiras e a subexpressão $a_{c_{i}}$ op $n_{i}$ foi avaliada como falsa. Se a condição for bem sucedida para todas as subexpressões de $C_{1}$, o aprendiz é encaminhado para responder à Avaliação Somativa, como indicado na Figura 4.4. Um caso particular desta condição é a substituição de $o p$ por $\geqslant$ e $n_{i}$ por 0 , para todo $n_{i}$, possibilitando que o aprendiz responda às questões apenas para auto-avaliação, sem que os resultados determinem seu posicionamento inicial no Curso, uma vez que a condição será avaliada como verdadeira.

\subsubsection{Avaliação Somativa}

Sendo $V C\left(\right.$ Tópico $\left._{1}\right)=c_{1} \wedge \ldots \wedge V C\left(\right.$ Tópico $\left._{k}\right)=c_{k}, k=1, \ldots$, numTops, a expressão que determina o desempenho do aprendiz em uma AS é dada por $C_{2}$ (ver Figura 4.4), tal que

$$
\begin{aligned}
C_{2} & =\text { a op } n, \text { ou } \\
& =\left(\left(a_{c_{1}} \text { op } n_{1}\right) \wedge\left(a_{c_{2}} \text { op } n_{2}\right) \wedge \ldots \wedge\left(a_{c_{k}} \text { op } n_{k}\right)\right), k \leqslant \text { numTops } \\
& =\left(\bigwedge_{k=1}^{n} a_{c_{k}} \text { op } n_{k}\right) \vee\left(\bigwedge_{k=1}^{n} a_{c_{k}} \text { op } n_{k}\right) \vee \ldots \vee\left(\bigwedge_{k=1}^{n} a_{c_{k}} \text { op } n_{k}\right), n \leqslant \text { numTops }
\end{aligned}
$$

Se $C_{2}$ for determinada pela Equação 4.2, o instrutor especifica um total de questões a serem respondidas corretamente, independentemente dos conceitos a que estas se referem. Um caso particular da Equação 4.2 é a substituição de $o p$ por $\geqslant$ e de $n$ por 0 , para que a AS funcione como auto-avaliação. Se for especificada a Equação 4.3, ele estabelece que a aprovação requer uma pontuação mínima no conjunto de questões associadas a cada conceito presente na expressão. Caso a Equação 4.4 represente $C_{2}$, o instrutor estipula a condição em termos de várias combinações de pontuações mínimas por conceito.

\subsubsection{Avaliação Formativa}

Assumindo que $V C\left(\right.$ Tópico $\left._{k}\right)=c_{k}$, a fórmula que determina a progressão do aprendiz do Tópico $k$ para o Tópico $k+1$ na $\mathrm{AF}$ associada ao Tópico $k$, é dada por $C_{3}$ (Figura 4.5), tal que

$$
C_{3}=a_{c_{k}} \text { op } n_{k}, k \leqslant \text { numTops }
$$

Se a Equação 4.5 para $C_{3}$ for avaliada como verdadeira, desde que op seja diferente de $\geqslant \mathrm{e}$ $a_{c_{k}} \neq 0$, o aprendiz pode avançar para o Tópico $k+1$. Mas, se $o p$ corresponder a $\geqslant$ e $a_{c_{k}}=0$, o aprendiz poderá avançar para o Tópico $k+1$ independentemente do seu resultado na AF 
associada ao Tópico $k$. Se a Equação 4.5 for falsa, ele deve voltar a estudar o Tópico $k$. Neste momento, o sistema pode mostrar-lhe uma página com conteúdo mais detalhado.

\subsection{Semântica Navegacional}

A semântica navegacional de um hiperdocumento define como a informação pode ser visitada e apresentada ao usuário que está navegando por ela, referindo-se às propriedades dinâmicas experimentadas pelo leitor enquanto navega no hiperdocumento (Stotts \& Furuta, 1989). No HMBS, ativar uma ligação hipertexto dispara um evento que desencadeia uma transição correspondente habilitada por esse evento no statechart subjacente. Esse disparo resulta em uma nova configuração do statechart que define um novo conjunto de páginas a serem exibidas. Páginas associadas a estados ancestrais podem também ser visualizadas simultaneamente àquelas associadas aos estados básicos na configuração atual do statechart. Esse é um recurso útil que possibilita aos usuários acessarem simultaneamente informações da aplicação disponíveis em diferentes níveis hierárquicos do hiperdocumento. O nível $N$ de visibilidade, ou navegacional, é um valor dinâmico que determina quantos níveis de hierarquia serão exibidos ao mesmo tempo (Oliveira et al., 2001).

\subsubsection{Nível de Visibilidade}

A semântica navegacional do MDE é baseada no HMBS, com restrição no valor de $N$. No caso, $N, 0 \leqslant N \leqslant 2$, determina o nível de visibilidade adotado para a exibição de Conteúdo $_{C}$. $\mathrm{O}$ instrutor pode usar o valor de $N$ para estabelecer a profundidade da hierarquia que define a estrutura organizacional do curso (Figuras $4.4 \mathrm{e} 4.5$ ) a ser exibida durante a navegação.

Se $N=0$, então apenas $P_{\text {Tópico }}$ ou $P_{Q u e s t a ̃ o}$ é apresentada. Se o estado ativo for Questão, $N$ é associado ao valor 0 na navegação do aprendiz, a fim de impedir que este visualize informações sobre conceitos avaliados na questão; portanto, enquanto o aprendiz responde às Avaliações, a visibilidade fica restrita ao nível atômico. Se o estado ativo for Tópico, $N$ pode variar entre 0 e 2. Com $N=1$, são exibidas $P_{\text {Tópico }}$ e $P_{U E} ; \operatorname{com} N=2, P_{\text {Curso }}$ também é apresentada.

\subsubsection{Apresentação do Conteúdo}

Como o MDE não especifica as mídias das páginas, a exibição do hiperdocumento didático é mais flexível do que se o modelo incluísse os canais de apresentação adotados em versões iniciais do HMBS. O MDE é suficientemente abstrato para possibilitar diferentes mídias ou mecanismos de exibição em um Curso, conforme as necessidades da aplicação. Cabe à implementação considerar características específicas do domínio, ao tratar a apresentação do conteúdo das páginas. Além de um conteúdo estático (texto ou multimídia), elas podem conter código executável ou referência para algum código executável, como applets Java ou progra- 
mas (scripts) PHP; por exemplo, a página associada ao estado Pausa na Figura 4.4 não contém conteúdo, mas sim um código que executa o término da sessão atual do aprendiz e armazena o contexto (configuração atual do statechart, data e hora correntes, dentre outros dados) para ser recuperado na próxima sessão do mesmo aprendiz.

\subsection{Exemplo: Curso Básico sobre HTML}

Nesta Seção é construído um exemplo com a estrutura completa de um Curso básico sobre HTML, disponível em http://www.icmc.usp.br/manuals/HTML.

$M C_{H T M L}$, um possível mapa conceitual para este Curso, é ilustrado na Figura 4.8.

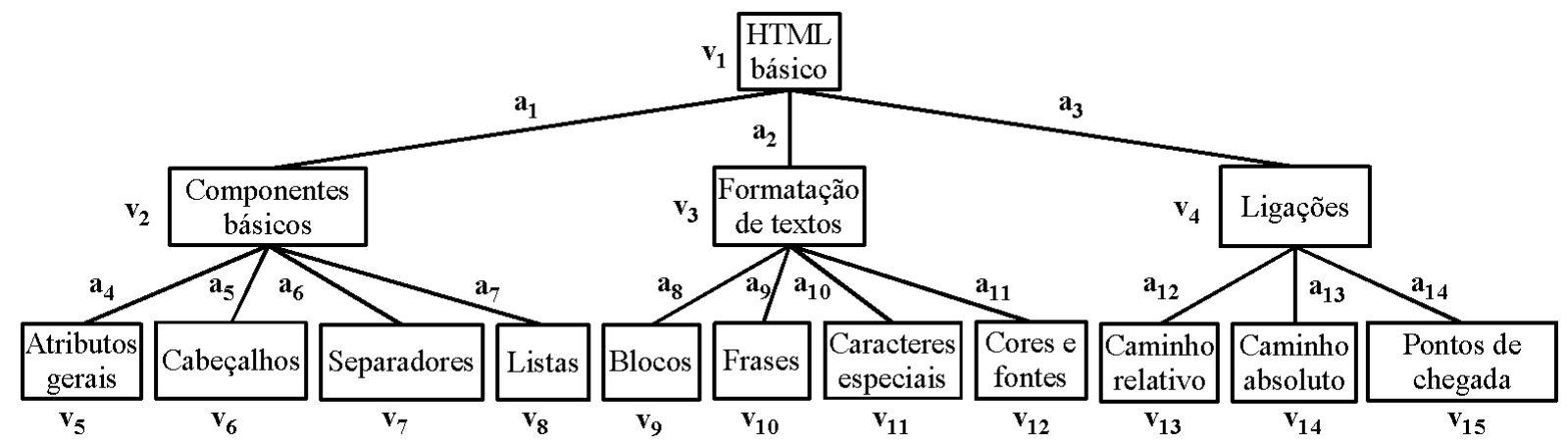

Figura 4.8: $M C_{H T M L}$ - Mapa Conceitual de um Curso básico sobre HTML

Formalmente, o Mapa Conceitual $M C_{H T M L}$ é uma tripla

$M C_{H T M L}=\left\langle A r v_{H T M L}\left(\operatorname{Vert}_{H T M L}, \operatorname{Are}_{H T M L}\right), \operatorname{Conc}_{H T M L}, V C_{H T M L}\right\rangle$, na qual:

- $\operatorname{Vert}_{H T M L}=\left\{v_{1}, v_{2}, \ldots, v_{15}\right\}$;

- Are $_{\text {HTML }}=\left\{a_{1}, a_{2}, \ldots, a_{14}\right\} ; \mathrm{e}$

- Conc $_{\text {HTML }}=\{$ HTML básico, Componentes básicos, Formatação de textos, Ligações, Atributos gerais, Cabeçalhos, Separadores, Listas, Blocos, Frases, Caracteres especiais, Cores e fontes, Caminho relativo, Caminho absoluto, Pontos de chegada\}.

A função $V C_{H T M L}$ é representada na Tabela 4.1

\begin{tabular}{|c|l||c|l|}
\hline Vert $_{\text {HTML }}$ & Conc $_{\text {HTML }}$ & Vert $_{\mathbf{H T M L}}$ & Conc $_{\mathbf{H T M L}}$ \\
\hline$v_{1}$ & HTML básico & $v_{2}$ & Componentes básicos \\
$v_{3}$ & Formatação de textos & $v_{4}$ & Ligações \\
$v_{5}$ & Atributos gerais & $v_{6}$ & Cabeçalhos \\
$v_{7}$ & Separadores & $v_{8}$ & Listas \\
$v_{9}$ & Blocos & $v_{10}$ & Frases \\
$v_{11}$ & Caracteres especiais & $v_{12}$ & Cores e fontes \\
$v_{13}$ & Caminho relativo & $v_{14}$ & Caminho absoluto \\
$v_{15}$ & Pontos de chegada & & \\
\hline
\end{tabular}

Tabela 4.1: Função $V C_{H T M L}$ de $M C_{H T M L}$ 
Este Curso é definido pela seguinte tupla:

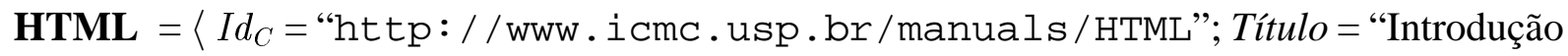
a HTML"; $\operatorname{Dados}_{C}=\langle$ Autora: "M. A. S. Castro", Descrição: "Tutorial básico sobre HTML", Ementa: "1. O documento básico e seus componentes. 2. Formatação de textos. 3. Ligações (uso de links)", Pré-requisito: "nenhum", Objetivo: "Exemplificar como construir um

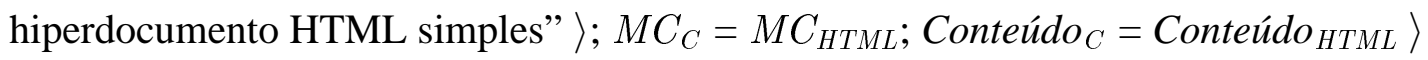

Conteúdo ${ }_{H T M L}$ é um modelo HMBS cujo statechart é representado parcialmente nas Figuras 4.9 a 4.14. São detalhadas aqui as estruturas organizacionais e o conteúdo dos seguintes elementos do modelo: a AD (Figura 4.10), uma UE (Figura 4.11), uma das AFs dessa UE (Figura 4.12), a AS (Figura 4.14) e os itens bibliográficos e webliográficos (Figura 4.15).

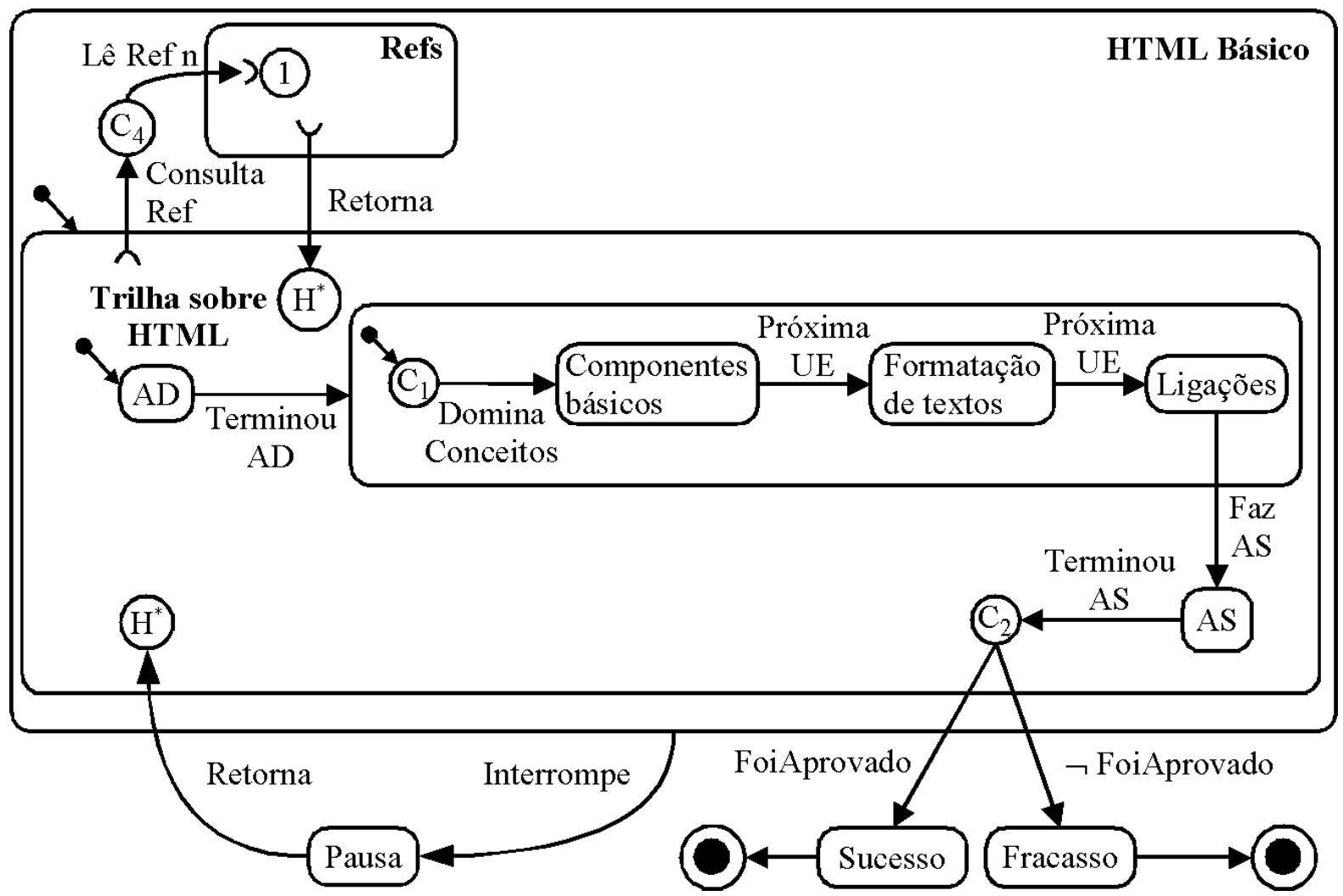

Figura 4.9: Representação gráfica, mais abstrata, de Conteúdo ${ }_{H T M L}$

As páginas associadas a alguns estados mais abstratos (Figura 4.9) do Curso sobre HTML são descritas pelas tuplas:

$P_{\text {HTML básico }}=\left\langle I d P=\right.$ "intro.html $" ;$ Título = "Linguagem HTML"; Conceito HTML básico $_{\text {int }}=$ "HTML básico" $\rangle$

$P_{A D}=\langle I d A D=$ "IdAD_HTML"; Título = "Avaliação Diagnóstica de HTML"; TextoIntro =

"Acelere seu aprendizado respondendo estas questões, para não reestudar o que já sabe"; PercentualDif $1=100 \% ;$ PercentualDif $2=0 \% ;$ PercentualDif $3=0 \% ;$ NroQuests $=4\rangle$ $P_{\text {Ligações }}=\langle I d P=$ "links.html "; Título = "Ligações (uso de links)"; Conceito Ligações $=$ "Ligações" $\rangle$ 
$P_{A S}=\langle I d A S=$ "IdAS_HTML"; Título = "Avaliação Somativa sobre HTML"; TextoIntro = "Esta é a última avaliação do curso"; PercentualDif $1=64 \%$; PercentualDif $2=29 \%$; PercentualDif $3=7 \% ;$ NroQuests $=14 ;$ NroTentativa $=0 ;$ MaxTent $=2\rangle$

Devido ao fato das Avaliações serem geradas dinamicamente, as questões variam de uma Avaliação para outra. Portanto, o conteúdo das páginas das questões em cada Avaliação não é fixo, embora a quantidade de questões o seja. Uma das possíveis páginas associadas às questões da AD sobre HTML (Figura 4.10) é descrita pela tupla:

$P_{q \text { Caixa }}=\langle I d Q=$ "qCaixa"; Enunc = "Há distinção entre maiúsculas e minúsculas em tags HTML?"; NivDifQ = 1; Dica = "Leia o fonte de um texto HTML"; Alternativas = $\{$ "Sim", "Não" \}; Soluc = "Não"; TempoMax = "1 min"; Conceitos $q$ Caixa $=$ "Componentes básicos" $\rangle$

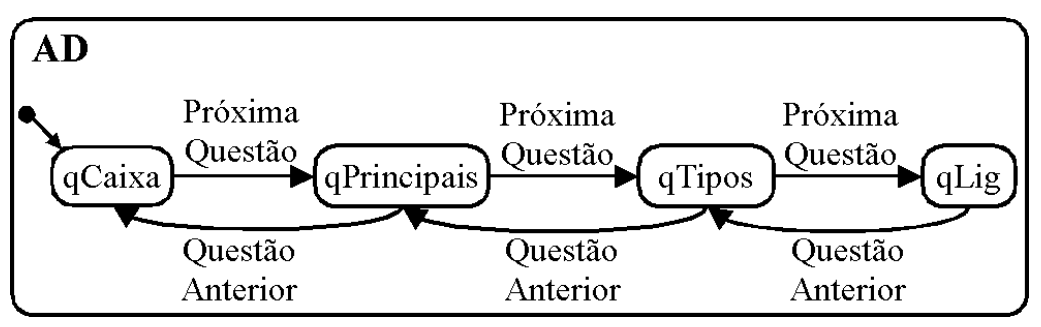

Figura 4.10: Possível estado associado à $\mathrm{AD}$ do Curso básico sobre HTML

Páginas associadas ao primeiro Tópico da $U E_{\text {Ligações }}$ (Figura 4.11) são descritas pelas tuplas: $P_{\text {Caminho relativo }}=\langle I d P=$ "links. html\# relativo"; Título = "Caminho relativo"; NivDet $=1 ;$ Conceito $_{\text {Caminho relativo }}=$ "Caminho relativo"; OrdemApres $\left.=1\right\rangle$

$P_{\text {Caminho relativo }}=\langle I d P=$ "exemplos $/$ doc $2 . \mathrm{html}\rangle " ;$ Título $=$ "Exemplo de caminho relativo"; NivDet $=2 ;$ Conceito $_{\text {Caminho relativo }}=$ "Caminho relativo"; OrdemApres $\left.=2\right\rangle$

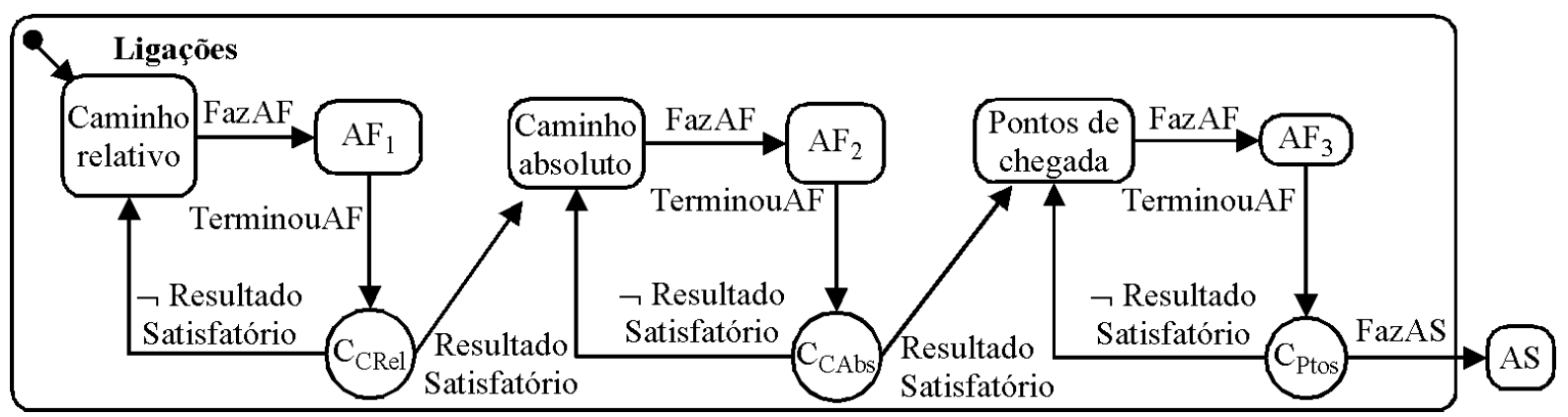

Figura 4.11: Estado associado à $U E_{\text {Ligações }}$ do Curso básico sobre HTML

Um possível conjunto de páginas associadas à terceira $\mathrm{AF}$ da $U E_{\text {Ligações }}$ (Figura 4.12) é descrito pelas tuplas:

$P_{A F 3}=\langle I d A F=$ "IdAF_PontosChegada" ; Título = "Avaliação Formativa sobre Pontos de Chegada de Ligações"; TextoIntro $=\varnothing ;$ PercentualDif $1=0 \%$; PercentualDif 2 $=100 \% ;$ PercentualDif $3=0 \% ;$ NroQuests $=2 ;$ NroTentativa $=0\rangle$

$P_{q \text { CarCheg }}=\langle I d Q=$ "qCarCheg"; Enunc $=$ "Qual caracter possibilita criar ligação para um trecho do mesmo documento?"; NivDifQ $=2 ;$ Dica $=\varnothing ;$ Alternativas $=\{$ “\#”, “\&”, "A" $\}$; Soluc $=$ "\#”; TempoMax = 838:59:59; Conceitos $_{\text {qCarCheg }}=$ "Pontos de chegada" $\rangle$ 
$P_{\text {qIndice }}=\langle I d Q=$ "qIndice"; Enunc = "Como referenciar o índice do documento atual?"; NivDifQ $=2 ;$ Dica $=\varnothing ;$ Alternativas $=\{$ " $<$ LINK index=", " $<\mathrm{A}$ href=\# index", " $<\mathrm{A}$ href = index.htm" $\} ;$ Soluc $=$ "<LINK index="; TempoMax = 838:59:59; Conceitos $_{\text {qIndice }}=\{$ "Caminho relativo", "Pontos de chegada" $\left.\}\right\rangle$

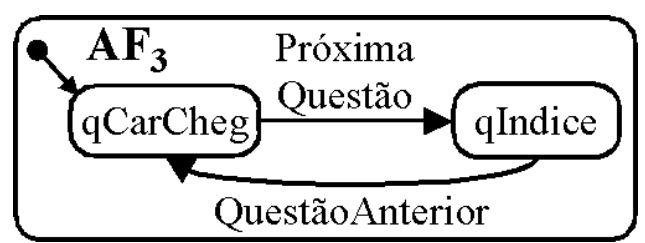

Figura 4.12: Possíveis subestados da AF relacionada ao Tópico sobre pontos de chegada

A AS sobre HTML é exibida nas formas parametrizada e decomposta (Figuras 4.13 e 4.14). A parametrização, aqui, é semelhante à Figura 4.6. A diferença entre as Figuras 4.6 e 4.13 está no índice, que passou de $N u m Q$ para 14 - a quantidade exata de questões da AS. Ao parametrizar o statechart da Figura 4.14, o nome das questões é generalizado para $q A S$ na Figura 4.13. Os estados expandidos não precisam ter o mesmo nome do estado parametrizado, seguido pelo índice. Para facilitar a legibilidade, cada questão recebeu um nome mais adequado ao seu conteúdo; por exemplo, ao invés de $q A S_{1}$, a primeira questão chama-se qMeta. Uma página que pode ser associada a esta questão é descrita pela tupla:

$P_{\text {qMeta }}=\langle I d Q=$ "qMeta"; Enunc = "Quais são os principais atributos dos campos META?";

NivDifQ $=2 ;$ Dica = "Protocolo HTTP"; Alternativas = \{ "name, http-equiv", "content, http-equiv", "name, http" \}; Soluc = "name, http-equiv"; TempoMax = "1 min"; Conceitos $_{\text {qMeta }}=$ "Atributos gerais" $\rangle$

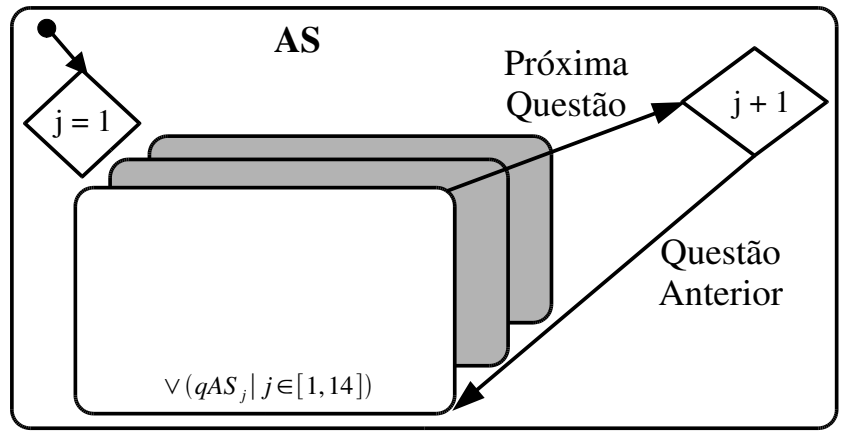

Figura 4.13: Statechart parametrizado da AS sobre HTML

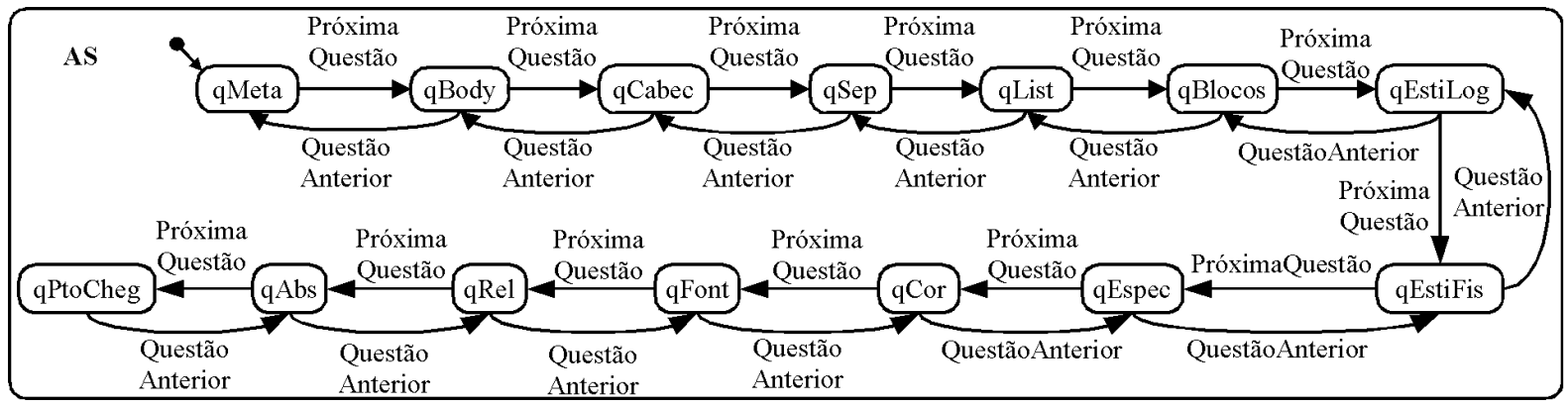

Figura 4.14: Possíveis subestados associados à AS do Curso sobre HTML 
Uma página associada a um item webliográfico do Curso de HTML (Figura 4.15) é identificada pela tupla:

$P_{\text {Raggett } 1999}=\langle$ IdItem $=$ "Ragget99"; Título $=$ "HTML 4.01 Specification"; Autor $=$ "Dave Raggett, Arnaud Le Hors, Ian Jacobs"; Data = "24 dez. 1999"; Resumo = "This specification defines the version 4.01 of the HyperText Markup Language (HTML). In addition to the text, multimedia, and hyperlink features of the previous versions of HTML, HTML 4 supports more multimedia options, scripting languages, style sheets, better printing facilities, and documents that are more accessible to users with disabilities"; Tipo = "Recomendação da W3C"; Local $=\varnothing ;$ ISBN $=\varnothing ;$ Editora $=\varnothing ;$ Periódico $=\varnothing ;$ Congresso $=\varnothing ;$ Edição $=\varnothing ; U R L=$ "http $: / /$ www.w3 . org/TR/html4"; ÚltimoAcesso = “12 abr. 2002” >

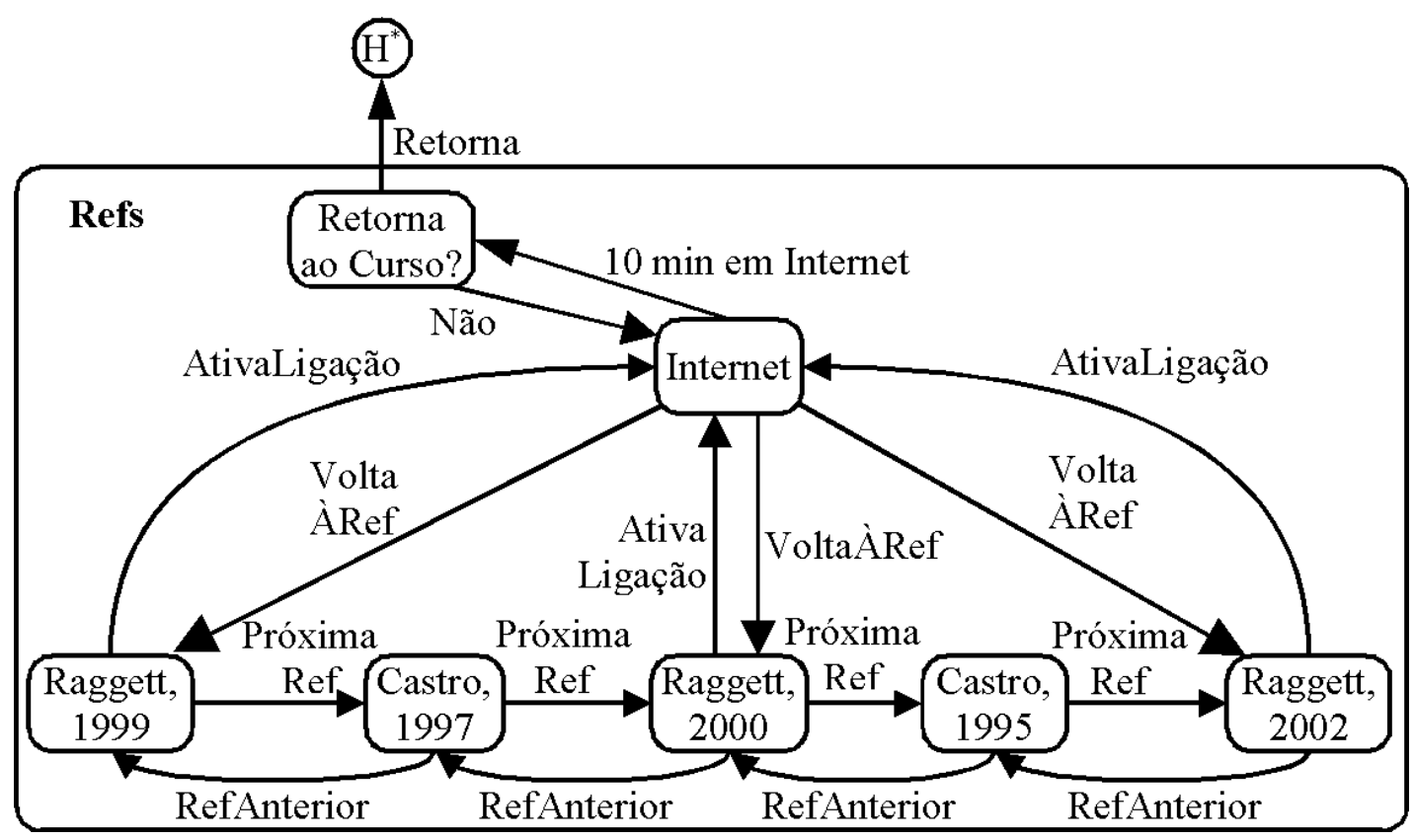

Figura 4.15: Statechart das referências do Curso de HTML

Para as Avaliações representadas nas Figuras 4.10, 4.12 e 4.14, foram definidas as condições:

$$
\begin{aligned}
C_{1}= & \left(a_{\text {Componentes básicos }}>1\right) \wedge\left(a_{\text {Formatação de textos }}>0\right) \wedge\left(a_{\text {Ligações }}>0\right) \\
C_{\text {Ptos }}= & a_{\text {Pontos de chegada }}>0 \\
C_{2}= & \left\{\left(\left(a_{\text {Atributos gerais }} \geqslant 2\right) \wedge\left(a_{\text {Cabeçalhos }}>0\right) \wedge\left(a_{\text {Separadores }}>0\right) \wedge\left(a_{\text {Listas }}>0\right) \wedge\right.\right. \\
& \left(a_{\text {Blocos }}>0\right) \wedge\left(a_{\text {Frases }} \geqslant 1\right) \wedge\left(a_{\text {Caracteres especiais }}>0\right) \wedge\left(a_{\text {Cores e fontes }}>1\right) \wedge \\
& \left.\left.\left(a_{\text {Caminho relativo }}>0\right) \wedge\left(a_{\text {Caminho absoluto }}>0\right) \wedge\left(a_{\text {Pontos de chegada }}>2\right)\right)\right\} \\
& \bigvee \\
& \left(\left(a_{\text {Atributos gerais }} \geqslant 1\right) \wedge\left(a_{\text {Cabeçalhos }}>0\right) \wedge\left(a_{\text {Separadores }}>0\right) \wedge\left(a_{\text {Listas }}>0\right) \wedge\right. \\
& \left.\left.\left(a_{\text {Caminho relativo }}>1\right) \wedge\left(a_{\text {Frases }}>0\right) \wedge\left(a_{\text {Caminho absoluto }}>0\right) \wedge\left(a_{\text {Pontos de chegada }}>1\right)\right)\right\}
\end{aligned}
$$


A condição $C_{1}$ é descrita pela Equação 4.6 e é utilizada para determinar a UE inicial para o aprendiz (como indicado na Figura 4.9). Essa equação especifica que o aprendiz precisa ter obtido pontuação maior do que 1 nas questões relativas ao conceito "Componentes Básicos", para ser dispensado de estudar a UE correspondente; senão, o aprendiz deve iniciar o estudo do Curso sobre HTML pela primeira UE. Se o número de acertos relativos ao conceito Componentes Básicos for maior que 1 e se o aprendiz acertou pelo menos uma questão sobre Formatação de Textos, então ele pode iniciar o estudo pela terceira UE. Analogamente, se tiver acertado também pelo menos uma questão relativa ao conceito "Ligações", ele é liberado para fazer a AS. Genericamente, o aprendiz é encaminhado para iniciar o curso a partir da UE na qual não obteve a pontuação mínima exigida.

A condição de aprovação na Avaliação Somativa $\left(C_{2}\right)$ é representada, matematicamente, pela Equação 4.8 (Figura 4.9). $C_{2}$ é estipulada em termos de duas combinações de pontuações mínimas relativas a diferentes conceitos, possivelmente porque o instrutor supõe que os acertos em alguns Tópicos compensam erros em outros.

A Equação 4.7 indica a condição $C_{P t o s}$ (statechart da Figura 4.11) imposta para que o aprendiz obtenha um resultado satisfatório na Avaliação Formativa sobre o Tópico Pontos de Chegada. Ele deve acertar pelo menos uma questão nesta Avaliação.

\subsection{Considerações Finais}

Neste capítulo foi apresentado um modelo para autoria e navegação de hiperdocumentos didáticos, denominado MDE e baseado no HMBS. As principais características do MDE são o apoio à avaliação contínua, a associação de conceitos ao conteúdo didático e às questões, a flexibilidade na elaboração das condições, e o controle de acesso a páginas do curso durante a navegação de aprendizes. No próximo capítulo será descrito o sistema ATEnA, implementado nesta tese. 


\section{ATEnA: um WIS para apoio ao EaD}

\subsection{Considerações Iniciais}

Para validar o modelo descrito no Capítulo anterior, foi implementado o protótipo de um sistema de administração de cursos a distância, denominado ATEnA (Ambiente de Treinamento, Ensino e Aprendizagem ou Adaptive Training Environment with Support for Assessment) e caracterizado como um WIS - Sistema de Informação na Teia ou Web Information System (Isakowitz \& Bieber, 1998) — para apoio ao Ensino a Distância (EaD). Ele foi desenvolvido com o objetivo principal de testar a aplicabilidade do MDE quanto à especificação e exibição de conteúdo educacional em sistemas de EaD.

O Capítulo está organizado da seguinte forma: a arquitetura do ATEnA é descrita na próxima Seção. Os modelos de classes são exibidos na Seção 5.3. A implementação, incluindo suas restrições, é apresentada na Seção 5.4. A interface com o usuário é ilustrada na Seção 5.5 por meio de um curso criado usando os recursos do sistema. As considerações finais sobre o ATEnA são incluídas na Seção 5.6.

\subsection{Projeto da Arquitetura}

Nesta tese, arquitetura refere-se à estrutura em alto nível de subsistemas e componentes, mais suas interfaces, conexões e interações. Todos estes elementos têm o objetivo de realizar as funções do sistema (Larman, 1997) e são especificados em um projeto arquitetural que separa um programa em um conjunto de módulos componentes.

A arquitetura do ATEnA é dividida em três camadas: apresentação (janelas, relatórios e outros elementos da interface com o usuário), aplicação (funções semânticas, tarefas e regras que direcionam o comportamento do sistema) e armazenamento (mecanismo persistente de armazenamento). A camada de aplicação foi desenvolvida em programas PHP que se conectam a um servidor Apache de WWW (Figura 5.1). Para armazenar os dados, são utilizadas tabelas MySQL. JavaScript é utilizado para verificar a consistência de alguns dados de entrada obtidos, na camada de apresentação, por meio de navegadores Web instalados nas máquinas clientes distribuídas. Devido à aplicação ser processada principalmente no servidor, esta arquitetura é caracterizada como cliente-leve (thin client) (Casagrande, 2001; Conallen, 1999). 


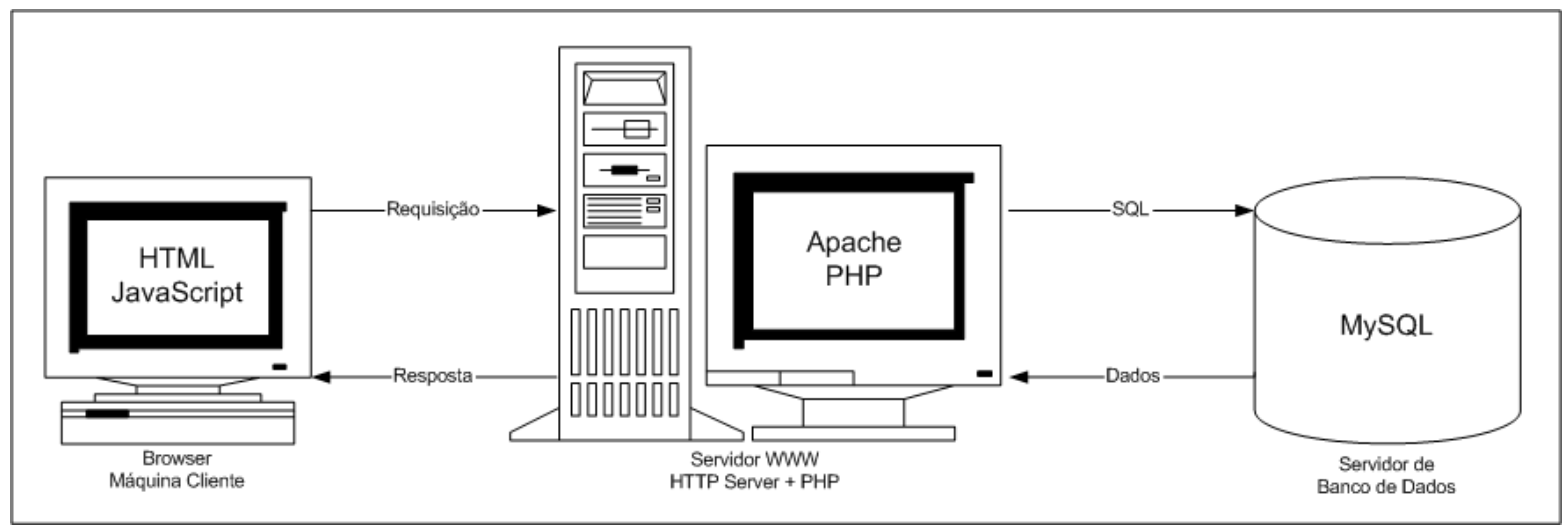

Figura 5.1: Arquitetura física do ATEnA

O projeto arquitetural do ATEnA (Figura 5.2) equivale a um nível mais abstrato da arquitetura física acima, mostrando como os tipos de usuários (autor, administradores acadêmicos, usuário genérico, candidato, instrutor e aprendiz) interagem com os módulos lógicos (autoria, administração e ensino) e com as subcamadas persistentes (estrutura e conteúdo, usuários, processos, atividades dos aprendizes).

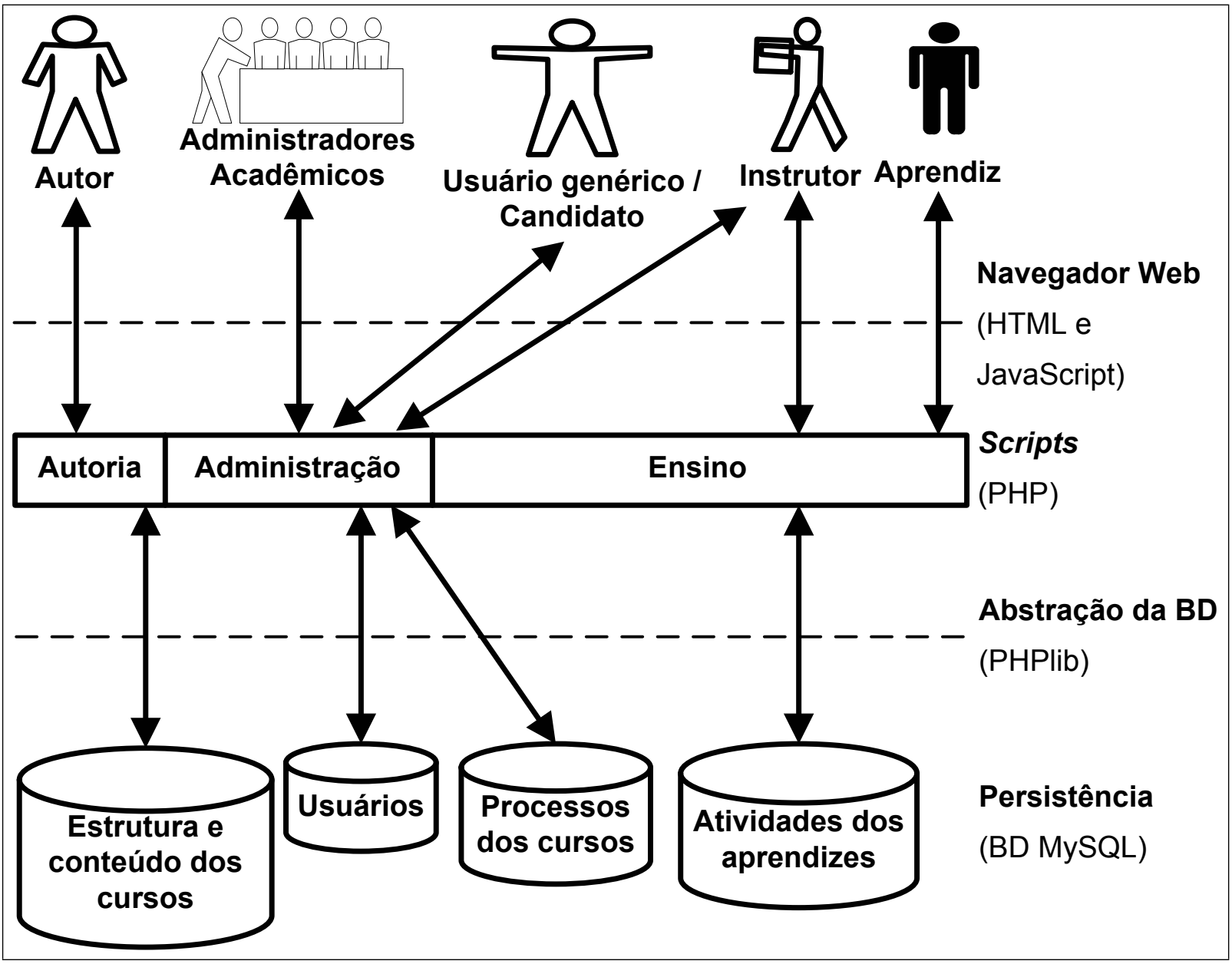

Figura 5.2: Arquitetura funcional do ATEnA 
Há cinco subtipos de administradores acadêmicos: Assistente Acadêmico, Chefe de Departamento, Diretor de Unidade, Presidente da CCEx (Comissão de Cultura e Extensão Universitária) e Pró-reitor de Cultura e Extensão. Considerando que os papéis de autor e instrutor são tipicamente, ainda que não necessariamente, exercidos pela mesma pessoa, a qual atua nos três módulos, são definidas na Tabela 5.1 as ações realizadas por estes papéis tanto em cursos presenciais quanto em cursos a distância. Nos cursos presenciais o material didático disponibilizado no ATEnA serve como referência ou complemento para o curso presencial, enquanto nos cursos a distância esse material é o conteúdo principal. Embora as ações sejam as mesmas em ambos os tipos de curso, elas são geralmente usadas de maneira distinta. Por exemplo, nos cursos presenciais, as inscrições são de fato realizadas na instituição que oferecerá o curso e, portanto, já foram aprovadas fora do ATEnA; entretanto, como é necessário incluir os aprendizes no sistema, os candidatos são automaticamente aprovados no ATEnA. Além disso, em cursos a distância, as freqüências podem ser definidas, por exemplo, com base na entrega de trabalhos, ao passo que em cursos presenciais elas são calculadas pelo instrutor e transcritas para o ATEnA. Nas próximas subseções são detalhados os módulos lógicos do ATEnA.

\begin{tabular}{|l|l|l|}
\hline \multicolumn{1}{|c|}{ Ações } & Autor & Instrutor \\
\hline Editar mapa conceitual & & \\
\hline Criar estrutura e conteúdo & & \\
\hline Editar questões e avaliações & & \\
\hline Associar mapa conceitual à estrutura & & \\
\hline Associar estrutura e conteúdo a curso & & \\
\hline Propor curso & & \\
\hline Navegar pelo conteúdo do curso & & \\
\hline Editar calendário de aulas e de avaliações & & \\
\hline Aprovar inscrições & & \\
\hline Atribuir notas e freqüências & & \\
\hline Consultar relatórios & & \\
\hline
\end{tabular}

Tabela 5.1: Ações do autor e do instrutor

\subsubsection{Administração}

Os papéis envolvidos na administração de cursos de extensão são: Assistente Acadêmico, Chefe do Departamento, Presidente da CCEx, Pró-reitor de Cultura e Extensão, Diretor de Unidade, Autor, Instrutor, Candidato a curso, e Usuário Genérico. As funções semânticas disponíveis para cada papel são as seguintes:

Assistente Acadêmico: cria, atualiza e exclui Unidades, Departamentos e usuários (exceto candidatos e aprendizes); autoriza docentes; abre e arquiva processos;

Chefe Departamental, Presidente da CCEx e Pró-reitor: aprovam cursos; 
Diretor da Unidade: encaminha cursos;

Autor: solicita sua inclusão no ATEnA;

Instrutor: solicita sua inclusão no ATEnA; edita propostas de cursos; aprova inscrições; atribui notas; calcula freqüências;

Candidato: inscreve-se em cursos; e

Usuário Genérico: obtém informações sobre cursos e inscrições; consulta candidatos com inscrição aprovada.

O módulo de administração, que gerencia especificamente o componente burocrático do oferecimento de cursos a distância, é resultado de um trabalho de Mestrado (Casagrande, 2001) e foi construído para apoiar o aspecto burocrático do oferecimento de cursos de extensão na USP. Além de gerenciar cursos, departamentos, unidades, instrutores, aprendizes, funcionários etc., ele também inclui elaboração das propostas de cursos, processo de aprovação dos cursos, inscrições e aprovações dos candidatos, e acompanhamento da frequiência e dos resultados das avaliações dos aprendizes para posterior certificação. A integração deste módulo ao servidor de cursos possibilita, tecnicamente, que um curso de extensão seja ministrado pela Web.

O fluxo de trabalho inicia-se pela proposta do curso, elaborada pelo instrutor responsável pelo curso. Ele preenche um formulário no ATEnA, informando os dados gerais do curso e quem irá ministrá-lo. É possível que um curso seja ministrado por até quatro instrutores e que o conteúdo didático de outro curso seja incluído no curso proposto; além disso, mais de um autor pode editar o conteúdo e a estrutura do mesmo curso. Essa proposta é encaminhada ao Assistente Acadêmico, que abre um processo para registrar o curso. Ela é, então, submetida à aprovação do Conselho Departamental e da CCEx da Unidade. Caso a proposta seja aprovada nas duas instâncias, são abertas as inscrições no ATEnA.

Os interessados em participar do curso podem acessar o formulário de inscrição, preenchê-lo e encaminhá-lo para aprovação. O instrutor responsável recebe esses pedidos, avalia as informações fornecidas e verifica se o candidato interessado atende aos pré-requisitos exigidos pelo curso, caso existam, e então aprova ou não a sua solicitação. Quando a inscrição de uma pessoa é aprovada, ela deixa de assumir o papel de candidato e passa a assumir o papel de aprendiz. Para isso, recebe uma identificação e uma senha de acesso que são atribuídas pelo instrutor. Se o curso não possuir nenhum pré-requisito ou se o instrutor não aprovar os candidatos até uma data-limite, os pedidos de inscrição são aceitos conforme a ordem de chegada até que todas as vagas tenham sido preenchidas. Ao término dessa atividade, é divulgada no ATEnA a lista de candidatos aprovados.

Ao término do curso, o instrutor envia as médias e as freqüências finais para a Diretoria da Unidade. Em seguida, o Diretor encaminha à Pró-Reitoria de Cultura e Extensão Universitária o demonstrativo do aproveitamento obtido pelos aprendizes e solicita autorização para a emissão 
dos certificados. O Pró-Reitor avalia essa solicitação e encaminha o processo à Assistência Acadêmica com a autorização para a emissão dos certificados. Após a emissão de certificados, não realizada pelo ATEnA, o Assistente Acadêmico reencaminha o processo à Pró-Reitoria para conhecimento do Conselho de Cultura e Extensão Universitária (CoCEx). Estando ciente, o CoCEx devolve o processo ao Assistente Acadêmico, que irá arquivá-lo.

\subsubsection{Autoria}

O autor define a estrutura básica de um Curso, associando-a ao conteúdo. Qualquer mídia é aceita, desde que exista um arquivo HTML associado a cada Tópico, UE e Curso. Outra restrição é a impossibilidade de acrescentar novos arquivos após a criação da estrutura e conteúdo, a não ser que sejam incluídos, fora do ATEnA, pelo administrador do servidor Web. Antes de incluir a estrutura para um curso, no entanto, é necessário que seu respectivo mapa conceitual já tenha sido criado no ATEnA e esteja associado ao curso. O autor desse mapa não precisa ser o mesmo autor da estrutura. Para evitar alterações no mapa quando já existem estrutura e conteúdo baseados nele, o sistema impede a edição de mapas associados a cursos.

Questões relativas aos conceitos abordados no Curso também podem ser criadas e editadas. Com base nelas, são elaboradas as avaliações, de forma automática ou manual. Na avaliação manual o autor escolhe as questões a partir de uma lista, enquanto na avaliação automática ele apenas especifica a quantidade de questões sobre cada conceito, por nível de dificuldade, cabendo ao sistema selecionar dinamicamente entre as questões da lista as que comporão a avaliação. Não se exige que o autor das questões seja o mesmo autor da avaliação.

Para verificar a estrutura e o conteúdo, o autor pode navegar seqüencialmente pelos cursos que criou, a partir da Avaliação Diagnóstica ou (se esta não existir) a partir do primeiro Tópico. Não é possível o acesso isolado, não seqüencial, a uma página do curso — por exemplo, Tópico ou Avaliação. Quanto ao mapa conceitual, ele é editado por meio de formulários e exibido graficamente logo após a sua criação ou alteração.

\subsubsection{Ensino}

Este módulo corresponde ao oferecimento de cursos criados no módulo anterior. Os papéis presentes aqui são o de instrutor e de aprendiz. Usuários genéricos não interagem com este módulo porque acessam apenas informações públicas. Quando um candidato tem seu pedido de inscrição aceito, ele assume o papel de aprendiz e pode começar a estudar o curso, cujo conteúdo lhe é apresentado de uma forma controlada e adaptada ao seu conhecimento dos conceitos abordados; por exemplo, se existir a AD, o aprendiz pode ser dispensado de estudar uma ou mais UEs, caso ela indique que ele já domina os conceitos associados à(s) UE(s). Além disso, ele pode consultar Tópicos já estudados, bem como obter o resultado da Avaliação imediatamente após respondê-la. 
O instrutor pode ser avisado, por e-mail, quando um aprendiz começa a ler um Tópico ou a responder uma Avaliação; pode também obter relatórios sobre o estágio de estudo do aprendiz, classificados por aprendiz ou curso. No primeiro caso são relatadas as notas e a duração de cada tentativa das Avaliações, a UE inicial (conforme o desempenho na AD), os Tópicos estudados e revisados (incluindo número de sessões e sua duração) e o tempo de consulta às referências webliográficas. No relatório por curso, são informadas também as notas médias, bem como a duração média das avaliações, do estudo de cada Tópico e da consulta a cada referência.

\subsection{Modelos de Classes}

Foi definido inicialmente um modelo de classes para os módulos de autoria e ensino, usando a notação UML (Unified Modeling Language). Esse modelo (Figura 5.3) detalha a estrutura dos documentos didáticos, do Mapa Conceitual e das Avaliações. As classes localizadas à direita da figura, e demarcadas pela linha tracejada, pertencem ao módulo Ensino; as demais, ao módulo Autoria. Esta divisão é apenas de natureza didática, pois classes de diferentes módulos podem participar do mesmo relacionamento (por exemplo, Avaliação e Avaliação Realizada) e uma classe pode estar presente em mais de um módulo (como as classes Curso e Aprendiz, que estão nos módulos Administração e Ensino).

As classes relativas ao módulo administrativo, incluindo atributos do Curso, são apresentadas na Figura 5.4. Considerando que nesta tese enfatiza-se o ensino a distância e a autoria de hiperdocumentos educacionais, este módulo não será detalhado aqui. Mais informações sobre ele podem ser obtidas na dissertação de Casagrande (2001).

No módulo de Autoria, as classes podem ser separadas conceitualmente em quatro grupos:

Mapa conceitual: contém as classes Curso, Mapa Conceitual, Vértice e Conceito;

Estrutura do curso: Curso, Conteúdo, UE e Tópico;

Avaliação: Conteúdo, Avaliação, AD, AF, AS, AvalAuto, Questão, ValorQuestão, as subclasses de Questão e as classes agregadas a tipos de questão; e

Referências: Curso, Referências, Item Webliográfico e Item Bibliográfico.

No módulo de Ensino, os relatórios disponíveis ao instrutor baseiam-se em atributos persistentes (contidos nas classes Documento Consultado, Avaliação Realizada, Questão Respondida e Referência Consultada) ou em atributos derivados da comparação entre os aprendizes inscritos no mesmo curso. 


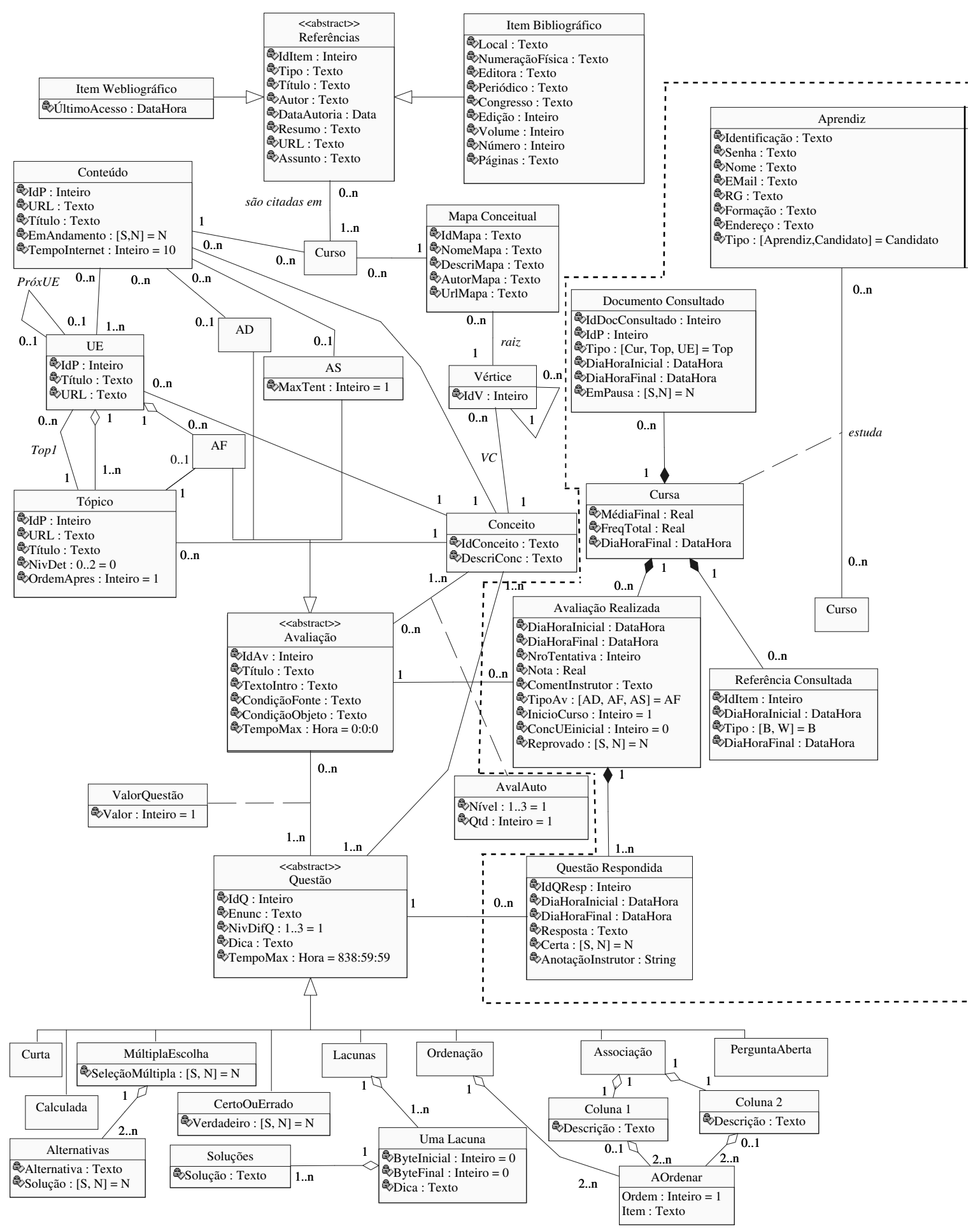

Figura 5.3: Classes dos Módulos Autoria e Ensino 


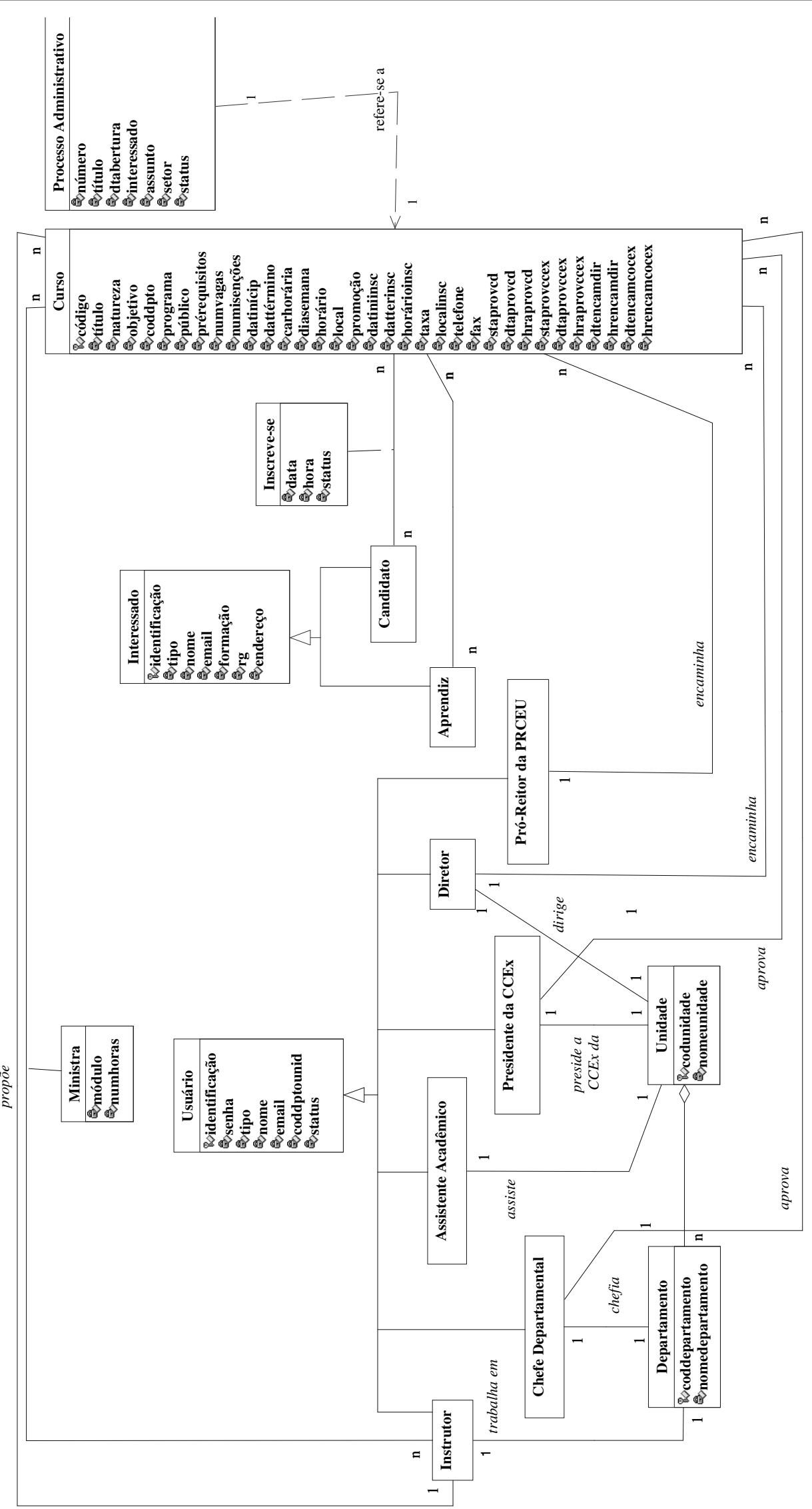

Figura 5.4: Classes do Módulo Administrativo, adaptadas de (Casagrande, 2001) 


\subsection{Implementação}

Conforme mencionado na Seção 5.2, o sistema foi desenvolvido em PHP, HTML, JavaScript e MySQL. A maior parte do código-fonte consiste em programas PHP que geram comandos em HTML e JavaScript; além disso, é a partir do PHP que se realiza o acesso às tabelas MySQL. $\mathrm{Na}$ Tabela 5.2 constam as quantidades de linhas de código dos programas PHP separadas por módulo, bem como a porcentagem do módulo em relação a todo o sistema. O termo "genérico" refere-se a código pertencente a mais de um módulo, ou a programas responsáveis pela entrada e saída dos usuários. As seguintes funcionalidades foram desenvolvidas por terceiros: envio de mensagens eletrônicas, validação de endereços eletrônicos, tratamento de strings, autenticação de usuários, e comunicação com a base de dados. Os dois últimos recursos são gerenciados pela biblioteca PHP Base Library ou, abreviadamente, PHPlib (PHPlib Group, 2002). Na contagem de linhas do PHPlib foram incluídos apenas os programas utilizados no ATEnA. O módulo administrativo foi implementado por Casagrande. Visando integrá-lo aos demais módulos, seu código-fonte passou por algumas pequenas modificações, principalmente quanto ao controle de acesso e à interface com a base de dados.

\begin{tabular}{|l|r|r|}
\hline \multicolumn{1}{|c|}{ Módulo } & Linhas de código & Porcentagem \\
\hline Autoria & 11.203 & $34,57 \%$ \\
\hline Ensino & 11.038 & $34,06 \%$ \\
\hline Administração & 4.506 & $13,91 \%$ \\
\hline PHPlib & 2.262 & $6,99 \%$ \\
\hline Outros & 1.888 & $5,83 \%$ \\
\hline Genérico & 1.503 & $4,64 \%$ \\
\hline Total & 32.400 & $100 \%$ \\
\hline
\end{tabular}

Tabela 5.2: Dados quantitativos dos programas PHP

Para exibir graficamente os mapas conceituais, foi usado o aplicativo dot do pacote graphviz - um conjunto de ferramentas para desenho de grafos (AT\&T, 2000). Após especificar o mapa conceitual na linguagem DOT (AT\&T, 2002), desenvolvida para descrever dígrafos textualmente na forma hierárquica, um programa PHP chama o dot para gerar o arquivo GIF do mapa a partir de um arquivo temporário que contém essa especificação.

\subsubsection{Restrições}

O protótipo implementado compreende os aspectos principais do modelo e pode ser utilizado para cursos-piloto, mas não é completo. Foi implementado, por exemplo, o apoio a apenas um tipo de questão - múltipla escolha. Também falta permitir que o instrutor anote comentários nas avaliações realizadas pelos aprendizes, o que será útil quando forem incluídas questões abertas e dissertativas. 
Embora seja possível reaproveitar a estrutura e o conteúdo completo de outro curso, não foram implementados o reuso individual de Tópicos e UEs, nem a inclusão do conteúdo parcial de um outro curso, com exceção de conceitos, mapa conceitual ou questões. Quanto às referências do curso, não há interface para a sua edição. Apesar disso, o ATEnA gera referências webliográficas a partir das URLs apontadas por ligações contidas em Tópicos e em UEs.

\subsection{Interface com o Usuário}

A seguir, serão exibidas algumas telas que exemplificam o uso de cada módulo.

\subsubsection{Acesso ao Sistema}

A tela principal do ATEnA, ilustrada na Figura 5.5, possui ligações que possibilitam acesso à tela de entrada - usada para identificar os usuários do sistema e propiciar o acesso ao mesmo — e a páginas públicas, que podem ser acessadas por usuários genéricos. A interface de opções é adaptada segundo o papel e certas pré-condições. O ATEnA não exibe ações semânticas cujo critério de execução não foi satisfeito.

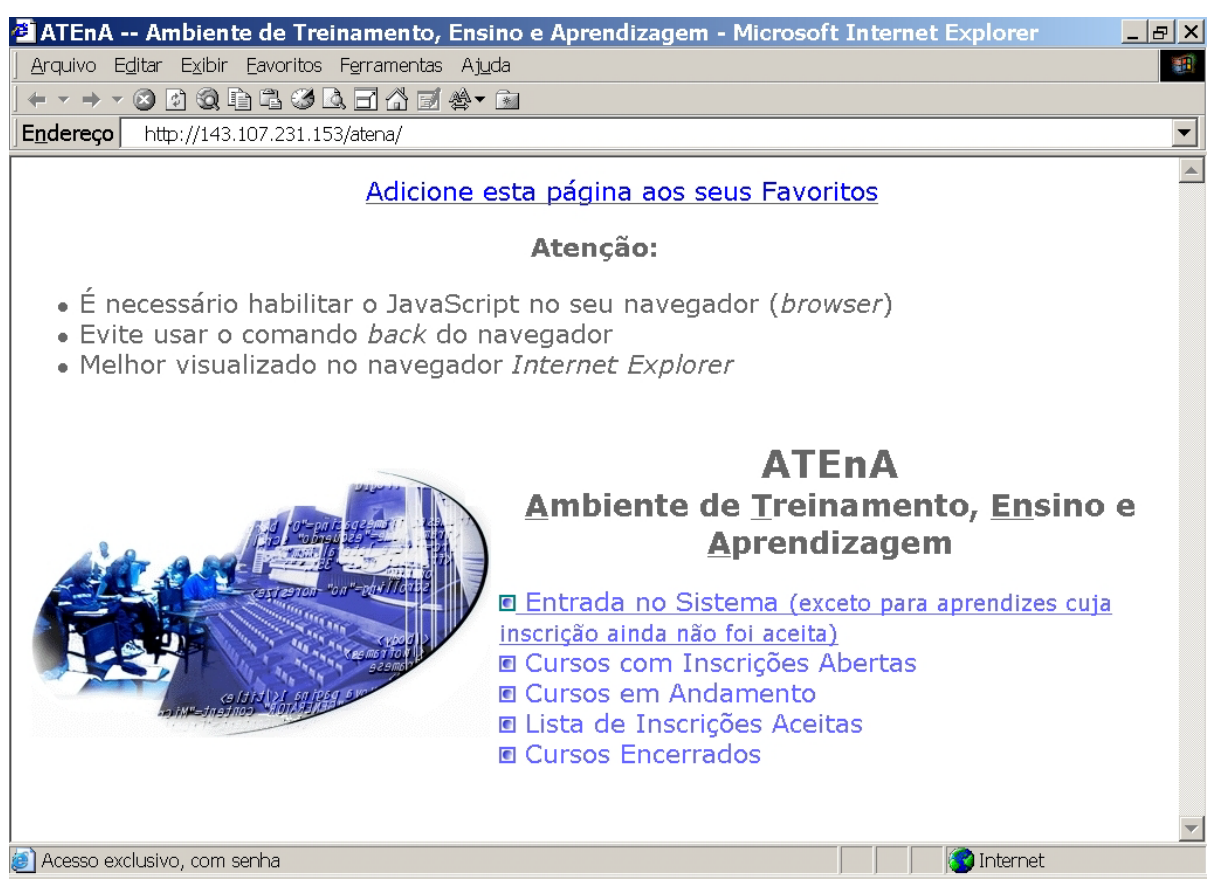

Figura 5.5: Tela principal do sistema ATEnA

A interface da Figura 5.6 é pública e é acessada pela ligação "Cursos Encerrados" da tela principal. Esta e as ligações "Cursos em Andamento", "Cursos com Inscrições Abertas" e "Lista de Inscrições Aceitas" são exibidas apenas quando um critério de seleção, baseado no estado dos cursos, for satisfeito. Se nenhum curso estiver no período de inscrição, o texto "Cursos com Inscrições Abertas" não constará da interface. Se nenhum curso estiver em andamento, não aparecerão as frases "Cursos em Andamento" e "Lista de Inscrições Aceitas". 


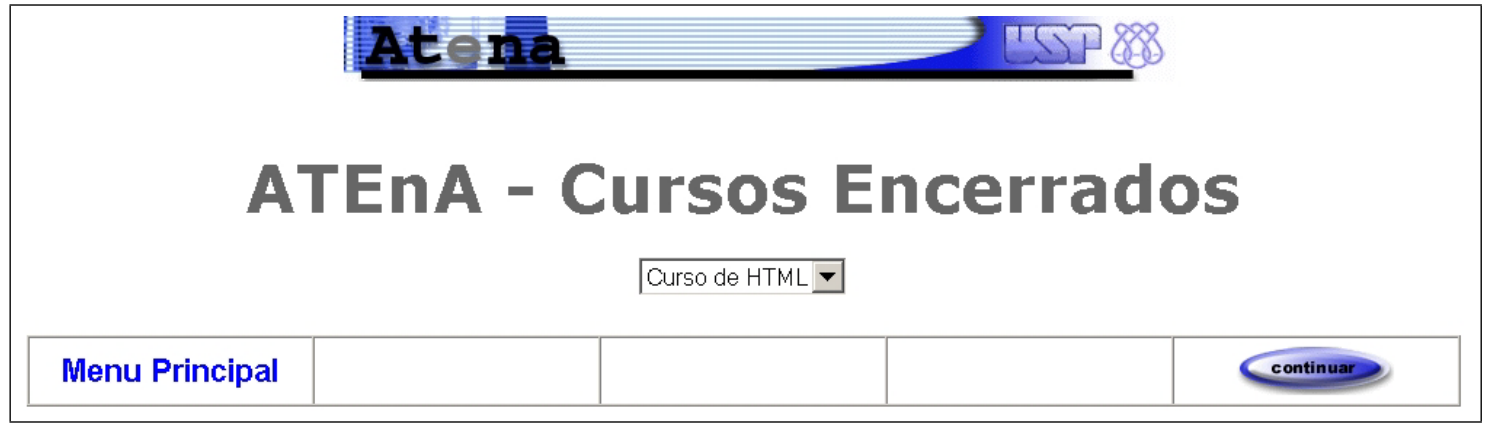

Figura 5.6: Lista de cursos encerrados

Ao selecionar um item da lista de cursos encerrados, é ativada uma página contendo informações sobre o curso escolhido (Figura 5.7), com uma opção para consultar informações sobre a inscrição (já concluída) neste curso. Para minimizar o tamanho da figura, não estão sendo exibidas as seguintes informações que constam da página: número de vagas e de isenções, data de início e de término, dias da semana, horário, carga horária total, local e promoção.

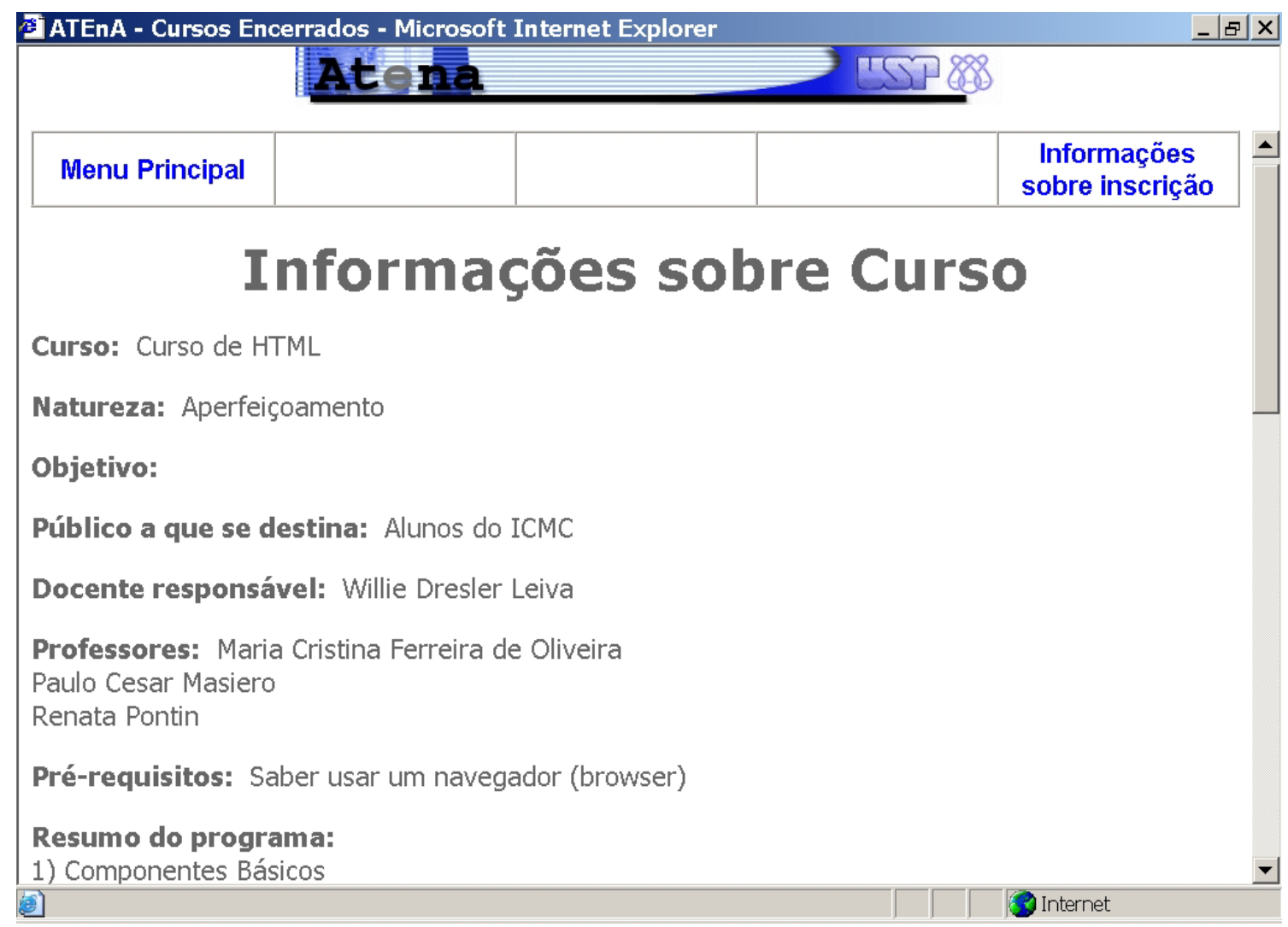

Figura 5.7: Exemplo de uma página com informações sobre curso

A partir da tela principal (Figura 5.5), acessa-se a tela de entrada no sistema. Assim como no AulaNet e no WebCT, os dados fornecidos na tela de entrada (identificação e senha) são utilizados para identificar o usuário, o seu perfil e o seu nível de acesso ao sistema. No ATEnA, quando o perfil do usuário é reconhecido, o ambiente relativo a esse perfil é ativado. $\mathrm{O}$ ambiente do Assistente Acadêmico, por exemplo, é apresentado na Figura 5.8. 


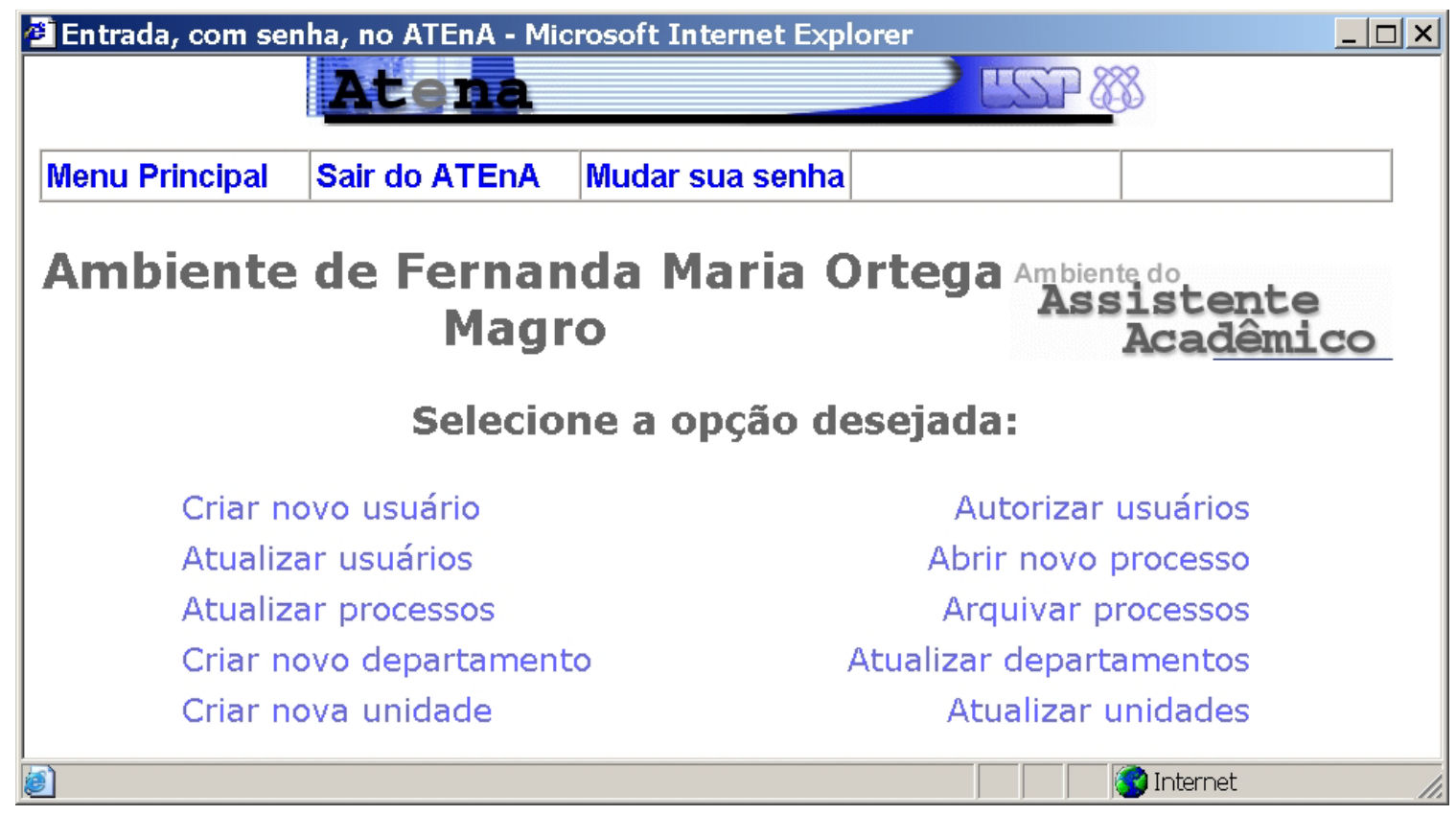

Figura 5.8: Ambiente do assistente acadêmico

\subsubsection{Administração}

Parte da funcionalidade do módulo administrativo foi descrita na subseção anterior, no que se refere às funções semânticas disponíveis aos usuários genéricos (ilustradas nas Figuras 5.6 e 5.7). Nesta subseção é detalhada uma atividade que está sob responsabilidade do autor, a proposta de cursos, pois ela está relacionada mais diretamente aos demais módulos do ATEnA.

O formulário para proposta de um novo curso é parcialmente exibido na Figura 5.9. Este formulário contém todos os campos referentes aos atributos apresentados na página com informações sobre o curso (Figura 5.7) e sobre inscrição, além de dois atributos cujos valores foram obtidos do módulo de autoria: o identificador do conteúdo (no caso, Curso de HTML) e do mapa conceitual. Neste exemplo é apresentada uma lista de mapas conceituais já criados, a partir da qual o autor escolherá apenas um para associar ao curso. Após submeter o formulário, o oferecimento do curso é criado e entra na lista de cursos cuja abertura de processos encontra-se pendente. Esta lista é gerenciada pelo Assistente Acadêmico a partir da ligação "Abrir novo processo" (Figura 5.8).

\subsubsection{Autoria}

Enquanto no módulo administrativo são registradas as informações sobre o oferecimento do curso, bem como as referências para sua estrutura e seu mapa conceitual, é no módulo de autoria que o mapa e a estrutura são de fato criados e editados. O primeiro passo deve ser o de especificar os dados gerais do mapa conceitual e os conceitos. O resultado do mapa conceitual do curso básico sobre HTML é mostrado na Figura 5.10. 


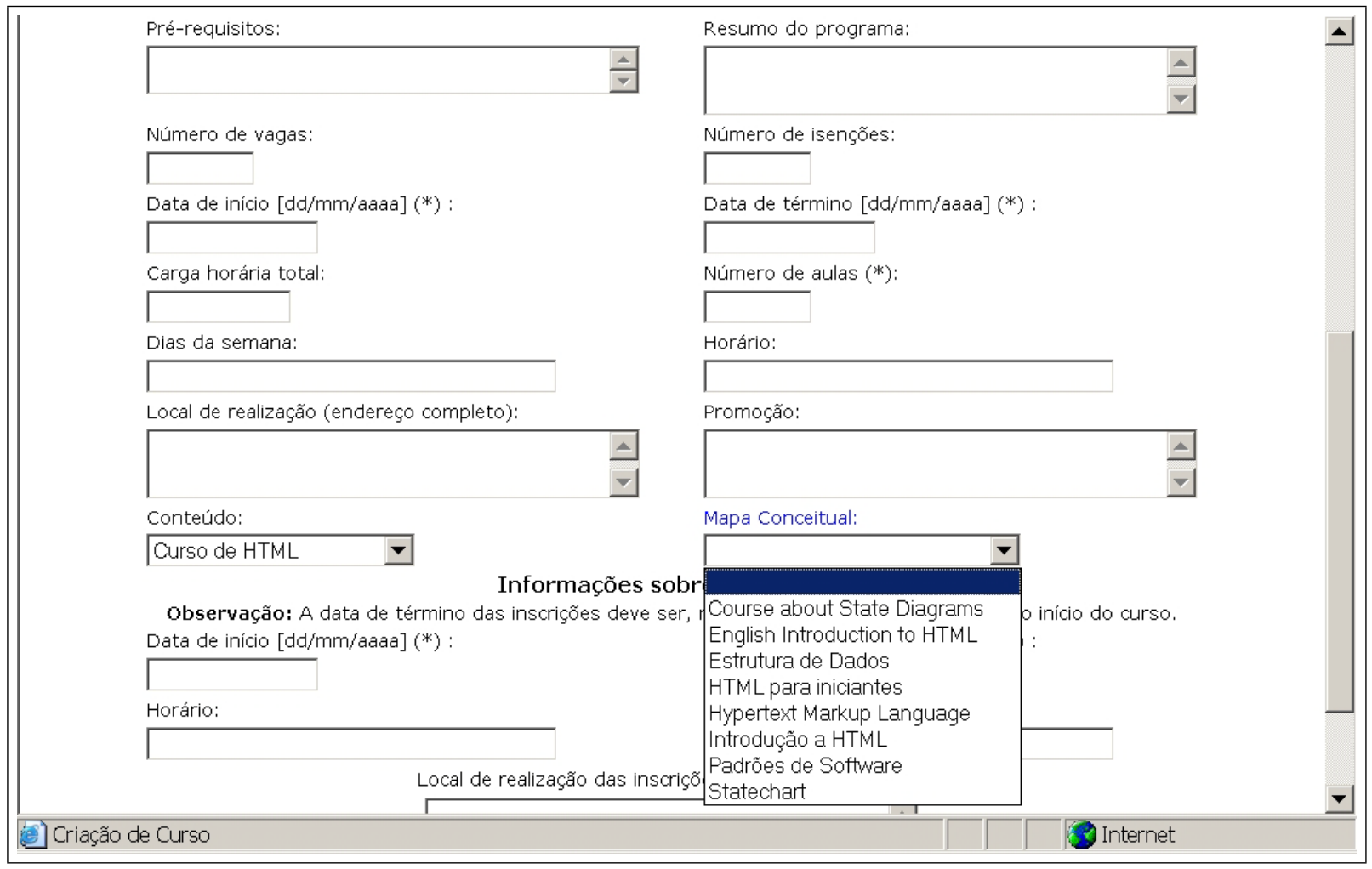

Figura 5.9: Formulário para proposta de novo curso

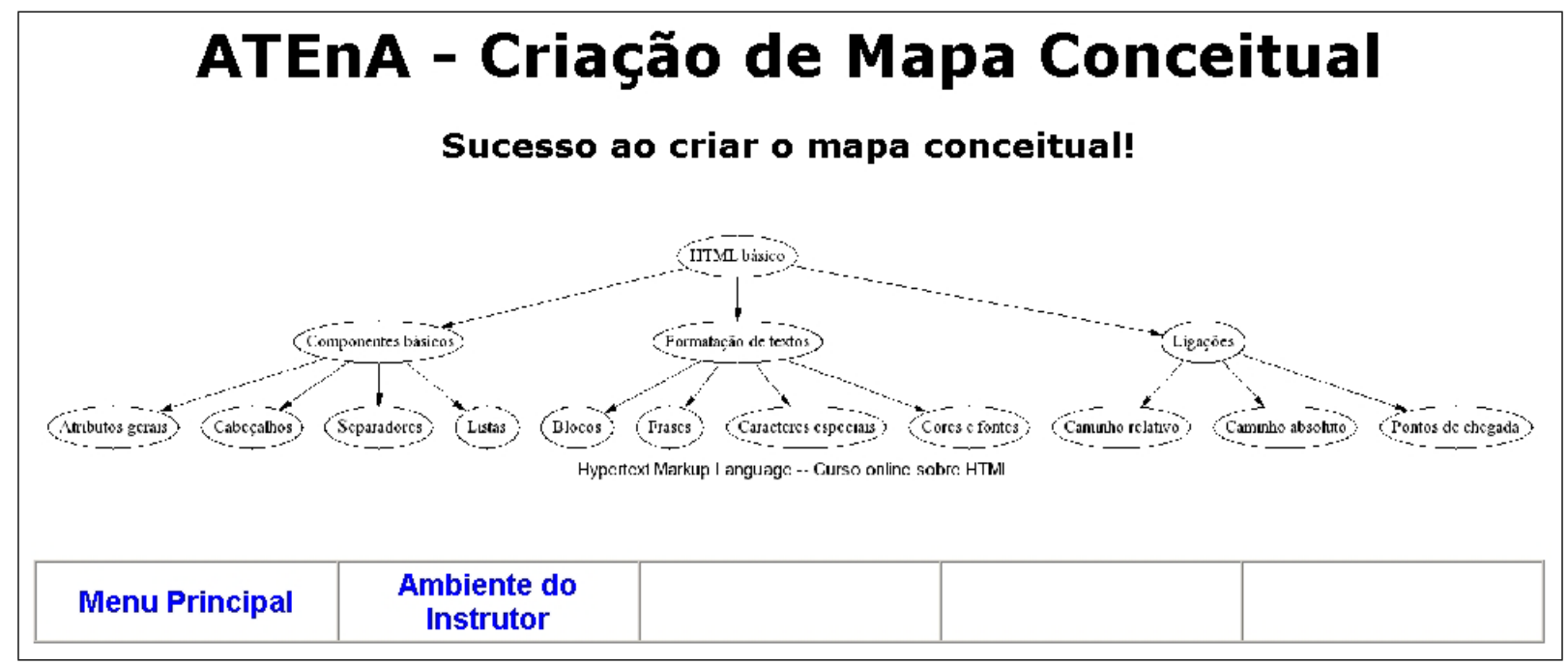

Figura 5.10: Visualização gráfica do Mapa Conceitual gerado automaticamente

Existindo no ATEnA pelo menos um mapa conceitual sobre o domínio de conhecimento abordado no curso, é possível associá-lo ao curso. O próximo passo consiste em definir o conteúdo das UEs e dos Tópicos, a partir de um arquivo com extensão zip que contém todo o material didático exceto as questões. A primeira tela deste passo é ilustrada na Figura 5.11. A estrutura é organizada logo em seguida, por meio de dois formulários HTML. 


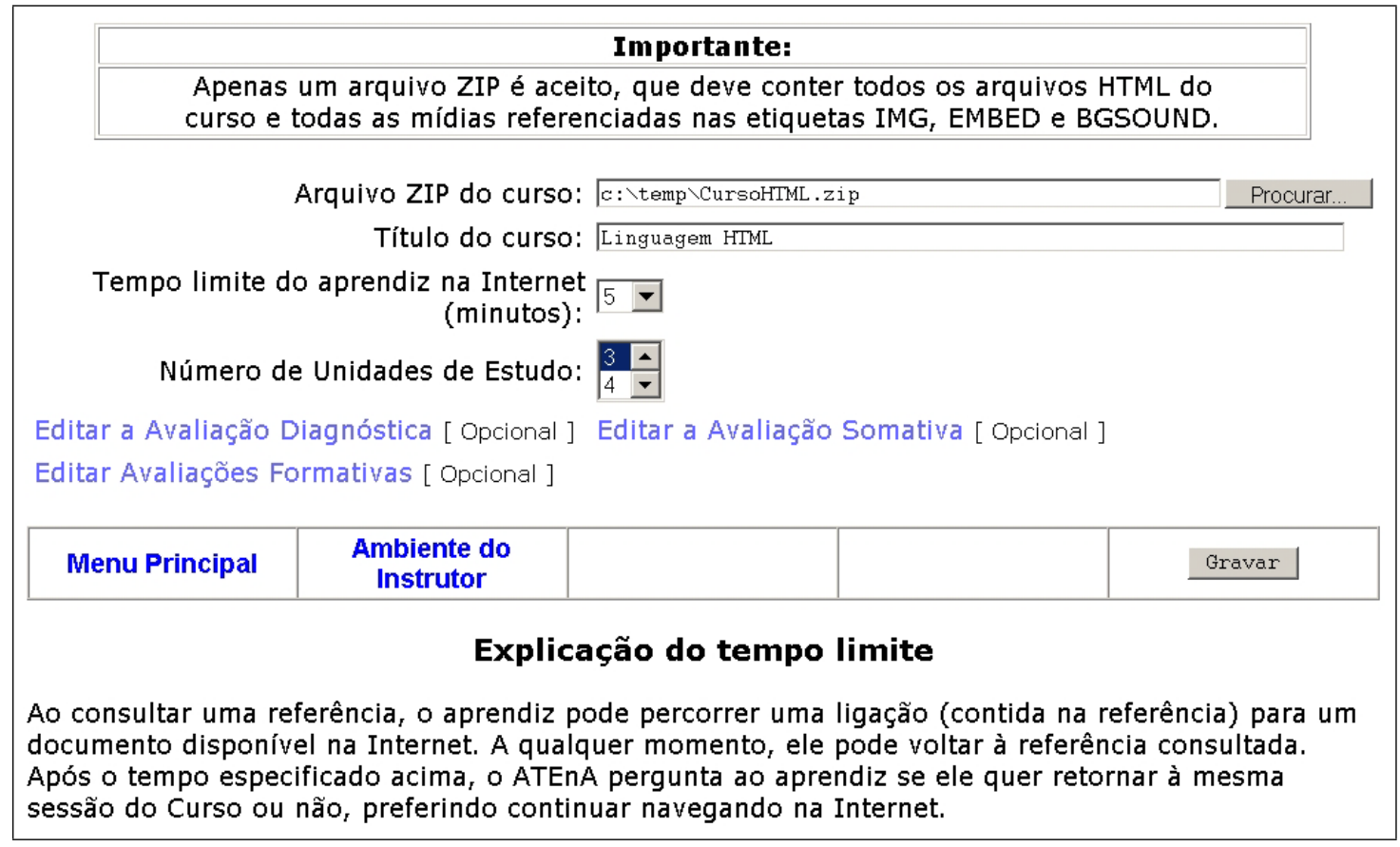

Figura 5.11: Inclusão dos principais dados do Curso

Se o autor quiser incluir avaliações no Curso, deve primeiramente criar as questões, cujos principais dados são solicitados pelo formulário ilustrado na Figura 5.12.

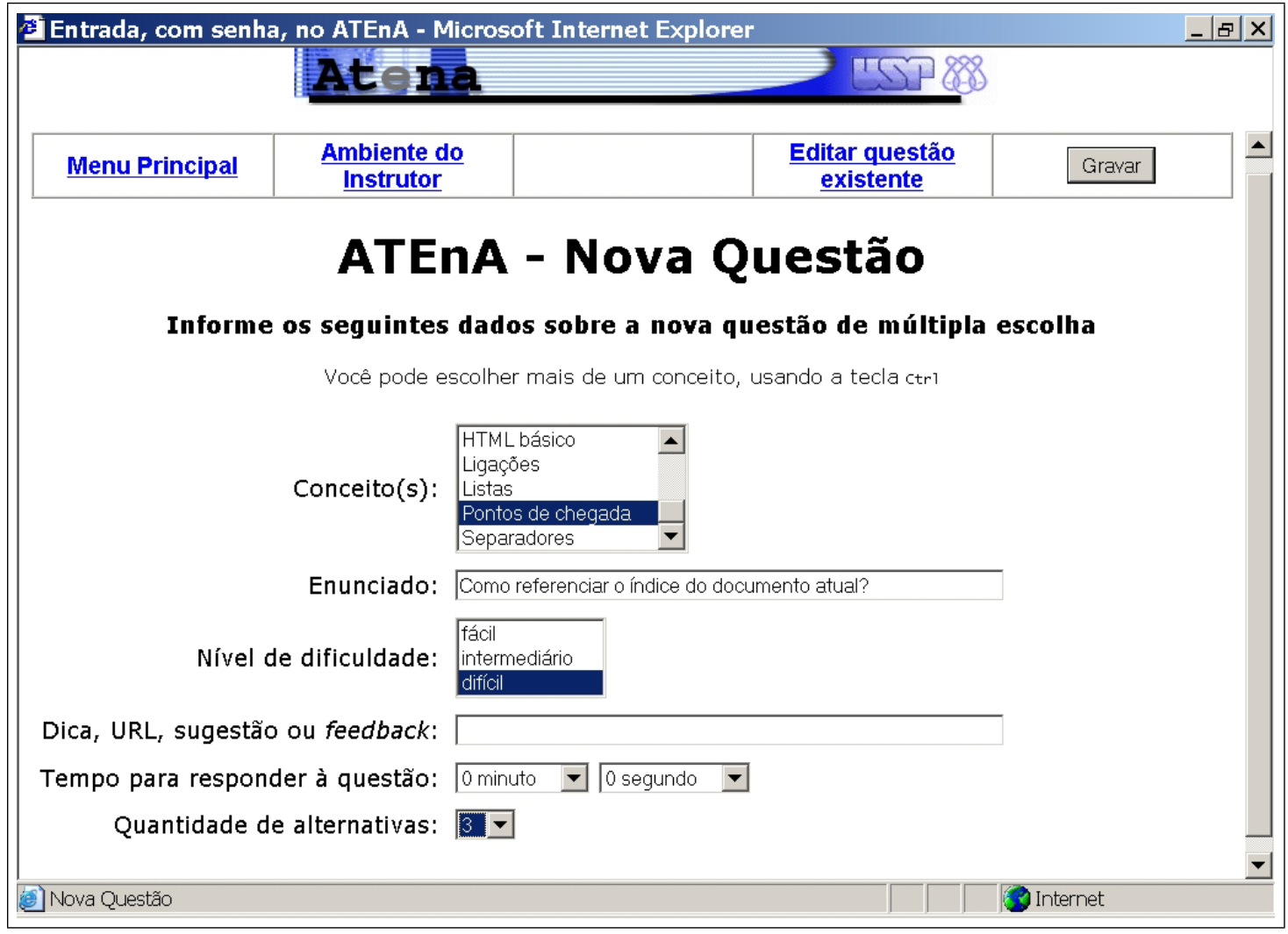

Figura 5.12: Entrada dos principais dados de uma questão 
$\mathrm{Na}$ Figura 5.13 é ilustrado o formulário que possibilita definir a condição da AD conforme a Equação 4.6. O formulário que possibilita escolher as questões da AF sobre o conceito "pontos de chegada", segundo a Figura 4.12, é exibido na Figura 5.14.

\section{Critério de aprovação nesta AD}

Para cada conceito, escolha um operador e uma nota

(o valor máximo da nota equivale ao número de questões por conceito):

Conceito
Componentes básicos
Formatação de textos
Ligações
Observação

Figura 5.13: Condição para aprovação na $A D$

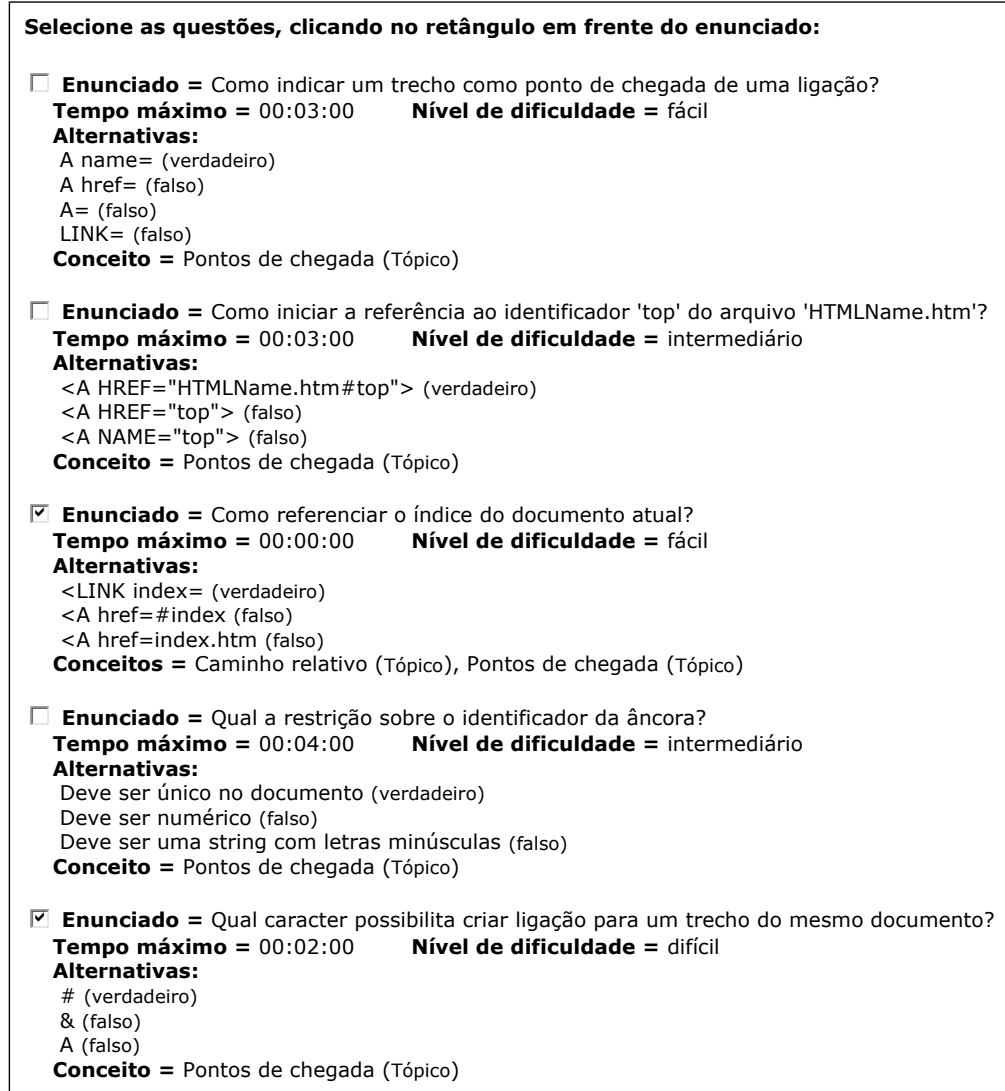

Figura 5.14: Questões sobre pontos de chegada

Uma possível expansão do statechart ilustrado na Figura 4.13, relativo à Avaliação Somativa sobre HTML, pode ser definida por meio do formulário apresentado na Figura 5.15. 


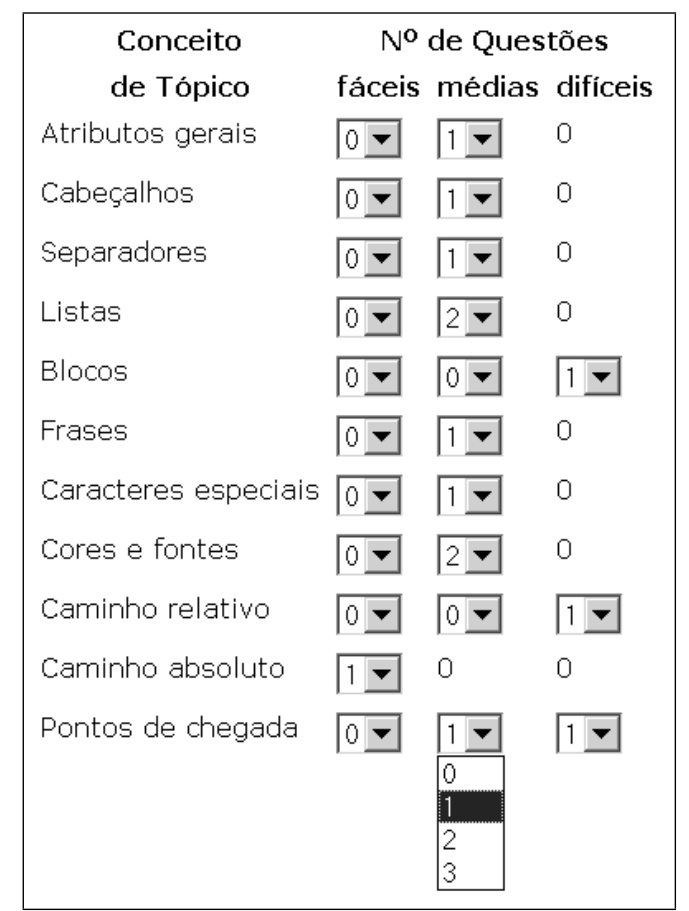

Figura 5.15: Elaboração automática da AS sobre HTML

\subsubsection{Ensino}

No ambiente do aprendiz, as duas únicas opções disponíveis são: inscrever-se em Curso e estudar curso. No primeiro acesso do aprendiz ao estudo de um curso, é exibida a Avaliação Diagnóstica (se o autor optou por incluí-la no curso) ou o primeiro Tópico (se não existir a AD). $\mathrm{Na}$ Figura 5.16 é ilustrada a interface inicial da AD sobre HTML. Cada botão, quando selecionado, exibe uma questão específica com prazo determinado para ser respondida (Figura 5.17).

\section{Avaliação Diagnóstica de HTML}

A avaliação diagnóstica permite detectar se você já conhece alguns conceitos tratados neste curso, podendo ser dispensado de cursar as Unidades de Estudo e Tópicos que apresentam esses conceitos

\section{$29 \quad \begin{array}{llll}70 & 26 & 76 & 44\end{array}$}

Figura 5.16: Interface inicial da AD sobre HTML

O desempenho na AD pode dispensar o aprendiz do estudo de uma ou mais UEs. Terminando a AD, o ATEnA informa em qual UE o aprendiz iniciará o estudo (Figura 5.18). É possível, até mesmo, que ele já esteja habilitado para responder à AS ou, se esta não existir, ele pode ser aprovado sem precisar estudar qualquer Tópico. Se o autor definiu que a condição associada à $\mathrm{AD}$ será sempre verdadeira, então os acertos não determinarão o posicionamento inicial do aprendiz no curso; neste caso, todos os aprendizes iniciarão o estudo pela primeira UE do curso. Na figura a mensagem de "Parabéns!" refere-se ao acerto do aprendiz na questão mais recentemente respondida que, neste caso, é a última questão da AD. Conforme a condição definida pelo instrutor, os acertos deste aprendiz o possibilitam a começar o estudo pela UE 3 . 


\section{ATEnA - Responda a seguinte questão:}

Após responder esta questão, selecione o identificador de outra questão

Você tem 1 minuto e 10 segundos para responder esta Questão.

$\mathrm{Na}$ barra de status desta janela, você pode verificar quanto tempo Ihe falta.

Enunciado: Qual etiqueta HTML insere uma ligação em um documento?

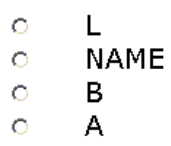

\section{7 8}

Você tem 43 segundos para responder esta Questão

Figura 5.17: Uma questão da AD sobre HTML

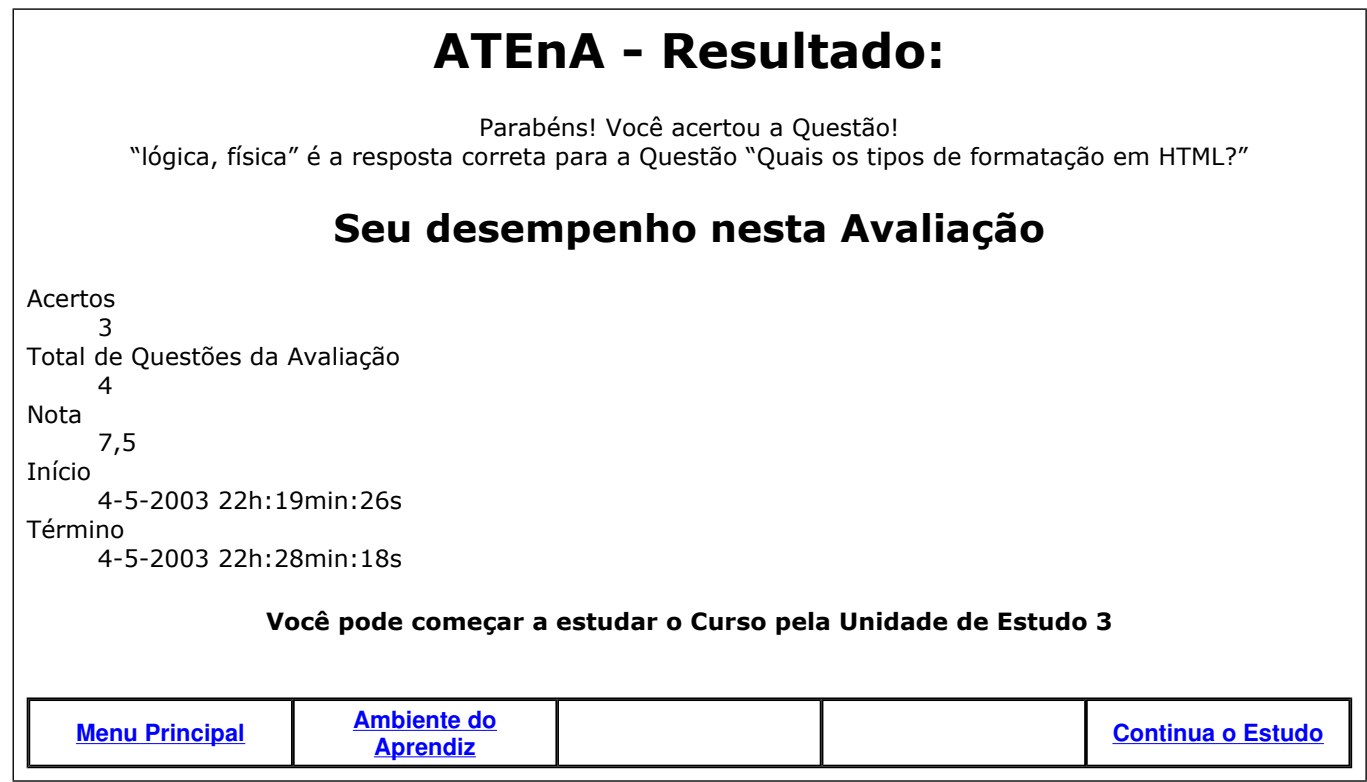

Figura 5.18: Desempenho de um aprendiz na AD sobre HTML

O início de um Tópico, incluindo suas ações semânticas, é exibido na Figura 5.19. Os nós coloridos do mapa conceitual indicam o posicionamento do aprendiz no Curso: o nó marrom destaca o conceito associado ao Tópico atualmente em estudo, enquanto o nó verde caracteriza o conceito referente à UE que contém esse Tópico. Além das ligações para o menu principal do ATEnA (Figura 5.5) e para o ambiente do aprendiz, há ligações para a página principal do curso e da UE atual. O aprendiz pode também interromper temporariamente o estudo; neste caso, quando ele voltar para o curso o sistema apresenta o Tópico no qual foi solicitada a pausa. Após estudar o Tópico, o aprendiz deve selecionar o texto "Tópico foi estudado" que dispara uma ligação para a $\mathrm{AF}$ correspondente ou, se esta não existir, para o próximo Tópico; se o Tópico estudado tiver sido o último do curso, e se não houver AF, é exibida a AS. Outra ação semântica, não ilustrada na figura, refere-se à possibilidade do aprendiz consultar um Tópico anterior e, depois, voltar ao Tópico mais recentemente estudado. 


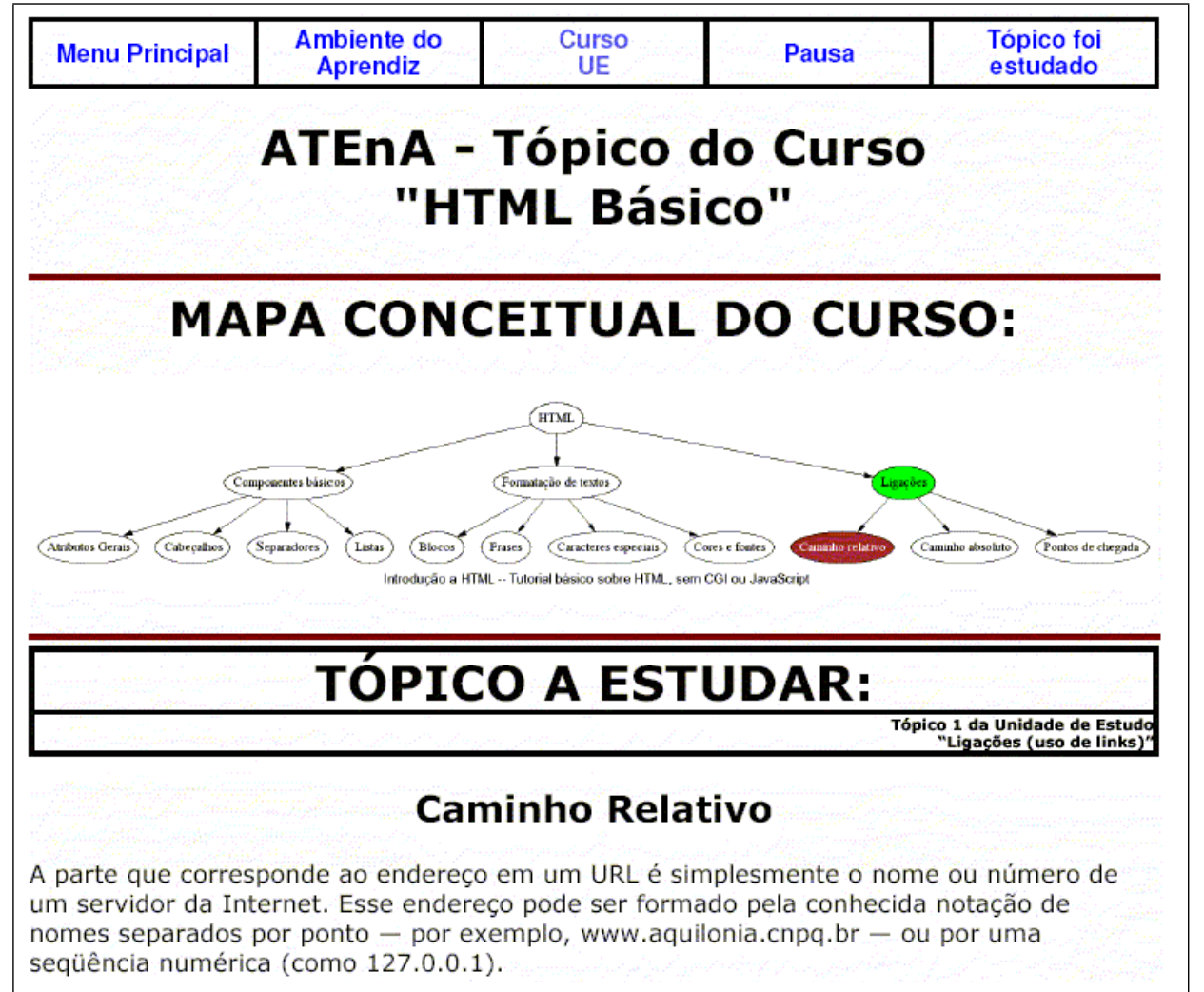

Figura 5.19: Início de um Tópico sobre HTML

$\mathrm{Na}$ Figura 5.20 (a) é ilustrado um tipo de avaliação cujo prazo de resposta não é estipulado por questão, mas segundo um limite de tempo para toda a avaliação; além disso, todas as questões são exibidas em uma única página. Independentemente do tipo da avaliação, quando o aprendiz solicita uma dica clicando no enunciado, esta é exibida em uma janela à parte. Em todas as avaliações, com exceção da $\mathrm{AD}$, é detalhado o desempenho do aprendiz, conforme a Figura 5.20 (b).

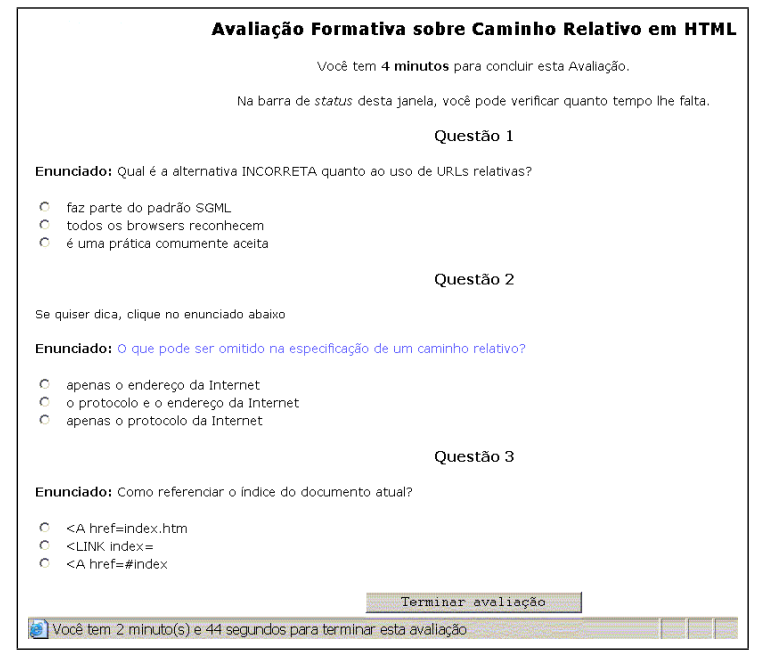

(a) Página com todas as questões da $\mathrm{AF}$

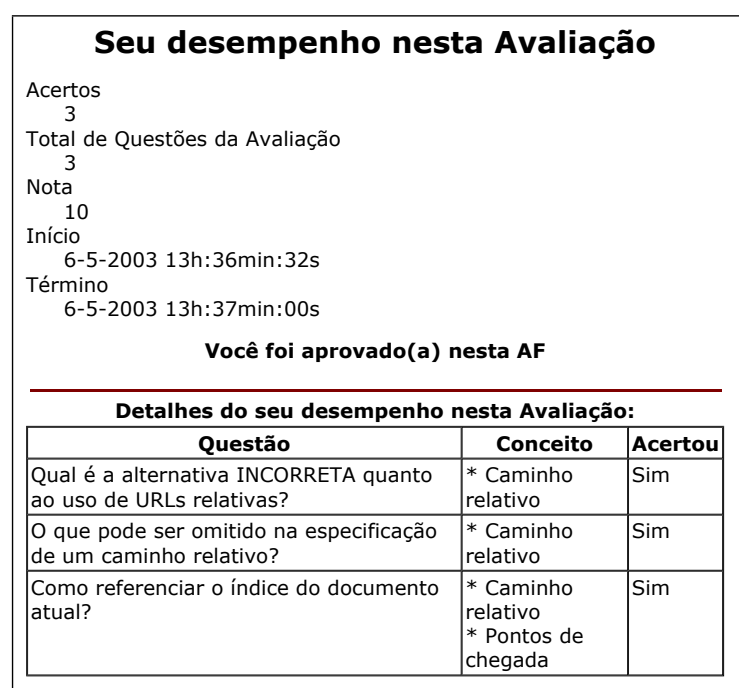

(b) Desempenho de um aprendiz na AF

Figura 5.20: Exibição de uma $A F$ ao aprendiz 
Se o instrutor criou uma ligação entre um Tópico e um Tópico avançado, como ilustrada na Figura 5.21 pela âncora Tópico sobre atributos básicos de imagens, o destino desta ligação pode ser visualizado como se fosse uma referência webliográfica do curso ou um outro Tópico. O primeiro caso ocorre se o aprendiz selecionar a ligação; neste exemplo, clicando na âncora citada, a parte final da página visualizada é mostrada como na Figura 5.22, A outra possibilidade é realizada quando o aprendiz percorre seqüencialmente os Tópicos deste curso até que o Tópico avançado seja exibido, conforme a Figura 5.23.

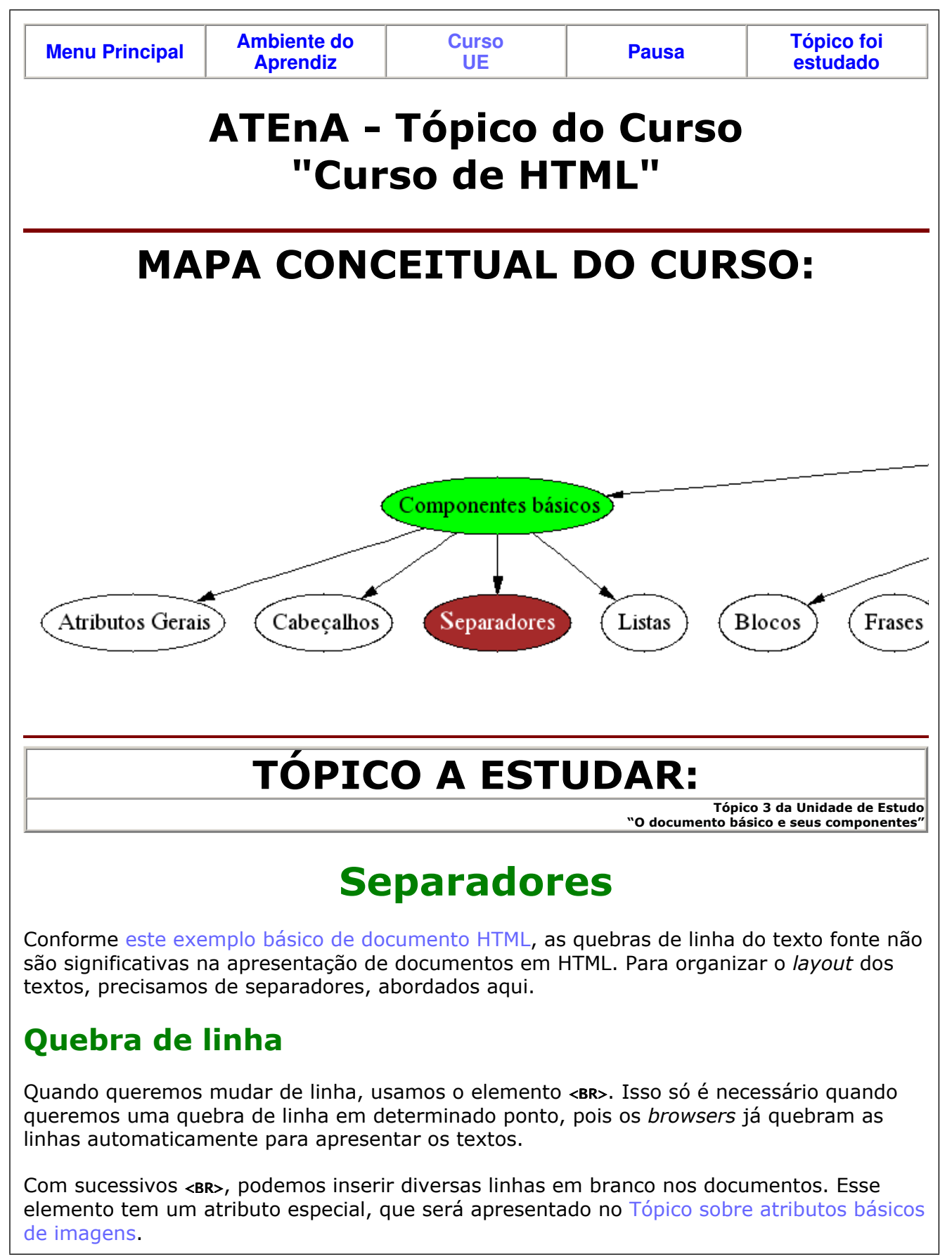

Figura 5.21: Tópico com ligação embutida para outro Tópico 


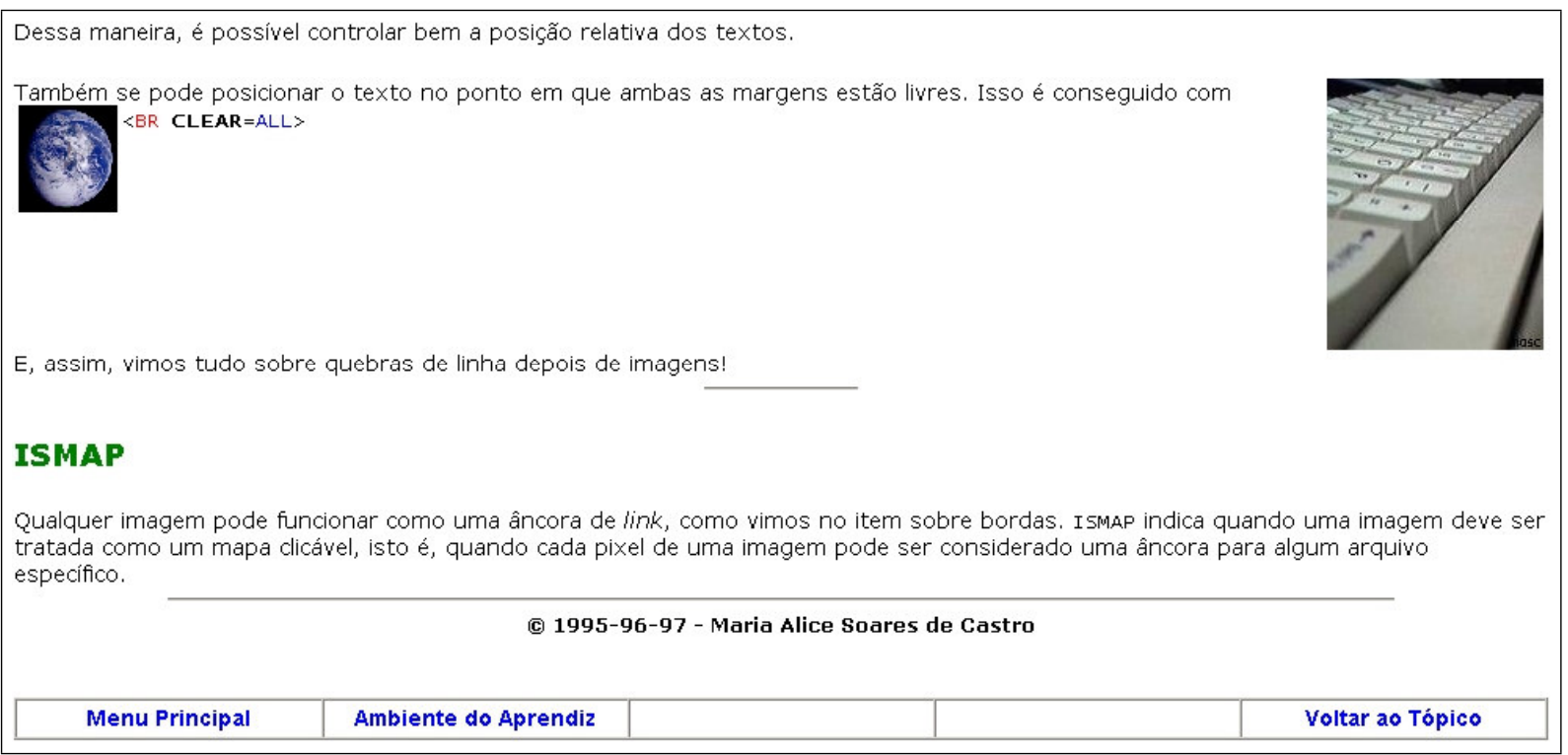

Figura 5.22: Conteúdo visualizado como referência webliográfica

Dessa maneira, é possível controlar bem a posição relativa dos textos.

Também se pode posicionar o texto no ponto em que ambas as margens estão livres. Isso é conseguido com

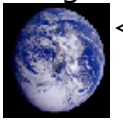

$\langle B R \quad C L E A R=A L L>$

E, assim, vimos tudo sobre quebras de linha depois de imagens!

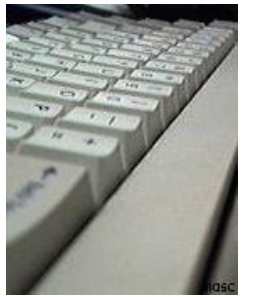

\section{ISMAP}

Qualquer imagem pode funcionar como uma âncora de link, como vimos no item sobre bordas. ISMAP indica quando uma imagem deve ser tratada como um mapa clicável, isto é, quando cada pixel de uma imagem pode ser considerado uma âncora para algum arquivo específico.

(C) 1995-96-97 - Maria Alice Soares de Castro

\begin{tabular}{|l|c|c|c|c|}
\hline Menu Principal & $\begin{array}{c}\text { Ambiente do } \\
\text { Aprendiz }\end{array}$ & $\begin{array}{c}\text { Curso } \\
\text { UE }\end{array}$ & Pausa & $\begin{array}{c}\text { Tópico foi } \\
\text { estudado }\end{array}$ \\
\hline
\end{tabular}

\begin{tabular}{||c|c|c|c|c|}
\hline \multicolumn{5}{|c|}{ Se quiser, pode reestudar um Tópico anterior: } \\
\hline $\begin{array}{c}\text { Atributos gerais de } \\
\text { um documento }\end{array}$ & Cabeçalhos & Separadores & $\begin{array}{c}\text { Listas em } \\
\text { HTML }\end{array}$ & $\begin{array}{c}\text { Blocos de } \\
\text { texto }\end{array}$ \\
\hline \begin{tabular}{c|c|c|c} 
Formatação de frases & $\begin{array}{c}\text { Caracteres } \\
\text { Especiais }\end{array}$ & Cores e & Fontes \\
relativo
\end{tabular} & $\begin{array}{c}\text { Caminho } \\
\text { absoluto }\end{array}$ \\
\cline { 1 - 2 } $\begin{array}{c}\text { Ligações para trechos } \\
\text { de documentos }\end{array}$ & $\begin{array}{c}\text { Inserção de } \\
\text { Imagens }\end{array}$ & & & \\
\hline
\end{tabular}

Figura 5.23: Conteúdo visualizado como Tópico 
Durante ou após o oferecimento de um curso, o instrutor pode consultar informações relativas ao desempenho dos aprendizes, agrupadas por curso (Figura 5.24) ou por aprendiz (Figura 5.25), além de dados estatísticos por curso (Figura 5.26).

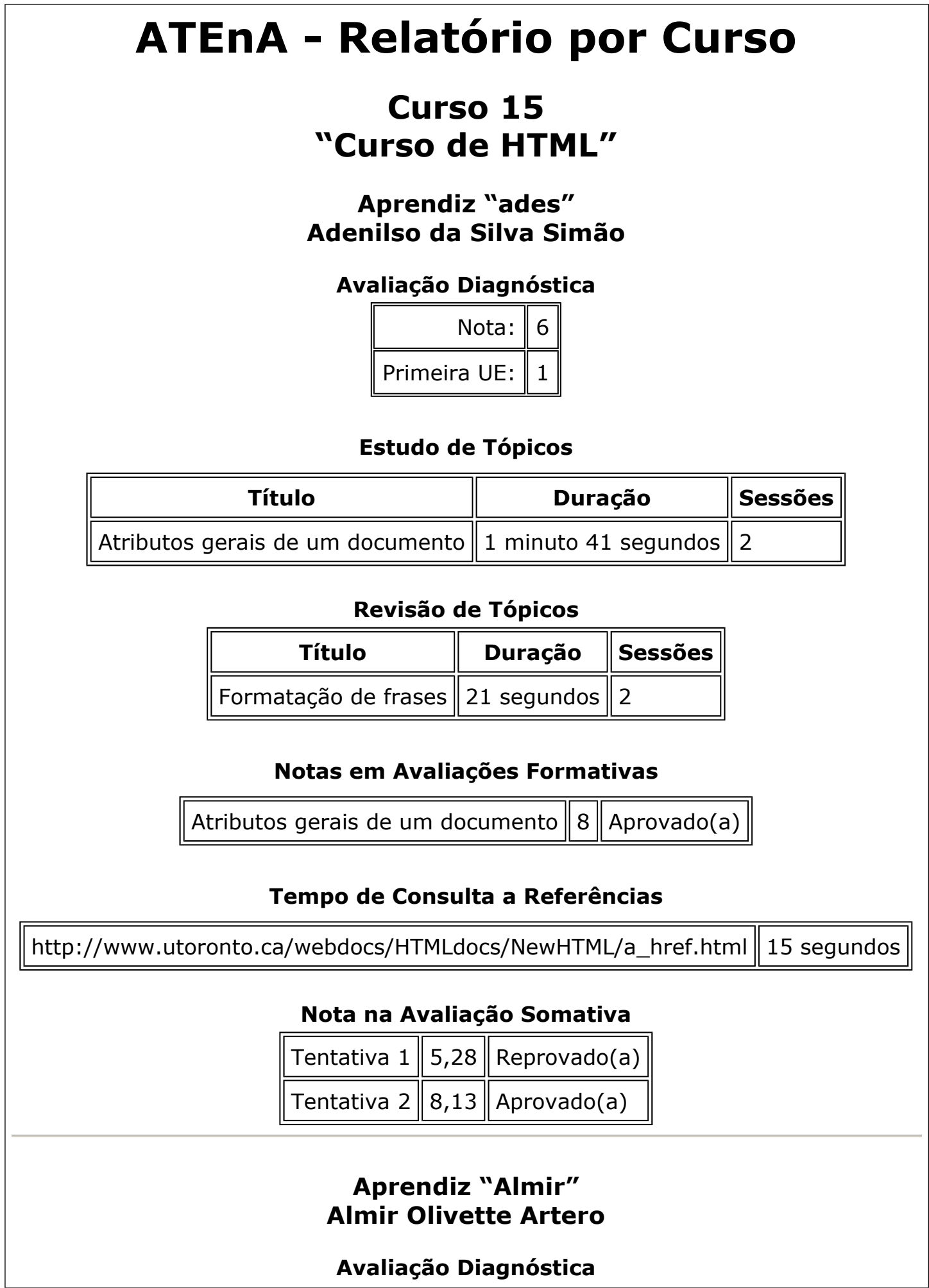

Figura 5.24: Relatório parcial de um curso 


\section{ATEnA - Relatório por Aprendiz Almir \\ Almir Olivette Artero \\ Curso 15 \\ Curso de HTML \\ Avaliação Diagnóstica

\begin{tabular}{|r||c|l||}
\hline Nota & Duração & Primeira UE \\
\hline \hline 2 & 2 minutos 9 segundos & 1 \\
\hline
\end{tabular} \\ Estudo de Tópicos

\begin{tabular}{|c|c|l|}
\hline Título & Duração & Sessões \\
\hline \hline Cabeçalhos & 13 minutos 2 segundos & 1 \\
\hline
\end{tabular}

Avaliações Formativas

\begin{tabular}{||c||c||c|}
\hline Tópico & Nota & Duração \\
\hline \hline Cabeçalhos & 6 & 10 minutos \\
\hline
\end{tabular}

\section{rtvb}

\section{Rosana T. Vaccare Braga}

Curso 15

Curso de HTML

Avaliação Diagnóstica

\begin{tabular}{||c||c||c||}
\hline Nota & Duração & Primeira UE \\
\hline \hline 4,67 & 4 minutos 57 segundos & 1 \\
\hline
\end{tabular}

Estudo de Tópicos

\begin{tabular}{|c||c||l|}
\hline Título & Duração & Sessões \\
\hline \hline Formatação de frases & 2 minutos 34 segundos & 1 \\
\hline
\end{tabular}

Avaliações Formativas

\begin{tabular}{||c||l|l||}
\hline Tópico & Nota & Duração \\
\hline \hline Formatação de frases & 10 & 32 segundos \\
\hline
\end{tabular}

Avaliação Somativa

\begin{tabular}{|r||l|l|}
\hline Tentativa & Nota & Duração \\
\hline 1 & 7,14 & 21 minutos 7 segundos \\
\hline 2 & 7,88 & 8 minutos 43 segundos \\
\hline
\end{tabular}

Figura 5.25: Relatório parcial por aprendiz 


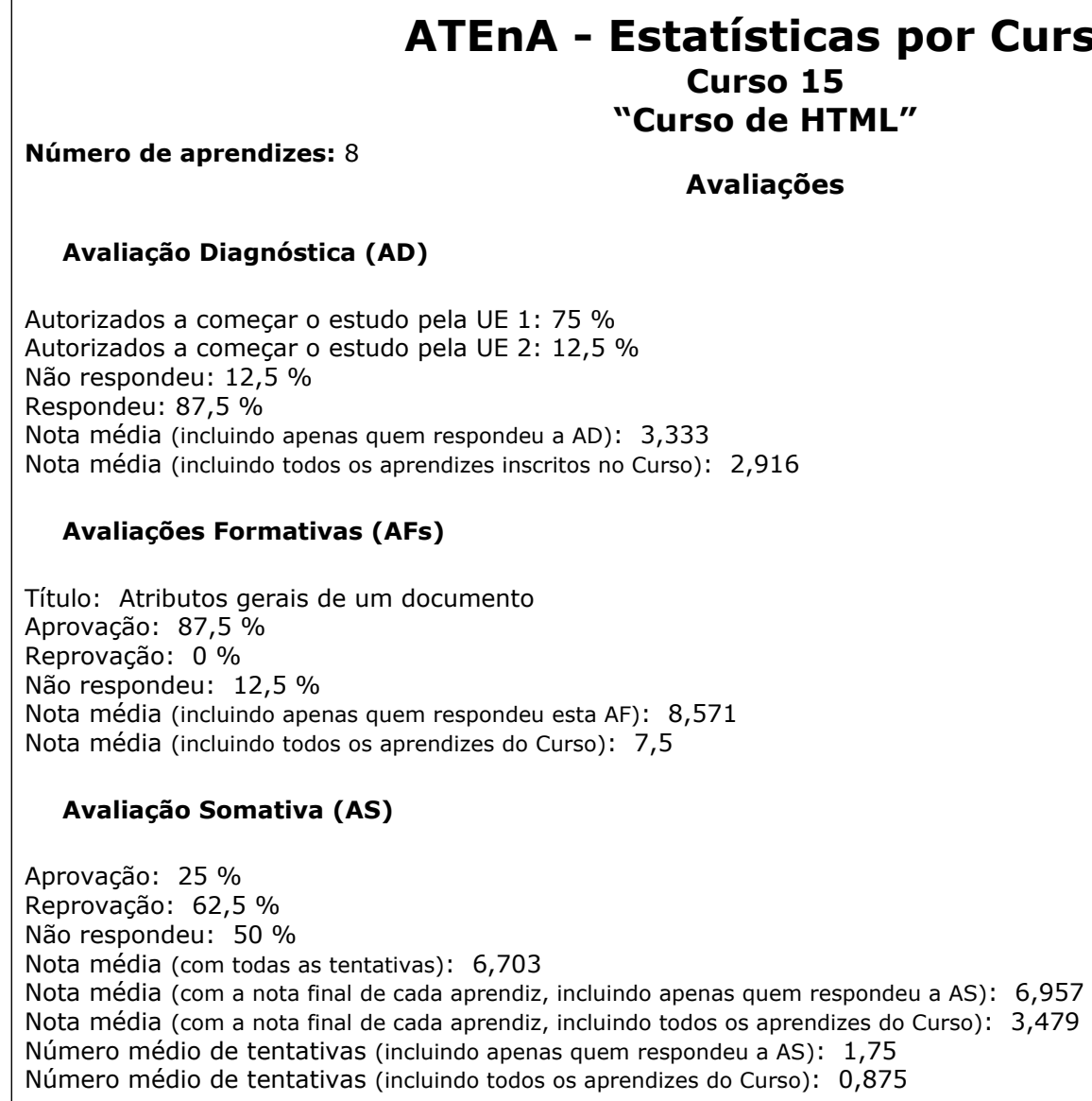

\section{Tempo médio das Avaliações}

$A D$ (incluindo apenas quem a respondeu): 3 minutos 58 segundos

$A D$ (incluindo todos os aprendizes): 4 minutos 27 segundos

AF: Avaliação sobre atributos gerais de um documento

Tempo (incluindo apenas quem respondeu esta AF): 1 minuto 41 segundos

Tempo (incluindo todos os aprendizes deste Curso): 2 minutos 19 segundos

AS (incluindo apenas quem a respondeu): 7 minutos 14 segundos

AS (incluindo todos os aprendizes deste Curso): 6 minutos 19 segundos

Tempo médio de todas as Avaliações realizadas neste Curso: 1 minuto 51 segundos

\section{Estudo de Tópicos}

Título: Atributos gerais de um documento

Tempo médio (incluindo apenas quem estudou o Tópico): 16 minutos 55 segundos

Tempo médio (incluindo todos os inscritos no Curso): 35 minutos 57 segundos

Número médio de sessões deste Tópico (incluindo todos os inscritos no Curso): 2,125

\section{Consulta a Referências}

Referência: http://www.utoronto.ca/webdocs/HTMLdocs/NewHTML/a_href.html Tempo médio de consulta (incluindo apenas quem consultou): 15 segundos

Tempo médio de consulta (incluindo todos os aprendizes do Curso): 1 segundo

Tempo médio de consulta às referências deste Curso (incluindo apenas quem consultou): 55 segundos Tempo médio de consulta às referências deste Curso (incluindo todos os inscritos no Curso): 55 segundos

Figura 5.26: Estatísticas parciais de um curso 


\subsection{Considerações Finais}

ATEnA (Ambiente de Treinamento, Ensino e Aprendizagem ou Adaptive Training Environment with Support for Assessment) é um sistema de informação baseado na Web cujo objetivo principal é testar a aplicabilidade de um novo modelo para hiperdocumentos educacionais, denominado MDE, na especificação e exibição de conteúdo didático em sistemas de ensino a distância.

O ATEnA é composto por três módulos: administração, autoria e ensino. O módulo administrativo, implementado durante o Mestrado de Casagrande para apoiar o oferecimento de cursos de extensão na USP, inclui o gerenciamento de usuários, processos relativos aos cursos, inscrições e aprovações dos candidatos, e acompanhamento da freqüência e dos resultados das avaliações dos aprendizes.

O tipo de autoria proporcionado é a autoria global (authoring-in-the-large), referente ao projeto de aspectos estruturais de hiperdocumentos educacionais (Garzotto et al., 1993). Formulários HTML possibilitam a edição de questões e da estrutura do curso. Para criar formatos específicos de arquivos (HTML, GIF, JPEG, dentre outros), deve ser utilizado um programa externo ao ATEnA.

No módulo de ensino, questões escolhidas de forma automática ou manual, a partir de uma base de dados, compõem três tipos diferentes de avaliação (diagnóstica, formativa, somativa) que podem ser utilizados para verificar o desempenho do aprendiz. A navegação dos aprendizes pelo material didático pode ser acompanhada pelo instrutor em três tipos de relatórios: por curso, por aprendiz e com estatísticas de curso(s). Desta maneira, dados coletados sobre o comportamento dos aprendizes durante sua navegação pelos hiperdocumentos do ATEnA poderão enriquecer seu processo avaliativo, contribuindo para que a nota final de cada aprendiz reflita mais adequadamente seu conhecimento acumulado durante o oferecimento do curso.

Naturalmente, visando a complementar os recursos oferecidos pelo ATEnA, ele poderia ser integrado a um ambiente mais geral que proporcione outros recursos, como uma interação maior entre os participantes por meio de fórum, chat, lista de discussão, etc. Isso, entretanto, foge do escopo deste trabalho.

No próximo capítulo o MDE e o ATEnA são avaliados em relação às características hipermídia descritas no Capítulo 3. O ATEnA é contrastado com outros sistemas hipermídia educacionais e avaliado quanto a alguns requisitos para sistemas de autoria hipermídia educacional estabelecidos em Paiva (2001) e em Paiva \& Nunes (2001). São relatados alguns usos do sistema realizados por docentes e alunos do ICMC com vistas à avaliação do protótipo. Além disso, o modelo é comparado com modelos hipermídia descritos anteriormente nesta tese. 


\section{Avaliação da Proposta}

\subsection{Considerações Iniciais}

Uma validação preliminar do modelo proposto foi realizada de forma conceitual e prática, avaliando a aplicação que o implementa. Observa-se que a validação da aplicação é uma forma indireta de validar o modelo no qual ela está baseada, uma vez que restrições do software podem ser causadas por restrições do modelo. Por outro lado, nem todos os aspectos do modelo foram implementados na aplicação, uma vez que esta se trata de uma prova de conceito e procurou-se, limitado pelo tempo disponível para a implementação, implementar os aspectos mais fundamentais e importantes do modelo.

Uma validação preliminar de natureza prática foi realizada com usuários reais, que usaram o sistema em condições próximas de uma situação de uso operacional, e em testes efetuados pelo próprio desenvolvedor do sistema, bem como por comparação com os principais softwares desse domínio discutidos no Capítulo 2. Foi feita também uma avaliação conceitual utilizando como referencial um conjunto de requisitos identificados como desejáveis em aplicações hipermídia em geral e aplicações para o domínio educacional (Paiva, 2001; Paiva \& Nunes, 2001). Adicionalmente, o modelo proposto é comparado, de maneira informal e sucinta, com os modelos similares apresentados e discutidos no Capítulo 2, visando ao uso no domínio de aplicações para o ensino e aprendizado on-line.

Na próxima Seção é apresentada a avaliação conceitual do sistema segundo o conjunto de requisitos para sistemas de autoria hipermídia educacional estabelecido em Paiva (2001) e em Paiva \& Nunes (2001). A seguir, o modelo MDE é comparado com os modelos hipermídia discutidos no Capítulo 3. A validação preliminar realizada com usuários é descrita na Seção 6.4. $\mathrm{Na}$ Seção 6.5 descreve-se como algumas funcionalidades hipermídia descritas no Capítulo 3 foram incluídas no MDE e no ATEnA. Na Seção 6.6 o ambiente é comparado com outros sistemas hipermídia educacionais e, na Seção 6.7, são apresentadas as considerações finais. 


\subsection{Avaliação Conceitual do Sistema ATEnA}

Paiva e Nunes propuseram um conjunto de requisitos para sistemas de autoria hipermídia educacional (Paiva, 2001; Paiva \& Nunes, 2001) que enfoca principalmente aspectos relacionados à preparação de material de ensino pelo instrutor. Os requisitos estão subdivididos em requisitos gerais para sistemas de autoria hipermídia e requisitos para sistemas de autoria hipermídia educacional. $\mathrm{O}$ primeiro tipo de requisitos inclui as seguintes categorias: recursos de apoio à geração de material, recursos de edição e alteração da aplicação, recursos que facilitam a evolução da aplicação, amenidade de uso, recursos de auxílio oferecidos ao usuário autor e recursos de documentação. Os requisitos que consideram aspectos inerentes ao domínio de ensino incluem: recursos disponíveis para a fase de projeto de aplicações hipermídia para ensino, recursos de distinção de material e recursos de apoio à construção de aplicações para ensino.

Buscou-se utilizar um subconjunto desses requisitos como referencial para avaliar conceitualmente alguns aspectos do ambiente ATEnA. Como o conjunto completo de requisitos enfoca principalmente recursos de autoria para o instrutor, e aborda um conjunto completo de funcionalidades desejáveis em um sistema de autoria, nem todos os critérios se aplicam ao ATEnA, já que este não foi concebido para ser um sistema de autoria completo, mas apenas para validar a proposta do modelo MDE como um modelo de autoria e navegação em conteúdo didático. Embora não enfoquem explicitamente o uso do sistema pelo aprendiz, alguns dos requisitos propostos também são úteis para avaliar aspectos de uso nesse contexto.

Nas Tabelas 6.1 e 6.2, são apresentadas as categorias e subcategorias de requisitos de avaliação propostos por Paiva e Nunes, os quais serão utilizados, quando aplicáveis, como base para avaliar criticamente o sistema ATEnA. A coluna "ATEnA" indica a adequação (ou não) do ATEnA relativamente à subcategoria correspondente. Nessa coluna foram utilizadas as seguintes abreviações: NSA, quando não se aplica ao ATEnA; NA, quando o ATEnA não atende à subcategoria; $\mathrm{AP}$, se atende parcialmente; e $\mathrm{AB}$, se atende bem àqueles requisitos.

Apenas duas subcategorias não se aplicam ao ATEnA. A primeira delas aborda a detecção de referências cegas e de ligações incorretas. Devido ao fato das ligações estruturais entre os nós do curso não serem editadas pelo autor, e sim geradas automaticamente pelo sistema, torna-se desnecessária a exibição de uma lista contendo as ligações que chegam e saem do nó que está sendo editado. A subcategoria de recursos para armazenamento de informações sobre nós não foi aplicada porque não foi útil, para a concretização dos objetivos propostos nesta tese, incluir informações adicionais para cada nó do curso, tais como: data de criação, dados do usuário e comentários relativos aos nós. 
Tabela 6.1: Requisitos Gerais para Sistemas de Autoria Hipermídia

\begin{tabular}{|c|c|c|}
\hline Categorias & Subcategorias & ATEnA \\
\hline \multirow{5}{*}{$\begin{array}{l}\text { Recursos de apoio à } \\
\text { geração de material }\end{array}$} & $\begin{array}{l}\text { O sistema deve fornecer recursos que apóiam laços de reali- } \\
\text { mentação }\end{array}$ & $\mathrm{AP}$ \\
\hline & $\begin{array}{l}\text { O sistema deve fornecer recursos que possibilitam prototipa- } \\
\text { ção do material }\end{array}$ & AP \\
\hline & $\begin{array}{l}\text { O sistema deve fornecer recursos que permitam utilizar abor- } \\
\text { dagens de desenvolvimento ascendente e descendente }\end{array}$ & NA \\
\hline & $\begin{array}{l}\text { O sistema deve fornecer recursos que proporcionam geração } \\
\text { de roteiros }\end{array}$ & AP \\
\hline & $\begin{array}{l}\text { O sistema deve fornecer recursos que permitam especificar to- } \\
\text { dos os aspectos do domínio de conhecimento da aplicação }\end{array}$ & AP \\
\hline \multirow{6}{*}{$\begin{array}{l}\text { Recursos de edição e } \\
\text { alteração da aplicação }\end{array}$} & $\begin{array}{l}\text { O sistema deve fornecer recursos que informam as referências } \\
\text { dos nós ao usuário autor }\end{array}$ & NA \\
\hline & $\begin{array}{l}\text { O sistema deve fornecer recursos que facilitam a correção } \\
\text { (manutenção) das aplicações }\end{array}$ & AP \\
\hline & $\begin{array}{l}\text { O sistema deve fornecer recursos que verificam a coerência } \\
\text { das ligações }\end{array}$ & $\mathrm{AB}$ \\
\hline & $\begin{array}{l}\text { O sistema deve fornecer recursos que promovam a propagação } \\
\text { de modificações }\end{array}$ & $\mathrm{AB}$ \\
\hline & O sistema deve fornecer recursos que facilitam a edição de nós & AP \\
\hline & $\begin{array}{l}\text { O sistema deve fornecer recursos que permitam a edição de } \\
\text { textos, sons e gráficos a partir do próprio sistema de autoria }\end{array}$ & NA \\
\hline \multirow[t]{2}{*}{$\begin{array}{l}\text { Recursos que facilitam } \\
\text { a evolução da aplicação }\end{array}$} & $\begin{array}{l}\text { O sistema deve fornecer recursos que apóiem o gerenciamento } \\
\text { e armazenamento de versões das aplicações hipermídia }\end{array}$ & NA \\
\hline & $\begin{array}{l}\text { O sistema deve fornecer recursos que apóiam o trabalho coo- } \\
\text { perativo }\end{array}$ & NA \\
\hline \multirow{5}{*}{ Amenidade de uso } & $\begin{array}{l}\text { O sistema deve fornecer recursos que promovam autoria } \\
\text { eficiente }\end{array}$ & AP \\
\hline & $\begin{array}{l}\text { O sistema deve fornecer recursos que promovam redução de } \\
\text { custos (tempo) envolvidos na criação de aplicações }\end{array}$ & AP \\
\hline & $\begin{array}{l}\text { O sistema deve fornecer recursos que possibilitam ao autor } \\
\text { criar aplicações hipermídia de acordo com suas necessidades } \\
\text { e preferências }\end{array}$ & AP \\
\hline & $\begin{array}{l}\text { O sistema deve fornecer recursos que detectam a presença de } \\
\text { referências cegas e ligações incorretas }\end{array}$ & NSA \\
\hline & O sistema deve fornecer recursos que sejam claros e intuitivos & AP \\
\hline
\end{tabular}


Tabela 6.1: Requisitos Gerais para Sistemas de Autoria Hipermídia (continuação)

\begin{tabular}{|l|l|l|}
\hline \multicolumn{1}{|c|}{ Categorias } & \multicolumn{1}{|c|}{ Subcategorias } & ATEnA \\
\hline \multirow{2}{*}{ Amenidade de uso } & $\begin{array}{l}\text { O sistema deve fornecer recursos que promovam o conforto na } \\
\text { utilização do sistema }\end{array}$ & AP \\
\cline { 2 - 3 } & $\begin{array}{l}\text { O sistema deve fornecer recursos que promovam a customiza- } \\
\text { ção do ambiente de autoria }\end{array}$ & AP \\
\hline $\begin{array}{l}\text { Recursos de auxílio } \\
\text { help } \text { ) oferecidos ao } \\
\text { usuário autor }\end{array}$ & $\begin{array}{l}\text { O sistema deve fornecer recursos que promovam auxílio ao } \\
\text { usuário }\end{array}$ & A sistema deve fornecer recursos de tutorial para autoria \\
\cline { 2 - 3 } $\begin{array}{l}\text { Recursos de } \\
\text { documentação }\end{array}$ & $\begin{array}{l}\text { O sistema deve fornecer recursos que possibilitam o armaze- } \\
\text { namento de informações sobre os nós }\end{array}$ & NSA \\
\cline { 2 - 3 } & O sistema deve fornecer recursos de documentação & AP \\
\hline
\end{tabular}

Tabela 6.2: Requisitos para Sistemas de Autoria Hipermídia Educacional

\begin{tabular}{|l|l|l|}
\hline \multicolumn{1}{|c|}{ Categorias } & \multicolumn{1}{|c|}{ Subcategorias } & ATEnA \\
\hline $\begin{array}{l}\text { Recursos disponíveis à } \\
\text { fase de projeto de } \\
\text { aplicações hipermídia } \\
\text { para ensino }\end{array}$ & $\begin{array}{l}\text { O sistema deve fornecer recursos que proporcionam liber- } \\
\text { dade de projeto dos aspectos navegacionais da aplicação }\end{array}$ & AP \\
\cline { 2 - 3 } & $\begin{array}{l}\text { O sistema de autoria deve fornecer recursos que permitam } \\
\text { estabelecer o tipo de controle sobre a navegação }\end{array}$ & AB \\
\hline $\begin{array}{l}\text { Recursos de distinção de } \\
\text { material }\end{array}$ & $\begin{array}{l}\text { O sistema de autoria deve fornecer recursos que permitam } \\
\text { fixação de material específico }\end{array}$ & NA \\
\cline { 2 - 3 } & $\begin{array}{l}\text { O sistema de autoria deve fornecer recursos que possibilitam } \\
\text { inclusão de material essencial e complementar }\end{array}$ & AP \\
\hline $\begin{array}{l}\text { Recursos de apoio à } \\
\text { construção de aplicações } \\
\text { para ensino }\end{array}$ & $\begin{array}{l}\text { O sistema de autoria deve fornecer recursos que proporcio- } \\
\text { nem visualização da estrutura da aplicação hipermídia }\end{array}$ & AP \\
\cline { 2 - 3 } & $\begin{array}{l}\text { O sistema de autoria deve fornecer recursos que possibilitem } \\
\text { ao autor qualificar os elementos (componentes) do material }\end{array}$ & AP \\
\hline
\end{tabular}

\subsubsection{Requisitos Gerais para Sistemas de Autoria Hipermídia}

\subsubsection{Recursos de Apoio à Geração de Material}

O conjunto de requisitos englobados nesta subcategoria busca avaliar a adequação e simplicidade do processo de preparação de material e se os recursos oferecidos pelo sistema para realizar essa atividade são adequados e suficientes. A avaliação dos recursos do ATEnA nesse contexto deve levar em consideração o fato de que a proposta do ATEnA é apoiar a organização e a estruturação do conteúdo, também denominada "autoria em ponto grande". O sistema assume que o conteúdo dos arquivos associados a Tópicos e UEs é gerado externamente e importado. 
A preparação de material no ATEnA parte da definição de um Mapa Conceitual que estabelece o conjunto de conceitos a serem abordados e a estruturação e sequiência de apresentação desses conceitos. Um dos aspectos considerados nos requisitos de apoio à preparação de material é o apoio a laços de realimentação entre as fases de projeto da aplicação (no caso do ATEnA, o curso). O ATEnA apóia parcialmente laços de realimentação ao possibilitar que: (1) o autor edite mapas conceituais que ainda não estejam associados a cursos; (2) um mapa seja desassociado de um curso, editado e posteriormente reassociado ao mesmo curso; e (3) conceitos do mapa sejam associados a Tópicos ou a Unidades de Estudo. O apoio seria total se o ATEnA permitisse que o autor editasse a estrutura do curso (por exemplo, mover Tópico de uma Unidade de Estudo para outra), o que não é possível na implementação atual.

Outro aspecto considerado é o auxílio à organização e avaliação do curso. No caso do ATEnA, o próprio processo de criação de um curso pressupõe a definição de uma estruturação hierárquica. Um recurso útil é a possibilidade do autor conferir a estruturação que criou; por exemplo, após inserir textualmente todos os conceitos no mapa, o sistema os exibe graficamente na forma de árvore. Entretanto, a restrição de que mapas conceituais só podem ser editados enquanto não estão associados a cursos pode dificultar a autoria. Além disso, seria interessante ter recursos adicionais para editar a estrutura e o conteúdo do curso, como poder alterar o conteúdo do material dentro do ATEnA; editar a estrutura graficamente, a partir do statechart; ou ter múltiplos autores editando um mesmo curso. Durante o oferecimento, seria interessante que o aprendiz pudesse incluir notas ou comentários acessíveis aos outros aprendizes.

Outro aspecto desejável é a possibilidade de prototipação dos cursos. De forma limitada o ATEnA oferece esse recurso, pois o autor pode navegar pelo curso que criou, como um aprendiz, para conferir se o conteúdo e a estrutura estão de acordo com o planejamento. É possível depois alterar as avaliações e alguns dados estruturais. No entanto, a definição da estrutura do curso, tanto na forma de um mapa conceitual quanto na especificação detalhada das UEs, ocorre em uma única etapa e não é evolutiva.

A abordagem adotada na criação do conteúdo didático principal não é flexível (ascendente ou descendente). O processo de criação de curso é descendente, pois a estrutura é instanciada a partir de um mapa conceitual previamente criado. Depois, o autor insere no ATEnA os arquivos do curso conforme esta estrutura. Por outro lado, as avaliações são elaboradas de forma ascendente. Primeiramente é necessário incluir as questões e, depois, os principais dados da avaliação (condição, título, texto introdutório e duração máxima). Se a avaliação for gerada manualmente, é unicamente neste ponto que o autor deve associar as questões à avaliação.

O ATEnA apóia diferentes roteiros do aprendiz pelo curso em algumas situações específicas e segundo alguns critérios mas, de forma geral, existe um roteiro fixo de navegação pelo material. Esse roteiro, definido pelo autor do curso, consiste em uma seqüência de Tópicos que orienta o aprendiz durante a exploração do conteúdo didático, de forma que os objetivos dos autores e dos 
aprendizes possam ser de fato concretizados. A navegação do aprendiz segue essencialmente a estrutura definida pelo mapa conceitual e pelos tipos de avaliação efetuadas, e não é possível definir roteiros diferentes de navegação, visando a diversos grupos de usuários. Para melhorar a flexibilidade na geração desses roteiros, o sistema poderá possibilitar futuramente que o autor crie diferentes versões do mesmo curso com roteiros diferentes, visando até mesmo a grupos diferenciados de aprendizes.

\subsubsection{Recursos de Edição e Alteração da Aplicação}

Nessa segunda subcategoria estão englobados requisitos relacionados à facilidade de alteração do conteúdo do curso. Novamente, é realizada uma análise voltada para organização e estruturação do conteúdo, sem contemplar a edição do conteúdo de arquivos individuais.

O ATEnA não oferece muitos recursos para a manutenção do conteúdo do curso. Assume-se que a estrutura, uma vez disponibilizada, permanece razoavelmente estável. Não é possível remover arquivos, Tópicos e UEs após a criação de um curso ou durante seu oferecimento. No entanto, as avaliações podem ser facilmente modificadas.

Segundo o MDE, um Tópico é referenciado por uma AF e referencia outra AF, a não ser que alguma dessas Avaliações não exista; neste caso, a ligação ocorre entre Tópicos. Adicionalmente, o primeiro Tópico do curso pode suceder-se à AD; por sua vez, o último Tópico pode preceder a AS. Quando a Avaliação é gerada automaticamente, não é possível determinar durante a edição qual questão referencia e é referenciada por outra questão. Devido a esse tipo de modelagem, o sistema não lista as ligações estruturais do nó que está sendo editado; dessa forma, os autores não visualizam os nós que referenciam e são referenciados por determinado nó. Contudo, uma característica útil que poderá ser implementada futuramente é a relação das ligações embutidas no conteúdo dos Tópicos, as quais referenciam material didático complementar.

O conteúdo de UEs e Tópicos pode ser alterado durante o oferecimento do curso, incluindo no curso um arquivo com o mesmo nome daquele arquivo que se deseja modificar. Avaliações já respondidas não são modificáveis. Quando uma questão ou Avaliação é modificada ou removida, as referências a ela são atualizadas ou removidas automaticamente.

No caso dos nós modificáveis e que aparecem em mais de um nível (questões e conceitos), as alterações realizadas em um nó são automaticamente atualizadas em todos os níveis em que ele aparece. Tópicos e UEs não se repetem, nem as Avaliações - seja em um único Curso ou em mais de um Curso.

O ATEnA permite alteração dos conceitos e dados gerais sobre os mapas conceituais, bem como dos títulos de Tópicos, UEs e Curso. Também é fácil editar as características de Avaliações, incluindo suas questões. É possível atualizar arquivos existentes ou incluir novos arquivos. Entretanto, os arquivos só podem ser associados a Tópicos, UEs ou cursos em uma única etapa. 
O sistema não oferece recursos para autoria em ponto pequeno. Não há o acesso (a partir do ATEnA) a um editor de textos, de sons e de gráficos externos, nem existem recursos de edição equivalentes. A ênfase do ATEnA é na autoria da estrutura, em grande escala. O conteúdo deve ser criado e editado externamente, por meio de outros programas, com exceção das avaliações.

\subsubsection{Recursos que Facilitam a Evolução da Aplicação}

Conforme mencionado, o processo de criação de cursos no ATEnA assume que, uma vez criado, o curso permanece relativamente estável. O sistema não gerencia nem armazena versões dos cursos ou dos mapas conceituais.

Um curso pode ser editado por mais de um usuário; por exemplo, um usuário prepara a $\mathrm{AD}$, outro elabora a AS, um terceiro escolhe as questões para as AFs, e os Tópicos são criados por outra pessoa. Contudo, não existe controle de concorrência, nem há uma área comum para colaboração na autoria de um mesmo nó; além disso, apenas um usuário pode criar a estrutura principal do curso. Portanto, o trabalho de autoria pode ser distribuído, mas não cooperativo.

\subsubsection{Amenidade de Uso}

Essa subcategoria engloba requisitos indicativos da facilidade de uso do sistema, tanto do ponto de vista do professor / instrutor (autor) como do aprendiz. Uma questão a ser considerada refere-se às vantagens em utilizar o sistema de autoria, em contraste à construção direta de um curso por meio de linguagens como HTML, Java e PHP. Percebeu-se que o ATEnA facilita a organização consistente do conteúdo e a elaboração de avaliações, as quais podem ser geradas automaticamente a partir de questões previamente armazenadas. O conteúdo é automaticamente organizado segundo o modelo do sistema, sem que o autor precise explicitar todas as ligações da estrutura - por exemplo, relacionar o Tópico anterior ao posterior —, pois o sistema cria tais ligações entre Tópicos com base na estrutura do Curso. Como essas ligações estruturais são produzidas automaticamente, a possibilidade de erros na autoria de ligações é minimizada.

Pode ser considerada uma limitação o fato de a organização e a interface do curso serem determinadas pelas características do sistema de autoria. Todos os cursos consistem basicamente em uma trilha de Tópicos com desvios para outros tipos de página (Unidade de Estudo, curso e referência). Existe flexibilidade na inclusão dos diferentes tipos de avaliação. Avaliações podem ser exibidas em uma página HTML ou na forma de um roteiro guiado de questões.

Outras possíveis limitações são as necessidades de hierarquizar os conceitos e de elaborar avaliações que contêm apenas questões de múltipla escolha. Estas restrições podem ser mais gravemente percebidas quando a hierarquização e o tipo de questão não são adequados ao assunto abordado e ao estilo do autor. Algumas adaptações previstas em trabalhos futuros, para facilitar ao usuário autor a criação de aplicações conforme suas necessidades e preferências, são a variação no número de níveis hierárquicos do mapa conceitual, possibilitando conseqüentemente a inclusão de subtópicos na estrutura, e a implementação de outros tipos de questões. 
Uma subcategoria atendida parcialmente pelo ATEnA refere-se à necessidade de recursos claros e intuitivos. Alguns comandos fornecidos pelo sistema de autoria, na forma de menus e botões, são auto-explicativos. Outros comandos exigem que o autor compreenda os termos usados - Mapa Conceitual, Avaliação Diagnóstica, Unidade de Estudo, Tópico, Avaliação Formativa e Avaliação Somativa. Para superar essa dificuldade, um curso de treinamento poderá ser preparado e ministrado no próprio ambiente. Uma vez assimilados os termos citados, o ATEnA é facilmente compreensível ao usuário durante o processo de autoria. A utilização de formulários que mantêm consistência em seus menus e botões, incluindo as suas posições na interface e os termos utilizados, facilita esse processo, em especial para usuários experientes da World Wide Web.

\subsubsection{Recursos de Auxílio (Help) Oferecidos ao Autor}

Um aspecto valorizado nessa categoria é a disponibilidade de informações explicativas sobre o processo de autoria no instante em que o usuário desejar. O sistema ATEnA atende de forma muito simples a esse requisito, pois não possui atualmente ajuda on-line contextual nem um glossário dos termos utilizados na interface. Contudo, em algumas páginas do ATEnA, há explicações sobre os tipos de avaliações, mapas conceituais e tempo limite do aprendiz na Internet. Adicionalmente, o processo é bastante dirigido, o que deve diminuir o número de erros.

Para apoio ao uso, não há material de treinamento que explique detalhadamente o funcionamento do ATEnA, seus objetivos, os benefícios obtidos a partir de seu uso e as etapas envolvidas na construção de um curso. Esse material poderia ser elaborado na forma de dois cursos introdutórios, um para aprendizes e outro para autores, disponibilizados no próprio ambiente.

Apesar do ATEnA não oferecer atualmente um treinamento completo, são enumeradas no ambiente do autor as principais atividades necessárias à elaboração de cursos e o sistema oferece algumas informações on-line, as quais podem ser melhoradas (ver Subseção anterior e Seção 6.5) e complementadas com um manual de uso. Para os aprendizes, o ambiente é controlado e é simples usá-lo, exigindo pouco conhecimento para iniciar o uso. De qualquer forma, um documento que forneça algumas informações básicas aos aprendizes também é necessário. Essa documentação poderia fazer distinção entre os usuários novatos e experientes, o que não ocorre atualmente.

\subsubsection{Recursos de Documentação}

A implementação atual do ATEnA priorizou o armazenamento de informações sobre nós que tivessem importância para a atividade-fim do sistema, a qual consiste no apoio ao ensino e à avaliação. Assim, por exemplo, são coletadas informações sobre o número de vezes que um Tópico ou avaliação é visitado, a duração dessas visitas, o resultado das avaliações, e as visitas a referências webliográficas. Todas essas informações são disponibilizadas para o instrutor e algumas delas para o aprendiz. Por outro lado, o sistema não armazena informações, por exem- 
plo, de registro e de segurança, como a data e o usuário responsável pela criação / modificação de um nó e versões do material didático associado aos Tópicos. Essas funcionalidades poderiam ser acrescentadas em futuras versões, caso a prática de uso do sistema indique que são importantes para esse domínio.

Como se trata de um protótipo acadêmico em sua primeira versão, o ATEnA não possui documentação técnica detalhada para apoiar sua evolução, embora disponha das informações básicas essenciais, tais como: o modelo no qual está apoiado, o modelo de dados, a arquitetura e o código, além das regras de negócio (no caso, software de apoio ao EaD) documentadas nesta tese. Essas informações poderão ser reaproveitadas em um curso on-line sobre o uso do ATEnA.

\subsubsection{Requisitos para Sistemas Autoria Hipermídia Educacional}

\subsubsection{Recursos Disponíveis ao Projeto de Hiperdocumentos para Ensino}

O sistema oferece grande liberdade para que o autor organize os aspectos navegacionais do curso, de forma a satisfazer aos seus objetivos didáticos, desde que o material seja estruturado hierarquicamente. Tópicos são organizados segundo a sequiência que parecer mais adequada ao autor, o qual pode intercalá-los ou não com AFs. Avaliações podem ser mais ou menos rígidas quanto ao critério de aproveitamento e quanto às características das questões, podendo ser formadas por questões com diferentes níveis de dificuldade. Portanto, o aprendiz pode ter mais liberdade para estudar o material de forma exploratória ou seguir para o Tópico seguinte apenas se demonstrar que adquiriu conhecimentos relativos ao Tópico anterior. Conteúdos associados às UEs e ao Curso não interferem no fluxo navegacional e podem ser usados para oferecer informações contextuais.

A navegação do aprendiz pelo curso é controlada por meio das avaliações. O tipo de fluxo navegacional varia continuamente desde um fluxo livre (sem avaliações), fluxo semi-livre (avaliações fáceis) e fluxo mais controlado (avaliações mais difíceis). A forma segundo a qual o usuário autor estabelece o controle sobre a navegação no ATEnA é determinada pela seguinte seqüência: AD opcional, Tópicos intercalados ou nãopor AFs, e AS opcional.

\subsubsection{Recursos de Distinção de Material}

O sistema ATEnA não foi preparado para fazer distinção de material para grupos específicos. Essa é uma funcionalidade que poderia ser incluída no sistema, mas exigiria um esforço médio de reformulação do projeto. Todos os aprendizes matriculados em um curso estudarão essencialmente o mesmo conteúdo, na mesma seqüência, com duas exceções:

1. Os aprendizes poderão ser dispensados de estudar algumas UEs iniciais desde que tenham sido aprovados, segundo critérios do autor, na Avaliação Diagnóstica;

2. Os aprendizes que não apresentarem desempenho satisfatório em uma Avaliação Formativa para terem acesso a material didático diferenciado, relativo ao mesmo conceito, conforme mencionado na Subseção acima. 
O sistema não trata internamente o acesso a material complementar. O material essencial consiste na trilha de Tópicos. O material complementar consiste em páginas da Web, referenciadas no material do curso. Entretanto, o sistema registra as referências navegadas pelos aprendizes e o tempo gasto na consulta a essas referências externas, como informação para o instrutor. Em versões futuras do ATEnA poderão ser disponibilizadas interfaces para que o autor edite as referências bibliográficas e webliográficas do curso e controle internamente o acesso.

\subsubsection{Recursos de Apoio à Construção de Aplicações para Ensino}

Nesta categoria são enfatizados os recursos para visualização da estrutura da aplicação e para qualificação dos elementos do material didático. É possível visualizar a estrutura do curso de diferentes formas. Uma delas, graficamente, é a estrutura do mapa conceitual, por onde se pode inferir a estrutura de Unidades de Estudo e Tópicos do curso. Essa estrutura pode ser vista ainda de forma textual e, durante o estudo do material (navegação), o aprendiz pode saber sempre a qual UE, curso e conceito está associado o Tópico. Não existe uma ferramenta implementada para permitir a visualização do statechart associado ao curso, que possibilitaria uma visão geral de todos os elementos do curso. Adicionalmente, é difícil para o autor visualizar o conjunto de questões pertencentes às avaliações geradas automaticamente, pois as questões mudam a cada avaliação produzida desta maneira. Além da interface de edição, a única maneira de visualizar o conjunto das questões, mesmo no caso da avaliação manual, é simular a avaliação toda. Adicionalmente, o ATEnA permite que o autor qualifique os Tópicos de acordo com o nível de detalhamento (muito, pouco e razoavelmente detalhado). Questões podem ser qualificadas segundo o nível de dificuldade de sua resolução (baixa, regular, alta).

\subsection{Comparação do MDE com Outros Modelos}

A comparação do MDE com os modelos hipermídia descritos no Capítulo 3 é parcial, considerando que eles não apóiam o mesmo domínio nem se baseiam na mesma estrutura. A maioria dos modelos é genérica e baseada em alguma extensão de grafos. Nesta análise comparativa foram incluídos o modelo informal do WebCT e o modelo conceitual hierárquico do EHDM (Educational Hyperdocuments Design Method), não descritos anteriormente nesta tese.

Foram adotados os seguintes critérios de comparação: existência de um modelo formal subjacente, apoio à estrutura hierárquica de nós, adequação ao domínio de $\mathrm{EaD}$, uso de mapas conceituais, representação gráfica de avaliações, e modelagem de dados relevantes para a AF.

Com respeito à especificação formal, todos os modelos são associados a algum tipo de formalismo, com exceção do modelo para o conteúdo de cursos disponíveis no WebCT. Deduz-se que ele adota uma estrutura na forma de árvore, pois a organização do conteúdo é hierárquica e o acesso é imediato a qualquer Tópico, subtópico ou página individual. Ao contrário do MDE, o modelo do WebCT não restringe a quantidade de subtópicos nem impede, por default, que uma página do conteúdo seja estudada antes de outra. 
Sobre o apoio à estruturação hierárquica de nós, o Trellis é o único que não possibilita esse tipo de modelagem. Quanto à adequação ao domínio de EaD, os modelos Tompa e Trellis são genéricos e, portanto, não representam explicitamente características típicas de hiperdocumentos educacionais. HDM, MCA, RMDM e HMBS são também utilizados para propósitos gerais, porém exibem características interessantes para a modelagem de hiperdocumentos educacionais. Já o WebCT, EHDM e MDE foram elaborados especificamente para este domínio.

Considerando a junção com mapas conceituais, essa característica está presente apenas no MDE e no EHDM. A primeira fase do processo de projeto de um curso no EHDM consiste em construir um modelo conceitual hierárquico, baseado no Modelo de Michener (Michener, 1978) e na teoria de Mapas Conceituais. Assim como o MDE, ele possibilita estruturar conceitos e inclui também duas outras categorias de conhecimento (resultado e exemplo), definindo primitivas gráficas para as categorias e para as relações entre elas (precedência preferencial, precedência necessária, dedução, complexidade, motivação / ilustração, utilização, necessidade). Em uma fase posterior, o EHDM traduz um diagrama navegacional (modelo navegacional de contextos) para uma especificação descrita no MCA (Pansanato \& Nunes, 1999a b).

Com relação à modelagem de avaliações, o MDE é o único — entre os modelos comparados - que representa graficamente, e formaliza, três tipos de avaliações baseadas em questões: diagnóstica, formativa e somativa. Outra funcionalidade do MDE inexistente nesses modelos é a captação de dados relevantes sobre a interação do aprendiz, para apoio à Avaliação Formativa.

\subsection{Avaliação de Uso do Sistema ATEnA}

Nesta Seção é descrita a validação preliminar do ATEnA realizada por potenciais usuários do sistema. O objetivo é avaliar as vantagens, desvantagens e lições aprendidas durante esses usos, além de destacar os aspectos mais relevantes apontados pelos usuários. Inicialmente, o autor desta tese preparou dois cursos — que não chegaram a ser oferecidos a usuários externos visando ao teste e depuração do sistema. O conceito principal do primeiro curso é HTML, enquanto no segundo são apresentados os conceitos de statecharts e diagramas de estados. Após corrigir os principais defeitos, foi elaborado um terceiro curso, também sobre HTML. Ele contém mais UEs que o primeiro e foi oferecido a 8 aprendizes ligados ao ICMC/USP: 2 docentes, 5 pós-graduandos e um graduando. Concluído esse curso, foi solicitado aos aprendizes que comentassem sua experiência na utilização do ATEnA. Eles poderiam conversar pessoalmente com o autor desta tese ou enviar-lhe as anotações por e-mail. Além disso, eles poderiam se expressar livremente e/ou responder a um questionário. Um desses aprendizes também exerceu o papel de autor e elaborou um novo curso, ainda não oferecido, com a principal finalidade de verificar facilidades e dificuldades na utilização do módulo de autoria por quem não conhece profundamente o sistema. Nas próximas subseções são detalhadas estas experiências de uso. 


\subsubsection{Autoria}

Durante a autoria dos dois primeiros cursos, foram encontrados e corrigidos erros no código PHP e algumas restrições desnecessárias de chaves estrangeiras nas tabelas MySQL. Para criar o terceiro curso, sobre HTML, foram reutilizados os arquivos do primeiro curso. Além desse material, foram criadas UEs, questões e avaliações sobre imagens e tabelas. O autor desta tese foi autor e instrutor dos três cursos, e a maior dificuldade percebida neste processo de autoria consistiu na manutenção e no reuso dos arquivos por meio do ATEnA.

A autora do quarto curso recebeu um treinamento sobre criação de mapa conceitual, organização da estrutura e elaboração de avaliações. Durante o treinamento, visando exemplificar o processo de autoria, foram incluídos temporariamente arquivos de outro curso. Após o treinamento, ela criou o mapa e a estrutura, colocando no curso os arquivos apropriados aos conceitos abordados sobre padrões (patterns) de software. Também foram especificadas algumas Avaliações Formativas e a Avaliação Somativa.

Segundo a autora, a implementação de estrutura hierárquica do ATEnA atendeu às necessidades dela e o ATEnA não impôs nenhuma restrição aos objetivos conceituais e didáticos, embora o projeto de aspectos navegacionais do curso dependa da hierarquia do mapa conceitual. Ela propôs uma mudança no processo de estruturação do curso, de forma que não seja necessário digitar toda a hierarquia de uma só vez. Quando o autor pára em algum ponto desse processo, ele precisa refazer tudo posteriormente. Esta alteração ainda não foi implementada.

Um trabalho futuro, também sugerido por ela, é a preparação de um curso de treinamento para uso do ATEnA pelos autores de cursos, visando esclarecer o uso do ambiente, os critérios de avaliação e o relacionamento entre mapa conceitual e estrutura do curso, além de explicar outras funcionalidades do sistema. Esse curso poderia ficar disponível permanentemente no ATEnA e basear-se em exemplos práticos.

Para a autora, é importante que o ATEnA permita ao usuário autor especificar material para grupos de aprendizes, editar conteúdo de forma externa ou interna ao sistema, e apoiar o gerenciamento de versões. A ausência destas funcionalidades no ATEnA foi relatada na avaliação teórica, conforme a Seção anterior. A experiência de preparar um curso no ATEnA foi relevante para ela, pois "nunca havia pensado em preparar um curso desse tipo" e "foi interessante tentar pensar no assunto do curso em termos hierárquicos".

Comparando-se o processo de modelagem do curso no ATEnA à construção direta de um site com o material do curso, a autora percebeu vantagens ao criar um curso no ATEnA, principalmente quanto às avaliações. Ela conseguiria criar o conteúdo, mas não seria capaz de implementar as avaliações nem de garantir a sequiência do aprendiz pelo material, por falta de conhecimento em HTML, PHP e outras linguagens. 


\subsubsection{Oferecimento}

Dos oito aprendizes que se inscreveram no curso de HTML, um não o estudou e quatro concluíram. Para um deles, faltou estudar dois Tópicos e responder às três últimas AFs e à AS. Outro aprendiz só não realizou a AS. No início do oferecimento foram incluídos, externamente ao ATEnA, novos Tópicos e questões; por isso, um aprendiz concluiu a AS sem estudar as últimas UEs. O autor desta tese também atuou como aprendiz. A maior limitação percebida por ele foi a ausência de mecanismos para interação entre os usuários. A implementação desses mecanismos foge do objetivo desta tese, mas poderá ser executada. Um relatório das estatísticas desse oferecimento é exibido nas Figuras $6.1 \mathrm{a} 6.3$, composto a partir dos relatórios oferecidos pelo ATEnA conforme as Figuras 5.24 a 5.26 . Na Figura 6.4 são listadas todas as atividades, monitoradas pelo sistema, desempenhadas por um aprendiz específico durante esse oferecimento.

Quanto à avaliação do ATEnA, dois aprendizes responderam ao questionário proposto, um preferiu comentar pessoalmente e outros três enviaram suas anotações por e-mail. Um questionário não foi preenchido adequadamente e, portanto, suas respostas foram descartadas desta avaliação de uso. Para quem comentou pessoalmente, o ATEnA é fácil de usar e sugeriu que o mapa conceitual fosse exibido durante o estudo de Tópicos, destacando os conceitos relativos ao Tópico e à UE atuais. Esta sugestão foi implementada, conforme as Figuras 5.19 e 5.21.

Um dos aprendizes que comentou livremente por $e$-mail sugeriu a inclusão de outros tipos de questões para avaliar o sistema, além de uma parte prática nos cursos. O ATEnA poderia estar integrado a um editor de HTML que permitisse exercitar os conceitos, ou mesmo prototipar a solução internamente. Para ele, o sistema funcionou bem, principalmente após a inclusão de duas funcionalidades: retornar a Tópicos já estudados e consultar o resultado da avaliação assim que o aprendiz a finaliza. Como esse aprendiz teve acesso também aos relatórios do ATEnA, ele destacou a relevância deles para o instrutor. Enquanto o instrutor sabe no ATEnA quanto o aprendiz está estudando, em cursos puramente presenciais o instrutor só sabe o resultado do desempenho ao verificar provas, projetos e participação em aulas, com pouca ou nenhuma informação sobre o quanto o aprendiz estuda fora da sala de aula. Portanto, o estudo no ATEnA aumenta a documentação sobre as atividades dos aprendizes. Ele acredita que, à medida que o sistema for utilizado, surgirão outros tipos de relatórios úteis.

Outro aprendiz sugeriu que, após a correção das avaliações, seja possível consultar o Tópico avaliado e verificar as perguntas, a resposta fornecida e a resposta correta. Estas sugestões foram implementadas, exceto a exibição da resposta correta, pois a questão pode se repetir em avaliações futuras. Ele não compreendeu o motivo de sua reprovação em algumas AFs, apesar de haver respondido corretamente à maioria das questões nessas AFs. Portanto, é necessário que o ATEnA exiba aos aprendizes o critério de aprovação em cada avaliação. Quando esse critério é baseado no acerto mínimo por conceito, o aprendiz pode ser reprovado quando não atinge esse valor. 


\begin{tabular}{|c|c|c|c|c|}
\hline \multicolumn{5}{|c|}{ Avaliação Diagnóstica (AD) } \\
\hline $\begin{array}{c}\text { Autorizados a } \\
\text { começar pela UE } \\
\qquad\end{array}$ & $\begin{array}{c}\text { Autorizados a } \\
\text { começar pela UE } \\
2\end{array}$ & $\begin{array}{c}\text { Não } \\
\text { responderam }\end{array}$ & $\begin{array}{c}\text { Nota média } \\
\text { (incluindo apenas } \\
\text { quem respondeu a AD) }\end{array}$ & $\begin{array}{c}\text { Nota média (incluindo } \\
\text { todos os aprendizes do } \\
\text { Curso) }\end{array}$ \\
\hline $75 \%$ & $12,5 \%$ & $12,5 \%$ & 3,333 & 2,916 \\
\hline
\end{tabular}

Avaliações Formativas (AFs)

\begin{tabular}{|c|c|c|c|c|c|}
\hline Título & Aprovação & Reprovação & $\begin{array}{c}\text { Não } \\
\text { responderam }\end{array}$ & $\begin{array}{c}\text { Nota média } \\
\text { (incluindo apenas } \\
\text { quem respondeu } \\
\text { esta AF) }\end{array}$ & $\begin{array}{c}\text { Nota média } \\
\text { (incluindo todos os } \\
\text { aprendizes do } \\
\text { Curso) }\end{array}$ \\
\hline $\begin{array}{l}\text { Atributos gerais de } \\
\text { um documento }\end{array}$ & $87,5 \%$ & $0 \%$ & $12,5 \%$ & 8,571 & 7,5 \\
\hline Cabeçalhos & $87,5 \%$ & $0 \%$ & $12,5 \%$ & 8,857 & 7,75 \\
\hline Separadores & $87,5 \%$ & $12,5 \%$ & $0 \%$ & 8 & 8 \\
\hline Listas & $87,5 \%$ & $0 \%$ & $12,5 \%$ & 8,857 & 7,75 \\
\hline Blocos de texto & $75 \%$ & $0 \%$ & $25 \%$ & 9 & 6,75 \\
\hline $\begin{array}{l}\text { Formatação de } \\
\text { frases }\end{array}$ & $87,5 \%$ & $0 \%$ & $12,5 \%$ & 9,429 & 8,25 \\
\hline $\begin{array}{l}\text { Caracteres } \\
\text { especiais }\end{array}$ & $75 \%$ & $0 \%$ & $25 \%$ & 8 & 6 \\
\hline Cores e fontes & $75 \%$ & $0 \%$ & $25 \%$ & 8,333 & 6,25 \\
\hline Caminho relativo & $75 \%$ & $0 \%$ & $25 \%$ & 8,667 & 6,5 \\
\hline Caminho absoluto & $75 \%$ & $0 \%$ & $25 \%$ & 10 & 7,5 \\
\hline $\begin{array}{l}\text { Ligações para } \\
\text { trechos de } \\
\text { documentos }\end{array}$ & $75 \%$ & $0 \%$ & $25 \%$ & 8,333 & 6,25 \\
\hline $\begin{array}{l}\text { Inserção de } \\
\text { imagens }\end{array}$ & $75 \%$ & $0 \%$ & $25 \%$ & 9 & 6,75 \\
\hline $\begin{array}{l}\text { Atributos básicos } \\
\text { de imagens }\end{array}$ & $75 \%$ & $0 \%$ & $25 \%$ & 8,667 & 6,5 \\
\hline Moldura & $50 \%$ & $12,5 \%$ & $37,5 \%$ & 9,332 & 5,832 \\
\hline $\begin{array}{l}\text { Imagem } \\
\text { alternativa }\end{array}$ & $62,5 \%$ & $0 \%$ & $37,5 \%$ & 8,002 & 5,001 \\
\hline Células e borda & $62,5 \%$ & $0 \%$ & $37,5 \%$ & 8,8 & 5,5 \\
\hline $\begin{array}{l}\text { Alinhamentos em } \\
\text { tabelas }\end{array}$ & $50 \%$ & $0 \%$ & $50 \%$ & 9 & 4,5 \\
\hline Largura de tabelas & $50 \%$ & $0 \%$ & $50 \%$ & 10 & 5 \\
\hline $\begin{array}{l}\text { Espaçamentos em } \\
\text { tabelas }\end{array}$ & $50 \%$ & $0 \%$ & $50 \%$ & 8,335 & 4,168 \\
\hline
\end{tabular}

\section{Avaliação Somativa (AS)}

\begin{tabular}{l|l} 
* Aprovação: $25 \%$ & $*$ Reprovação: $75 \%$ \\
* Nota média (com a nota final de cada aprendiz, incluindo & $*$ Nota média (com todas as tentativas, incluindo \\
apenas quem respondeu a AS): 6,957 & $\begin{array}{l}\text { apenas quem respondeu a AS): } 6,703 \\
\text { * Número médio de tentativas (incluindo apenas quem } \\
\text { respondeu a AS): } 1,75\end{array}$ \\
a Número médio de tentativas (incluindo todos os \\
aprendizes do Curso): 0,875
\end{tabular}

* Nota média (com a nota final de cada aprendiz, incluindo todos os aprendizes do Curso): 3,479

Figura 6.1: Estatísticas de um oferecimento (primeira parte) 


\begin{tabular}{|c|c|c|c|}
\hline \multicolumn{4}{|c|}{ Tempo médio das Avaliações } \\
\hline Tipo & $\begin{array}{l}\text { Tempo (com todas as tentativas, } \\
\text { incluindo quem respondeu) }\end{array}$ & \multicolumn{2}{|c|}{$\begin{array}{l}\text { Tempo (incluindo todos os } \\
\text { aprendizes do Curso) }\end{array}$} \\
\hline$A D$ & $4 \min 48 s$ & \multicolumn{2}{|l|}{$4 \min 12 s$} \\
\hline $\begin{array}{l}\text { AF: atributos gerais de um } \\
\text { documento }\end{array}$ & 2 minutos & \multicolumn{2}{|l|}{$2 \min 15 s$} \\
\hline AF: cabeçalhos & $1 \mathrm{~min} 56 \mathrm{~s}$ & \multicolumn{2}{|l|}{$1 \mathrm{~min} 56 \mathrm{~s}$} \\
\hline AF: separadores & $1 \mathrm{~min} 49 \mathrm{~s}$ & \multicolumn{2}{|l|}{$2 \mathrm{~min} 30 \mathrm{~s}$} \\
\hline AF: listas & $1 \mathrm{~min} 20 \mathrm{~s}$ & \multicolumn{2}{|l|}{$1 \mathrm{~min} 30 \mathrm{~s}$} \\
\hline AF: formatação de frases & $2 \min 2 s$ & \multicolumn{2}{|l|}{$2 \min 33 s$} \\
\hline AF: caracteres especiais & $1 \min 53 s$ & \multicolumn{2}{|l|}{$1 \mathrm{~min} 25 \mathrm{~s}$} \\
\hline AF: cores e fontes & 56 segundos & \multicolumn{2}{|l|}{49 segundos } \\
\hline AF: caminho relativo & $1 \mathrm{~min} 40 \mathrm{~s}$ & \multicolumn{2}{|l|}{$1 \mathrm{~min} 40 \mathrm{~s}$} \\
\hline AF: blocos de texto & $1 \mathrm{~min} 2 \mathrm{~s}$ & \multicolumn{2}{|l|}{54 segundos } \\
\hline AF: caminho absoluto & 48 segundos & \multicolumn{2}{|l|}{36 segundos } \\
\hline $\begin{array}{l}\text { AF: ligações para trechos de } \\
\text { documento }\end{array}$ & $1 \min 15 s$ & \multicolumn{2}{|l|}{$1 \min 5 s$} \\
\hline AF: inserção de imagens & 1 minuto & \multicolumn{2}{|l|}{53 segundos } \\
\hline $\begin{array}{l}\text { AF: atributos básicos de } \\
\text { imagens }\end{array}$ & $1 \mathrm{~min} 40 \mathrm{~s}$ & \multicolumn{2}{|l|}{$1 \min 28 s$} \\
\hline AF: moldura & 53 segundos & 53 segundos & \\
\hline AF: imagem alternativa & $1 \mathrm{~min} 27 \mathrm{~s}$ & 54 segundos & \\
\hline $\begin{array}{l}\text { AF: células e borda de } \\
\text { tabelas }\end{array}$ & $1 \mathrm{~min} 15 \mathrm{~s}$ & 47 segundos & \\
\hline AF: largura de tabelas & 53 segundos & 33 segundos & \\
\hline AF: alinhamentos em tabelas & $2 \min 1 s$ & $1 \min 16 s$ & \\
\hline $\begin{array}{l}\text { AF: espaçamentos em } \\
\text { tabelas }\end{array}$ & 52 segundos & 26 segundos & \\
\hline AS & $7 \min 14 s$ & $6 \min 19 s$ & \\
\hline Tempo mé & tio de todas as Avaliações realizadas & este Curso: $1 \mathrm{~min} 53$ & \\
\hline & Consulta a Referências & & \\
\hline & ferência & $\begin{array}{l}\text { Tempo médio } \\
\text { (incluindo apenas } \\
\text { quem consultou) }\end{array}$ & $\begin{array}{l}\text { Tempo médio } \\
\text { (incluindo todos os } \\
\text { aprendizes do } \\
\text { Curso) }\end{array}$ \\
\hline $\begin{array}{l}\text { http://143.107.183.144/atena } \\
\text { 15/HTMLcomponentes.htm }\end{array}$ & /cursos/HTML- & $6 \min 3 s$ & 45 segundos \\
\hline http://143.107.183.144/atena & /cursos/HTML-15/HTMLprimeiro.htm & 15 segundos & 5 segundos \\
\hline $\begin{array}{l}\text { http://143.107.183.144/atena } \\
\text { 15/HTMLatributos.htm\#body }\end{array}$ & /cursos/HTML- & 17 segundos & 2 segundos \\
\hline http://www.icmc.usp.br & & 4 segundos & 0,5 segundos \\
\hline http://www.utoronto.ca/webd & cs/HTMLdocs/NewHTML/a_href.html & 15 segundos & 1 segundo \\
\hline Todas & & 49 segundos & 55 segundos \\
\hline
\end{tabular}

Figura 6.2: Estatísticas de um oferecimento (segunda parte) 


\begin{tabular}{|c|c|c|c|}
\hline \multicolumn{4}{|c|}{ Estudo de Tópicos } \\
\hline Título & $\begin{array}{l}\text { Tempo médio de estudo on-line } \\
\text { (incluindo apenas quem estudou o } \\
\text { Tópico, dividindo pelo número de } \\
\text { acessos ao Tópico) }\end{array}$ & $\begin{array}{l}\text { Tempo médio de } \\
\text { estudo on-line } \\
\text { (incluindo todos os } \\
\text { inscritos no Curso) }\end{array}$ & $\begin{array}{l}\text { Número médio de } \\
\text { acessos ao Tópico } \\
\text { (incluindo todos os } \\
\text { inscritos no Curso) }\end{array}$ \\
\hline $\begin{array}{l}\text { Atributos gerais de } \\
\text { um documento }\end{array}$ & $21 \min 1 \mathrm{~s}$ & $34 \mathrm{~min} 9 \mathrm{~s}$ & 1,625 \\
\hline Cabeçalhos & $8 \mathrm{~min} 47 \mathrm{~s}$ & $13 \min 11 \mathrm{~s}$ & 1,5 \\
\hline Separadores & $2 \min 35 s$ & $4 \mathrm{~min} 51 \mathrm{~s}$ & 1,875 \\
\hline Listas & $9 \min 5 s$ & $27 \mathrm{~min} 17 \mathrm{~s}$ & 3 \\
\hline Blocos de texto & $3 \mathrm{~min} 25 \mathrm{~s}$ & $3 \min 51 s$ & 1,125 \\
\hline $\begin{array}{l}\text { Formatação de } \\
\text { frases }\end{array}$ & $2 \min 16 s$ & $2 \min 51 s$ & 1,25 \\
\hline $\begin{array}{l}\text { Caracteres } \\
\text { especiais }\end{array}$ & $2 \min 35 s$ & $1 \mathrm{~min} 56 \mathrm{~s}$ & 0,75 \\
\hline Cores e fontes & $2 \min 4 s$ & $2 \mathrm{~min} 50 \mathrm{~s}$ & 1,375 \\
\hline Caminho relativo & $16 \mathrm{~h} 45 \mathrm{~min} 47 \mathrm{~s}$ & $20 \mathrm{~h} 57 \mathrm{~min} 14 \mathrm{~s}$ & 1,25 \\
\hline Caminho absoluto & 42 segundos & 31 segundos & 0,75 \\
\hline $\begin{array}{l}\text { Ligações para } \\
\text { trechos de } \\
\text { documentos }\end{array}$ & $2 \min 9 s$ & $2 \min 9 s$ & 1 \\
\hline $\begin{array}{l}\text { Inserção de } \\
\text { imagens }\end{array}$ & $1 \mathrm{~min} 11 \mathrm{~s}$ & $1 \mathrm{~min} 2 \mathrm{~s}$ & 0,875 \\
\hline $\begin{array}{l}\text { Atributos básicos } \\
\text { de imagens }\end{array}$ & $6 \mathrm{~min} 45 \mathrm{~s}$ & $5 \mathrm{~min} 54 \mathrm{~s}$ & 0,875 \\
\hline Moldura & $1 \mathrm{~min} 32 \mathrm{~s}$ & $2 \mathrm{~min} 7 \mathrm{~s}$ & 1,375 \\
\hline $\begin{array}{l}\text { Imagem } \\
\text { alternativa }\end{array}$ & $1 \mathrm{~min} 38 \mathrm{~s}$ & $1 \min 13 s$ & 0,75 \\
\hline Células e borda & $1 \mathrm{~min} 44 \mathrm{~s}$ & $1 \mathrm{~min} 31 \mathrm{~s}$ & 0,875 \\
\hline $\begin{array}{l}\text { Alinhamentos em } \\
\text { tabelas }\end{array}$ & $9 \mathrm{~h} 9 \min 11 \mathrm{~s}$ & $6 \mathrm{~h} 51 \mathrm{~min} 53 \mathrm{~s}$ & 0,75 \\
\hline Largura de tabelas & $1 \mathrm{~min} 20 \mathrm{~s}$ & 50 segundos & 0,625 \\
\hline $\begin{array}{l}\text { Espaçamentos em } \\
\text { tabelas }\end{array}$ & $1 \mathrm{~min} 38 \mathrm{~s}$ & 49 segundos & 0,5 \\
\hline Todos & $1 \mathrm{~h} 20 \mathrm{~min} 17 \mathrm{~s}$ & $1 \mathrm{dia} 5 \mathrm{~h} 36 \mathrm{~min} 17 \mathrm{~s}$ & 22,13 \\
\hline
\end{tabular}

Figura 6.3: Estatísticas de um oferecimento (terceira parte) 


\begin{tabular}{|c|c|c|c|c|c|c|c|}
\hline \multicolumn{8}{|c|}{ Avaliação Diagnóstica } \\
\hline \multicolumn{2}{|c|}{ Nota: 2} & \multicolumn{2}{|c|}{ Duração: $2 \min 9 \mathrm{~s}$} & \multicolumn{2}{|c|}{ Primeira UE: 1} & & \\
\hline \multicolumn{8}{|c|}{ Estudo de Tópicos } \\
\hline Título & \multicolumn{3}{|c|}{ Duração } & Sessões & Título & Duração & Sessões \\
\hline $\begin{array}{r}\text { Atributos gerais de um } \\
\text { documento }\end{array}$ & \multicolumn{3}{|c|}{$7 \min 37 s$} & 1 & Cabeçalhos & $13 \min 2 s$ & 1 \\
\hline Separadores & \multicolumn{3}{|c|}{$5 \mathrm{~min} 13 \mathrm{~s}$} & 1 & Listas em HTML & $8 \min 17 s$ & 1 \\
\hline Blocos de texto & \multicolumn{3}{|c|}{$3 \min 1 s$} & 1 & $\begin{array}{r}\text { Formatação de } \\
\text { frases }\end{array}$ & $\begin{array}{l}3 \\
\text { minutos }\end{array}$ & 1 \\
\hline Caracteres Especiais & \multicolumn{3}{|c|}{$3 \min 13 s$} & 1 & Cores e Fontes & $3 \min 14 \mathrm{~s}$ & 1 \\
\hline Caminho relativo & \multicolumn{3}{|c|}{$\begin{array}{l}6 \text { dias } \\
23 \mathrm{~h} 2 \min 56 \mathrm{~s}\end{array}$} & 3 & Caminho absoluto & $1 \min 18 \mathrm{~s}$ & 1 \\
\hline $\begin{array}{r}\text { Ligações para trechos de } \\
\text { documentos }\end{array}$ & \multicolumn{3}{|c|}{$3 \min 5 s$} & & $\begin{array}{r}\text { Inserção de } \\
\text { Imagens }\end{array}$ & $\begin{array}{l}3 \\
\text { minutos }\end{array}$ & 1 \\
\hline Atributos Básicos de Imagens & $4 \mathrm{~min}$ & $45 s$ & 1 & & Moldura & $2 \min 40 s$ & 2 \\
\hline Imagem Alternativa & $2 \mathrm{~min}$ & $47 s$ & 1 & & Células e Borda & $1 \mathrm{~min} 34 \mathrm{~s}$ & 1 \\
\hline Alinhamentos em tabelas & $2 \mathrm{~min}$ & & 1 & & Largura de Tabelas & $1 \mathrm{~min} 42 \mathrm{~s}$ & 1 \\
\hline Espaçamentos em Tabelas & $1 \mathrm{~min}$ & $15 s$ & 1 & & & & \\
\hline & & Avali & ações Forı & mativa & & & \\
\hline Tópico & & Nota & Duração & & Tópico & Nota & Duração \\
\hline Atributos gerais de um docum & nento & 8 & $4 \min 28 s$ & & Cabeçalhos & 6 & 10 minutos \\
\hline Separac & dores & 8 & $5 \min 10 \mathrm{~s}$ & & Listas em HTML & 8 & $3 \min 39 s$ \\
\hline Blocos de & texto & 8 & $3 \min 37 s$ & & Formatação de frases & 10 & $2 \min 16 s$ \\
\hline Caracteres Espe & eciais & 10 & $3 \min 33 \mathrm{~s}$ & & Cores e Fontes & 10 & $1 \mathrm{~min} 8 \mathrm{~s}$ \\
\hline Caminho rel & lativo & 6 & $2 \min 58 s$ & & Caminho absoluto & 10 & $1 \mathrm{~min} 22 \mathrm{~s}$ \\
\hline Ligações para trechos de docume & entos & 6 & $2 \min 35 s$ & & Inserção de Imagens & 10 & 1 minuto \\
\hline Atributos Básicos de Ima & gens & 10 & $4 \min 3 s$ & & Moldura & 3,33 & $1 \mathrm{~min} 24 \mathrm{~s}$ \\
\hline Mo & Idura & 6,67 & $1 \min 18 \mathrm{~s}$ & & Imagem Alternativa & 6,67 & $4 \mathrm{~min} 40 \mathrm{~s}$ \\
\hline Células e $\mathrm{E}$ & Borda & 10 & $2 \min 33 \mathrm{~s}$ & Alin & hamentos em tabelas & 8 & $5 \min 13 s$ \\
\hline Largura de $\mathrm{Ta}$ & belas & 10 & $1 \mathrm{~min} 47 \mathrm{~s}$ & Espac & çamentos em Tabelas & 10 & $2 \min 14 s$ \\
\hline & & Ava & liação Son & nativa & & & \\
\hline Ten & tativa & a: 1 & ota: 8,13 & Duras & ção: $5 \min 19 \mathrm{~s}$ & & \\
\hline
\end{tabular}

Figura 6.4: Atividades de um aprendiz durante um curso 
O último aprendiz que comentou por $e$-mail notou a ausência de mecanismos para recuperação de senha e para contato com o administrador do sistema. Para ele, faltam também indicações sobre o processo de inscrição; assim, o usuário não recebe orientação do que acontece após a inscrição (preenchimento dos campos e envio), nem sabe se a inscrição foi bem sucedida. Uma sugestão é um texto explicando as "regras do jogo", pelo menos para a inscrição. Ele não recomenda um tutorial, pois acredita que muitos não se motivariam a realizar sua leitura, preferindo algumas dicas curtas e contextuais. Quanto à interface, ele sugere que a tabela de ações semânticas - sair do ATEnA, ir para o menu principal, dentre outras - seja exibida sempre na mesma posição (acima ou abaixo do conteúdo principal) e que quadros (frames) e cores sejam explorados para evitar desorientação do usuário. Nas AFs ele prefere que a resposta correta seja exibida quando o aprendiz erra uma questão, mas é aprovado no respectivo Tópico. Por fim, ele sugere a verticalização da visão geral, ou estrutura, do curso.

A autora do curso sobre padrões relatou sua experiência como aprendiz do curso sobre HTML, respondendo ao questionário proposto. Ela sentiu dificuldade em consultar Tópicos anteriores e em aprender sem nenhum auxílio como, por exemplo, tutorial ou manual. Apesar disso, para ela os comandos do sistema foram auto-explicativos e a implementação dos recursos para visualização da estrutura do curso é satisfatória. Ela sugeriu que, após a reprovação do aprendiz na AS, o sistema informe os Tópicos em que ele não obteve a nota mínima aceitável pelo instrutor. Para ela, o ATEnA é muito útil para EaD e treinamentos. Ele oferece toda a infra-estrutura para o estudo sem a presença do instrutor. O sucesso do aprendizado dependerá das características do aprendiz e da forma pela qual o curso foi estruturado. Essa estruturação depende, para ela, da experiência e habilidade do instrutor em oferecer esse tipo de curso.

\subsection{Utilização de Recursos Hipermídia}

Alguns recursos hipermídia (Seção 2.4) foram incluídos no MDE e no ATEnA, com o objetivo de minimizar alguns pontos fracos típicos de hipertextos (desorientação do usuário e sobrecarga cognitiva), coletar dados sobre os aprendizes e acompanhar a navegação que reflete o progresso do aprendiz. Por exemplo, a coleta de dados foi facilitada com o armazenamento das listas de história das interações do aprendiz, enquanto o acompanhamento navegacional é possível por meio de uma trilha principal no curso. A seguir, é discutida a aplicação destas funcionalidades.

No MDE, o conceito de ligações dinâmicas é explorado, de maneira associada às condições dos statecharts, para flexibilizar e/ou controlar as avaliações realizadas pelos aprendizes. Neste modelo há uma ligação dinâmica, denominada "Domina Conceitos", entre a Avaliação Diagnóstica e a primeira Unidade de Estudo (Figura 4.4). Esta ligação varia conforme a condição $C_{1}$ definida pelo autor e o desempenho do aprendiz na $\mathrm{AD}$. Ligação semelhante, designada como "Terminou AF", ocorre entre a Avaliação Formativa e o Tópico (Figura 4.5). Se o re- 
sultado do aprendiz na AF for satisfatório, esta ligação apontará para o próximo Tópico; caso contrário, o destino da ligação será o Tópico mais recentemente estudado.

Uma característica avançada de ligações consiste no controle de acesso a elas, requerendo que o sistema conceda acesso de informações específicas a certos usuários. No ATEnA, algumas ligações são exibidas apenas se certos critérios de seleção forem satisfeitos. Um destes critérios é o papel do usuário; por exemplo, o papel de aprendiz não habilita o usuário a editar cursos. $\mathrm{Na}$ Subseção 5.5.1 foi exemplificado outro critério, utilizado para exibir a interface pública do sistema. Além disso, ao estudar on-line, um aprendiz pode ativar apenas as ligações aos cursos em oferecimento nos quais sua inscrição foi aprovada.

Além dos nós estáticos e mais comuns em hiperdocumentos, existem nós que são gerados para o usuário pelo sistema. No ATEnA, o conteúdo dos nós referentes a Tópicos, Questões e Avaliações é computado a partir de dados armazenados em tabelas MySQL. Para exibir ao aprendiz o conteúdo de um Tópico, um programa PHP obtém em uma tabela a URL desse Tópico, carrega em memória o conteúdo principal associado a essa URL e, finalmente, reúne em uma única página esse conteúdo às ações semânticas correspondentes (Figura 5.19). Outra computação realizada consiste em tornar aleatória a ordem das questões em uma Avaliação e das alternativas em uma Questão de múltipla escolha.

Trilhas e roteiros guiados conectam uma cadeia de ligações. Enquanto na trilha são permitidos desvios para nós que não pertencem a ela, em um roteiro guiado os usuários podem navegar apenas pela sequiência de nós incluída no roteiro. No MDE, os nós principais (Avaliações e Tópicos) formam uma trilha. Os únicos nós que não pertencem à trilha são as referências e as páginas de UEs e do curso. Uma Avaliação é um roteiro guiado de Questões, pois nenhum desvio é permitido enquanto o aprendiz se submete às Avaliações. Não é permitido consultar o conteúdo de um Tópico durante uma Avaliação.

No ATEnA, a trilha principal é transformada em uma trilha composta apenas por Tópicos e Avaliações, a qual é claramente marcada de forma que os aprendizes saibam quais ligações os conservam na trilha - "Continua o Estudo" na Figura 5.18, "Tópico foi estudado" na Figura 5.19 e "Terminar avaliação" na Figura 5.20 (a) - e quais os desviam da trilha (todas as ligações exibidas internamente a um Tópico, com exceção de "Tópico foi estudado"). Além disso, enquanto o aprendiz estuda um Tópico, ele tem acesso à visão hierárquica do curso, representada pelo mapa conceitual, na qual são destacados o Tópico atual e a UE em que está inserido (Figura 5.19).

Uma lista de história relaciona todos os nós já visitados pelo usuário, possibilitando a navegação para qualquer um deles. O ATEnA exibe uma lista ordenada cronologicamente de Tópicos já estudados pelo aprendiz, que pode ir para qualquer Tópico anterior e deste para o Tópico atualmente em estudo. É desaconselhável percorrer a lista de história gravada pelo navegador. Como o sistema executa páginas dinâmicas, com dados obtidos em tabelas MySQL, a reati- 
vação de algumas delas pode desestabilizar o ambiente do usuário. Este risco é parcialmente minimizado pelo ocultamento, via JavaScript, do botão "Voltar" (ou Back) do navegador.

Um marco, em hipertexto, pode ser a a página principal de um sítio WWW ou um nó introdutório de um hiperdocumento ao qual o sistema possibilita acesso mais rápido. Para cada papel do ATEnA, exceto o Usuário Genérico, há um marco ou página principal cujo título é iniciado por "Ambiente". Para os aprendizes, o marco consiste na página intitulada "Ambiente do Aprendiz", enquanto o marco dos instrutores e dos autores é o "Ambiente do Instrutor". Na Figura 5.8 é ilustrado o ambiente do Assistente Acadêmico.

\subsubsection{Adaptatividade}

Segundo Kobsa et al. (2001), adaptações em sistemas hipermídia podem ocorrer em três níveis: conteúdo, apresentação mais modalidade (ou tipo de mídia) e estrutura. No primeiro nível são utilizados métodos para personalizar o conteúdo de páginas e objetos hipermídia conforme dados do ambiente, usuário e utilização. No segundo caso são alterados o formato da mídia e da apresentação, além dos elementos de interação como menus ou botões. Na adaptação da estrutura as ligações são personalizadas com base nos dados aplicados para adaptar o conteúdo.

Na maioria dos textos estudados sobre Hipermídia Adaptativa (Brusilovsky, 1996a b; Brusilovsky et al., 1997; Wu et al., 2001), ela é classificada em apresentação adaptativa, englobando os dois primeiros níveis anteriores, e apoio à navegação adaptativa, equivalente à adaptação da estrutura.

O ATEnA contém alguns recursos limitados de adaptatividade viabilizados pelo modelo subjacente de hipertexto, o MDE. Ele não adota modelos de usuário, interação e ambiente computacional (Kobsa et al., 2001), embora armazene um perfil simplificado para cada aprendiz. Esse perfil contém Tópicos estudados e revisitados, referências consultadas, Avaliações e questões respondidas, e páginas de UEs e Curso visualizadas. Essas informações podem ser úteis para que seja elaborado um melhor modelo do usuário em futuras versões do ambiente. Os recursos de adaptatividade aplicados atualmente no ATEnA não diferenciam usuários com o mesmo papel (aprendiz e instrutor, dentre outros). Portanto, não se trata de um ambiente hipermídia adaptativo completo. Nas próximas subseções descrevem-se as técnicas adaptativas implementadas, que são em nível de conteúdo e de estrutura.

\subsubsection{Apresentação e Conteúdo Adaptativos}

De acordo com Brusilovsky (1996a), apresentação adaptativa consiste em adaptar o conteúdo de uma página, acessada por determinado usuário, às características desse usuário (seu nível atual de conhecimento e seus objetivos, dentre outras). Por exemplo, a um usuário qualificado pode-se fornecer informações mais detalhadas, enquanto um usuário novato pode receber esclarecimentos complementares na forma de um tutorial. 
No ATEnA, um Tópico pode ser apresentado adaptativamente conforme o desempenho do aprendiz na Avaliação Formativa correspondente, desde que o autor tenha associado múltiplos conteúdos alternativos a esse Tópico. Se a condição de aprovação associada à Avaliação Formativa não for satisfeita, será aplicada a técnica "página variante" que implementa o método "explicação variante". O sistema exibirá ao aprendiz outra página explicando de outra forma o conceito abordado no Tópico e na AF. Além disso, a interface de opções, ou ações semânticas, é adaptada segundo o papel do usuário e certas restrições para a execução dessas ações. Na tela inicial e no ambiente do instrutor / autor, não são exibidas ações semânticas cujos critérios de execução não foram satisfeitos; por exemplo, se o autor / instrutor não ministrou ou propôs cursos, não há a ligação para o programa PHP que possibilita listar e/ou editar cursos ministrados ou propostos. A opção para remoção de conceito não aparece no ambiente do autor, pois ela só é útil enquanto ele estiver editando mapas conceituais. Outros exemplos semelhantes foram mencionados na Subseção 5.5.1.

\subsubsection{Navegação Adaptativa}

Um dos métodos de apoio à navegação adaptativa é a condução global. Ele ocorre quando cada usuário tem algum objetivo global de informação localizado em um ou mais nós do hiperespaço e é "conduzido" pelo sistema nessa direção. O objetivo desse método é ajudar o usuário a encontrar o caminho mais curto à informação desejada, minimizando as dificuldades. Pode ser implementado pela técnica de orientação direta, na qual o sistema decide qual nó será visitado a seguir, considerando os objetivos, preferências, conhecimento e outros parâmetros representados no modelo do usuário. Ela pode ser aplicada em qualquer sistema que pode decidir qual é o próximo melhor nó a ser seguido pelo usuário. O ATEnA, em particular, orienta o aprendiz quanto ao primeiro Tópico do curso a ser estudado, com base no resultado da AD.

\subsection{Comparação do ATEnA com Ambientes de EAD}

A comparação de ambientes educacionais, incluindo o ATEnA, é resumida na Tabela 6.3, a qual retoma a Tabela 2.1. Nelas são tratadas as seguintes características, descritas na Subsubseção 2.6.1.10 monitoração do desempenho, auto-avaliação, estrutura proprietária, estruturação dos cursos e avaliação personalizada. Nesta Seção, apenas o ATEnA é analisado em relação a essas características.

O ATEnA possibilita que o instrutor acompanhe o progresso dos aprendizes, visualizando as páginas percorridas por eles, conforme as Figuras 5.24 a 5.26, bem como verificando os resultados das avaliações. Dependendo da condição definida para a avaliação, o aprendiz pode responder a questões auto-corrigíveis como treinamento, sem que a nota obtida seja oficialmente considerada pelo instrutor. 


\begin{tabular}{|l|l|l|l|l|l|}
\hline & $\begin{array}{l}\text { Monitoração } \\
\text { do desempenho }\end{array}$ & Auto-avaliação & $\begin{array}{l}\text { Estrutura } \\
\text { proprietária }\end{array}$ & $\begin{array}{l}\text { Estruturação } \\
\text { de cursos }\end{array}$ & $\begin{array}{l}\text { Avaliação } \\
\text { personalizada }\end{array}$ \\
\hline ATEnA & $\operatorname{sim}$ & $\operatorname{sim}$ & $\operatorname{sim}$ & $\operatorname{sim}$ & $n \tilde{a} o$ \\
\hline AulaNet & $\operatorname{sim}$ & $\operatorname{sim}$ & $\operatorname{sim}$ & $\operatorname{sim}$ & $n \tilde{a} o$ \\
\hline CALM & $n \tilde{a} o$ & $\operatorname{sim}$ & $\operatorname{sim}$ & $n \tilde{a} o$ & $n \tilde{a} o$ \\
\hline $\begin{array}{l}\text { Carnegie } \\
\text { Mellon }\end{array}$ & $\operatorname{sim}$ & $\operatorname{sim}$ & $n \tilde{a} o$ & $\operatorname{sim}$ & $\operatorname{sim}$ \\
\hline CyberQ & $\operatorname{sim}$ & $n \tilde{a} o$ & $\operatorname{sim}$ & $\operatorname{sim}$ & $\operatorname{sim}$ \\
\hline Eureka & $\operatorname{sim}$ & $n \tilde{a} o$ & $\operatorname{sim}$ & $n \tilde{a} o$ & $n \tilde{a} o$ \\
\hline HLM & $\operatorname{sim}$ & $\operatorname{sim}$ & $\operatorname{sim}$ & $n \tilde{a} o$ & $\operatorname{sim}$ \\
\hline $\begin{array}{l}\text { Learning } \\
\text { Space }\end{array}$ & $\operatorname{sim}$ & $\operatorname{sim}$ & $\operatorname{sim}$ & $\operatorname{sim}$ & $n \tilde{a} o$ \\
\hline TelEduc & $\operatorname{sim}$ & $n \tilde{a} o$ & $\operatorname{sim}$ & $\operatorname{sim}$ & $\operatorname{sim}$ \\
\hline Virtual-U & $\operatorname{sim}$ & $\operatorname{sim}$ & $n \tilde{a} o$ & $\operatorname{sim}$ & $n \tilde{a} o$ \\
\hline WebCT & $\operatorname{sim}$ & $\operatorname{sim}$ & $\operatorname{sim}$ & $\operatorname{sim}$ & $n \tilde{a} o$ \\
\hline
\end{tabular}

Tabela 6.3: ATEnA e outros ambientes de EaD

A estrutura escolhida para o hiperdocumento do curso é proprietária, visto que o relacionamento entre os nós é determinado por programas PHP que processam dados obtidos em tabelas MySQL. Os cursos no ATEnA são estruturados com base no MDE. Essa característica faz com que cada componente do curso - Tópico, UE, questão, avaliação e o próprio curso — seja associado a algum conceito. O ATEnA não proporciona avaliações personalizadas, pois não oferece questões e/ou avaliações diferentes para cada aprendiz conforme o seu desempenho. Esta é uma característica que poderia ser implementada no futuro com relativa facilidade, pois os dados coletados sobre o desempenho do aprendiz (AFs, tempo de estudo on-line por Tópico, etc.) poderiam ser utilizados para essa personalização. Outro tipo possível de personalização consiste em concentrar as questões nos conceitos mais difíceis ou mais fáceis para cada aprendiz, e não de uma maneira uniforme para todos os aprendizes de um curso. Quando um aprendiz apresentar facilidade com certos conceitos, os assuntos relacionados poderão ser exibidos em mais ou menos detalhes do que os assuntos em que ele demonstrou dificuldade (Silva Filho, 1999).

\subsection{Considerações Finais}

Neste Capítulo foi realizada uma avaliação parcial e informal do modelo MDE para hiperdocumentos educacionais e de um protótipo de ambiente para EaD - o sistema ATEnA, desenvolvido com base no MDE. Mais subsídios para completar essa avaliação surgirão quando outros cursos forem criados e/ou oferecidos no ATEnA. Especialistas em estatística e em teste de software poderão contribuir, respectivamente, na estruturação e na formalização de experimentos com o ATEnA. No próximo Capítulo resume-se o trabalho efetuado, listando suas principais contribuições, limitações e possíveis trabalhos futuros. 


\section{Conclusões}

\subsection{Considerações Gerais}

Nesta tese foram apresentados um modelo para hiperdocumentos educacionais e um protótipo implementado como prova de conceito para aplicar o modelo de forma prática e avaliar a sua adequação ao domínio de Ensino a Distância. Este modelo, denominado MDE (Modelo para Documentos Educacionais ou Model for Distance Education) e baseado no HMBS (Hyperdocument Model Based on Statecharts), foi descrito em linguagem natural e especificado formalmente por meio de statecharts e de outras notações.

O protótipo de um sistema para Ensino a Distância foi implementado como um sistema de informação baseado na Web. Ele é constituído pelos seguintes módulos: administração, desenvolvido no âmbito de um projeto de Mestrado (Casagrande, 2001); autoria, para a estruturação dos cursos; e navegação, para que os aprendizes estudem os cursos preparados no módulo anterior. Alguns alunos e professores do ICMC / USP testaram o protótipo como usuários, possibilitando a correção dos principais defeitos e o acréscimo de algumas funcionalidades.

Neste Capítulo, além do resumo apresentado acima, são descritas as contribuições desta tese para as áreas de Engenharia de Software, Hipertexto e software para Ensino a Distância, assim como as suas limitações. Também são sugeridos alguns trabalhos e pesquisas futuras que podem dar continuidade ao trabalho realizado.

\subsection{Contribuições}

A principal contribuição desta tese é a definição de um modelo computacional para apoio ao EaD baseado na Web. O MDE, até onde o autor desta tese tem conhecimento, apresenta como característica original o fato de ser o único modelo de hipertexto que formaliza três tipos de avaliações (Diagnóstica, Formativa e Somativa) e integra os conceitos de statecharts, mapas conceituais e tratamento de avaliações em um único modelo.

Uma característica importante do MDE, propiciada pela formalização baseada em statecharts, consiste em permitir a coleta de dados relevantes sobre a navegação do aprendiz, os quais auxiliam na avaliação formativa do aprendiz pelo instrutor. O MDE é suficientemente flexível para que o autor do curso escolha os parâmetros de avaliação e o fluxo de estudo do material didático segundo critérios e interesses pedagógicos diversos. Além disso, o modelo proposto associa um mapa conceitual hierárquico à estrutura do curso, relacionando o conteúdo e as avaliações aos conceitos explicados no curso. 
Uma contribuição desta tese à área de Engenharia de Software é a continuidade de pesquisas realizadas anteriormente pelo Grupo de Engenharia de Software do ICMC, mais especificamente quanto à investigação de técnicas para a especificação de aplicações hipertexto (Turine, 1998). Um dos modelos previamente desenvolvidos por pesquisadores desta instituição, denominado HMBS, foi estendido nesta tese e aplicado ao Ensino a Distância mostrando desta forma que o HMBS, embora seja um modelo genérico de hipertextos, pode ser utilizado em domínios específicos de informação como o EaD. Em relação ao HMBS, o MDE incorpora as seguintes extensões para atender ao domínio de aplicações para o Ensino a Distância na Web: estados parametrizados, condição avaliável por expressão lógico-matemática, semântica navegacional adaptável ao tipo de página, páginas com atributos estruturados, associação de mapa conceitual ao hiperdocumento, e atribuição de mais de uma página a um estado.

A contribuição da tese ao desenvolvimento de software para EaD consiste em um protótipo operacional de um sistema para apoiar o oferecimento de cursos reais, os quais podem ocorrer a distância ou de forma presencial. O protótipo permitiu também testar as principais características do MDE, tendo sido avaliado por alguns usuários (docentes e alunos do ICMC / USP), com resultados positivos.

\subsection{Trabalhos Futuros}

Esta tese poderá originar diversos outros trabalhos de pesquisa, relacionados ao MDE ou ao ATEnA. Quanto ao modelo, sugere-se que ele seja generalizado para tratar mapas conceituais descritos por árvores com mais de três níveis hierárquicos ou até mesmo por grafos cíclicos, com repetição de conceitos em um único mapa. Para personalizar o ambiente do aprendiz, será necessário especificar explicitamente um modelo do usuário, o qual pode ser baseado entre outras informações - nos dados colhidos pelo sistema sobre a navegação do aprendiz. A inclusão deste novo modelo no ATEnA aperfeiçoará a adaptatividade do sistema.

Pretende-se ainda aplicar o ATEnA em cursos que serão oferecidos no ICMC. Os dados automaticamente coletados durante a navegação do aprendiz, bem como os relatos transmitidos pelos usuários, serão analisados e utilizados como realimentação para a melhoria do modelo e do sistema. Desta forma, espera-se que tanto o MDE quanto o ATEnA possam evoluir e contribuir para o avanço do estado da arte na área de apoio ao EaD mediado pela Web.

O protótipo desenvolvido pode ser estendido e/ou usado de forma integrada com outros ambientes de EaD. Para torná-lo mais adaptativo, será útil apresentar questões e/ou avaliações diferentes para cada aprendiz conforme o seu desempenho concentrando as questões nos conceitos mais difíceis para cada aprendiz, e não de maneira uniforme para todos os aprendizes de um curso. Além disso, sugere-se melhorar a implementação dos recursos de apresentação alternativa de conteúdos / conceitos não assimilados pelo aprendiz. 
Para facilitar genericamente a utilização do sistema, podem ser incluídos no ATEnA alguns cursos permanentes de treinamento, conforme a sugestão de alguns usuários. Desta maneira, todos os tipos de usuário (autor, instrutor, aprendiz, assistente acadêmico e outros papéis administrativos) serão esclarecidos quanto às funcionalidades do ambiente.

O processo de autoria pode ser aperfeiçoado criando-se interfaces para a edição das referências bibliográficas e webliográficas do curso, bem como listando para o autor as ligações embutidas no conteúdo dos Tópicos. Aumentando no modelo os níveis do mapa conceitual, será possível flexibilizar mais ainda a elaboração de um curso, cuja estrutura poderá incluir subtópicos. A autoria colaborativa e o gerenciamento de versões serão viáveis quando o sistema armazenar a data e o usuário responsável pela criação / modificação de um nó, além das versões do material didático associado aos Tópicos.

Visando aprimorar a aprendizagem, pode-se oferecer outros tipos de questões — aberta, curta, dissertativa, baseada na execução de aplicações externas ao ATEnA, dentre outras - e mostrar aos aprendizes o critério de aprovação em cada avaliação. Existindo o controle de versões, poderão coexistir diferentes roteiros guiados em um curso, visando até mesmo a grupos diferenciados de aprendizes. Além disso, propõe-se um outro estilo de estudo no qual o usuário navegaria sem restrições pelos conceitos do mapa, exibido graficamente com ligações partindo de um conceito em direção a uma ou mais páginas. 


\section{Referências Bibliográficas}

Adriano, C.; Delgado, A.; Silveira Jr., L.; Bosnardo, R. C.; Ricarte, I. L. M.; MAgAlhães, L. P. Inquiring the course paradigm with CALM. In: International Conference on Engineering and Computer Education, Rio de Janeiro, 1999, p. 265-269. Disponível em: <http://www.dca.fee.unicamp.br/projects/sapiens/calm/References/ Papers/ICECE99/ICECE99.pdf >. Acesso em: 7 Jul. 2003.

Aho, A. V.; Sethi, R.; Ullman, J. D. Compilers: principles, techniques, and tools. Reading: Addison-Wesley, 1988. (Addison-Wesley Series in Computer Science)

AlenCAR, F. M. R. Mapeando a modelagem organizacional em especificações precisas. Tese de Doutorado, Universidade Federal de Pernambuco, Recife, 1999. Disponível em: $<$ http://www . cin.ufpe.br/ ler/teses.htm>. Acesso em: 7 Jul. 2003.

Alencar, P.; Cowan, D.; Crespo, S.; Fontoura, M.; Lucena, C. OwlNet: an object-oriented environment for WBE. Rel. Téc. MCC 18/98, Departamento de Informática, PUC-Rio, 1998. Disponível em: <http://citeseer.nj.nec.com/alencar98owlnet.html $>$. Acesso em: 7 Jul. 2003.

Alves, R. M.; Santos, A. B. Característica do ensino a distância. 2001. Disponível em: $<$ http://www.ied.ufla.br/modulos/ead/cap02.htm $>$. Acesso em: 7 Jul. 2003.

AMERICAN AsSOCIATION FOR ARTIFICIAL INTELLIGENCE Intelligent tutoring systems. 2003. Disponível em: <http://www.aaai.org/AITopics/html/tutor.html>. Acesso em: 7 Jul. 2003.

AT\&T Graphviz. 2000. Disponível em: <http://www.research.att.com/sw/tools/ graphviz/>. Acesso em: 7 Jul. 2003.

AT\&T The DOT language. 2002. Disponível em: <http://www.research.att.com/ uerg/graphviz/info/lang.html>. Acesso em: 7 Jul. 2003.

Ausubel, D. P.; NovaK, J. D.; Hanesian, H. Educational psychology: a cognitive view. New York: Hold, Rinchart and Winston, 1978.

BACKhOUSE, R. C. Syntax of programming languages: theory and practice. Londres: Prentice-Hall International, 1979. 
Balasubramanian, V.; Bashian, A. Document management and Web technologies: Alice marries the Mad Hatter. Communications of the ACM, v. 41, n. 7, p. 107-115, 1998. Disponível em: $<$ http://www.e-papyrus.com/cacm98/dmsweb.html >. Acesso em: 7 Jul. 2003.

BASSO JÚNIOR, E. Prototipação do ambiente CALM através de um curso Java. Rel. Téc. de Iniciação Científica, DCA / FEEC / Unicamp, Campinas, 1999. Disponível em: <http://www.dca.fee. unicamp.br/projects/sapiens/Reports/PrototJava/eneas.html>. Acesso em: 7 Jul. 2003.

Berners-Lee, T. Press FAQ. 2002. Disponível em: <http://www.w3.org/People/ Berners-Lee/FAQ.html>. Acesso em: 7 Jul. 2003.

Bieber, M.; Vitali, F.; Ashman, H.; Balasubramanian, V.; Kukkonen, H. O. Fourth generation hypermedia: some missing links for the World Wide Web. IJHCS "Web Usability" Special Issue, v. 47, n. 1, 1997. Disponível em: <http://ijhcs.open.ac.uk/bieber/>. Acesso em: 7 Jul. 2003.

Bloom, B. S.; Hastings, J. T.; Madaus, G. F. Handbook on formative and summative evaluation of student learning. New York: McGraw-Hill, 1971. 923 p.

Bochicchio, M.; PAolini, P. An HDM interpreter for on-line tutorials. In: MultiMedia Modeling, Lausanne: IEEE Computer Society Press, 1998, p. 184-190. Disponível em: $<$ http: //citeseer. nj.nec.com/457702.html>. Acesso em: 7 Jul. 2003.

Borges, M. A. F.; Baranauskas, M. C. C. A user-centered approach to the design of an expert system for training. British Journal of Educational Technology, v. 29, n. 1, p. 25-34, 1998. Disponível em: <http://www.dcc.unicamp.br/ maborges/BJET98.htm>. Acesso em: 11 Nov. 2003

Bray, T.; Paoli, J.; McQueen, C. M. S.; Maler, E. Extensible Markup Language (XML) 1.0. 2000. Disponível em: <http://www.w3.org/TR/REC-xml >. Acesso em: 7 Jul. 2003.

BRUSILOVSKy, P. Adaptive hypermedia: an attempt to analyze and generalize. Lecture Notes in Computer Science, v. 1077, p. 288-304, 1996a. Disponível em: <http://citeseer.nj.nec. com/brusilovsky96adaptive.html>. Acesso em: 7 Jul. 2003.

BRUSILOVSKY, P. Methods and techniques of adaptive hypermedia. User modeling and user-adapted interaction, v. 6, n. 2-3, p. 87-129, 1996b. Disponível em: <http://www.contrib.andrew. cmu.edu/ plb/UMUAI.ps $>$. Acesso em: 7 Jul. 2003.

Brusilovsky, P.; Miller, P.; Rehak, D.; Thyberg, C. Addressing assessment and adaptivity in Web-based undergraduate courses. 1997. Disponível em: <http://online.web.cmu.edu/ public/information/publications/ifip97/>. Acesso em: 7 Jul. 2003. 
Bush, V. As we may think. The Atlantic Monthly, v. 176, n. 1, p. 101-108, 1945. Disponível em: <http://www.theatlantic.com/unbound/flashbks/computer/bushf.htm $>$. Acesso em: 7 Jul. 2003.

Campbell, B.; Goodman, J. M. HAM: a general purpose hypertext abstract machine. Communications of the ACM, v. 31, n. 7, p. 856-861, 1988.

CARdoso, R. F.; Lima, J. V. AvalWeb - sistema interativo para gerência de questões e aplicação de avaliações na Web. In: Simpósio Brasileiro de Informática na Educação, Vitória, 2001. Disponível em: <http://www.rcardoso.com.br/pdf/sbie.pdf>. Acesso em: 7 Jul. 2003.

CARVAlho, M. R. HMBS/M - um método orientado a objetos para o projeto e o desenvolvimento de aplicações hipermídia. Dissertação de Mestrado, ICMC/USP, São Carlos, 1998.

Carvalho, M. R.; Oliveira, M. C. F.; Masiero, P. C. HMBS/M - an object oriented method for hypermedia design. In: V Simpósio Brasileiro de Sistemas Multimídia e Hipermídia, Goiânia: Instituto de Informática da UFG, 1999, p. 43-62. Disponível em: <http://www. det .ufms.br/ turine/hmbs/carvalhof.zip >. Acesso em: 7 Jul. 2003.

CASAGRANDE, L. M. Um método para análise e projeto de sistemas de workflow administrativo com interface para a Web. Dissertação de Mestrado, ICMC/USP, São Carlos, 2001.

Casanova, M. A.; Lima, M. J. D.; Rangel, J. L.; Rodriguez, N.; SoAres, L. F. G.; TucherMAN, L. The Nested Context Model for hyperdocuments. In: International ACM Hypertext'91 Conference, San Antonio, 1991, p. 193-201.

CAstro, M. A. S. Projeto e implementação de um sistema de auxílio à preparação de material didático para uso na World-Wide Web. Dissertação de Mestrado, ICMC/USP, São Carlos, 1997.

Cavallaro, U.; Garzotto, F.; Paolini, P.; Totaro, D. Hifi: Hypertext Interface for Information Systems. IEEE Software, v. 10, n. 6, p. 48-51, 1993. Disponível em: <http://www. computer.org/software/so1993/s6048abs.htm>. Acesso em: 7 Jul. 2003.

CEnter for the New Engineer Hyperlearning Meter home page. 1998. Disponível em: $<$ http://hlc.cs.gmu.edu/hlmeter/>. Acesso em: 7 Jul. 2003.

Chaves, E. Distance teaching and technology-mediated learning: a brief discussion. In: International Conference on Engineering and Computer Education, Rio de Janeiro, 2003. Disponível em: <http://www.chaves.com.br/TEXTSELF/EDTECH/disted.htm>. Acesso em: 7 Jul. 2003.

Choren, R.; Blois, M.; Fuks, H. QUEST: an assessment tool for Web-based learning. Rel. Téc. MCC05/98, Departamento de Informática, PUC-Rio, 1998. Disponível em: <ftp:// ftp.inf.puc-rio.br/pub/docs/techreports/98_05_choren.ps.gz>. Acesso em: 13 mar. 2001. 
ConAllen, J. Building Web Applications with UML. Boston: Addison-Wesley, 1999.

Conklin, J. A survey of hypertext. Rel. Téc. 2, MCC, Austin, 1987. Disponível em: $<$ http:// citeseer.nj.nec.com/conklin95survey.html >. Acesso em: 7 Jul. 2003.

Crespo, S.; Fontoura, M. F. M. C.; Lucena, C. J. P. Um modelo conceitual compatível com a plataforma EDUCOM/IMS para comparação de ambientes de educação na Web. In: Simpósio Brasileiro de Informática na Educação, Ceará, 1998. Disponível em: <http://www.almaden. ibm.com/cs/people/fontoura/papers/sbie98.pdf>. Acesso em: 7 Jul. 2003.

Delgado, A. L. N.; Adriano, C. M.; Vasconcelos, J. R.; Silveira JR., L. G.; Cardieri, M. A. C. A.; Barros, M. C. B.; Tomazeli, M. G. J. M.; Torres, M. F. C. F.; Bosnardo, R. C. CALM - Computer-Aided Learning Material. 1998. Disponível em: <ftp://ftp.dca. fee.unicamp.br/pub/docs/Sapiens/calm_v1.doc >. Acesso em: 7 Jul. 2003.

Denning, P. J.; Menascé, D. A.; Le, H. Hyperlearning Meter: toward on-line certification. In: Combined Research-Curriculum Development Program 1997, 1997. Disponível em: $<$ http://hlc. cs.gmu.edu/cne/publications/crcd97.html >. Acesso em: 7 Jul. 2003.

Dennis, A. Lessons from three years of Web development. Communications of the ACM, v. 41, n. 7, p. 112-113, 1998.

Eberspächer, H. F.; Vasconcelos, C. D.; Jamur, J. H.; Eleutério, M. A. M. Eureka: um ambiente de aprendizagem cooperativa baseado na Web para educação a distância. In: X Simpósio Brasileiro de Informática na Educação, Curitiba, 1999. Disponível em: <ftp://ftp.lami. pucpr.br/Pub/Docs/Art9907.doc). Acesso em: 7 Jul. 2003.

FUKs, H. Aprendizagem e trabalho cooperativo no ambiente AulaNet. Revista Brasileira de Informática na Educação, v. 1, n. 6, p. 53-73, 2000. Disponível em: <http://139.82.24.161/ groupware/publicacoes/aprendizagem.pdf>. Acesso em: 7 Jul. 2003.

FurutA, R. Trellis information. 1999. Disponível em: <http://bush.cs.tamu.edu/ furuta/trellis/>. Acesso em: 7 Jul. 2003.

Garzotto, F.; Mainetti, L.; Paolini, P. Adding multimedia collections to the Dexter model. In: European Conference on Hypermedia Technologies, Edinburgh, 1994, p. 70-80.

Garzotto, F.; Mainetti, L.; Paolini, P. Hypermedia design, analysis and evaluation issues. Communications of the ACM, v. 38, n. 8, p. 74-86, 1995. Disponível em: <http://citeseer. nj.nec.com/garzotto98hypermedia.html>. Acesso em: 7 Jul. 2003.

Garzotto, F.; Paolini, P.; Schwabe, D. HDM - a model-based approach to hypertext application design. ACM Transactions on Information Systems, v. 11, n. 1, p. 1-26, 1993. Disponível em: $<$ http://www.dsi.unive.it/ smm/2001/docs/garzotto93.pdfl $>$. Acesso em: 7 Jul. 2003. 
GoldberG, M. W.; SAlari, S. An update on WebCT (World-Wide-Web Course Tools) - a tool for the creation of sophisticated Web-based learning environments. In: NAUWeb '97-Current Practices in Web-Based Course Development, Flagstaff, 1997. Disponível em: <http://www.cs . ubc.ca/ wccce/program97/murray/murray.html>. Acesso em: 7 Jul. 2003.

Goose, S.; Hall, W.; Reich, S. Microcosm TNG: a framework for distributed open hypermedia. IEEE MultiMedia, v. 7, n. 3, p. 52-60, 2000. Disponível em: <http://www.computer.org/ multimedia/mu2000/u3052abs.htm>. Acesso em: 7 Jul. 2003.

Grønbæк, K.; Hem, J. A.; Madsen, O. L.; Sloth, L. Designing Dexter-based cooperative hypermedia systems. In: Hypertext'93 Proceedings, Seattle: ACM, 1993, p. 25-38. Disponível em: $<$ http://citeseer.nj.nec.com/90201.html>. Acesso em: 7 Jul. 2003.

GRønBÆK, K.; SLOTh, L.; ORBAEK, P. Webvise: browser and proxy support for open hypermedia structuring mechanisms on the WWW. In: Eighth International World Wide Web Conference, Toronto: Elsevier Science B.V., 1999, p. 253-268. Disponível em: <http://www.daimi.au.dk/ les/ papers/www8/Webvise.pdf >. Acesso em: 7 Jul. 2003.

GrønbÆK, K.; Trigg, R. H. Design issues for a Dexter-based hypermedia system. Communications of the ACM, v. 37, n. 2, p. 40-49, 1994. Disponível em: $<$ http: //citeseer.nj.nec.com/ 60253.html>. Acesso em: 7 Jul. 2003.

GRøNBÆK, K.; TRIGG, R. H. Toward a Dexter-based model for open hypermedia: unifying embedded references and link objects. In: Hypertext'96, Washington: ACM Press, 1996, p. 149-160. Disponível em: <http://www.cs.unc.edu/ barman/HT96/P71/Groenbaek-Trigg.html>. Acesso em: 7 Jul. 2003.

Grossman, O.; Harel, D. On the algorithmics of higraphs. Rel. Téc. CS97-15, The Weizmann Institute of Science, Rehovot, 1997. Disponível em: $<$ http://citeseer.nj.nec.com/55636. html >. Acesso em: 7 Jul. 2003.

Halasz, F. G.; Schwartz, M. The Dexter hypertext reference model. Communications of the ACM, v. 37, n. 2, p. 30-39, 1994. Disponível em: <http://citeseer.nj.nec.com/ halasz94dexter.html>. Acesso em: 7 Jul. 2003.

HARASIM, L. A framework for online learning: the Virtual-U. IEEE Computer Society, p. 44-49, 1999. Disponível em: <http://citeseer.nj.nec.com/harasim98framework.html >. Acesso em: 7 Jul. 2003.

Hardman, L.; Bulterman, D. C. A.; Rossum, G. V. Links in hypermedia: the requirement for context. In: ACM Hypertext'93, Seattle, 1993a, p. 183-191. Disponível em: <http://www. cwi. nl/ftp/mmpapers/ht93.ps.gz >. Acesso em: 13 Aug. 2003. 
Hardman, L.; Bulterman, D. C. A.; Rossum, G. V. The Amsterdam hypermedia model: extending hypertext to support real multimedia. Hypermedia Journal, v. 5, n. 1, p. 47-69, 1993b. Disponível em: <http://www.cwi.nl/ftp/CWIreports/CST/CS-R9306. ps.Z>. Acesso em: 7 Jul. 2003.

HAREL, D. Statecharts: a visual formalism for complex systems. Science of Computer Programming, v. 8, n. 3, p. 231-274, 1987. Disponível em: <http://www.wisdom.weizmann.ac.il/ $\sim$ dharel/SCANNED.PAPERS/Statecharts.pdf>. Acesso em: 7 Jul. 2003.

HAREL, D. On visual formalisms. Communications of the ACM, v. 31, n. 5, p. 514-530, 1988. Disponível em: <http://www.wisdom.weizmann.ac.il/ dharel/SCANNED.PAPERS/ VisualFormalisms.pdf>. Acesso em: 7 Jul. 2003.

HENZE, N.; NEJDL, W. Extendible adaptive hypermedia courseware: integrating different courses and Web material. In: International Conference on Adaptive Hypermedia and Adaptive Web-based Systems, Trient, 2000, p. 109-120. Disponível em: <http://www.kbs.uni-hannover.de/ Arbeiten/Publikationen/2000/HenzeNejdl.pdf >. Acesso em: 7 Jul. 2003.

HöÖK, K.; Karlgren, J.; Wærn, A.; Dahlbäck, N.; JAnsson, C. G.; Karlgren, K.; LEMAIRE, B. A glass box approach to adaptive hypermedia. User Modeling and User-Adapted Interaction, v. 6, n. 2-3, p. 157-184, 1996. Disponível em: <http://citeseer.nj.nec.com/ 63958.html . Acesso em: 7 Jul. 2003.

Hyperlearning Center HLM PowerPoint presentation. 1998. Disponível em: $<$ http:// hlc.cs.gmu.edu/hlmeter/hlmppt.html>. Acesso em: 7 Jul. 2003.

IBM IBM Lotus Software - LearningSpace. 2003. Disponível em: <http://www. lotus .com/ products/learnspace.nsf/wdocs/homepage/>. Acesso em: 7 Jul. 2003.

IEEE List of p1484 terms. 2000. Disponível em: <http://ltsc.ieee.org/doc/wg3/ interactive_glossary/Lp1484.htm>. Acesso em: 7 Jul. 2003.

Isakowitz, T.; Bieber, M. Web Information Systems. Communications of the ACM, v. 41, n. 7, p. 78-80, 1998. Disponível em: <http://www.cs.unibo.it/ fabio/bio/papers/1998/ CACM/wis-intro.pdf>. Acesso em: 7 Jul. 2003.

IsAkowitz, T.; Kamis, A.; Koufaris, M. The extended RMM methodology for Web publishing. Rel. Téc. IS-98-18, Center for Research on Information Systems, 1998. Disponível em: <http:// jmis.bentley.edu/rmm/papers/RMM-Extended.pdf >. Acesso em: 7 Jul. 2003.

Isakowitz, T.; Stohr, E. A.; Balasubramanian, P. RMM: a methodology for structured hypermedia design. Communications of the ACM, v. 38, n. 8, p. 34-44, 1995. Disponível em: $<$ http://jmis.bentley.edu/rmm/papers/rmd.pdf $>$. Acesso em: 7 Jul. 2003. 
Johnson, M. XML for the absolute beginner. JavaWorld, 1999. Disponível em: $<$ http:// www.javaworld.com/javaworld/jw-04-1999/jw-04-xml_p.html >. Acesso em: 7 Jul. 2003.

Kaplan-Leiserson, E. E-learning glossary. 2002. Disponível em: <http://www. learningcircuits.org/glossary.html>. Acesso em: 7 Jul. 2003.

Kobsa, A.; Koenemann, J.; Pohl, W. Personalised hypermedia presentation techniques for improving on-line customer relationships. The Knowledge Engineering Review, v. 16, n. 2, p. 111-155, 2001. Disponível em: <http://www.ics.uci.edu/ kobsa/papers/2001-KER-kobsa. pdf >. Acesso em: 7 Jul. 2003.

KonRath, M. L. P. Mapas conceituais. 2000. Disponível em: <http://penta2.ufrgs.br/ edutools/mapasconceituais/>. Acesso em: 7 Jul. 2003.

LABORATÓRIO DE TEledUCAÇÃO A theory of learning for long-term retention. 1997. Disponível em: $<$ http://penta.ufrgs.br/edu/telelab/5/learning.htm>. Acesso em: 7 Jul. 2003.

LANZing, J. W. A. The concept mapping homepage. 1997. Disponível em: $<$ http://users. edte.utwente.nl/lanzing/cm_home.htm>. Acesso em: 7 Jul. 2003.

LARMAn, C. Applying UML and patterns: an introduction to object-oriented analysis and design. Prentice Hall, 1997.

Lucena, C. J. P.; Fuks, H.; Blois, M.; Choren, R.; Assis, R. L.; Robichez, G. Tecnologia de informação aplicada à educação: um (meta) curso no ambiente AulaNet. Rel. Téc. MCC 17/00, Departamento de Informática, PUC-Rio, 2000a. Disponível em: $<$ http://lsm.dei.uc. pt/ribie/docfiles/txt200331220224fi8.pdf >. Acesso em: 7 Jul. 2003.

Lucena, C. J. P.; Fuks, H.; Laufer, C.; Ribeiro, M. B.; Choren, R.; Silva, V. T.; AsSis, R. L.; Ferraz, F.; Carvalho, G. R. Applying digital information technology to education: a Web-based course. In: International Conference on Engineering and Computer Education, São Paulo, 2000b. Disponível em: <http://139.82.24.161/groupware/publicacoes/ ICECE2000.pdf >. Acesso em: 7 Jul. 2003.

Lucena, C. J. P.; Fuks, H.; Milidiú, R.; Laufer, C.; Ribeiro, M. B.; Noya, R. C.; Silva, V. T.; Ferraz, F.; CARVAlho, G. R.; DAflon, L. AulaNet: ajudando professores a fazerem o seu dever de casa. In: XXVI SEMISH - Seminário Integrado de Software e Hardware, Rio de Janeiro, 1999a, p. 105-117. Disponível em: <http://139.82.24.161/groupware/publicacoes/ SEMISH991.pdf>. Acesso em: 7 Jul. 2003.

Lucena, C. J. P.; Fuks, H.; Milidiú, R.; Laufer, C.; Ribeiro, M. B.; Noya, R. C.; Silva, V. T.; Ferraz, F.; Carvalho, G. R.; Daflon, L. O AulaNet e as novas tecnolo- 
gias de informação aplicadas à educação baseada na Web. In: V Congresso Internacional de Educação a Distância, Rio de Janeiro: Associação Brasileira de Educação a Distância, 1999c, p. 3-14. Disponível em: <http://www.abed.org.br/antiga/htdocs/paper_visem/carlos_ jose_pereira/carlos_jose_pereira_de_lucena.htm $>$. Acesso em: 7 Jul. 2003.

Lucena, C. J. P.; Fuks, H.; Milidiú, R.; Laufer, C.; Ribeiro, M. B.; Noya, R. C.; Silva, V. T.; F.Ferraz; Carvalho, G. R.; Daflon, L. AulaNet technologies: future trends. In: International Conference on Engineering and Computer Education, Rio de Janeiro, 1999b, p. 312-316. Disponível em: <http://ritv.les.inf.puc-rio.br/groupware/ publicacoes/ICECE99.pdf>. Acesso em: 9 Jul. 2003.

Magalhães, L. P. Projeto SAPIENS: relatório de atividades. 1999. Disponível em: $<$ http:// WwW.dca.fee.unicamp.br/projects/sapiens/Reports/sapiens99.pdf>. Acesso em: 9 Jul. 2003.

Magalhães, L. P. Projeto SAPIENS: relatório final de atividades. 2001. Disponível em: $<$ http://www.dca.fee.unicamp.br/projects/sapiens/Reports/sapiens01. pdf $>$. Acesso em: 9 Jul. 2003.

Mellon, C. An overview of Carnegie Mellon Online. 2000. Disponível em: $<$ http://online. web.cmu.edu/public/about/overview $>$. Acesso em: 9 Jul. 2003.

Menezes, R. A.; FuKs, H.; GARCiA, A. C. B. Utilizando agentes no suporte à avaliação informal no ambiente de instrução baseada na Web - AulaNet. In: Simpósio Brasileiro de Informática na Educação, Ceará, 1998. Disponível em: <http://wwwedit.inf.ufsc.br:1998/materiais/ sbie98/anais/artigos/art22.html >. Acesso em: 9 Jul. 2003.

Merrall, G. PHP/MySQL tutorial. 1999. Disponível em: <http://hotwired.lycos.com/ webmonkey/programming/php/tutorials/tutorial4.html > . Acesso em: 9 Jul. 2003.

Michener, E. R. Understanding understanding mathematics. Cognitive Science, v. 2, n. 4, 1978. Disponível em: <http://www.math.ntnu.edu.tw/ cyc/_private/mathedu/ me9/me9_2/michener.doc >. Acesso em: 9 Jul. 2003.

Miller, A. H.; ImRIE, B. W.; Cox, K. Student assessment in higher education: a handbook for assessing performance. Londres: Kogan Page, 1998. 282 p.

Moreinis, M. B. What's a conceptual map? 1998. Disponível em: <http://www.cousinit. org/whyproject/readings/mapdesc.html>. Acesso em: 9 Jul. 2003.

NANARD, J.; NANARD, M. Hypertext design environments and the hypertext design process. Communications of the ACM, v. 38, n. 8, p. 49-56, 1995.

Nielsen, J. Multimedia and hypertext: the Internet and beyond. Boston: Academic Press Professional, 1995. $480 \mathrm{p}$. 
NovaK, J. D. The theory underlying concept maps and how to construct them. 2000. Disponível em: <http://cmap.coginst.uwf.edu/info/printer.html>. Acesso em: 9 Jul. 2003.

NovaK, J. D.; Gowin, D. Learning how to learn. New York: Cambridge University Press, 1984. $150 \mathrm{p}$.

Oliveira, M. C. F.; Turine, M. A. S.; Masiero, P. C. A Statechart-based model for hypermedia applications. ACM Transactions on Information Systems, v. 19, n. 1, p. 28-52, 2001. Disponível em: $<$ http://www.dct.ufms.br/ turine/hmbs/ACM.pdf $>$. Acesso em: 9 Jul. 2003.

Otsuka, J. L. Análise do processo de avaliação contínua em um curso totalmente a distância. In: Virtual Educa, Valença, 2002. Disponível em: <http://www.virtualeduca.org/ virtualeduca/virtual/actas2002/actas02/703.pdf>. Acesso em: 9 Jul. 2003.

Otsuka, J. L.; Lachi, R. L.; Ferreira, T. B.; Rocha, H. V. Suporte à avaliação formativa no ambiente de educação a distância TelEduc. In: VI Congresso Iberoamericano de Informática Educativa, Vigo, Espanha, 2002a. Disponível em: $\langle$ http://teleduc.nied.unicamp.br/pagina/ publicacoes/18_jrth_ie2002.pdf>. Acesso em: 9 Jul. 2003.

Otsuka, J. L.; Lachi, R. L.; Vahl Júnior, J. C.; Rocha, H. V. Uso de agentes de interface no ambiente TelEduc. In: IV Workshop de Ambientes de Aprendizagem Baseados em Agentes, São Leopoldo, 2002b. Disponível em: $<$ http://www.dcc.unicamp.br/ joice/artigos/ workshop_sbie.ps >. Acesso em: 9 Jul. 2003.

Otsuka, J. L.; Rocha, H. V. Avaliação formativa em ambientes de EaD. In: XIII Simpósio Brasileiro de Informática na Educação, São Leopoldo, 2002. Disponível em: <http: //www.dcc . unicamp.br/ joice/artigos/jh_sbie2002.ps >. Acesso em: 9 Jul. 2003.

PAIVA, D. M. B. Proposta e avaliação de um conjunto de requisitos para sistemas de autoria hipermídia educacional. Dissertação de Mestrado, ICMC/USP, São Carlos, 2001.

Paiva, D. M. B.; Nunes, M. G. V. Um conjunto de requisitos para sistemas de autoria hipermídia educacional. In: XXVII Latin-American Conference on Informatics, CLEI'2001, Mérida, Venezuela, 2001. Disponível em: <http://lsm.dei.uc.pt/ribie/docfiles/ txt200332515938Um\%20Conjunto 20 de 20 Requisitos $\% 20$ para $\% 20$ Sistemas\% 20 de $\% 20$ Autoria $\% 20$ HipermC $3 \circ$ ADdia $\% 20$ Educacional.pdf . Acesso em: 9 Jul. 2003.

Pansanato, L. T. E.; Nunes, M. G. V. Autoria de aplicações hipermídia para ensino. Revista Brasileira de Informática na Educação, v. 1, n. 5, 1999a. Disponível em: <http://www . cp. cefetpr.br/pessoal/luciano/public/rbie5.pdf>. Acesso em: 9 Jul. 2003.

Pansanato, L. T. E.; Nunes, M. G. V. EHDM: Método para projeto de hiperdocumentos para ensino. Rel. Téc. 43, ICMC/USP, São Carlos, 1999b. 
Paulo, F. B.; Masiero, P. C.; Oliveira, M. C. F. Hypercharts: extended Statecharts to support hypermedia specifications. IEEE Transactions on Software Engineering, v. 25, n. 1, p. 33-49, 1999. Disponível em: <http://www.dct.ufms.br/ turine/hmbs/hypercharts. zip >. Acesso em: 9 Jul. 2003.

Paulo, F. B.; Turine, M. A. S.; Oliveira, M. C. F.; Masiero, P. C. XHMBS: a formal model to support hypermedia specification. In: ACM Hypermedia'98, Pittburgh, 1998, p. 161-170. Disponível em: <http://citeseer.nj.nec.com/paulo98xhmbs.html >. Acesso em: 9 Jul. 2003.

PHPLiB Group PHP Base Library. 2002. Disponível em: <http://phplib.sourceforge. net>. Acesso em: 9 Jul. 2003.

Preto, T. M. O ensino de linguagens de programação para novatos: principais problemas e as novas tecnologias. In: International Conference on Engineering and Computer Education, São Paulo, 2000.

Preto, T. M.; Gabriel, C. P. Fatores determinantes na escolha de ambientes para ensino a distância. In: International Conference on Engineering and Computer Education, São Paulo, 2000.

PUC-PR Módulo de ajuda do Eureka. 2002. Disponível em: <http://wwws.lami.pucpr. br/eureka/Ajuda/index.asp >. Acesso em: 15 Mar. 2003.

ReHAK, D. Carnegie Mellon on-line: system architecture. 1999. Disponível em: <http:// online.web.cmu.edu/public/information/publications/architecture/>.

Acesso em: 9 Jul. 2003.

RochA, H. V. O ambiente TelEduc para educação a distância baseada na Web: princípios, funcionalidades e perspectivas de desenvolvimento. In: MorAEs, M. C. Educação a Distância: Fundamentos e Práticas. Campinas: UNICAMP, 2002. Disponível em: $<$ http://teleduc.nied.unicamp. br/oea/pub/livro3/Cap11_heloisa.zip >. Acesso em: 9 Jul. 2003.

Romanato, M. J.; Alamilla, S. T.; Monard, M. C. Descrição de cursos sobre inteligência artificial na Internet. Rel. Téc. 49, ICMC/USP, São Carlos, 1996.

Romani, L. A. S.; RochA, H. V. Interaction Map: information visualization techniques in Web-based distance education environments. Rel. Téc. IC-00-17, Unicamp, 2000. Disponível em: $<$ http://www.dcc.unicamp.br/ic-tr-ftp/2000/00-17.ps.gz $>$. Acesso em: 9 Jul. 2003.

Romiszowski, A. J.; Romiszowski, H. P.; TTS. Dicionário de terminologia de Educação a Distância. 1997. Disponível em: <http://sites.uol.com.br/cdchaves/ Dicionario-EAD.zip >. Acesso em: 9 Jul. 2003.

Santos, C. A. S.; Courtiat, J. P.; Souza, G. L.; Soares, L. F. G. Um modelo formal para verificação da consistência de documentos hipermídia NCM. In: IV Simpósio Brasileiro de Sistemas Multimídia e Hipermídia, Rio de Janeiro, 1998. Disponível em: <ftp://ftp.telemidia. 
puc-rio.br/pub/docs/conferencepapers/98_05_SANTOS.ps.gz >. Acesso em: 9 Jul. 2003.

Santos, N.; Ferreira, H. M. C. Aprendizagem cooperativa distribuída na Biblioteca Kidlink-Brasil. In: IX Simpósio Brasileiro de Informática na Educação, Fortaleza, 1998. Disponível em: $<$ http://www.cos.ufrj.br/ neide/artigos/artigo_sbie97.htm>. Acesso em: 9 Jul. 2003.

Schwabe, D.; Rossi, G. An object oriented approach to Web-based applications design. Theory and practice of object systems, v. 4, n. 4, p. 207-225, 1998. Disponível em: <http://www.inf . puc-rio.br/ schwabe/papers/OOWebAplDesign.pdf.gz >. Acesso em: 9 Jul. 2003.

Schwabe, D.; Rossi, G. The object-oriented hypermedia design model (OOHDM). 2003. Disponível em: <http://www.telemidia.puc-rio.br/oohdm/oohdm.html >. Acesso em: 9 Jul. 2003.

Secretaria de EducaÇão do Distrito Federal Currículo da educação básica das escolas públicas do Distrito Federal - educação infantil: 4 a 6 anos. 1999. Disponível em: <http:// www.se.df.gov.br/Curriculo/Volume2/infantil.pdf >. Acesso em: 9 Jul. 2003.

SHERRY, L. Issues in distance learning. International Journal of Educational Telecommunications, v. 1, n. 4, p. 337-365, 1996. Disponível em: <http://www.cudenver.edu/ lsherry/pubs/ issues.html >. Acesso em: 9 Jul. 2003.

Siebra, S. A.; Ramalho, G. Athena: an user-centered adaptive interface. In: 8th International Conference on Human-Computer Interaction, Munich: Lawrence Erlbaum, 1999, p. 346-350. Disponível em: <http://citeseer.nj.nec.com/265462.html >. Acesso em: 9 Jul. 2003.

Silva Filho, R. A. Técnicas advindas da elaboração de tutores inteligentes e suas aplicações dentro do ensino e da aprendizagem virtual. Dissertação de Mestrado, Universidade Salgado de Oliveira, São Gonçalo, 1999. Disponível em: <http://www.terravista.pt/aguaalto/ 2938/Dissert.html>. Acesso em: 9 Jul. 2003.

Soares, L. F. G.; Casanova, M. A. Uma arquitetura distribuída para o Modelo de Contextos Aninhados com intercâmbio de objetos MHEG. In: XI Simpósio Brasileiro de Redes de Computadores, Campinas, 1993. Disponível em: <ftp://ftp.telemidia.puc-rio.br/pub/docs/ conferencepapers/93_05_SOARES.DOC.gzP. Acesso em: 9 Jul. 2003.

Soares, L. F. G.; Rodrigues, N.; Casanova, M. A. NCM: a Conceptual Model for Hyperdocuments. In: I Workshop em Sistemas Hipermídia Distribuídos, São Carlos, 1995. Disponível em: $<$ http://www.icmc.usp.br/manuals/anais/wshd95/ncm.ps.z >. Acesso em: 9 Jul. 2003. 
SoAres, L. F. G.; SouzA, G. L. Modelo de Contextos Aninhados (segunda versão). Rel. Téc. 03/97, Laboratório TeleMidia, Departamento de Informática, PUC-Rio, 1997. Disponível em: <ftp://ftp.telemidia.puc-rio.br/pub/docs/techreports/97_03_ SOARES.ps.gz >. Acesso em: 9 Jul. 2003.

Stotts, P. D.; Furuta, R. Petri-Net based hypertext: document structure with browsing semantics. ACM Transactions on Information Systems, v. 7, n. 1, p. 3-29, 1989. Disponível em: <http:// citeseer.nj.nec.com/stotts89petri.html>. Acesso em: 9 Jul. 2003.

SzWARCFITER, J. L. Grafos e algoritmos computacionais. Rio de Janeiro: Campus, 1984.

TAKAhashi, K. Metalevel links: more power to your links. Communications of the ACM, v. 41, n. 7, p. 103-105, 1998.

Tanenbaum, A. S. Computer networks. 3. ed. Prentice-Hall, Inc., 1996.

TARouco, L. M. R. O processo de avaliação na educação a distância. 1999. Disponível em: <http://www.pgie.ufrgs.br/webfolioead/biblioteca/artigo6/artigo6. html >. Acesso em: 9 Jul. 2003.

Tompa, F. W. A data model for flexible hypertext database system. ACM Transactions on Information Systems, v. 7, n. 1, p. 85-100, 1989.

Torres, G. A história dos computadores. 1996. Disponível em: <http://www.rio40.hpg. ig.com.br/historia.htm>. Acesso em: 9 Jul. 2003.

TUCKER, R. W. Assessing the virtual classrooms: a progress report. Assessment and Accountability Forum, v. V, n. 2, 1995. Disponível em: $<$ http://www. intered.com/public/v5n2_ cyberq.htm>. Acesso em: 9 Jul. 2003.

TURINE, M. A. S. HMBS: um modelo baseado em Statecharts para a especificação formal de hiperdocumentos. Tese de Doutorado, Instituto de Física de São Carlos, Universidade de São Paulo, São Carlos, 1998. Disponível em: <http://www.dct.ufms.br/ turine/tese/tese.htm $>$. Acesso em: 10 Apr. 2003.

Turine, M. A. S.; Oliveira, M. C. F.; Masiero, P. C. Hypertext model based on Statecharts. In: ACM Hypertext'97, Southampton, 1997, p. 102-111.

Turine, M. A. S.; Oliveira, M. C. F.; Masiero, P. C. HySCharts: a hyperdocument authoring and browsing environment based on statecharts. Journal of Multimedia Tools and Applications, v. 8, p. 309-324, 1999. Disponível em: <http://www.dct.ufms.br/ turine/hmbs/ multimedia.pdf $>$. Acesso em: 9 Jul. 2003.

Vasconcelos, J. R.; Bosnardo, R. C.; Adriano, C. M.; Perlingeiro, F. R. Discussão sobre hipermídia. 1998. Disponível em: <http://www.dca.fee.unicamp.br/courses/ IA368F/1s1998/Hipermedia/revisao.html>. Acesso em: 9 Jul. 2003. 
VLEI VLEI in the media. 2000. Disponível em: <http://www.vlei.com/media.html $>$. Acesso em: 14 Mar. 2001.

WeвCT WebCT 3.0 help index. 2000. Disponível em: <http://www.webct.com/WYW/ ViewContent? content ID=2626622 >. Acesso em: 9 Jul. 2003.

WeBCT.com WebCT 3.6 designer help index. 2001. Disponível em: <http://webct.cisc. usp.br:8900/web-ct/help/en/designer/pages/questionsI.html>. Acesso em: 9 Jul. 2003.

WebCT.com WebCT Campus Edition 3.7: getting started tutorial. 2002. Disponível em: $<$ http://www.webct.com/service/ViewContent?content ID=9208691 >. Acesso em: 9 Jul. 2003.

WIERINGA, R. A survey of structured and object-oriented software specification methods and techniques. ACM Computing Surveys, v. 30, n. 4, p. 459-527, 1998. Disponível em: <http://cis.cs.tu-berlin.de/Lehre/WS-0001/Sonstiges/ konteng_sem/papers/survey_of_stuctured_and_object-oriented_software_ specification_methods_and_techniques.pdf >. Acesso em: 9 Jul. 2003.

Wu, H.; KorT, E.; BRA, P. Design issues for general-purpose adaptive hypermedia systems. In: 12th ACM Conference on Hypertext and Hypermedia, Arhus, Dinamarca, 2001, p. 141-150. Disponível em: $\langle$ http://wwwis.win.tue.nl/ debra/ht01/final.pdf $>$. Acesso em: 9 Jul. 2003.

Zambrini, M. S.; Lima, J. V. Histórico de desempenho em busca de adaptação navegacional. 2001. Disponível em: <http://www.inf.ufrgs.br/ tapejara/adaptweb/uel/ melissa.pdf>. Acesso em: 9 Jul. 2003. 